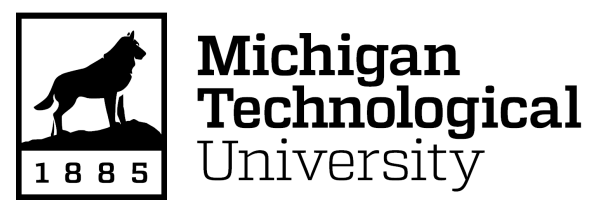

Michigan Technological University Digital Commons @ Michigan Tech

Dissertations, Master's Theses and Master's Reports

2017

\title{
A 3 D- FEM Study on the Stress Distributions in Pediatric Skull due to Impact from Free Fall
}

Suryanshu Walvekar

Michigan Technological University, swalveka@mtu.edu

Copyright 2017 Suryanshu Walvekar

\section{Recommended Citation}

Walvekar, Suryanshu, "A 3 D- FEM Study on the Stress Distributions in Pediatric Skull due to Impact from Free Fall", Open Access Master's Report, Michigan Technological University, 2017.

https://doi.org/10.37099/mtu.dc.etdr/548

Follow this and additional works at: https://digitalcommons.mtu.edu/etdr

Part of the Mechanical Engineering Commons 


\title{
A 3 D- FEM STUDY ON THE STRESS DISTRIBUTIONS IN PEDIATRIC SKULL DUE TO IMPACT FROM FREE FALL By
} Suryanshu Walvekar

\author{
A REPORT \\ Submitted in partial fulfillment of the requirements for the \\ degree of \\ MASTER OF SCIENCE \\ In Mechanical Engineering
}

MICHIGAN TECHNOLOGICAL UNIVERSITY 2017

(C) 2017 Suryanshu Walvekar 
This report has been approved in partial fulfillment of the requirements for the Degree of MASTER OF SCIENCE in Mechanical Engineering.

Department of Mechanical Engineering - Engineering Mechanics

Report Advisor: $\quad$ Dr. Gopal Jayaraman

Committee Member: $\quad$ Dr. K. V. C. Rao

Committee Member: $\quad$ Dr. Gregory Odegard

Department Chair: $\quad$ Dr. William Predebon 


\section{To my mother, father, brother, Lord Krishna}

and in loving memory of my younger brother Prakhar 


\section{Table of Contents}

Abstract

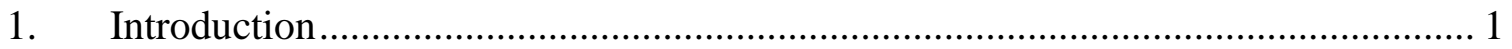

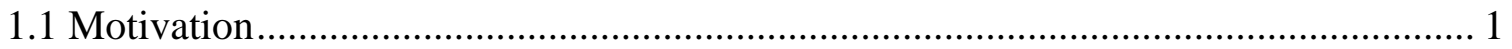

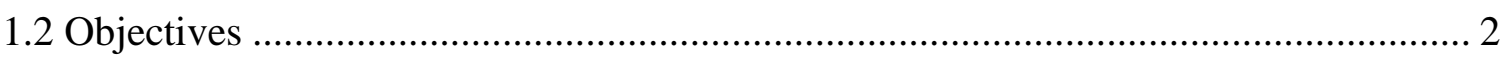

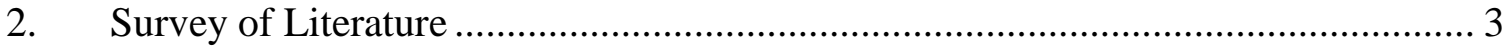

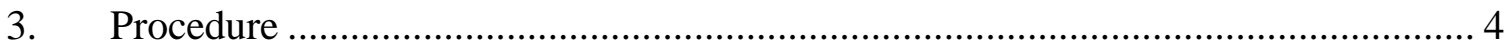

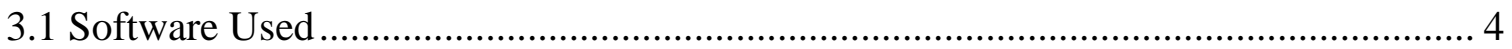

3.2 Development of 3 D FEM Model of Pediatric Head ................................................ 4

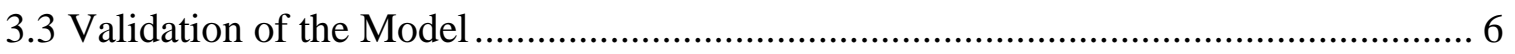

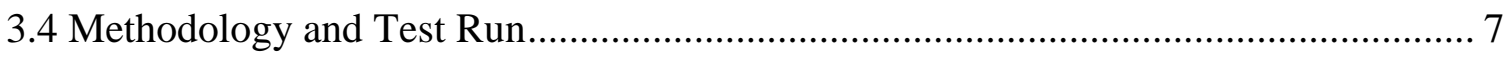

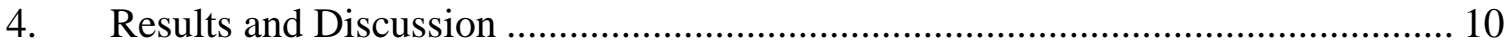

4.1 Maximum Principle Stress Distribution Patterns.................................................... 10

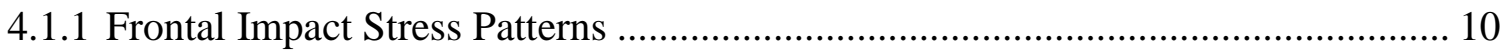

4.2 Von Mises Stress and Strain Pattern ...................................................................... 12

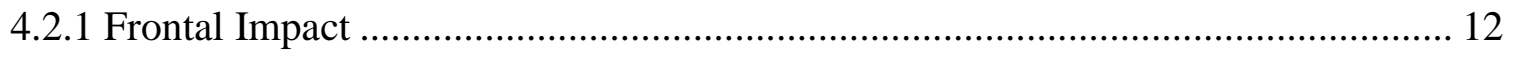

4.3 Tensile and Compressive Stress and Strain Patterns ........................................... 13

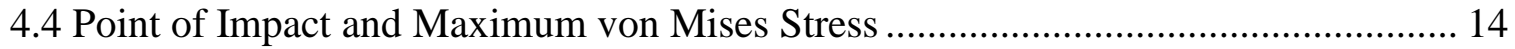

4.5 Point of Impact and Region of Potential Fracture ................................................ 15

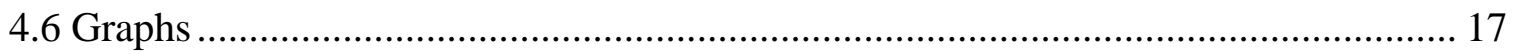

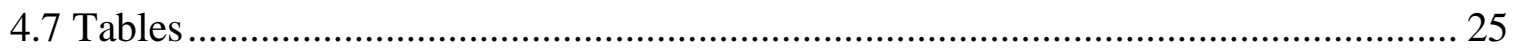

4.7.1 Von mises Stresses for Various Impacts ..................................................... 25

4.7.2 Principle Stresses for Various Impacts.............................................................. 25

4.7.3 Compressive Stresses for Various Impacts ................................................... 26

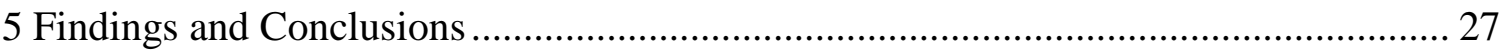

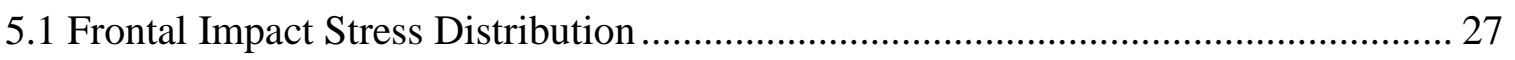

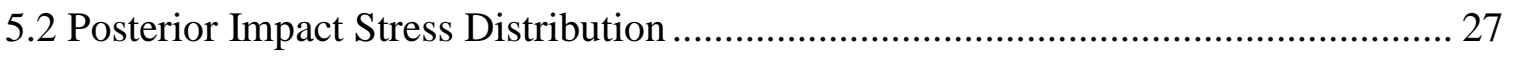

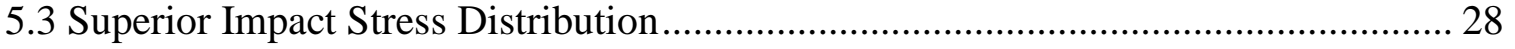

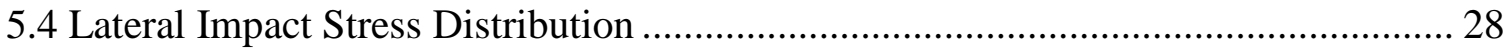

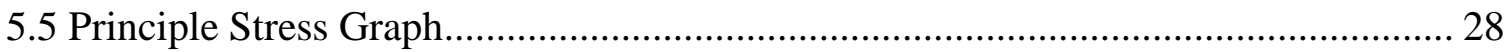

5.6 Von Mises and Compressive Stress Graph ........................................................ 29 
5.7 Critical Drop Height Calculations ........................................................................ 29

5.8 Point of Potential Fracture ………………………......................................... 30

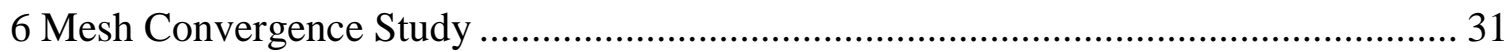

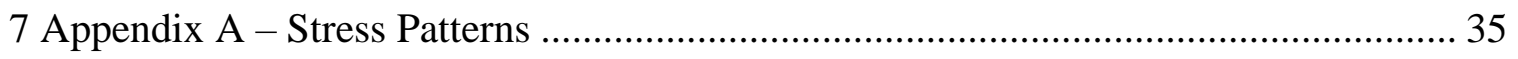

4.1 Maximum Principle Stress and Strain Distributions............................................... 35

4.1.1 Frontal Impacts for Various Drop Heights ........................................................ 35

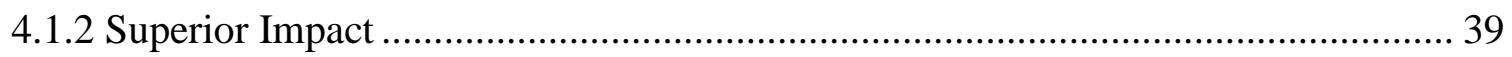

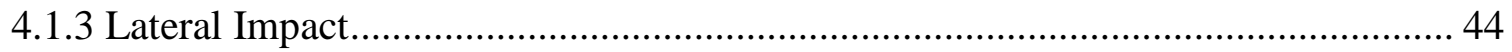

4.1.4 Posterior Impact ………………………………........................................ 49

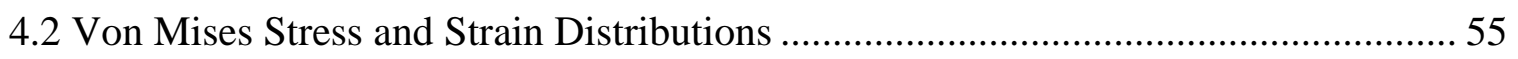

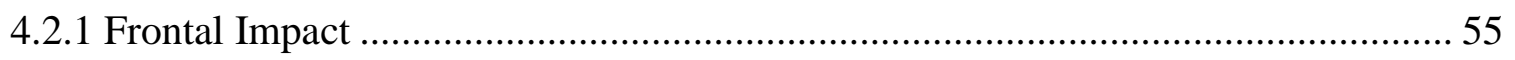

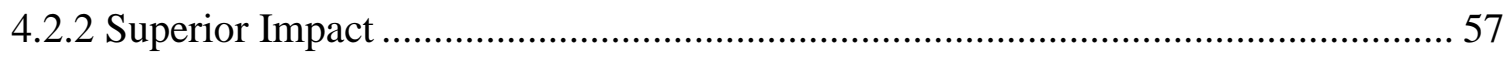

4.2.3 Lateral Impact.............................................................................................. 58

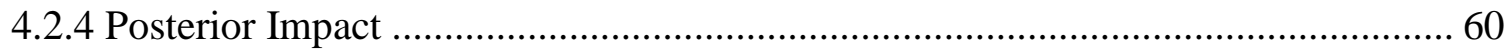

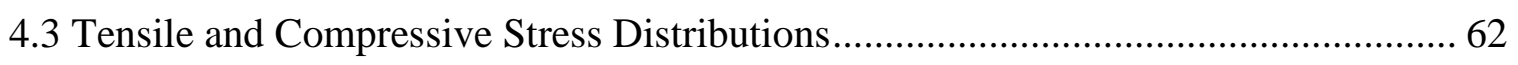

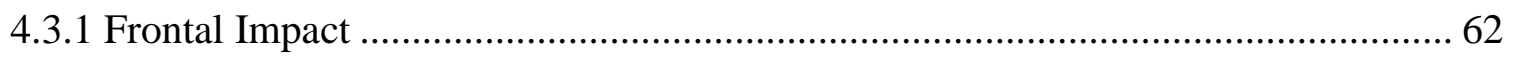

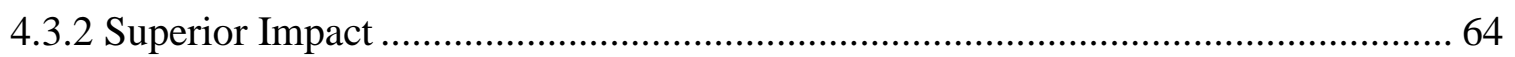

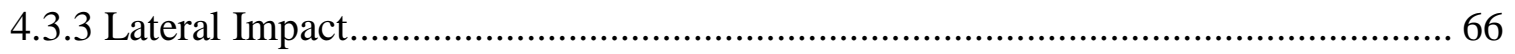

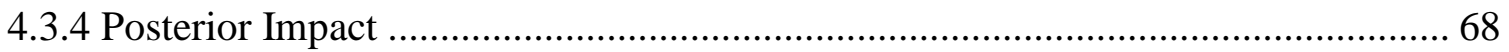

4.4 Point of Impact from Point of Maximum von Mises Stress ...................................... 70

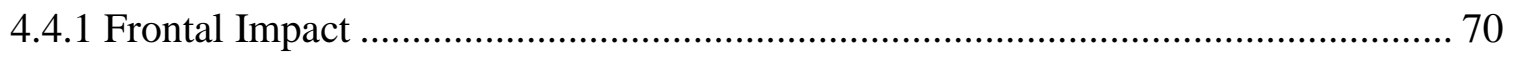

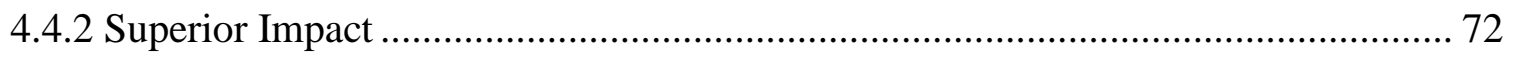

4.4.3 Lateral Impact............................................................................................... 74

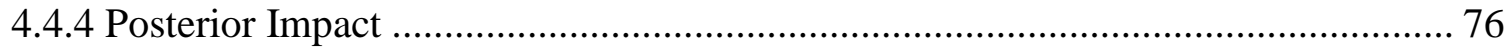

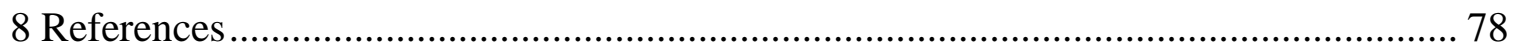




\section{Abstract}

Brain is vulnerable to injuries even from low heights of fall. There are many infant casualties who get severe brain injury each year. This research is a simulated study of the stress patterns and values when human infant skull is subjected to free fall.

The input velocity was calculated using simple free fall velocity formulas and was fed into the simulation. Model was meshed and refined using Hypermesh software. RADIOSS solver of the Hyperworks package was used to analyze and draw results for the simulation process. Various types of stresses and strains were extracted and plotted against respective drop heights. 


\section{Introduction}

Brain is one of the most sensitive organs of our body and its injuries can cause coma, permanent disabilities or even death. Brain injuries can be fatal to people belonging to every age group but infants are particularly more vulnerable. General injuries can be due to fall from small heights or head being smashed against some hard material. Human skull is the layer just beneath the scalp and is the hardest part of the head assembly. Thus, it would be beneficial to study the stress patterns and critical value of stresses and strains in the skull bone for a better understanding of the injuries. Also, thereby helping us design safer equipment to avoid any such injuries from happening.

\subsection{Motivation}

Brain injuries are dangerous and occur widely each year. Falls account for about 300,000 disabling injuries in North America and is the cause of nearly 20,000 deaths which is 55 per day [1]. As per the American College of Surgeons, falls account for around 3 million emergency visits and out of them, around $40 \%$ of the sufferers are infants and toddlers [2]. Falls and trauma on head account for $5.9 \%$ deaths in case of children. In general, for children of age below five, fall from a height less than 2 meters is not fatal, but may be a cause of severe mental trauma [2][3].

All the above numbers show that head injuries are dangerous and can cause deaths or severe trauma. Thus, it was important to study the effect of falls on the skull. I hope that the results from this report would offer a help for further research concerning the safety of infants from head injuries. 


\subsection{Objectives}

The pediatric head assembly is subjected to impacts from 5 different heights- $15,25,35$, 45 and $55 \mathrm{~cm}$. These account for common heights of fall. The major objectives of the test runs are as follows-

1) Obtain von mises and principle stress and strain distributions in the skull.

2) Obtain results that show how far is the point of impact from the point of maximum principle stress and point of maximum von mises stress.

3) Obtain the tensile stress and strain distribution of the skull just after the impact.

The point of maximum principle stress is a critical point and it is potentially very much possible that if a crack develops, it will start from the same point. The distribution of stress would give a better idea of terrains through which cracks may develop.

The results would give doctors an idea of a range of distances at which such critical points can be located from the point of impact. These points depend not only on the material properties but also the geometry of the skull.

The above information will help doctors and experts design some protection equipment that could save new born children from tragic brain injuries due to falls.

Hence the study was important as it has a further scope of development of life saving equipment for children. 


\section{Survey of Literature}

There were attempts in the past to develop and simulate $3 \mathrm{D}$ finite element infant head model. One of the early attempts was done by Thibault, Runge and Kurtz [4] to study the response of skull and brain and variation in the strains when subjected to variation in impact directions. The impacts on the head regions showed the dependence of the skull fracture on direction of impact and severe brain injury risk. The experiments were conducted on actual infant head and material properties were fed into FEM model which was later tested on posterior and lateral regions under trauma causing loading conditions for checking its response.

Another study was conducted by Margulies and Thibault with an attempt to correlate behavior of infant human head to that of infant pig skull case and extend the results of infant human case study to porcine data. Then two finite element models were designed, one with adult human properties and other with infant suture properties from the data. Both the models were subjected to identical loading conditions and intracranial strains were compared. Both data combined provided a bedrock for infant skull fracture response to traumatic loads [5].

Fracture patterns are important tools in the analysis of skull and have been studied in detail to distinguish between accident and abuse. A study on pediatric fracture samples was conducted by C. J. Hoggs in which 89 infant skull samples were analyzed and type of fracture was studied to make a demarcation between abuse and accident. [6]

An independent study was conducted by Britney Coats along with Susan Margulies on FEM infant head, which was obtained from radiological images. The study was confined to fractures caused by occipital impacts. The model was used to determine importance of brain material properties and structure of sutures and relative effect on principle stress value. The study helped determine the sensitivity of suture size to fracture. Stiffness of brain material was varied and results on the stress values were recorded. [7]

These were some of the previous studies done in the field pertaining to fracture in infant skull. 


\section{Procedure}

In this section I would like to walk through the procedure used to create the model and what all steps were followed to generate results.

\subsection{Software Used}

To carry on the simulations on a complex structure such as a skull, it was to be meshed first and later simulated as per the given conditions. To do so, a powerful analysis tool was needed. Thus, Hypermesh was used as it being a versatile software capable of efficiently carrying out the tasks. Hypermesh version 14.0 was used and results were viewed in HyperView software, which is a part of the package of Hyperworks family specifically used to view and extract results from a Hypermesh file.

\subsection{Development of 3 D FEM Model of Pediatric Head}

The model used for the simulations consist of 5 separate entities placed inside one another. These are -
1) Scalp
2) Skull
3) Duramater
4) Cerebrospinal Fluid (CSF)
5) Brain

These sit in the same order as mentioned, in one another. Hence the scalp forms the outermost part and brain is protected by all the layers above and hence forms the inner most layer of the assembly. 


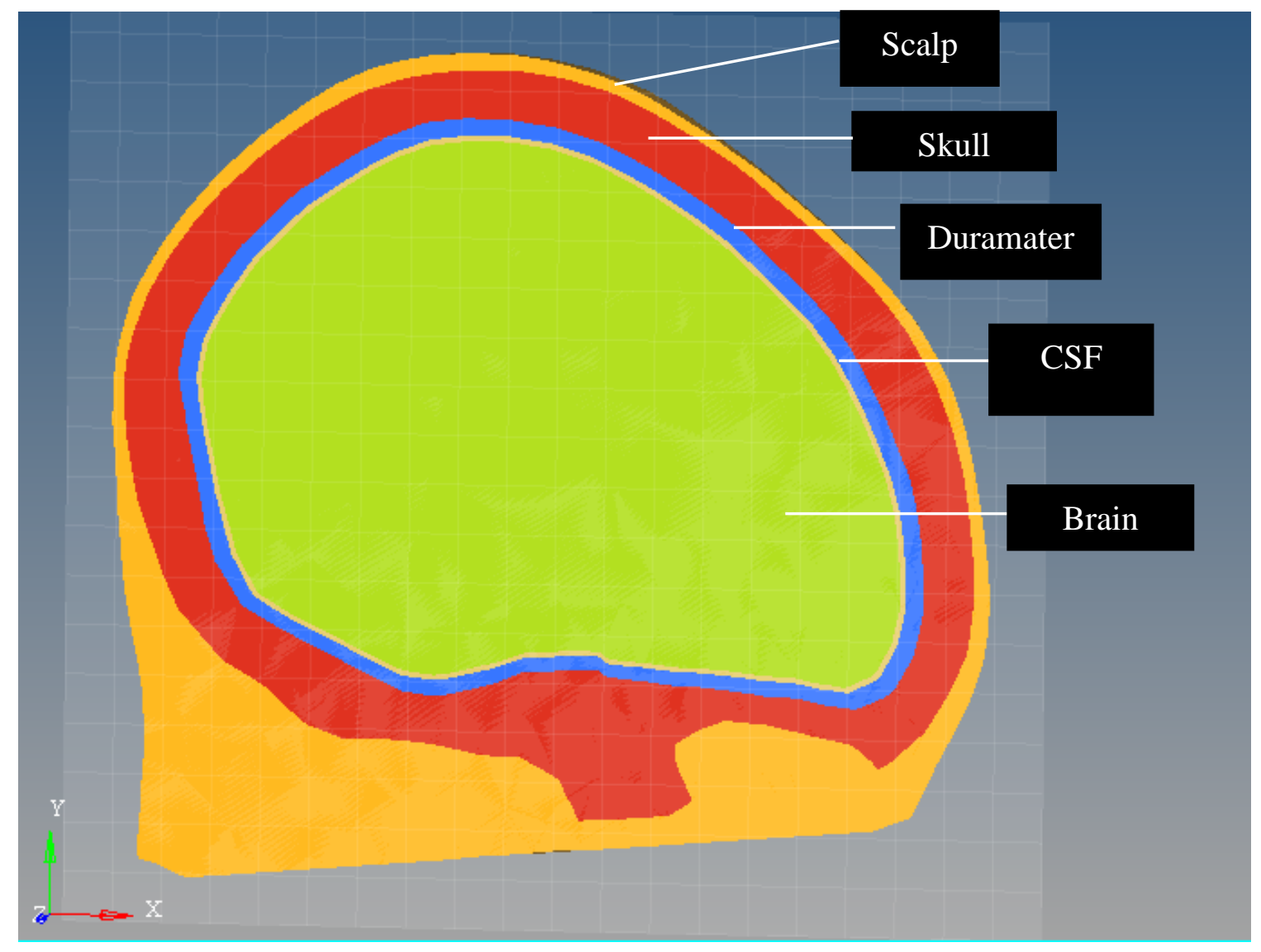

Figure 1: Sectional Cut of the Head Assembly

A CT scan of a 3-year-old girl child was obtained. Further, all the images were put together using a software MIMICS. Then the images were converted to CAD files using CATIA and assembly was made with the help of it. Once the CAD file was ready, it was imported in the Hypermesh environment to mesh it and carry out further simulations.

The mesh elements are Tetrahedral in shape and have element size of $10 \mathrm{~mm}$. In total, there are 12011 nodes and 65958 elements in the assembly. In detail bifurcation is shown below: 
Table 1: Element Data Table

\begin{tabular}{|c|c|}
\hline Component & No of Elements \\
\hline Scalp & 33735 \\
\hline Skull & 11799 \\
\hline Dura mater & 6199 \\
\hline CSF & 6204 \\
\hline Brain & 8021 \\
\hline
\end{tabular}

The material properties of the components of the assembly are listed below -

Table 2: Component Material Property Table

\begin{tabular}{|l|c|c|c|}
\hline Component & $\begin{array}{c}\text { Young's } \\
\text { Modulus(MPa) }\end{array}$ & Density $\left(\mathbf{k g} / \mathbf{m}^{\mathbf{3}}\right)$ & Poisson's Ratio \\
\hline Scalp & 16.7 & 1200 & $0.42[8]$ \\
\hline Skull & 2500 & 2150 & $0.22[9]$ \\
\hline Duramater & 31.5 & 1140 & $0.45[8]$ \\
\hline CSF & 0.012 & 1040 & $0.49[10]$ \\
\hline Brain & $\mathrm{G}_{0}=49 \mathrm{kPa} ; \mathrm{G}_{\infty}=16.2 \mathrm{kPa} ; \beta=145 / \mathrm{s} ; \mathrm{K}=1125 \mathrm{Mpa}[11]$ \\
\hline
\end{tabular}

\subsection{Validation of the Model}

The model used in this work was validated by Prajwal Mahesh [12]. The experiment setup by Prange [13] was used to validate the model. In the setup, the whole new born head was subjected to compression, against the walls moving with a constant velocity of $1 \mathrm{~mm} / \mathrm{s}$. The force and deformation tests were carried out by Mr. Prajwal and matched against the experimental results.

Also, linear accelerations were taken out for various parts of the skull at various times for a 30-cm drop. Impact velocity was calculated by the formula

$$
\mathrm{V}=\sqrt{2 g h}
$$

Some of the nodes and elements in the posterior part of the head were fixed and a metal plate was made to hit the head with a velocity of $1 \mathrm{~mm} / \mathrm{s}$. The metal plate was given a young's modulus of $200 \mathrm{GPa}$. The whole experiment was imitated in Hypermesh software and solved using Radioss solver. 


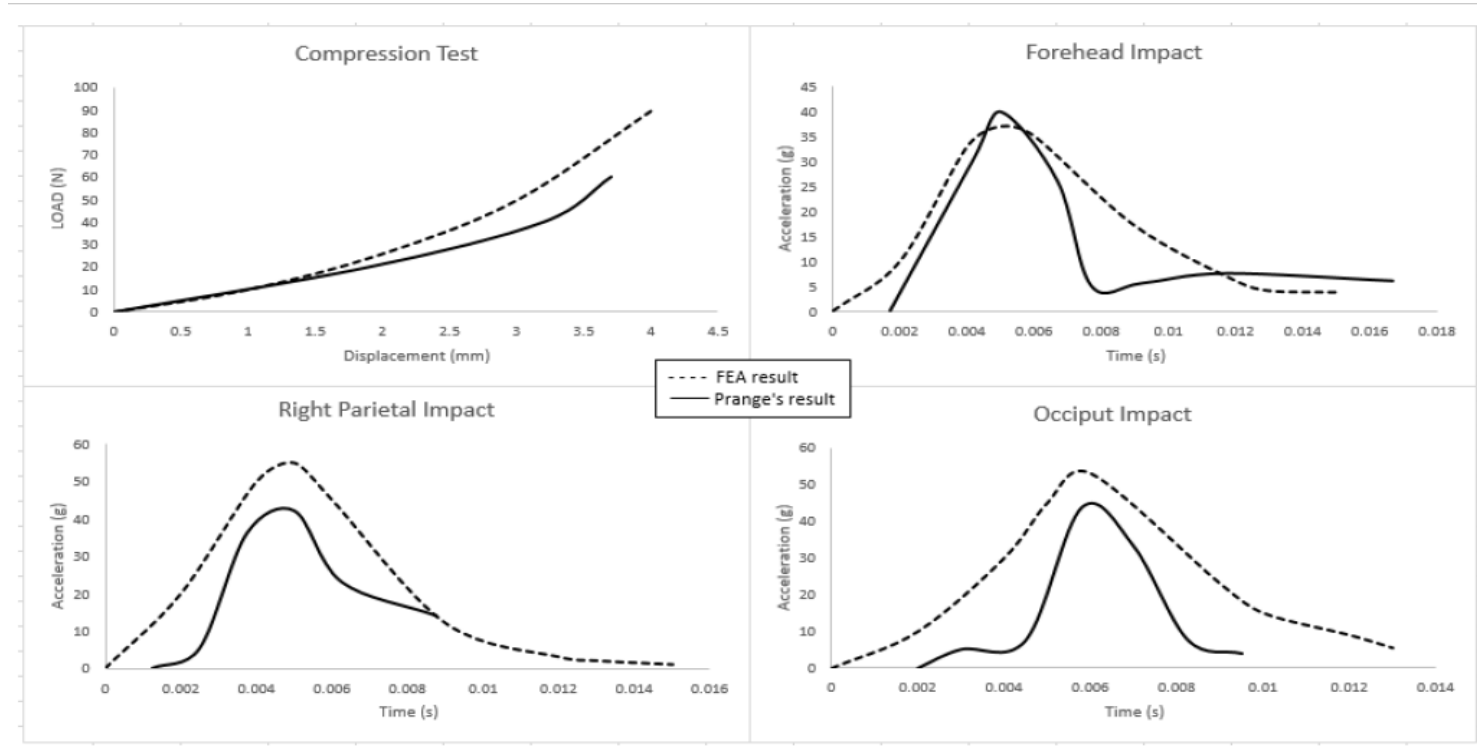

Figure 2 :Compression and $30 \mathrm{~cm}$ height free fall results comparison between FEA model and Prang's experiment

The above results show a near match of the results and ensures that the model is validated. The differences in the experiment and FEA results is due to the fact that it may be well assumed that since the model behaves correctly in quasi static loading conditions, it is expected to behave correctly in dynamic loading as well.

\subsection{Methodology and Test Run}

The test set was divided into 4 types of impacts on the skull namely-
1) Frontal Impact
2) Posterior Impact
3) Lateral Impact
4) Superior Impact

Each of the above mentioned was then sub divided into 5 heights of drops. In all there were 20 simulation runs in the test set. 
Various regions are shown below-

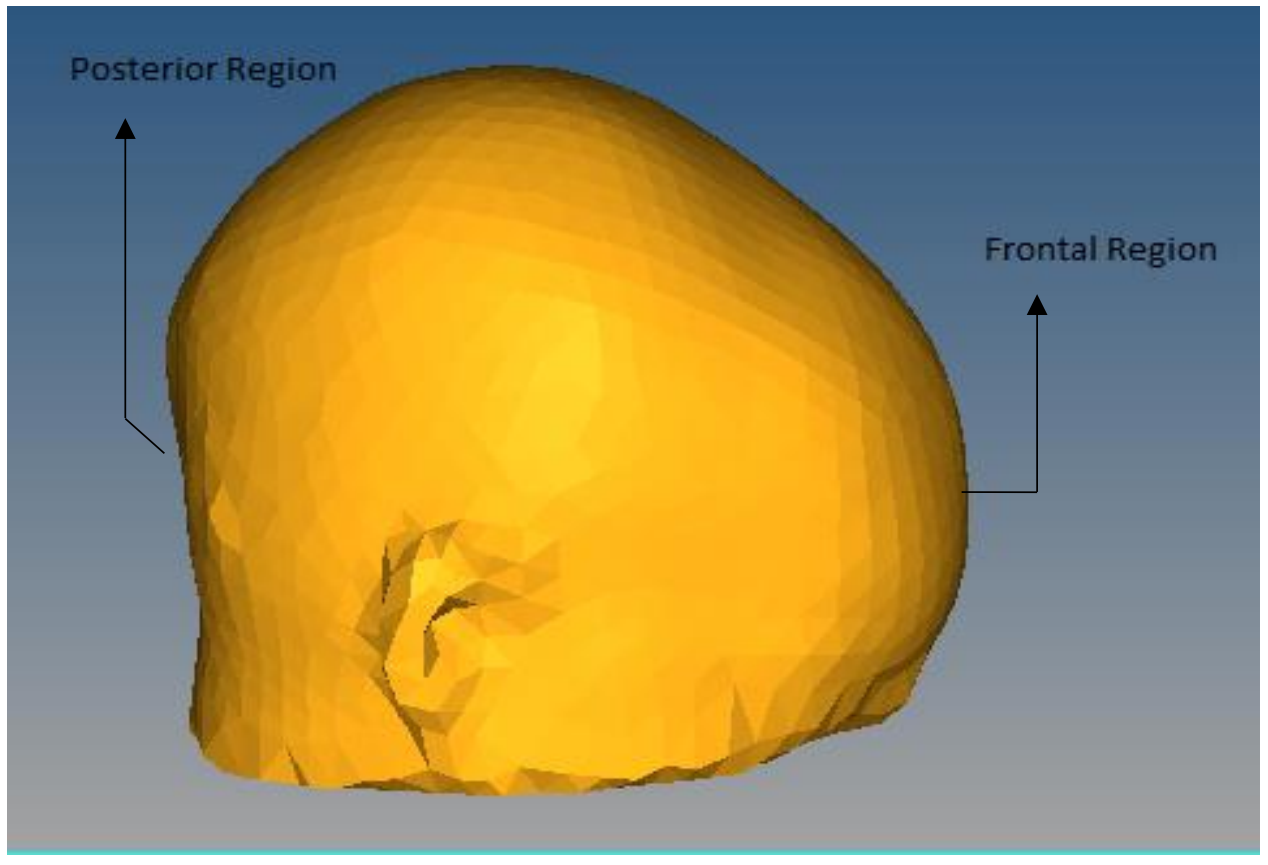

Figure 3: Side View of the Assembly

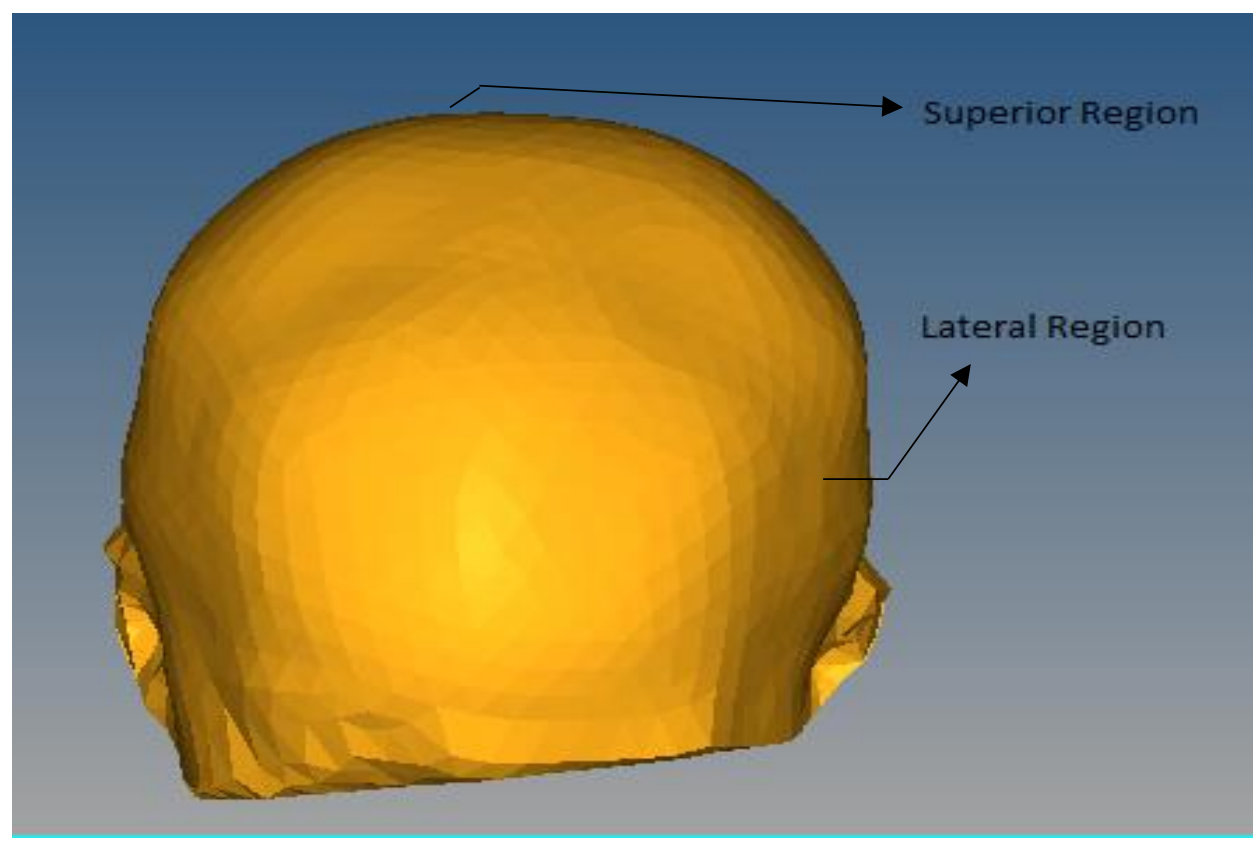

Figure 4: Front View of the Assembly

A rigid wall of very hard material was chosen to imitate the ground. The skull was then made to hit the wall normally, with speed under free fall keeping the wall stationary. The speed was calculated as per the following formula - 
$\mathrm{V}=\sqrt{2 g h}$

Where, $\mathrm{h}=$ height in meters

$\mathrm{g}=$ acceleration due to gravity $\left(9.81 \mathrm{~m} / \mathrm{s}^{2}\right)$

Table 3: Impact Velocity Vs Drop Heights

\begin{tabular}{|l|l|}
\hline Drop Height & Impact Velocity \\
\hline $55 \mathrm{~cm}$ & $328.44 \mathrm{~cm} / \mathrm{s}$ \\
\hline $45 \mathrm{~cm}$ & $297.04 \mathrm{~cm} / \mathrm{s}$ \\
\hline $35 \mathrm{~cm}$ & $262.01 \mathrm{~cm} / \mathrm{s}$ \\
\hline $25 \mathrm{~cm}$ & $221.43 \mathrm{~cm} / \mathrm{s}$ \\
\hline $15 \mathrm{~cm}$ & $171.52 \mathrm{~cm} / \mathrm{s}$ \\
\hline
\end{tabular}

After the test was run, postprocessing was carried out using HyperView. 


\section{Results and Discussion}

Following section contains pictorial and graphical representations of stress and strain distributions of the skull after impact.

\subsection{Maximum Principle Stress Distribution Patterns}

Following are the distribution patterns of Maximum Principle Stress and strain just after the impact has happened. Principle stress pattern is a major tool that highly determines the point of fracture initiation in the skull. The cranial bone is very strong in compression but weak in handling tensile loads. Hence the tensile stresses are the one causing the fractures.

\subsubsection{Frontal Impact Stress Patterns}

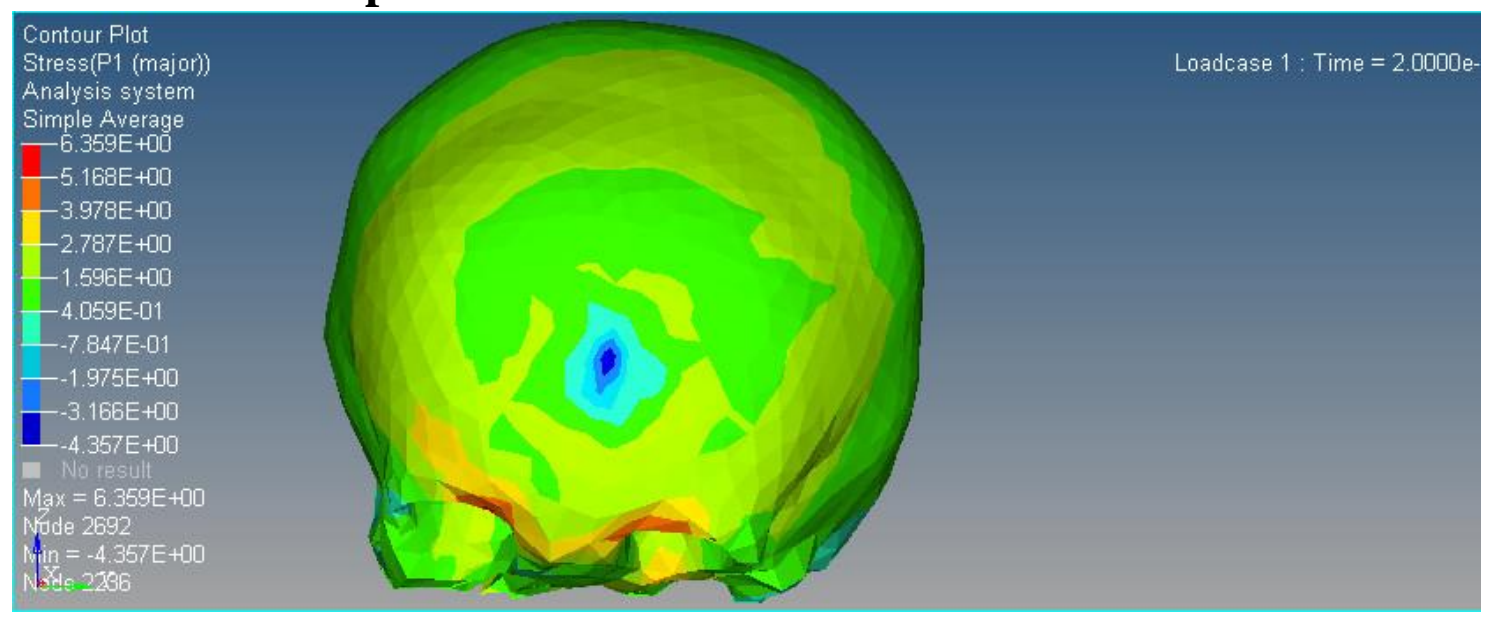

Figure 5 :55-cm Drop Frontal Impact Principle Stresses (Major)

The above is a depiction of principle stress along the principle major axis, the maximum value of which is $6.359 \mathrm{MPa}$ (Tensile). The dark blue region is the point of impact and is the site of maximum compressive stresses. The region surrounding it gradually transforms to tensile stress sites and as shown, the two sites in the lower frontal region, shown in orange and red color have maximum tensile stress concentration. Hence this region is most vulnerable to fractures in case of frontal impact and as visible, it is far away from the site of impact. 


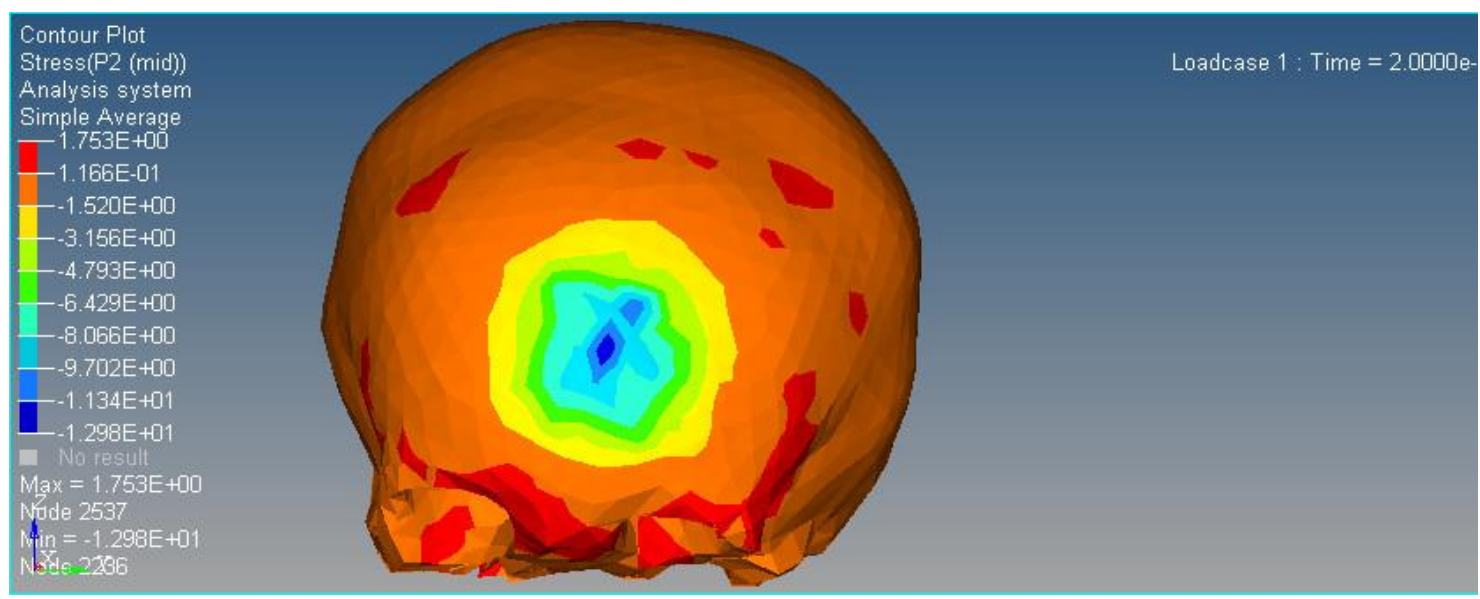

Figure 6 :55-cm Drop Frontal Impact Principle Stresses (Mid)

The above figure shows principle stresses along mid-principle axis, maximum value of which is $12.98 \mathrm{MPa}$ (compressive). The region shown in dark blue is the site of impact and stresses in that region are compressive in nature. As the figure depicts, most of the regions of the skull are having tensile stresses. The transition from compressive to tensile happens in the region shown in orange color. The region shown in red are the sites of maximum tensile stresses with magnitude ranging from 0.1166 to $1.753 \mathrm{MPa}$. This is the region most prone to fracture in the above case. As visible, this region is far away from site of impact.

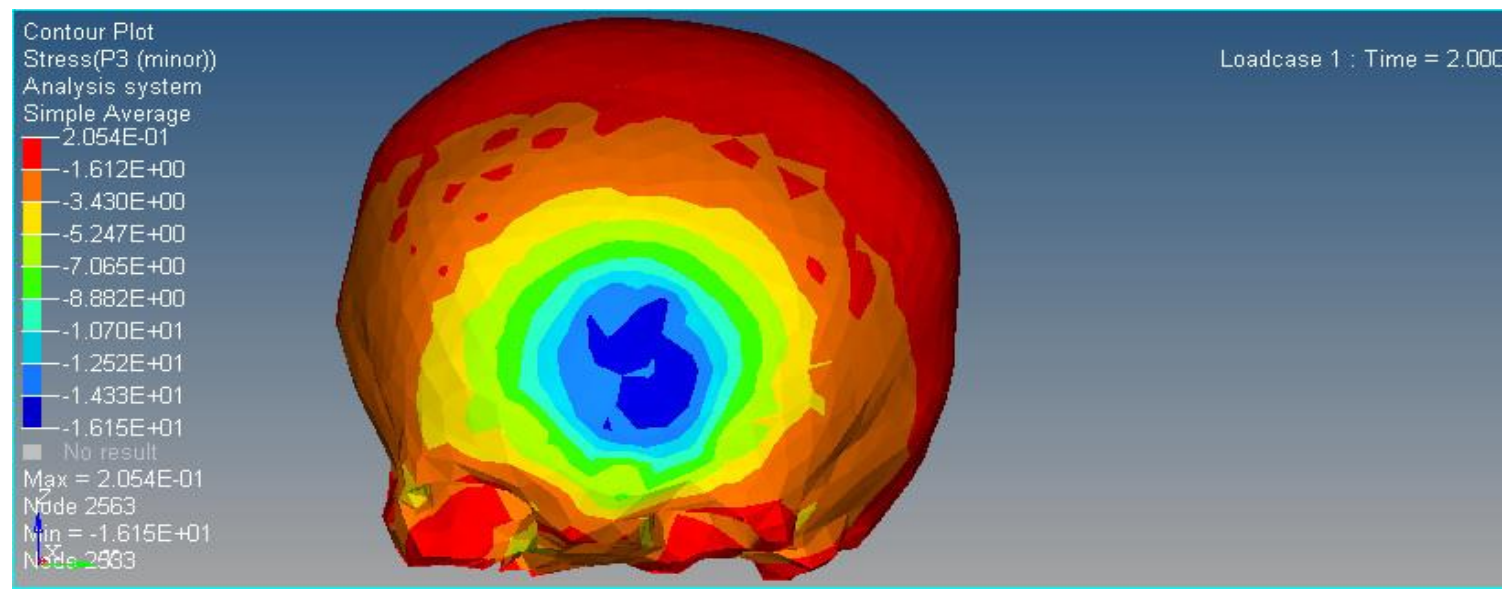

Figure 7: 55-cm Drop Frontal Impact Principle Stresses (Minor)

Above is the stress distribution measured along minor principle axis. The maximum value of which is $16.15 \mathrm{MPa}$ (compressive). The region shown in red is most vulnerable to fracture and has most of the tensile stresses in it. The tensile stresses are distributed over a large region hence smaller in intensity (magnitude). The region shown in dark blue is the 
site of impact and has maximum compressive stresses, which range between 16.15 to 14.33 $\mathrm{MPa}$.

\subsection{Von Mises Stress and Strain Pattern}

The following are the von mises stress and strain distribution patterns in the skull. It does not possess any direction and is just a value. It critically determines the failure and is an indicator of deformation for a given material.

\subsubsection{Frontal Impact}

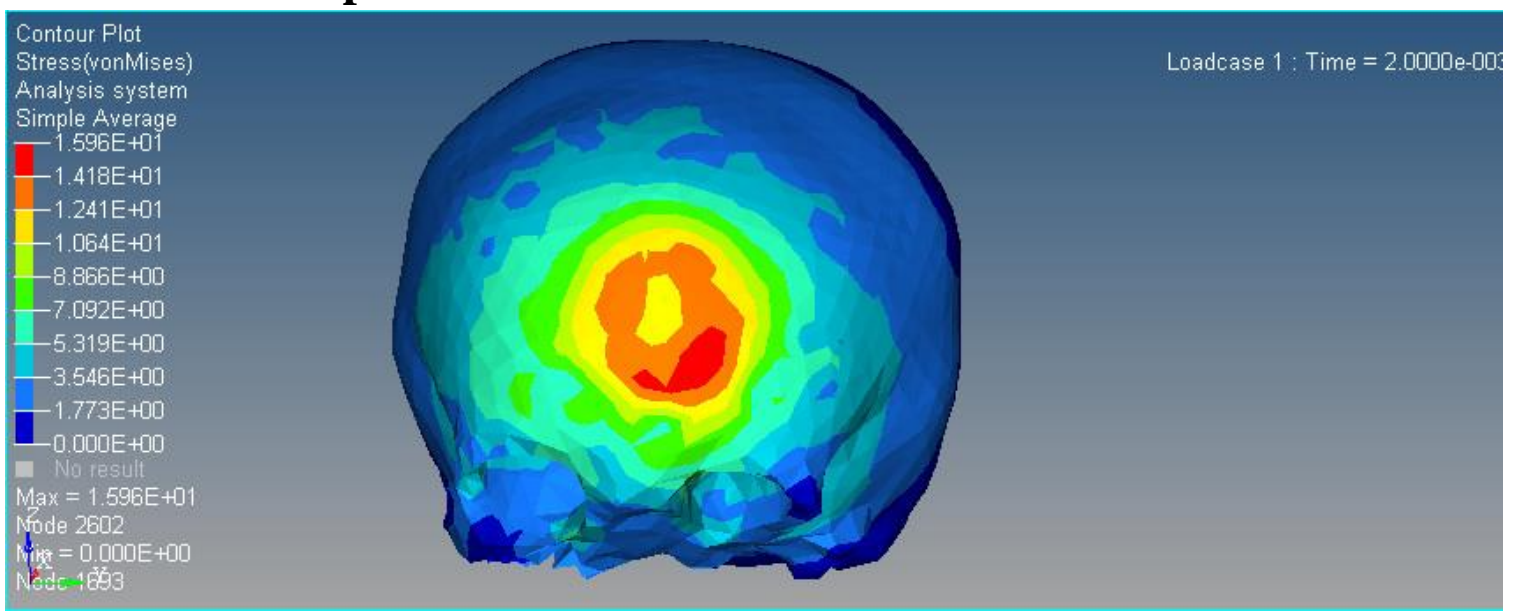

Figure 8: 55-cm Drop Frontal Impact von Mises Stresses

The above is a depiction of von Mises stresses pattern after the impact. The maximum value of the stress is $15.96 \mathrm{MPa}$ and is indicated by red color. As visible, the max von Mises and hence the maximum deformation is in the same region as the site of impact. The deformation and stress reduce to negligible values as we move away from site of impact.

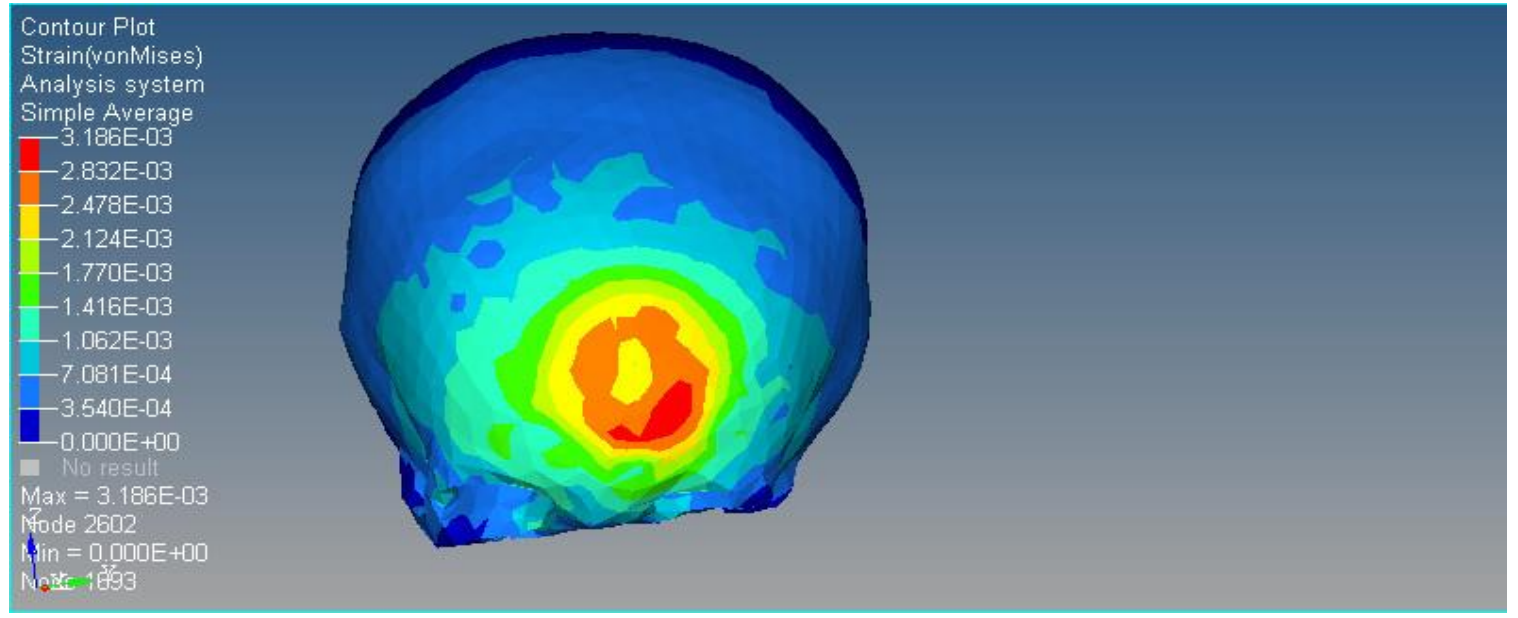

Figure 9: 55-cm Drop Frontal Impact von Mises Strain 
Above is the von Mises strain distribution in the skull. The maximum von mises strain value in the skull is 0.00318 , in the area near point of impact.

\subsection{Tensile and Compressive Stress and Strain Patterns}

The following figures depict the tensile stresses and strains in the skull after the impact. The stresses near the point of impact are compressive in nature and those away are generally tensile ones.

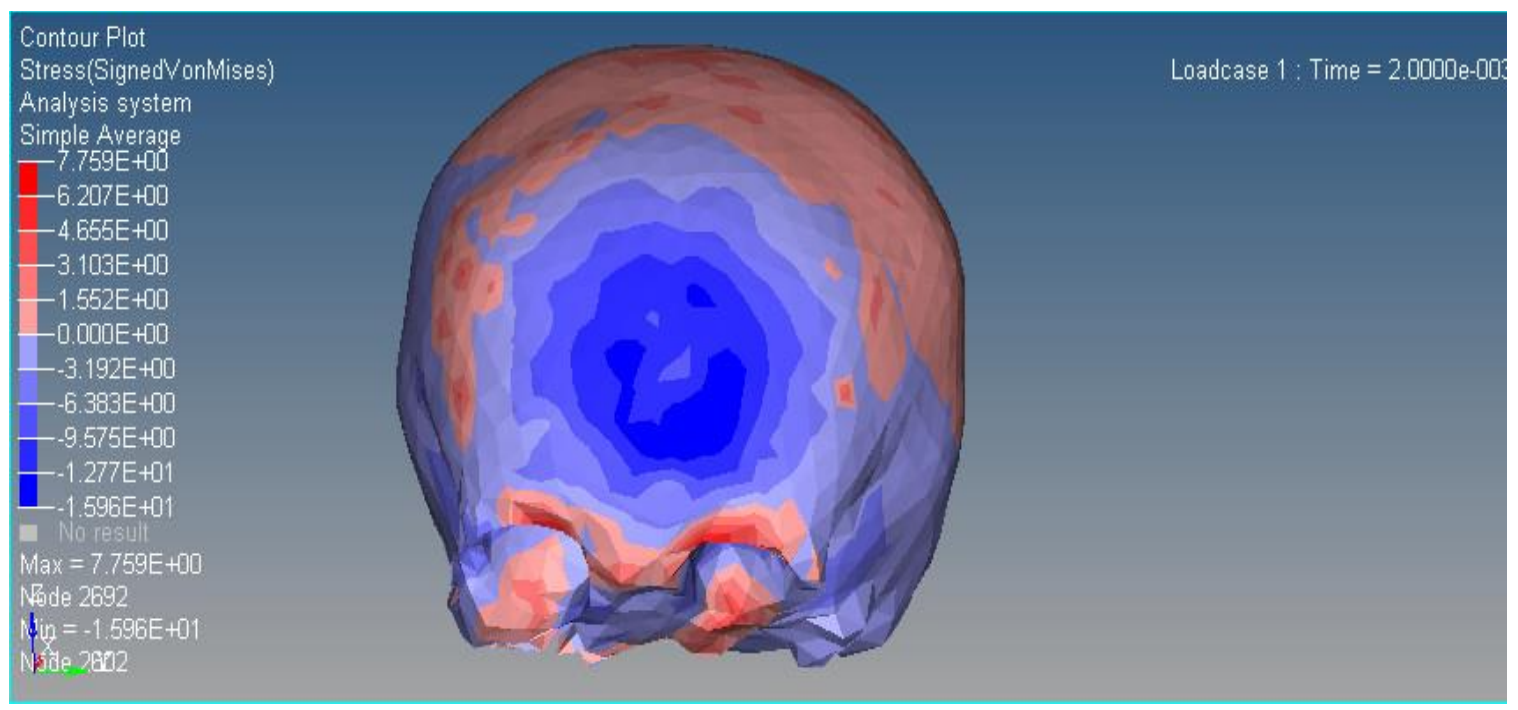

Figure 10: 55 cm Frontal Impact Tensile \& Compressive Stress Distribution

The maximum tensile stress in the above figure is $7.75 \mathrm{MPa}$ and maximum compressive stress is $15.96 \mathrm{MPa}$. A gradual transformation from compressive to tensile can be seen as we move away from the impact site which is depicted in dark blue color. The maximum compressive stresses range in between 12.77 to $15.96 \mathrm{MPa}$, depicted in dark blue color. The maximum tensile stresses are in the same region as maximum principle stress and range in between 6.2 to $7.75 \mathrm{MPa}$ and are depicted in red color. This would give us an estimate of point of fracture initiation. 


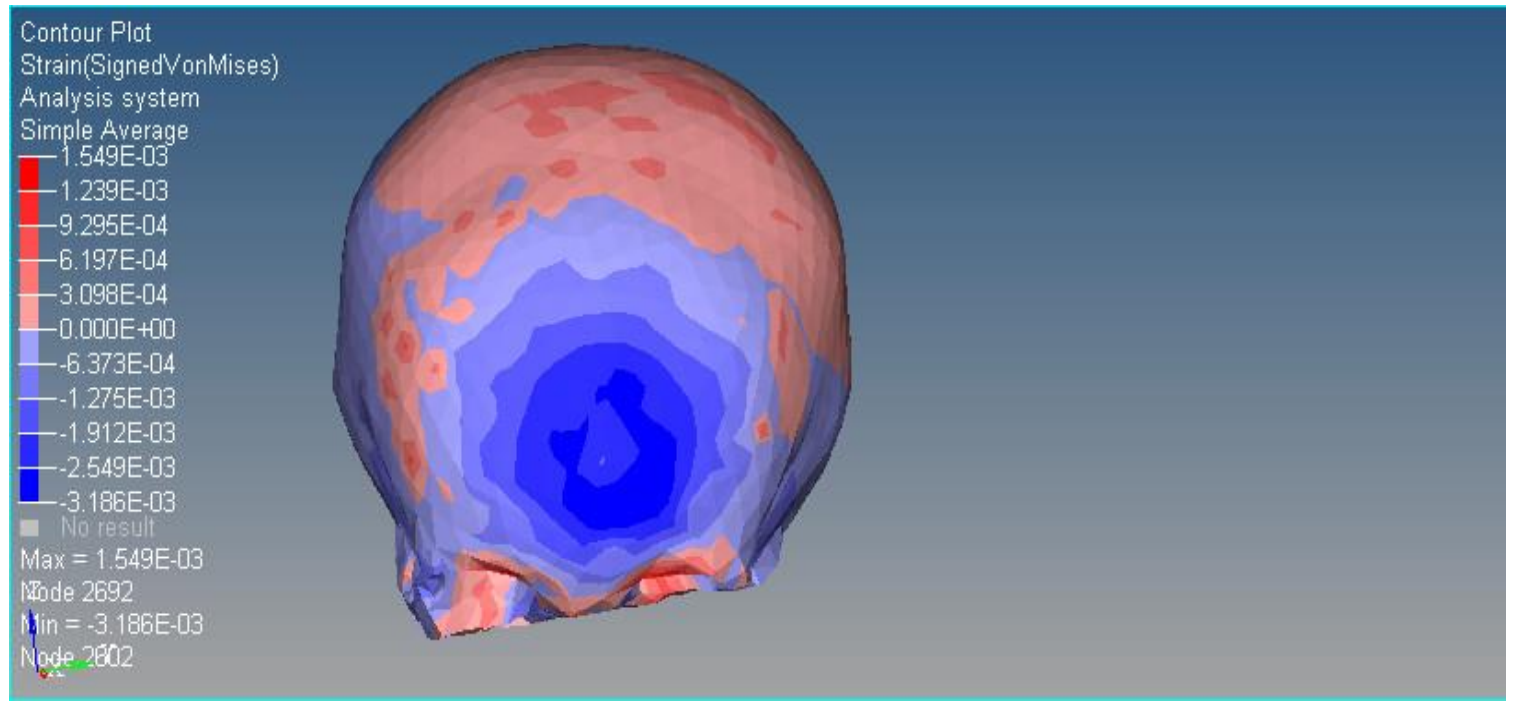

Figure 11: 55-cm Drop Frontal Impact Tensile \& Compressive Strains

As the above figure shows, the tensile and compressive strain values are 0.0015 and 0.00318 .

\subsection{Point of Impact and Maximum von Mises Stress}

Below is a depiction of how far is the point of impact from point of maximum von Mises stress. The white mesh shown in the below figure is wire mesh of scalp and stress pattern visible is in a layer beneath (skull). The black tetrahedral element shown is the point of impact on the scalp, and the black node (square) is the point of maximum von Mises stress.

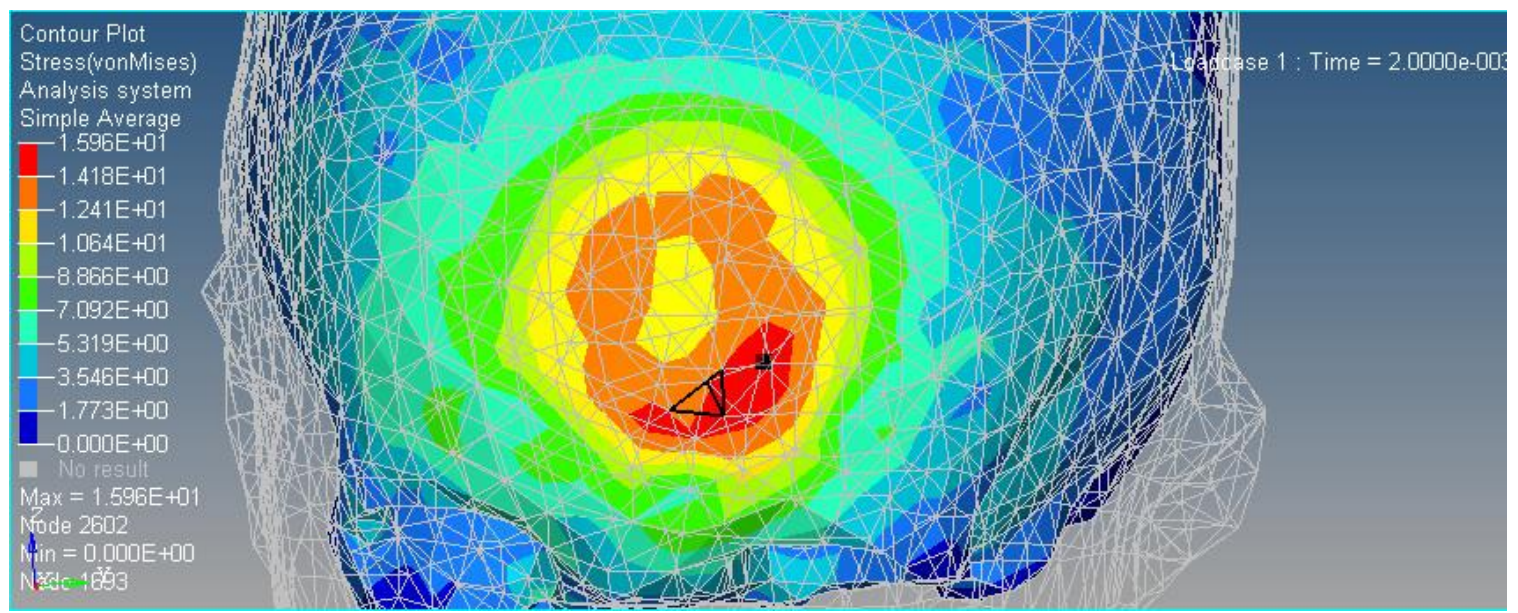

Figure 12: Point of Impact and Maximum von Mises Stress

The node with max stress value is numbered 2602, that with min stress value is numbered 1693. Element of impact is numbered 435612. The max stress in the region is $15.96 \mathrm{MPa}$. 


\subsection{Point of Impact and Region of Potential Fracture}

The stresses that are tensile in nature are the cause of fractures in the bone, as the skull is weaker in tension than in compression.

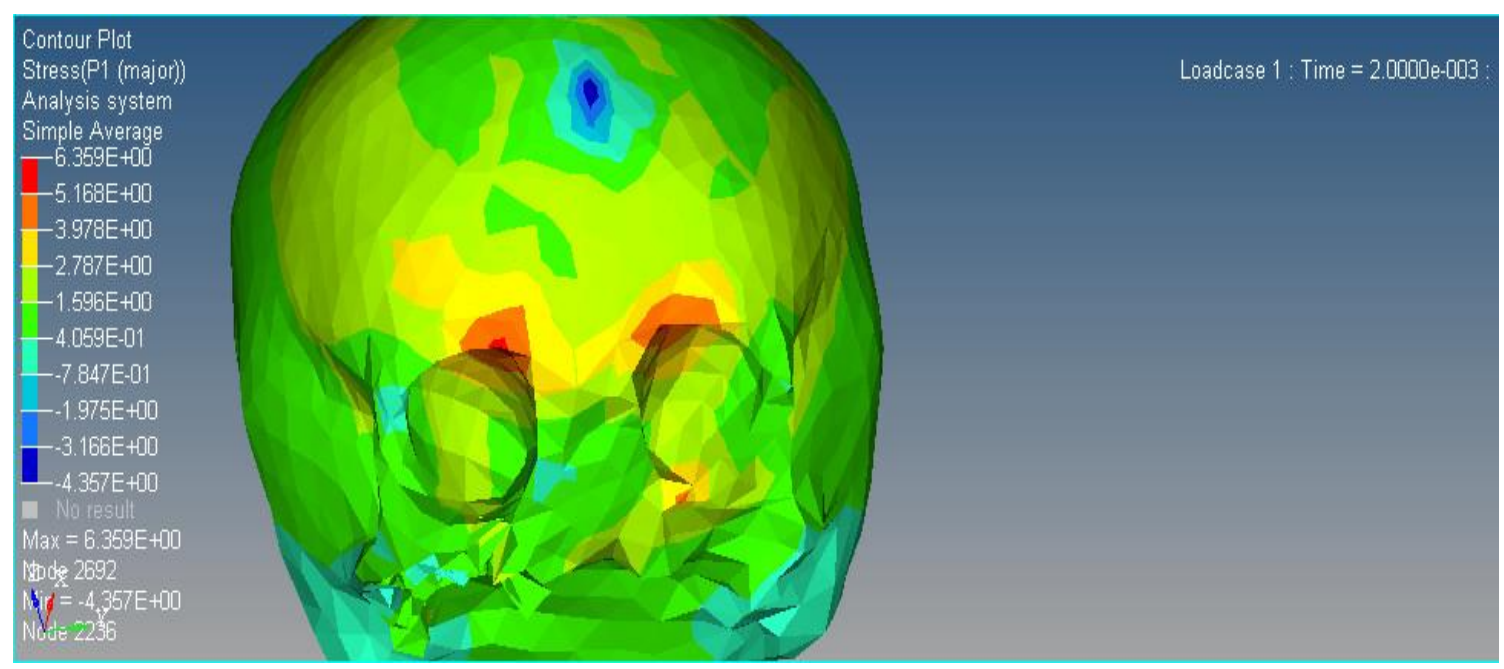

Figure 13: Frontal Impact \& Potential Fracture Site

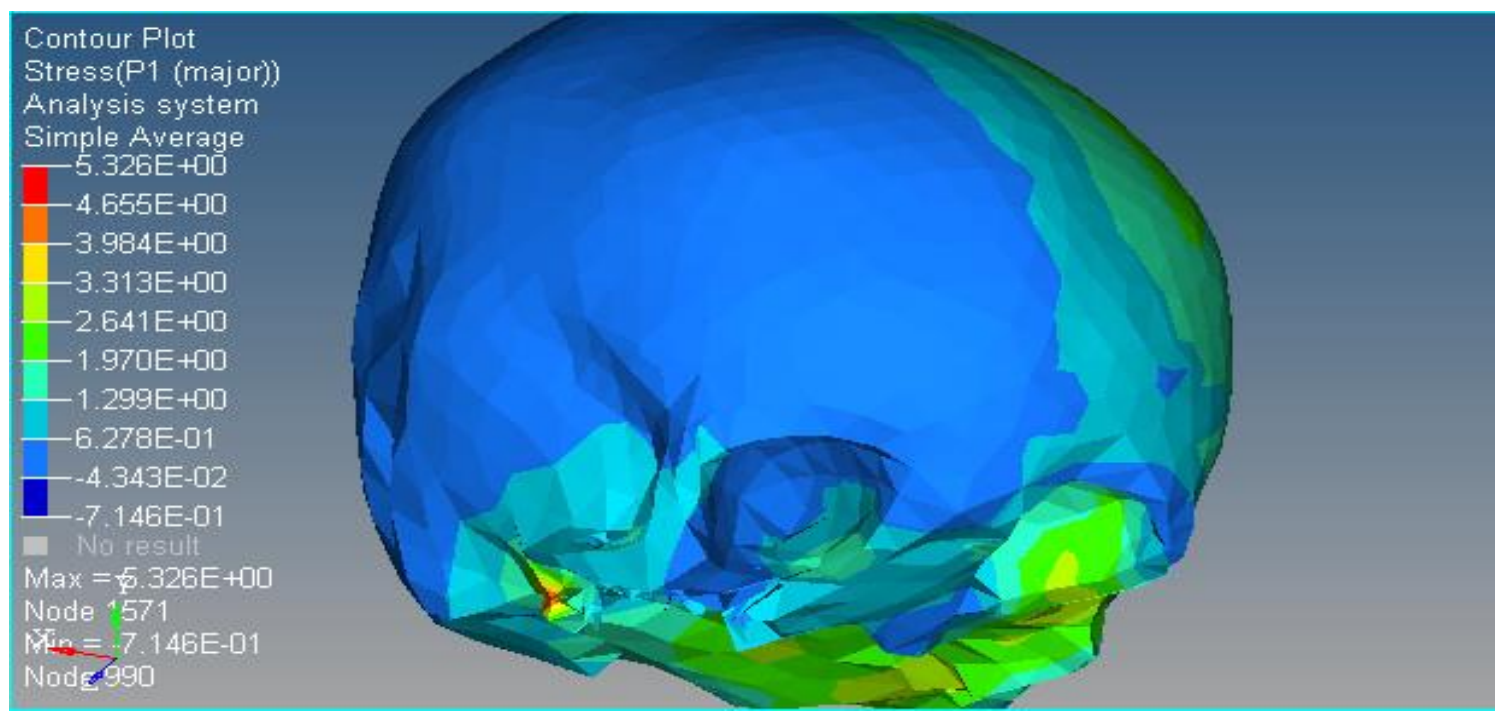

Figure 14: Lateral Impact \& Potential Fracture Site 


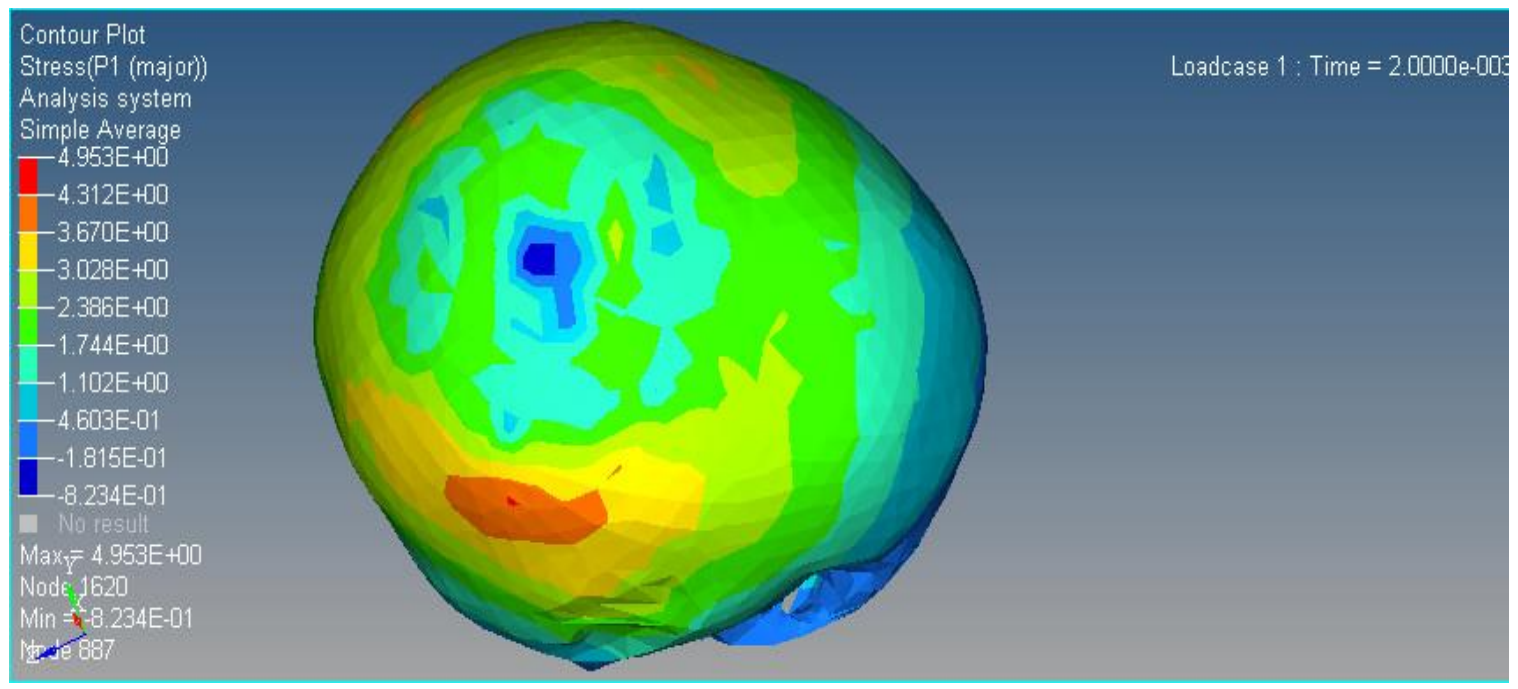

Figure 15: Superior Impact \& Potential Fracture Site

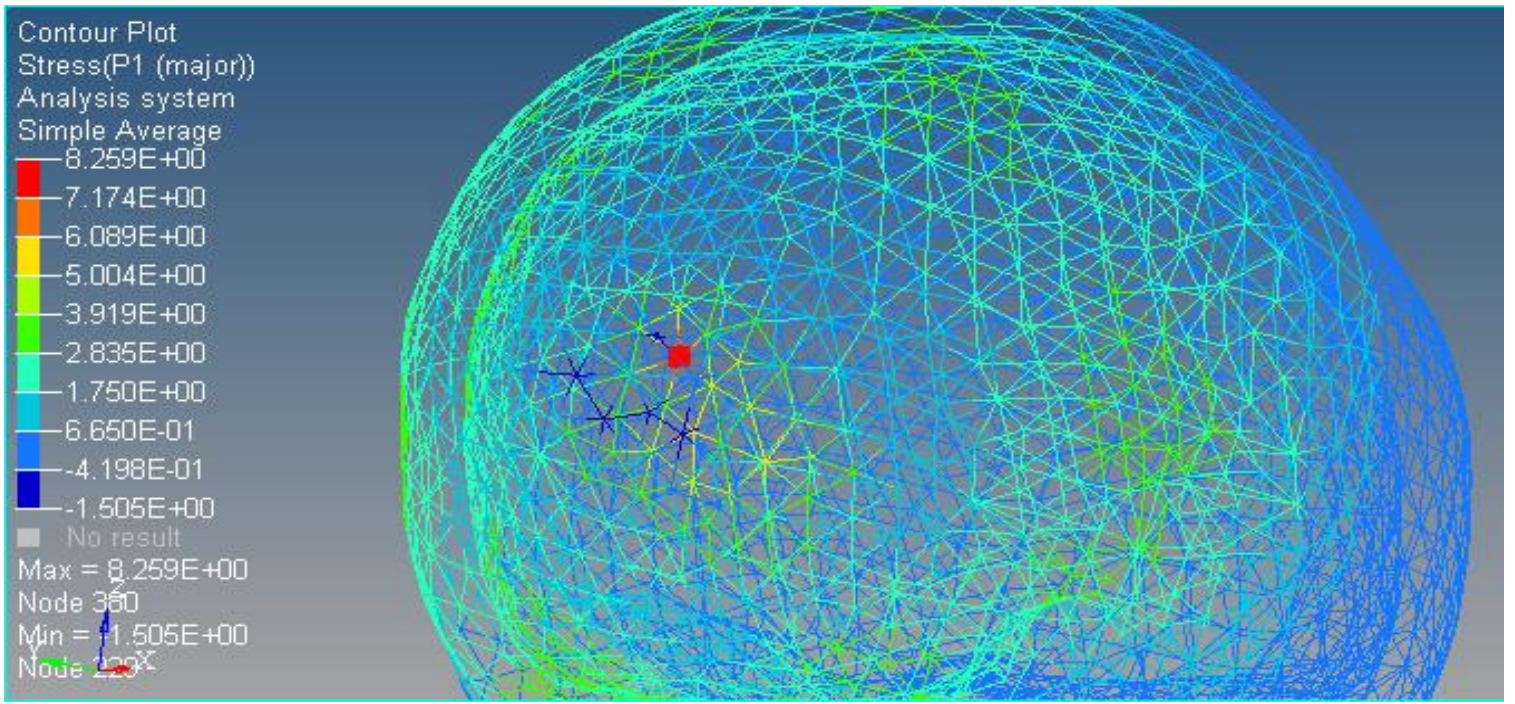

Figure 16:Posterior Impact \& Potential Fracture Site

The red regions are the regions of max principle stresses in the skull and potentially the fracture sites. The dark blue regions in the first three pictures show the site of impact. It is visible that the potential site of fracture may not be always the site of impact. For frontal impact, the region lies near the eye ball slot. For lateral impact, it lies in radially opposite direction to that of site of impact. For superior impact, it lies in lateral region of the skull near the point of impact.

For posterior region only, the site of impact and the site of max principle stress (tensile) happens to be the same. The point of potential fracture for this case happens to be beneath 
the point of impact, near the lower layer of the skull. Hence for better understanding of this case, the wire meshed view of skull is shown.

\subsection{Graphs}

This section shows graphical presentation of various stresses against respective drop heights for all impact situations (Lateral, Frontal, Posterior, Superior impacts). The scatter plots were then used to estimate a straight line through them, using least square regression method.

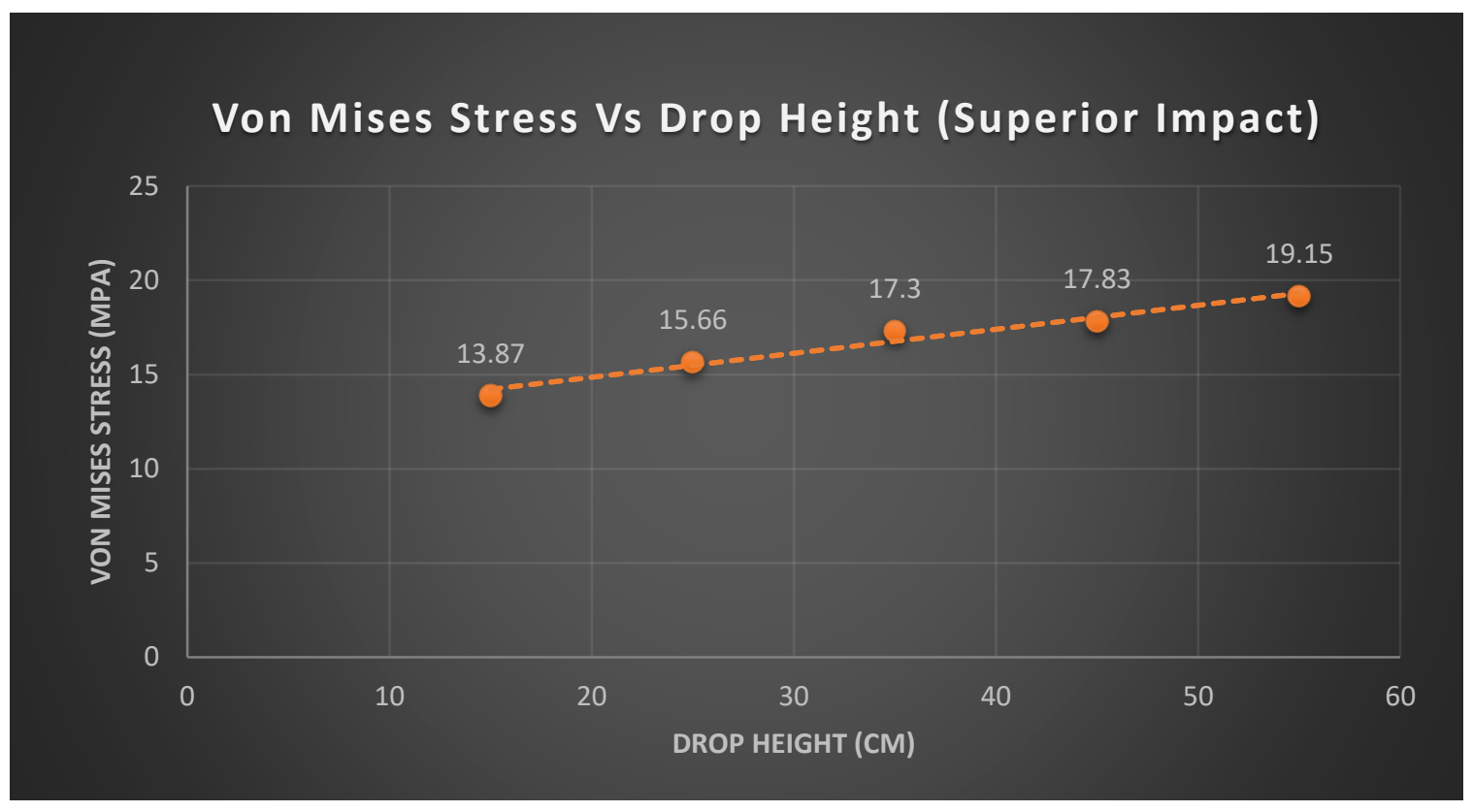

Graph 1: Von Mises Stress Vs Drop Height for Superior Impact 


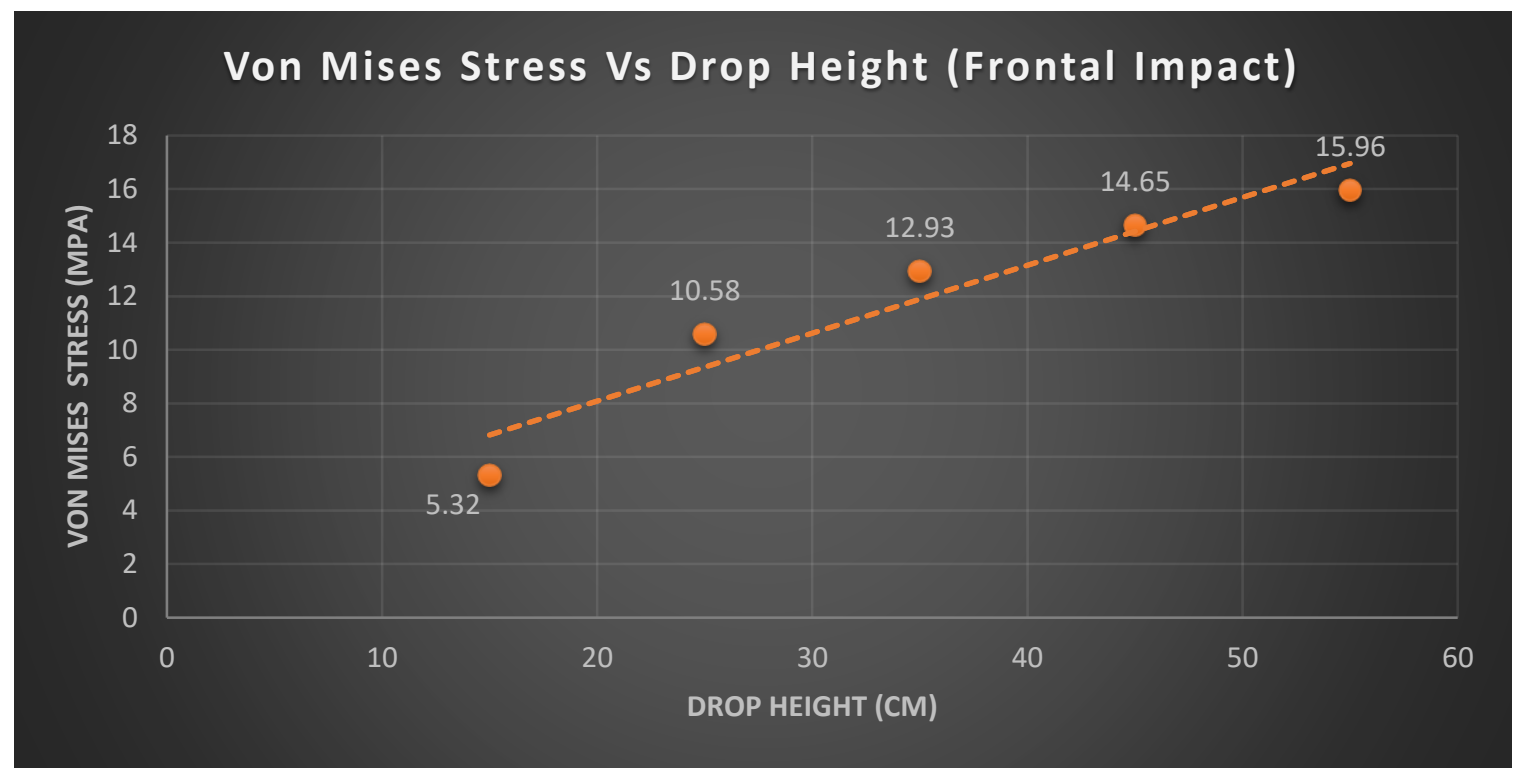

Graph 2: Von Mises Stress Vs Drop Height for Frontal Impact

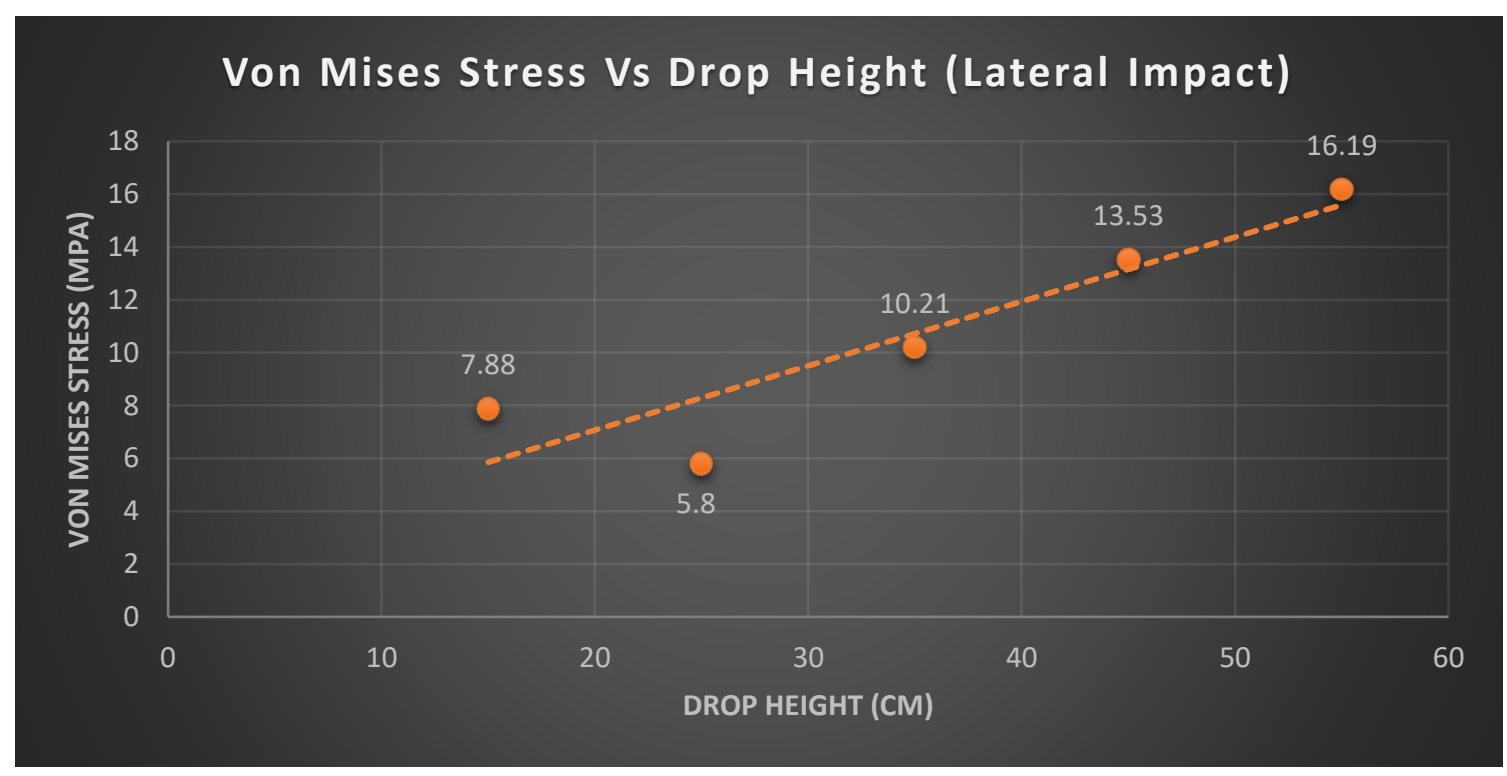

Graph 3: Von Mises Vs Drop Height for Lateral Impact 


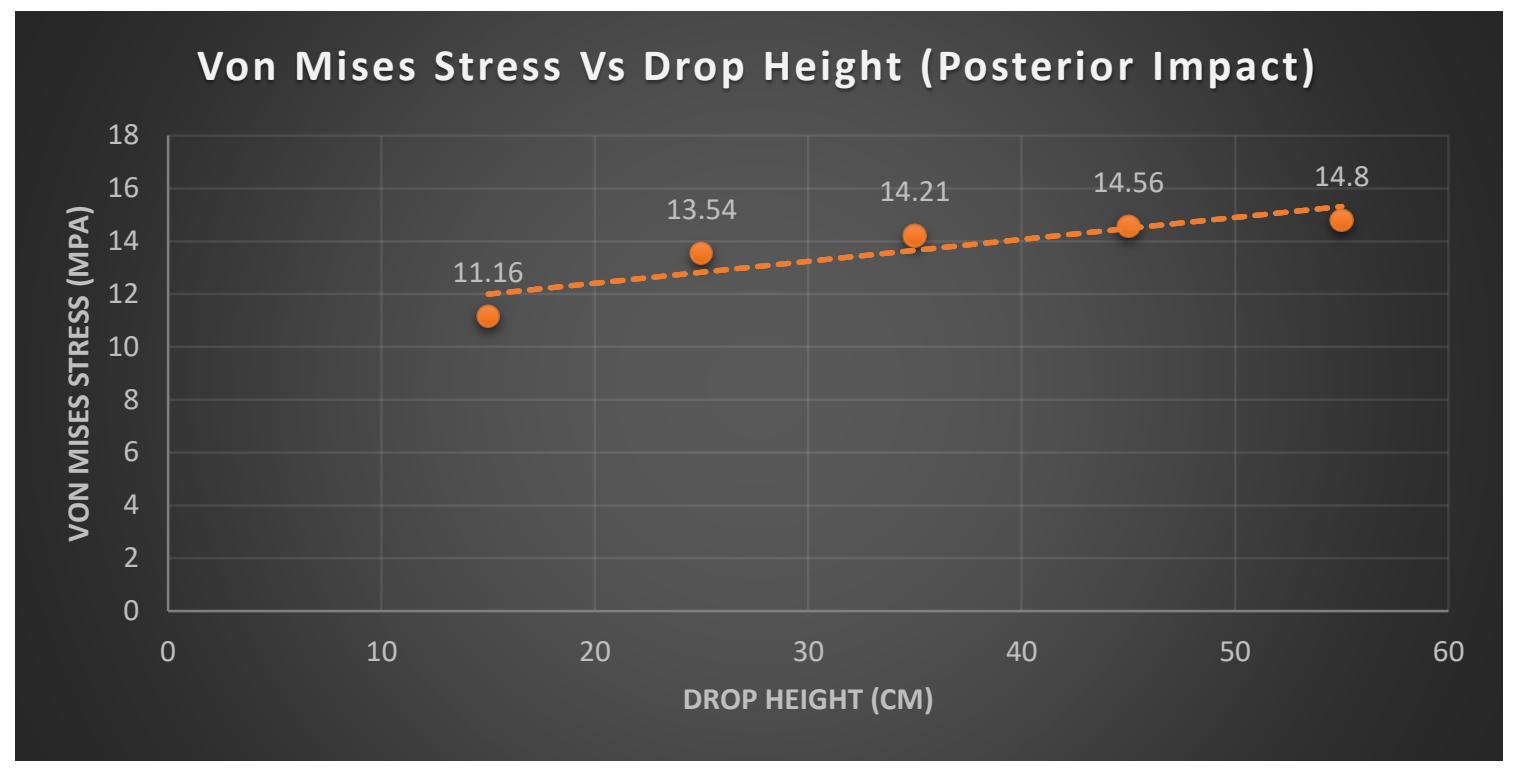

Graph 4: Von Mises Vs Drop Height for Posterior Impact

All the above graphs portray a linearly increasing trend in the stress values. The slope of the graphs for posterior and superior impact is less steep and gradual as compared to the graphs for lateral and frontal impact cases. The value of slope for a given curve indicates how rapidly the stresses induced are increasing with an increase on drop height.

Von Mises stress is a direct indicative of how much deformation is the impact causing on the skull.

The maximum value of stress is in superior impact case, which is $19.15 \mathrm{MPa}$, followed by lateral impact, with $16.19 \mathrm{MPa}$, frontal impact with stress magnitude of $15.96 \mathrm{MPa}$ and posterior region with the least stress of $14.8 \mathrm{MPa}$. All these values are for $55 \mathrm{~cm}$ drop. 


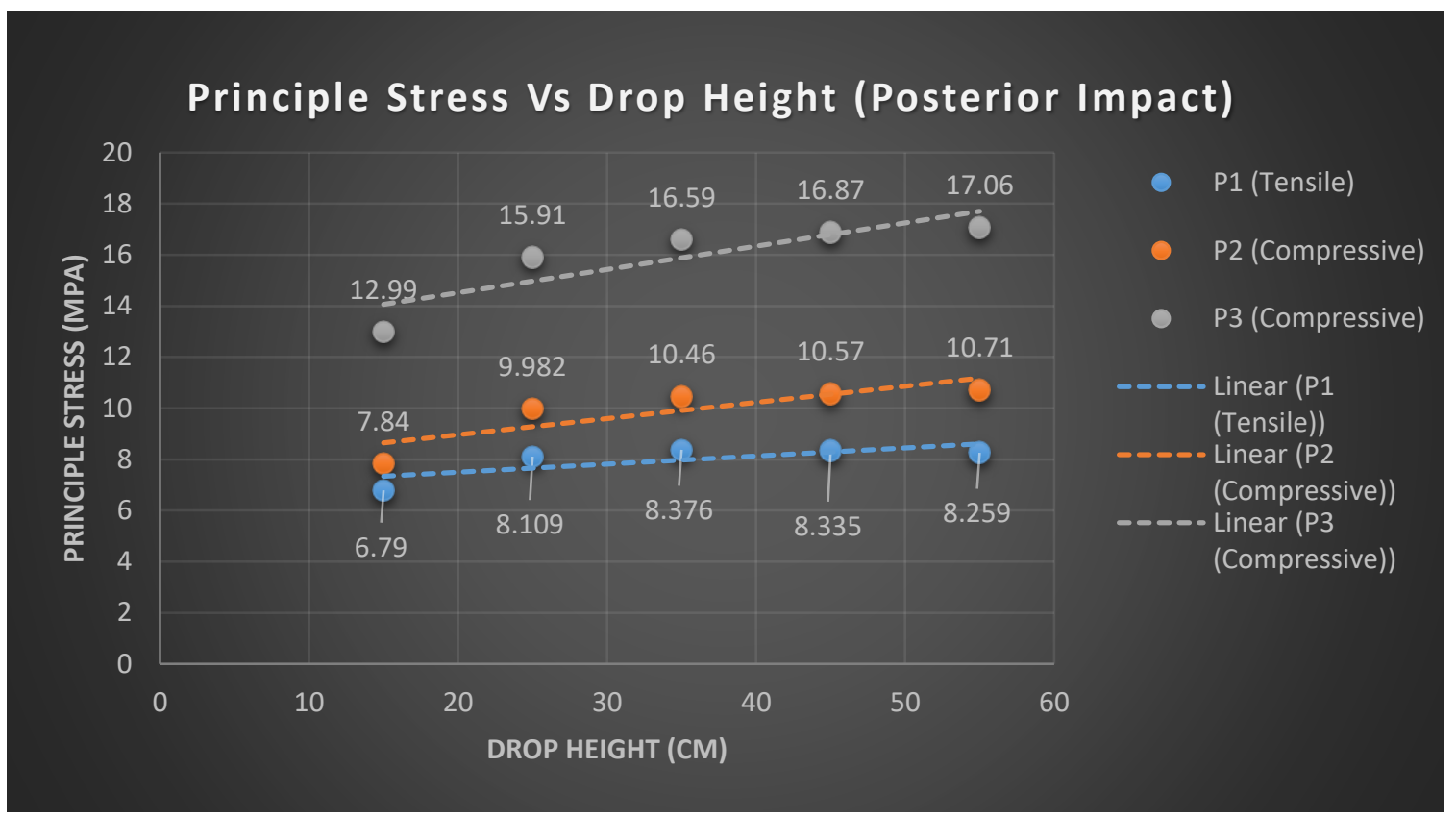

Graph 5: Principle Stress Vs Drop Height (Posterior Impact)

In the above graph, the stresses shown in blue line are tensile in nature and the others are compressive. The maximum value of tensile stress in the region is $8.376 \mathrm{MPa}$ for $35 \mathrm{~cm}$ drop, but as we know that stresses should increase with increase in drop height, the max stress is considered for $55 \mathrm{~cm}$ drop. The anomaly should be treated as computational error. Maximum principle compressive stress in the skull for the case is $17.06 \mathrm{MPa}$ (55 cm drop). The stresses responsible for fracture are always the tensile ones. For this case, the slope of the tensile stress curve is small. The slope of the graph indicates that rate of growth of tensile stress is small. This factor will highly affect the vulnerability of the region and its proneness to fracture. 


\section{Principle Stress Vs Drop Height (Superior Impact)}

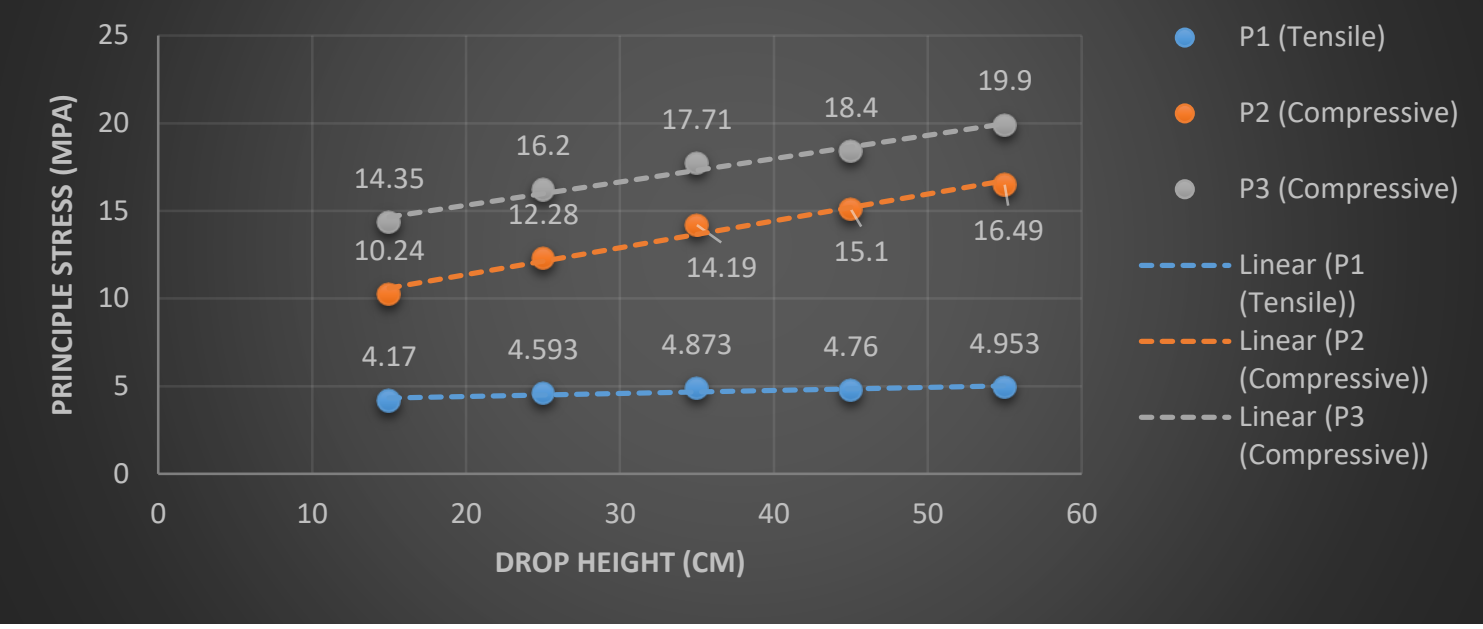

Graph 6: Principle Stress Vs Drop Height (Superior Impact)

In the above graph, the maximum value of compressive stress reached is $19.9 \mathrm{MPa}$ for 55 $\mathrm{cm}$ drop. As the graph depicts, the tensile curve (blue line) has a very small slope in comparison to graphs of other regions. Hence tensile stress does not increase over the drop heights much. The maximum tensile stress value is $4.95 \mathrm{MPa}$ (55 cm drop).

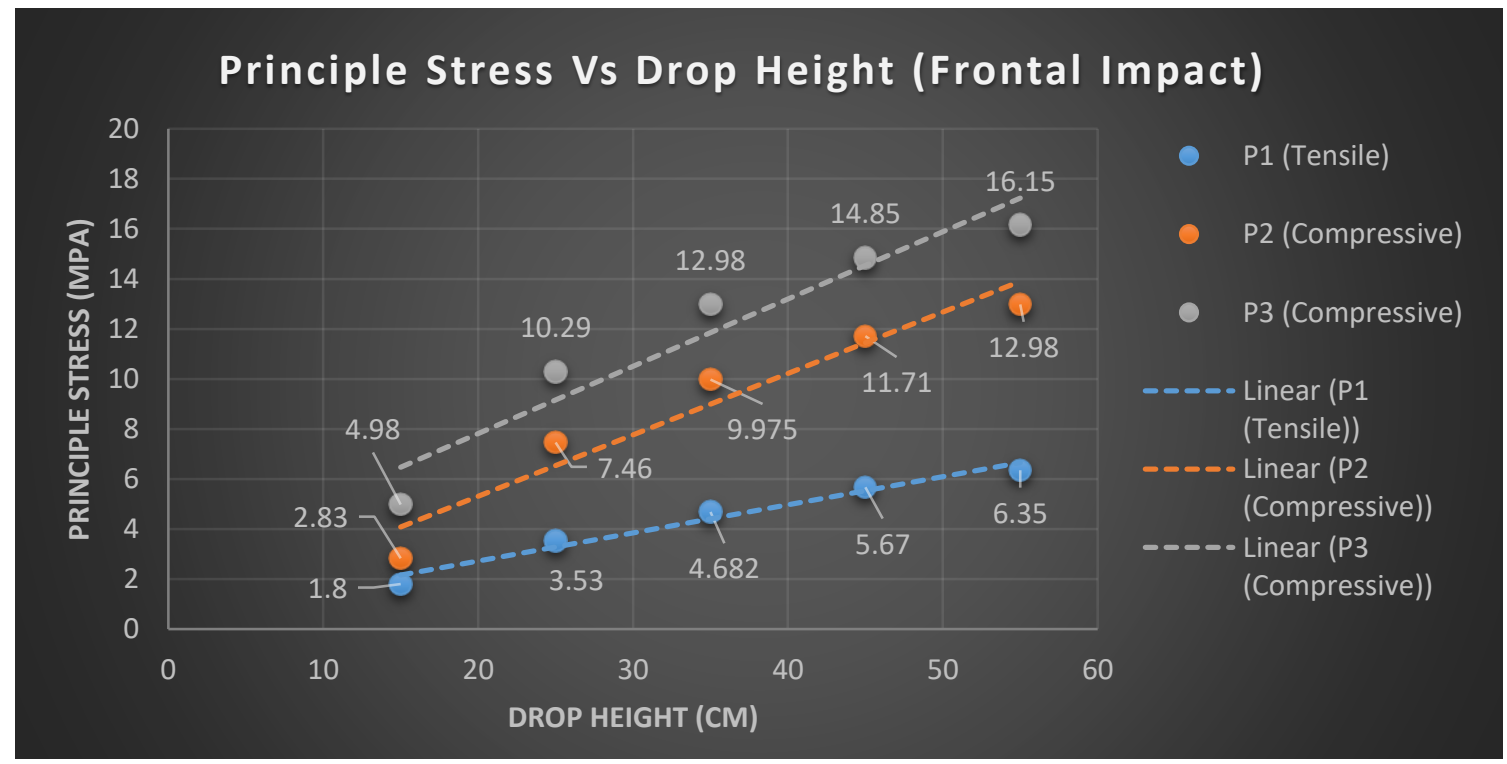

Graph 7: Principle Stress Vs Drop Height (Frontal Impact)

In the above graphical depiction, the maximum value of compressive stress is $16.15 \mathrm{MPa}$ and maximum tensile stress is noted to be $6.35 \mathrm{MPa}$. Both correspond to $55 \mathrm{~cm}$ drop case. As one can see, the slope of the tensile stress curve is more as compared to superior and 
posterior impact cases. Thus, the tensile stresses are likely to increase at a higher rate as compared to other cases. This makes the region more vulnerable to fractures.

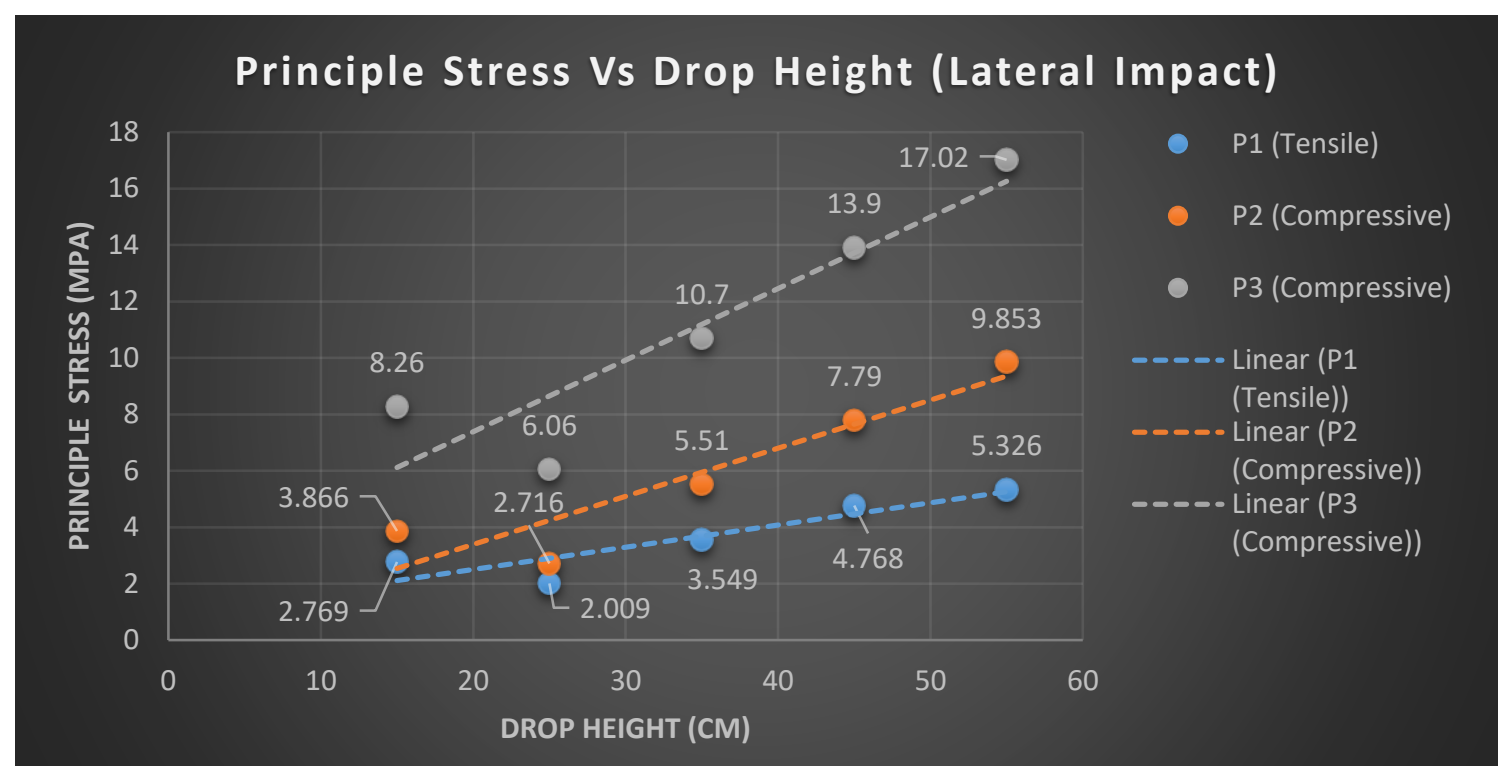

Graph 8: Principle Stress Vs Drop Height (Lateral Impact)

The above graph indicates the stress trends for lateral impact case. The maximum tensile stress corresponds to $55 \mathrm{~cm}$ drop height and is $5.32 \mathrm{MPa}$. The maximum value of stress in compression also corresponds to $55 \mathrm{~cm}$ drop and is $17.02 \mathrm{MPa}$. It can be noted that the slope of the tensile curve is higher as compared to posterior and superior impact cases. The stress would increase at a higher rate hence.

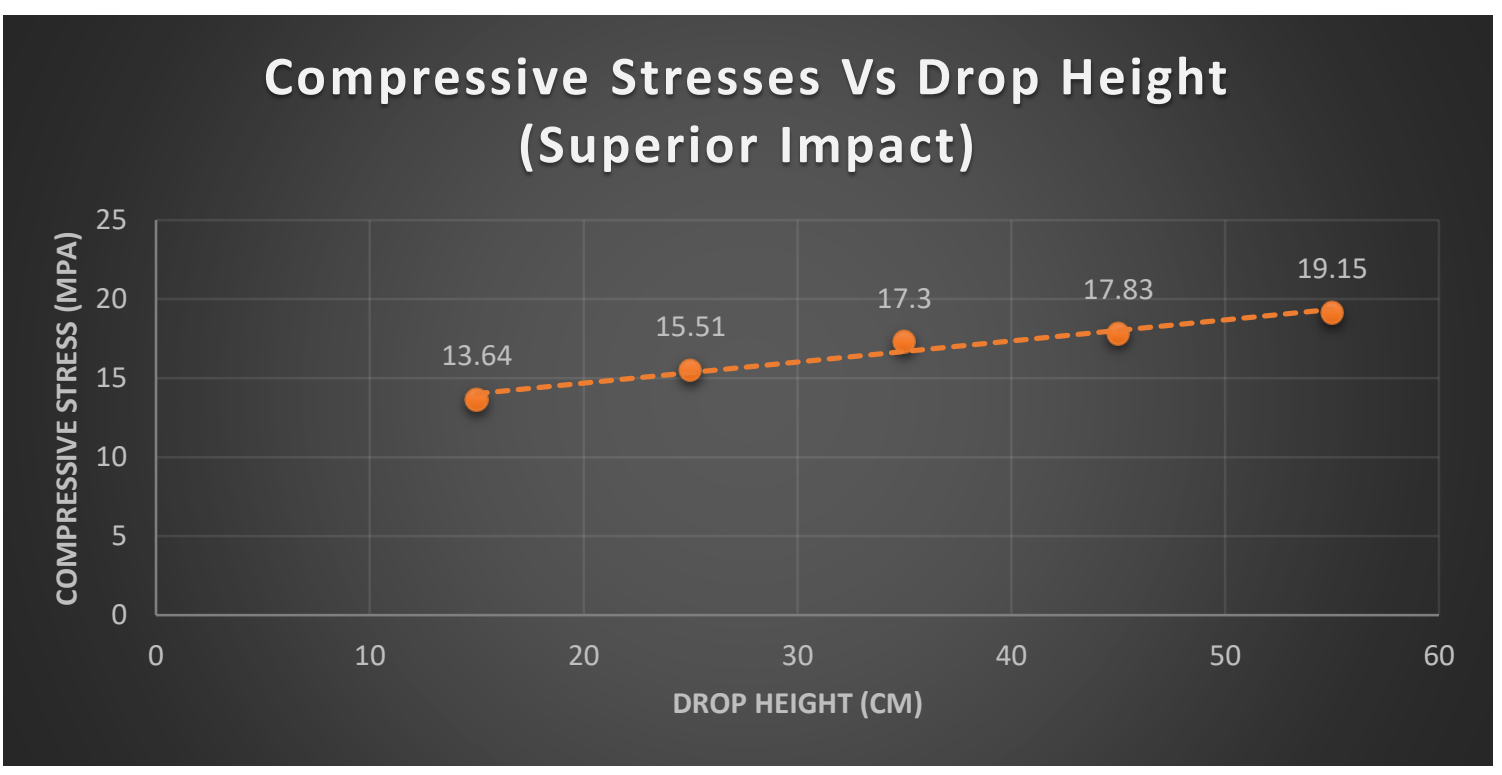

Graph 9: Compressive Stresses Vs Drop Height (Superior Impact) 
The above is the compressive stress graph for superior impact. The maximum and minimum values correspond to 55 and $15 \mathrm{~cm}$ drop heights and are 19.15 and $13.64 \mathrm{MPa}$ respectively. The graph clearly indicates the positive slope of the stress trend and hence the compressive stresses would increase with increase in drop height.

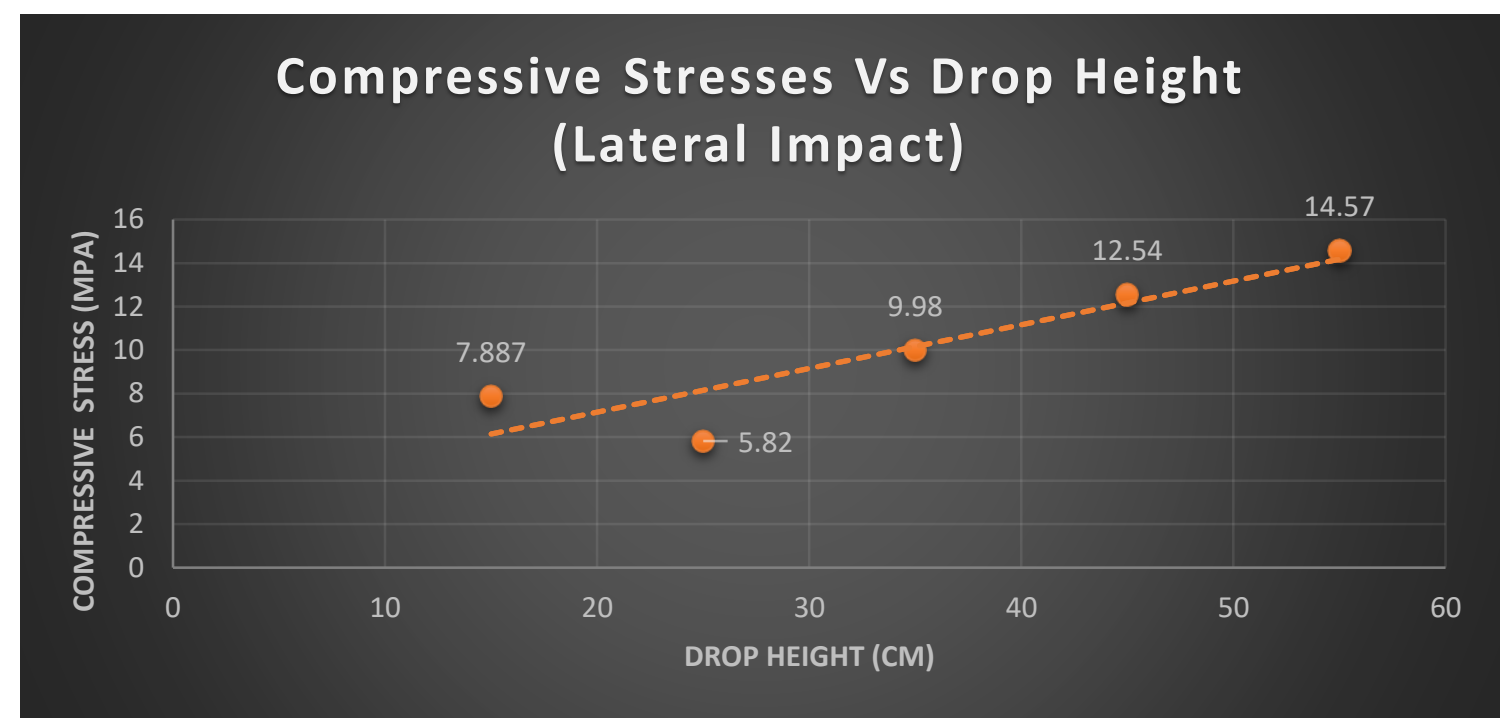

Graph 10: Compressive Stresses Vs Drop Height (Lateral Impact)

The maximum and minimum stress correspond to 55 and $25 \mathrm{~cm}$ drop and are 14.57 and 5.82 $\mathrm{MPa}$ respectively. The stresses show increasing trend as the drop height is increased. The graph shows that the slope of the graph is much higher than the other curves, thus deformation would rapidly increase with further increase in drop height.

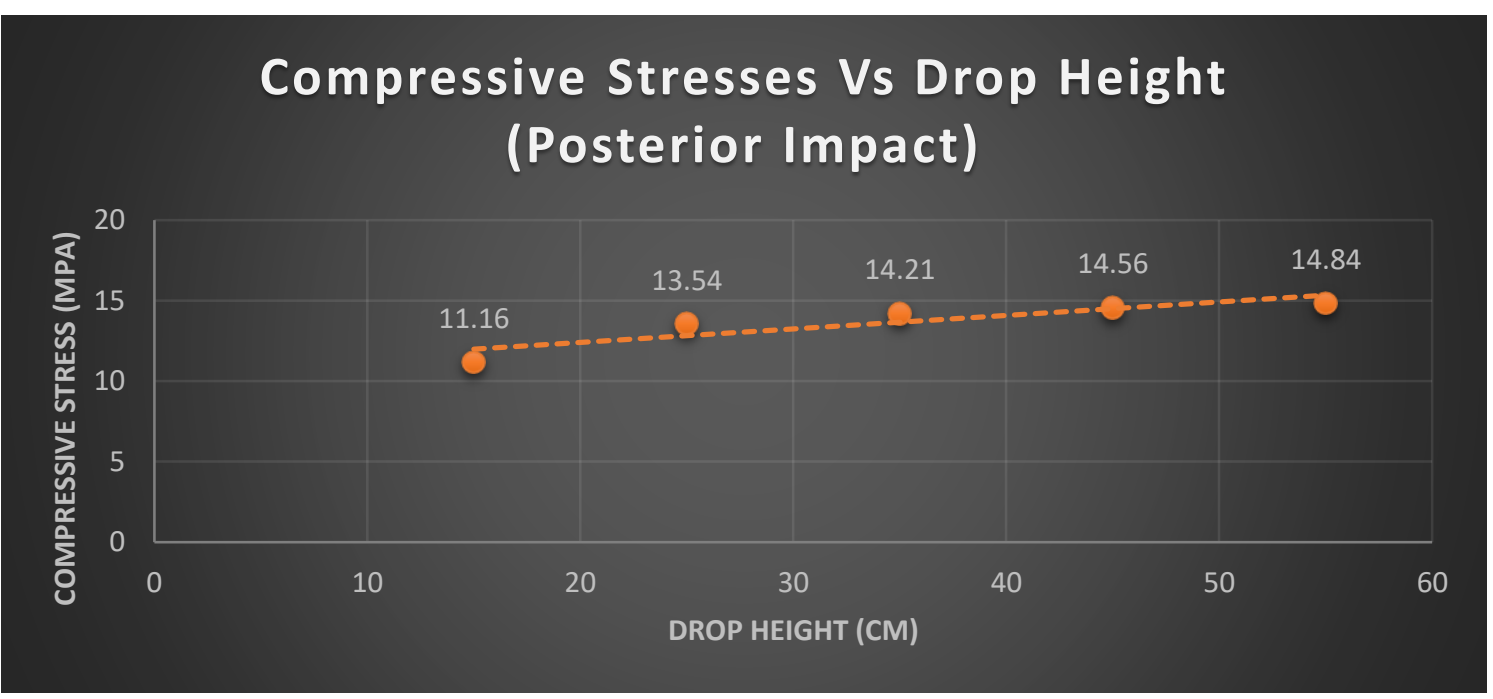

Graph 11: Compressive Stresses Vs Drop Height (Posterior Impact) 
The above graph depicts the stress trend in posterior region due to the impact. The maximum and minimum values are 14.84 and $11.16 \mathrm{MPa}$ for 55 and $15 \mathrm{~cm}$ drop heights respectively. The slope indicates that deformation is to less rapidly increase with further increase in drop heights.

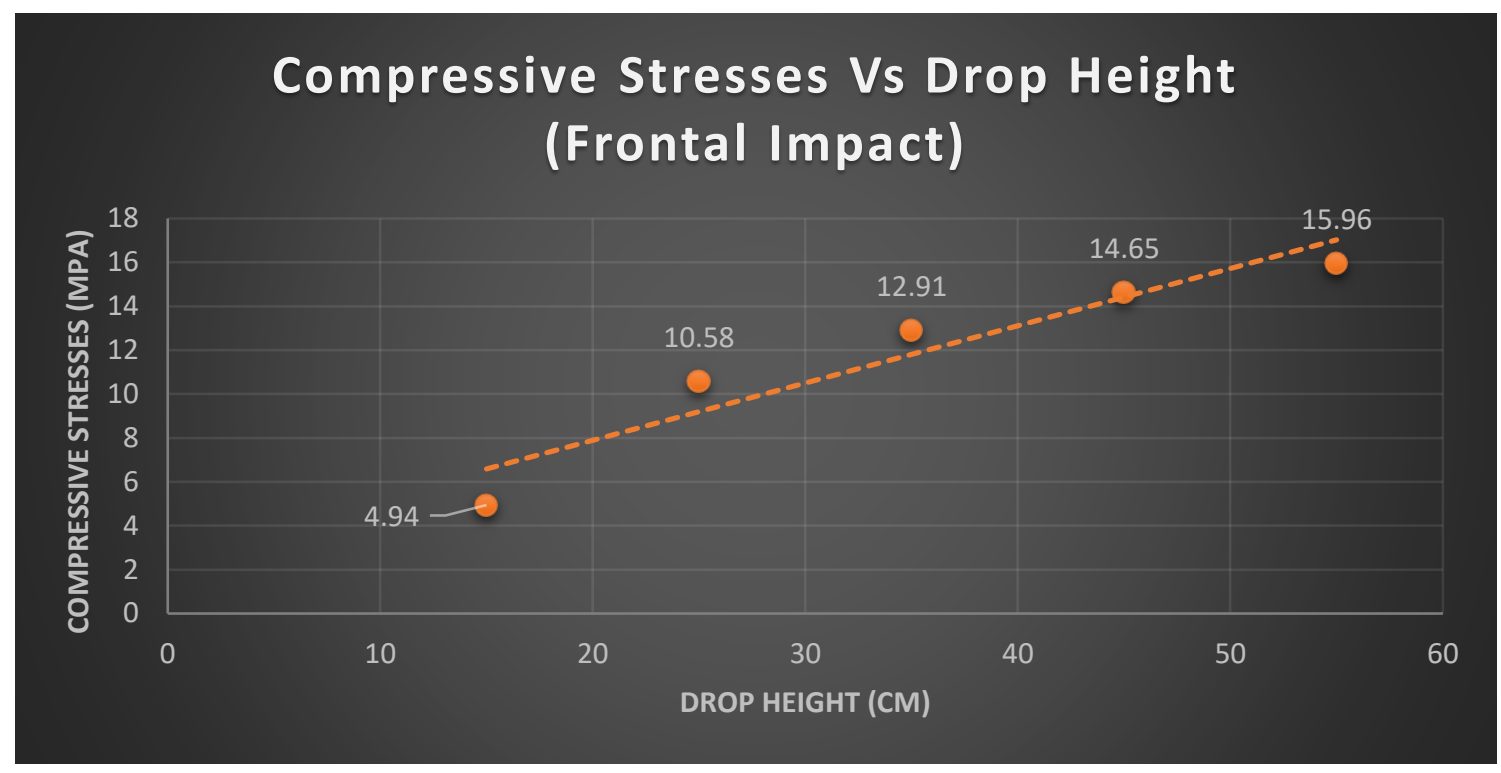

Graph 12: Compressive Stresses Vs Drop Height (Frontal Impact)

The maximum and minimum stress value for the above trend is 15.96 and $4.94 \mathrm{MPa}$ corresponding to 55 and $15 \mathrm{~cm}$ drop cases. The slope is on a higher side and thus the deformation stresses are more likely to reach a high value rapidly on increasing the drop height. 


\subsection{Tables}

Following section has the tabulated data for all the impact cases which are shown in the graphs above.

4.7.1 Von mises Stresses for Various Impacts

Table 4: Von Mises Stress Distribution Table

\begin{tabular}{|c|c|c|c|c|}
\hline $\begin{array}{c}\text { Drop } \\
\text { Height }(\mathbf{c m})\end{array}$ & $\begin{array}{c}\text { Posterior } \\
\text { Impact } \\
(\mathrm{MPa})\end{array}$ & $\begin{array}{c}\text { Lateral } \\
\text { Impact } \\
(\mathrm{MPa})\end{array}$ & $\begin{array}{c}\text { Frontal } \\
\text { Impact } \\
(\mathrm{MPa})\end{array}$ & $\begin{array}{c}\text { Superior } \\
\text { Impact } \\
(\mathrm{MPa})\end{array}$ \\
\hline 15 & 11.16 & 7.88 & 5.32 & 13.87 \\
\hline 25 & 13.54 & 5.8 & 10.58 & 15.66 \\
\hline 35 & 14.21 & 10.21 & 12.93 & 17.3 \\
\hline 45 & 14.56 & 13.53 & 14.65 & 17.83 \\
\hline 55 & 14.8 & 16.19 & 15.96 & 19.15 \\
\hline
\end{tabular}

\subsubsection{Principle Stresses for Various Impacts}

Table 5: Frontal Impact Principle Stress Distribution

\begin{tabular}{|c|c|c|c|}
\hline $\begin{array}{c}\text { Drop Height } \\
(\mathbf{c m})\end{array}$ & $\begin{array}{c}\text { Major Principle } \\
\text { Stress (MPa) }\end{array}$ & $\begin{array}{c}\text { Mid Principle } \\
\text { Stress (MPa) }\end{array}$ & $\begin{array}{c}\text { Minor Principle } \\
\text { Stress (MPa) }\end{array}$ \\
\hline 55 & 6.35 & 12.98 & 16.15 \\
\hline 45 & 5.67 & 11.71 & 14.85 \\
\hline 35 & 4.682 & 9.975 & 12.98 \\
\hline 25 & 3.53 & 7.46 & 10.29 \\
\hline 15 & 1.8 & 2.83 & 4.98 \\
\hline
\end{tabular}

Table 6: Posterior Impact Principle Stress Distribution

\begin{tabular}{|c|c|c|c|}
\hline $\begin{array}{c}\text { Drop Height } \\
(\mathbf{c m})\end{array}$ & $\begin{array}{c}\text { Major Principle } \\
\text { Stress (MPa) }\end{array}$ & $\begin{array}{c}\text { Mid Principle } \\
\text { Stress (MPa) }\end{array}$ & $\begin{array}{c}\text { Minor Principle } \\
\text { Stress (MPa) }\end{array}$ \\
\hline $\mathbf{5 5}$ & $\mathbf{8 . 2 5 9}$ & $\mathbf{1 0 . 7 1}$ & 17.06 \\
\hline 45 & $\mathbf{8 . 3 3 5}$ & $\mathbf{1 0 . 5 7}$ & 16.87 \\
\hline 35 & $\mathbf{8 . 3 7 6}$ & $\mathbf{1 0 . 4 6}$ & 16.59 \\
\hline 25 & $\mathbf{8 . 1 0 9}$ & $\mathbf{9 . 9 8 2}$ & 15.91 \\
\hline 15 & $\mathbf{6 . 7 9}$ & $\mathbf{7 . 8 4}$ & 12.99 \\
\hline
\end{tabular}


Table 7: Lateral Impact Principle Stress Distribution

\begin{tabular}{|c|c|c|c|}
\hline $\begin{array}{c}\text { Drop Height } \\
(\mathbf{c m})\end{array}$ & $\begin{array}{c}\text { Major Principle } \\
\text { Stress (MPa) }\end{array}$ & $\begin{array}{c}\text { Mid Principle } \\
\text { Stress (MPa) }\end{array}$ & $\begin{array}{c}\text { Minor Principle } \\
\text { Stress (MPa) }\end{array}$ \\
\hline 55 & 5.326 & 9.853 & 17.02 \\
\hline 45 & 4.768 & 7.79 & 13.9 \\
\hline 35 & 3.549 & 5.51 & 10.7 \\
\hline 25 & 2.009 & 2.716 & 6.06 \\
\hline 15 & 2.769 & 3.866 & $\mathbf{8 . 2 6}$ \\
\hline
\end{tabular}

Table 8: Superior Impact Principle Stress Distribution

\begin{tabular}{|c|c|c|c|}
\hline $\begin{array}{c}\text { Drop Height } \\
(\mathrm{cm})\end{array}$ & $\begin{array}{c}\text { Major Principle } \\
\text { Stress (MPa) }\end{array}$ & $\begin{array}{c}\text { Mid Principle } \\
\text { Stress (MPa) }\end{array}$ & $\begin{array}{c}\text { Minor Principle } \\
\text { Stress (MPa) }\end{array}$ \\
\hline 55 & 4.953 & 16.49 & 19.9 \\
\hline 45 & 4.76 & 15.1 & 18.4 \\
\hline 35 & 4.873 & 14.19 & 17.71 \\
\hline 25 & 4.593 & 12.28 & 16.2 \\
\hline 15 & 4.17 & 10.24 & 14.35 \\
\hline
\end{tabular}

\subsubsection{Compressive Stresses for Various Impacts}

Table 9: Compressive Stresses Distribution

\begin{tabular}{|c|c|c|c|c|}
\hline $\begin{array}{c}\text { Drop } \\
\text { Height } \\
(\mathrm{cm})\end{array}$ & $\begin{array}{c}\text { Superior } \\
\text { Impact } \\
(\mathrm{MPa})\end{array}$ & $\begin{array}{c}\text { Lateral } \\
\text { Impact } \\
(\mathrm{MPa})\end{array}$ & $\begin{array}{c}\text { Posterior } \\
\text { Impact } \\
(\mathrm{MPa})\end{array}$ & $\begin{array}{c}\text { Frontal } \\
\text { Impact } \\
(\mathrm{MPa})\end{array}$ \\
\hline 55 & 19.15 & 14.57 & 14.84 & 15.96 \\
\hline 45 & 17.83 & 12.54 & 14.56 & 14.65 \\
\hline 35 & 17.3 & 9.98 & 14.21 & 12.91 \\
\hline 25 & 15.51 & 5.82 & 13.54 & 10.58 \\
\hline 15 & 13.64 & 7.887 & 11.16 & 4.945 \\
\hline
\end{tabular}




\section{Findings and Conclusions}

The following observations and conclusions can be drawn from the above presented graphs and pictorial depictions.

\subsection{Frontal Impact Stress Distribution}

- The failure principle stress for the pediatric skull is $18.5 \mathrm{MPa}$ [4].

- The maximum principle tensile stresses (6.35 MPa for $55 \mathrm{~cm}$ drop) for all drop heights are well below the reference failure stresses.

- There is no pediatric skull fracture for any of the fall cases in frontal region, up to drop heights of $55 \mathrm{~cm}$.

- However, for frontal impacts, for all drop heights, the maximum principle tensile stress appears to be away from site of impact, in the lower frontal region near the eye slot.

- Thus, indicates that the potential fracture site is different from impact site.

- But the maximum von Mises stress occur to be in the region of or very close to the site of impact (15.96 MPa for $55 \mathrm{~cm}$ drop height). This stress is direct indicative of the deformation in the region, thus maximum deformation appears in a region close to the site of impact.

- For smaller drop heights, the magnitude of stresses decrease. Thus, we conclude that smaller heights cause smaller deformation and lesser is the vulnerability of skull to fracture.

\subsection{Posterior Impact Stress Distribution}

- The max principle tensile stress for posterior impacts corresponds to $55 \mathrm{~cm}$ drop height and has value of 8.259 MPa.

- This value is well below the fracture stress, thus the skull is safe against posterior impacts of drop heights up to $55 \mathrm{~cm}$.

- The stress distribution figures show that max tensile principle stress happens to be in the region same as that of the site of impact. Thus, it indicates that potential site of fracture for posterior impacts would be the same.

- But the maximum von Mises stress occur in the region of or very close to the site of impact. This stress is direct indicative of the deformation in the region, thus maximum deformation appears in a region close to the site of impact.

- The max von Mises stress happens to be $14.8 \mathrm{MPa}$ for $55 \mathrm{~cm}$ drop height and decreases with decreasing drop height. Thus, causing less deformation and fracture vulnerability as we go on reducing the drop height. 


\subsection{Superior Impact Stress Distribution}

- The max principle tensile stress happens to be $4.95 \mathrm{MPa}$ for $55 \mathrm{~cm}$ drop height. This value is well below the failure stress value.

- Thus, for all drop heights below $55 \mathrm{~cm}$, the skull is safe against fracture.

- The stress distribution figures show that the max principle stress (tensile) occurs in a region far away from point of impact. Thus, could be concluded that potential site of fracture initiation is not same as the site of impact.

- The max von Mises stress, or the deformation stress happens to be in the same region as the site of impact. The max value of it is $19.15 \mathrm{MPa}$ and corresponds to $55 \mathrm{~cm}$ drop height.

- There is a drop-in stress as we lower the height of drop.

\subsection{Lateral Impact Stress Distribution}

- The max principle tensile stress happens to be $5.32 \mathrm{MPa}$ for $55 \mathrm{~cm}$ drop height.

- This value is well below failure stress value thus the skull can be treated as safe against fractures.

- The figures show that the site of max von Mises stress is same as site of impact. Thus, the region undergoes maximum deformation.

- The max principle stress region is away from the site of impact; thus, site of crack initiation may not necessarily be the site of impact.

\subsection{Principle Stress Graph}

- The mid plane (P2) and minor principle stresses (P3) are compressive in nature and do not contribute to the fracture of the bone. Only tensile stresses cause fractures.

- It can be noticed that the principle tensile stresses for all the cases discussed are well below the fracture stress value, thus, it is safe to assume that no fracture appears in the skull for free fall drop heights discussed above.

- However, from the study, it can be concluded that the point of max principle stress (tensile) is not the same as point of maximum deformation for frontal, lateral and superior impact cases.

- Hence, it is safe to conclude that surgeons should look for fracture sites even away from the impact site (wound), in case of a fracture.

- The graphs show a linearly increasing trend as we increase the drop height.

- The graphs show that stresses range in between 4.17 to 4.95 MPa for superior impact.

- For lateral impact, stresses range from 2.7 to $5.3 \mathrm{MPa}$.

- For posterior impact, stresses range from 6.7 to $8.2 \mathrm{MPa}$.

- For frontal impact, stresses range from 1.8 to 6.35 MPa.

- All the above values also correspond for minimum and maximum drop heights respectively.

- The anomalies in the trends should be ignored as computational errors. The highest value in the scatter plot is considered for $55 \mathrm{~cm}$ drop height. 


\subsection{Von Mises and Compressive Stress Graph}

- The graphs for both type of stresses show linearly increasing trend.

- Both stresses indicate the deformation because of impact on the skull.

- The maximum von Mises and hence the deformation appears in the superior impact.

The maximum value of stress corresponds to $55 \mathrm{~cm}$ drop height and is $19.15 \mathrm{MPa}$.

- The superior impact is followed by lateral, frontal and posterior impacts in decreasing order, with corresponding von Mises values as 16.19 $\mathrm{MPa}, 15.96 \mathrm{MPa}$ and 14.8MPa. All these values correspond to $55 \mathrm{~cm}$ drop height.

- The slopes of the graphs of von mises stress for front and lateral impact are much steeper as compared to that of posterior and superior impact cases.

- Thus, it could be proposed that on increasing drop heights, the stress values of front and lateral will surpass those of superior and posterior impact cases.

\subsection{Critical Drop Height Calculations}

From the tensile principle stress graph above, the equation of the line is calculated as follows -

Superior Impact Case: $\quad Y=(0.0173) X+4.0633$

Lateral Impact Case: $\quad Y=(0.0787) X+0.9287$

Frontal Impact Case: $\quad Y=(0.1128) X+0.4544$

Posterior Impact Case: $\quad Y=(\mathbf{0 . 0 3 1 6}) \mathrm{X}+\mathbf{6 . 8 6 6 4}$

If we insert critical stress value as $18.5 \mathrm{MPa}$, we shall get the respective critical drop heights. These are as follows -

Table 10: Critical Height Calculation Table

\begin{tabular}{|c|l|}
\hline Impact Region & Critical Height \\
\hline Superior & $835 \mathrm{~cm}(27.37 \mathrm{ft})$ \\
\hline Posterior & $368 \mathrm{~cm}(12.07 \mathrm{ft})$ \\
\hline Lateral & $223 \mathrm{~cm}(7.32 \mathrm{ft})$ \\
\hline Frontal & $160 \mathrm{~cm}(5.24 \mathrm{ft})$ \\
\hline
\end{tabular}

From the above table, it could be concluded that superior region is the strongest and frontal region is the weakest against impacts. 


\subsection{Point of Potential Fracture}

- The distance between point of impact and potential site of fracture is farthest in the lateral impact case and least for posterior impact case. It was nearly same for superior and frontal impact cases.

- The potential site for posterior impact was beneath the point of impact itself.

- For lateral impact, it happens to be radially opposite in direction, in lower skull region.

- For frontal impact, it was in the region where eye ball slot meets fore skull.

- For superior impact, it is in the region adjacent to point of impact in lateral region of the skull.

Table 11: Displacement Between Point of Impact and Point of Potential Fracture

\begin{tabular}{|c|c|}
\hline Impact Type & Displacement Value \\
\hline Lateral & $121.6 \mathrm{~mm}$ \\
\hline Superior & $53.58 \mathrm{~mm}$ \\
\hline Frontal & $49.22 \mathrm{~mm}$ \\
\hline Posterior & $16.1 . \mathrm{mm}$ \\
\hline
\end{tabular}




\section{Mesh Convergence Study}

The results obtained after doing the analysis highly depend upon the size of mesh chosen to mesh the given model. The results vary a lot in values if the mesh chosen is wrong. To verify that the mesh chosen is right, we need to confirm that results from various mesh sizes converge. For this purpose, models with various mesh sizes were generated and subjected to similar loading conditions. The results of stresses in the skull were compared and checked for convergence.

Mesh sizes selected were $6 \mathrm{~mm}, 5 \mathrm{~mm}, 4.5 \mathrm{~mm}, 4 \mathrm{~mm}, 3.5 \mathrm{~mm}$ and $3 \mathrm{~mm}$. All the models were impacted on the superior region from a drop height of $55 \mathrm{~cm}$. Stresses in the skull with mesh sizes $3.5 \mathrm{~mm}$ and $3 \mathrm{~mm}$ showed convergence with a difference of $6.2 \%$ in the result. $3.5 \mathrm{~mm}$ mesh was selected as it was less time consuming as compared to $3 \mathrm{~mm}$ mesh.

Hence for further tests on the model, $3.5 \mathrm{~mm}$ mesh should be used to get reliable results.
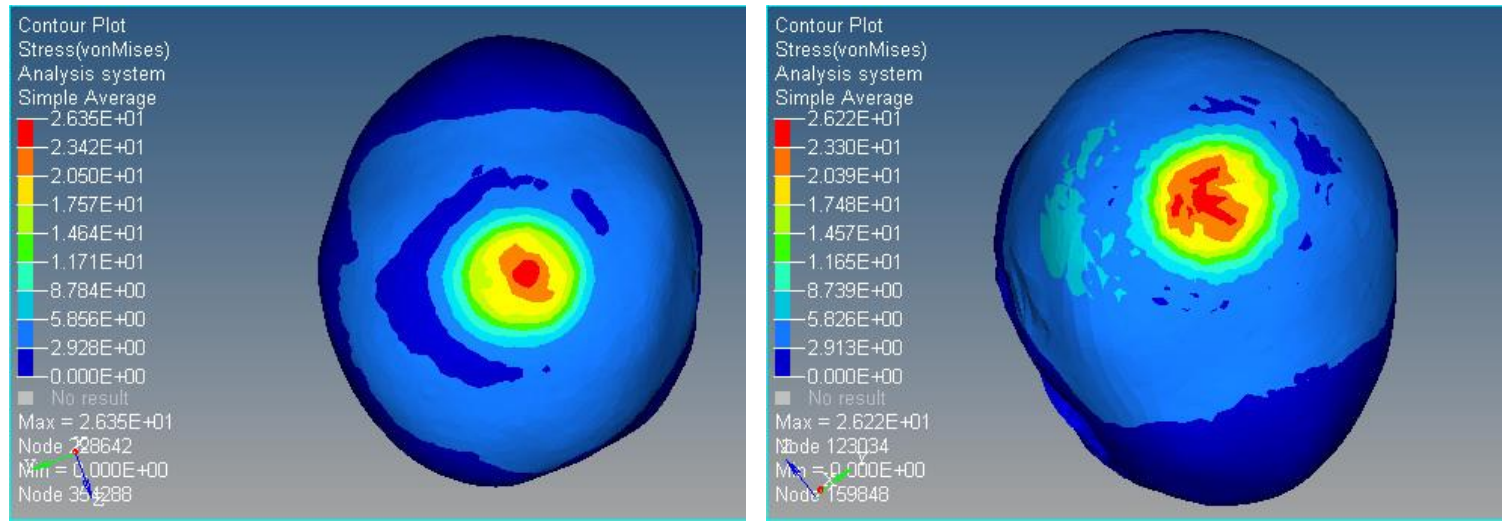

Figure 17: Von Mises Stress Comparison for $3.5 \mathrm{~mm}$ and $3 \mathrm{~mm}$ Mesh
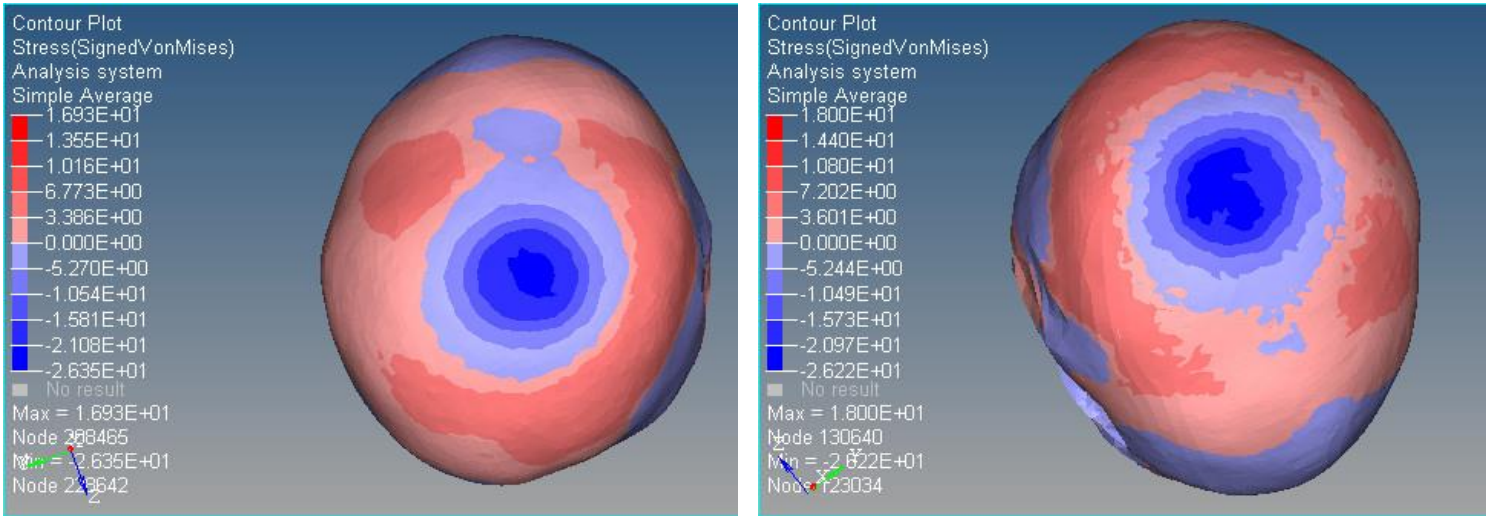

Figure 18: Tensile and Compressive Stress Comparison for $3.5 \mathrm{~mm}$ and $3 \mathrm{~mm}$ Mesh 

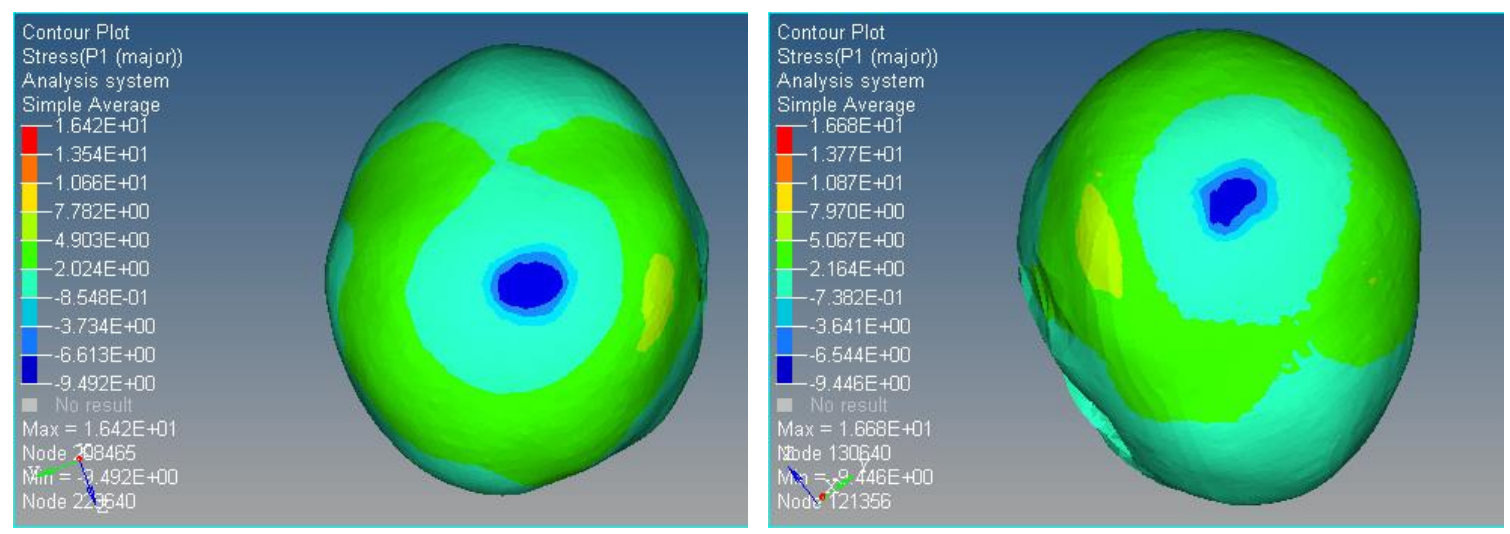

Figure 19: Major Principle Stress Comparison for $3.5 \mathrm{~mm}$ and $3 \mathrm{~mm}$ Mesh
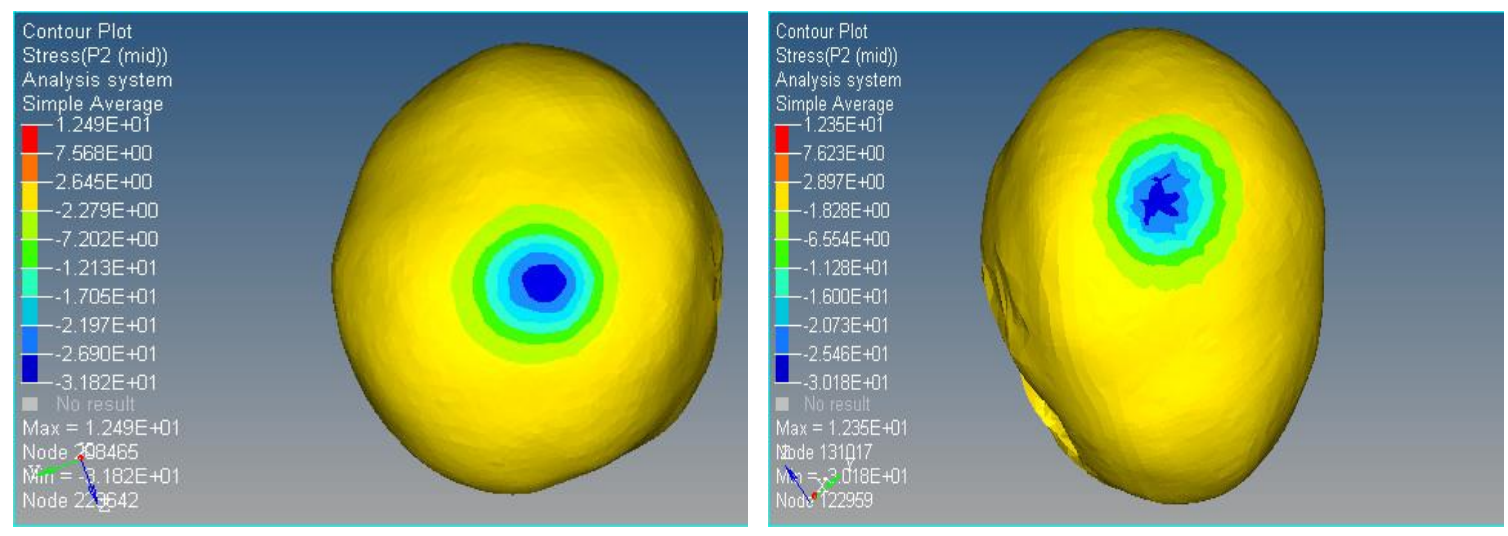

Figure 20: Principle Stress (Mid) Comparison for 3.5mm and $3 \mathrm{~mm}$ Mesh 
Table 12: Mesh Convergence Table for Various Mesh Sizes

\begin{tabular}{|l|c|c|c|c|}
\hline Mesh Size & $\begin{array}{c}\text { Von Mises } \\
\text { Stresses } \\
(\text { MPa })\end{array}$ & $\begin{array}{c}\text { Signed von } \\
\text { Mises Stresses } \\
(\text { MPa })\end{array}$ & \multicolumn{2}{|l|}{ Principle Stresses (MPa) } \\
\hline 6.0 mm & 19.15 & $5.12,-19.15$ & 4.95 & 16.49 \\
\hline $5.0 \mathrm{~mm}$ & 21.28 & $13.32,-21.28$ & 9.78 & 16.11 \\
\hline $4.5 \mathrm{~mm}$ & 23.37 & $13.93,-23.37$ & 12.48 & 27.06 \\
\hline $4.0 \mathrm{~mm}$ & 31.37 & $17.75,-31.37$ & 16.83 & 36.43 \\
\hline $3.5 \mathrm{~mm}$ & 26.35 & $16.93,-26.35$ & 16.68 & 31.82 \\
\hline $3.0 \mathrm{~mm}$ & 26.22 & $18.00,-26.22$ & 16.42 & 30.18 \\
\hline
\end{tabular}

Various mesh sizes were used and it is obvious that as we make the mesh finer, the results generally more towards true solution. The optimum mesh size is achieved when error \% between the results of consecutive mesh size approach minimum value.

Most result values increase as we decrease the mesh size from 6 to $4 \mathrm{~mm}$, and then show a decreasing trend. $4 \mathrm{~mm}$ and $3.5 \mathrm{~mm}$ analysis also show closeness in results but maximum error percentage between the results is $16 \%$ where as it is less between $3.5 \& 3 \mathrm{~mm}$ mesh analysis.

In the above table, the maximum percentage difference in the values for $3.5 \mathrm{~mm} \& 3 \mathrm{~mm}$ mesh is $6.2 \%$, also the values show a convergence, hence it is good assumption to take the value of mesh size $3.5 \mathrm{~mm}$ as ideal for impact analysis on this head model. The anomaly in the result below for signed von mises should be considered as computational error. 


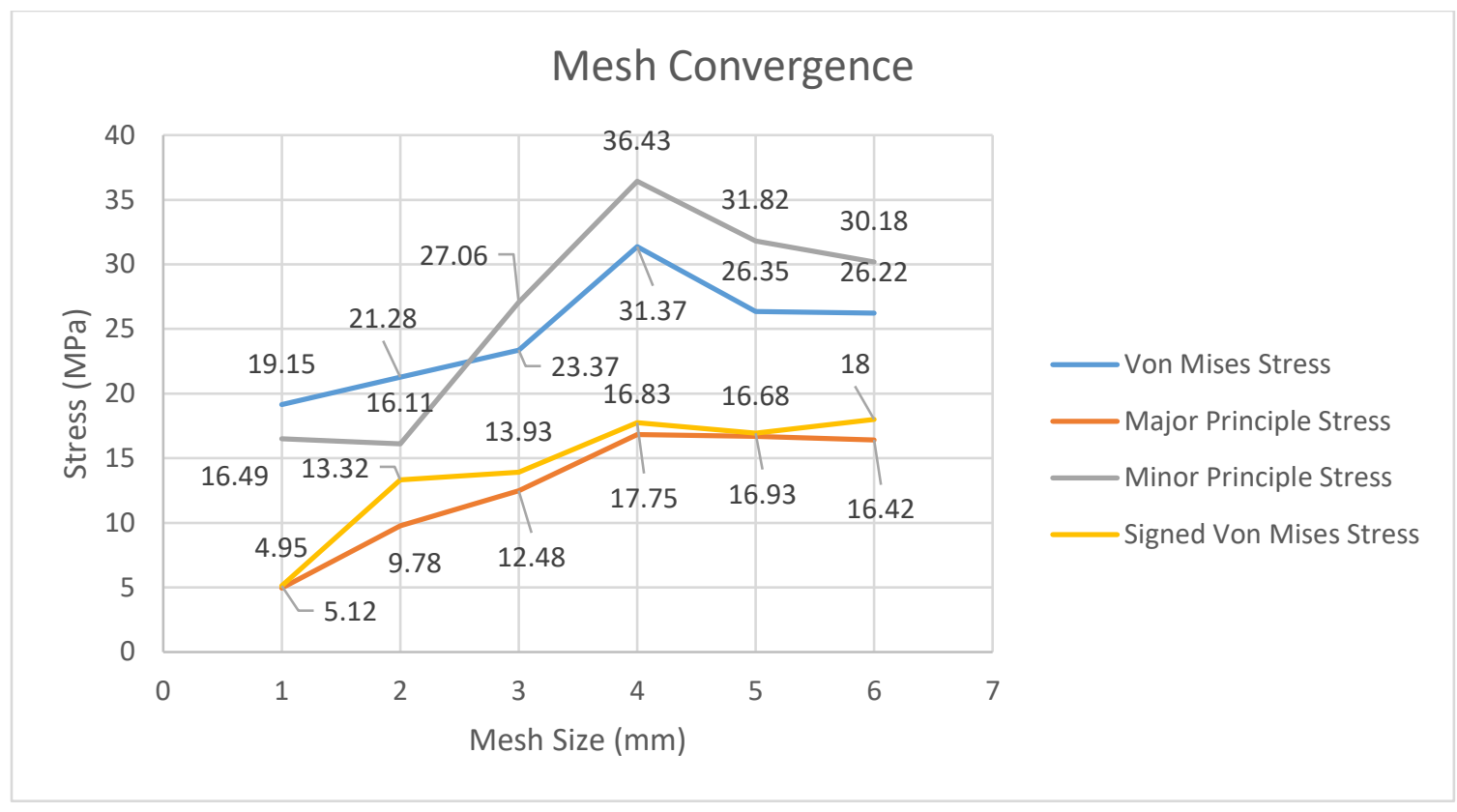

Graph 13: Mesh Convergence Graph

The results in this report are based on mesh size of $6 \mathrm{~mm}$, hence the results need further improvement and discussion. I would suggest finding the strain energy values for various simulations as it would be a better tool for impact test analysis. 


\section{Appendix A - Stress Patterns}

\subsection{Maximum Principle Stress and Strain Distributions}

The following section has the additional principle stress patterns, as a continuation of those in the previous section.

\subsubsection{Frontal Impacts for Various Drop Heights}

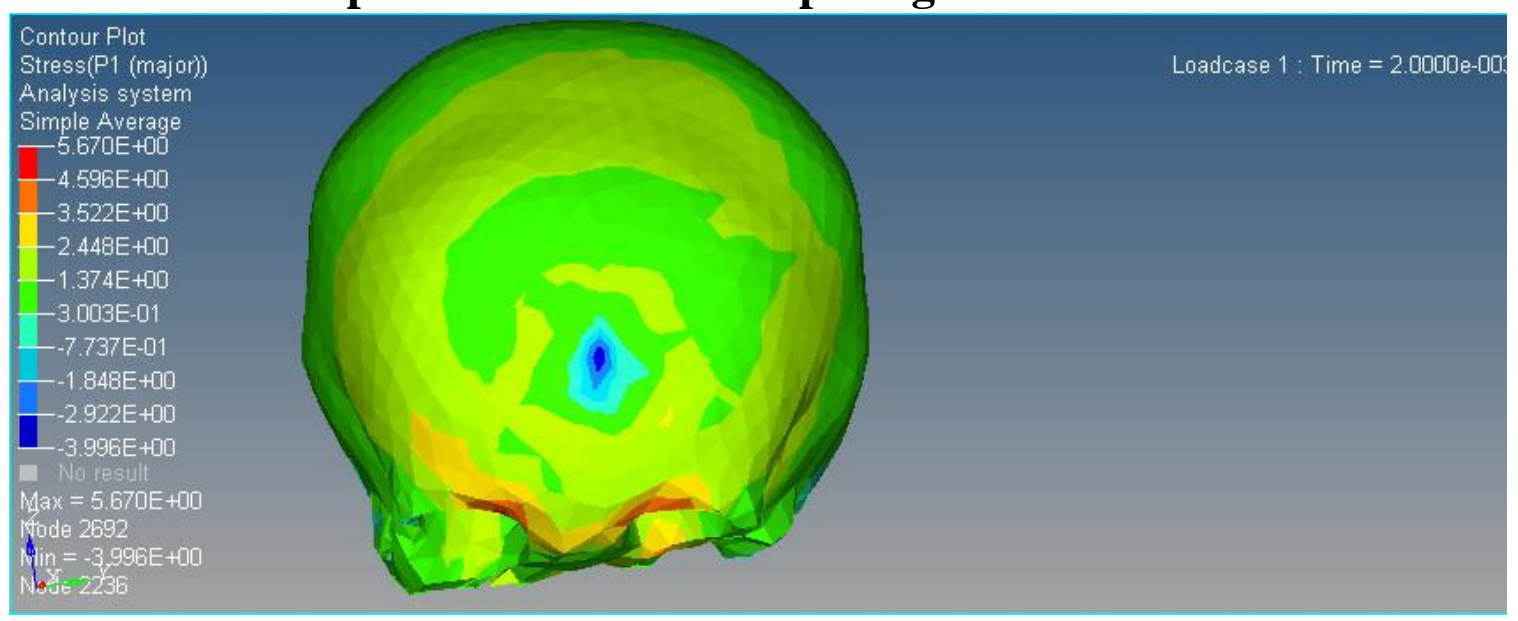

Figure 21: 45-cm Drop Major Principle Stress Distribution (Frontal Impact)

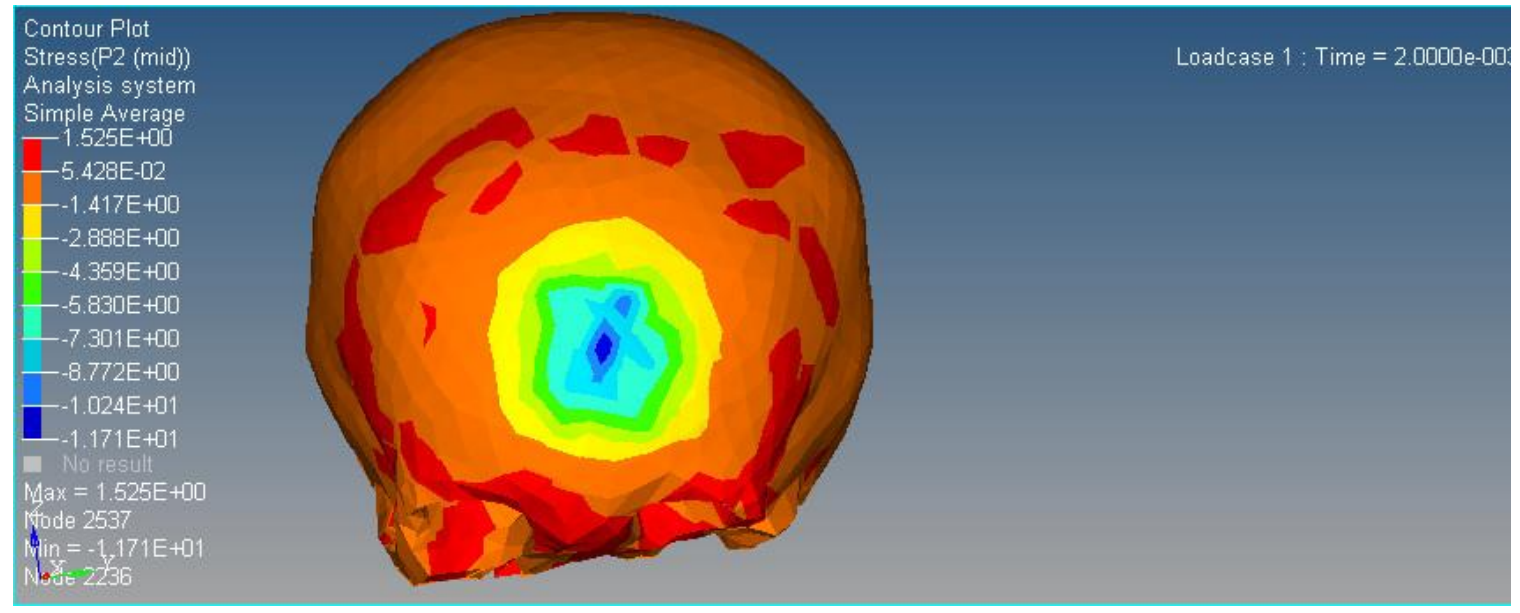

Figure 22: 45-cm Drop Mid Principle Stress Distribution (Frontal Impact) 


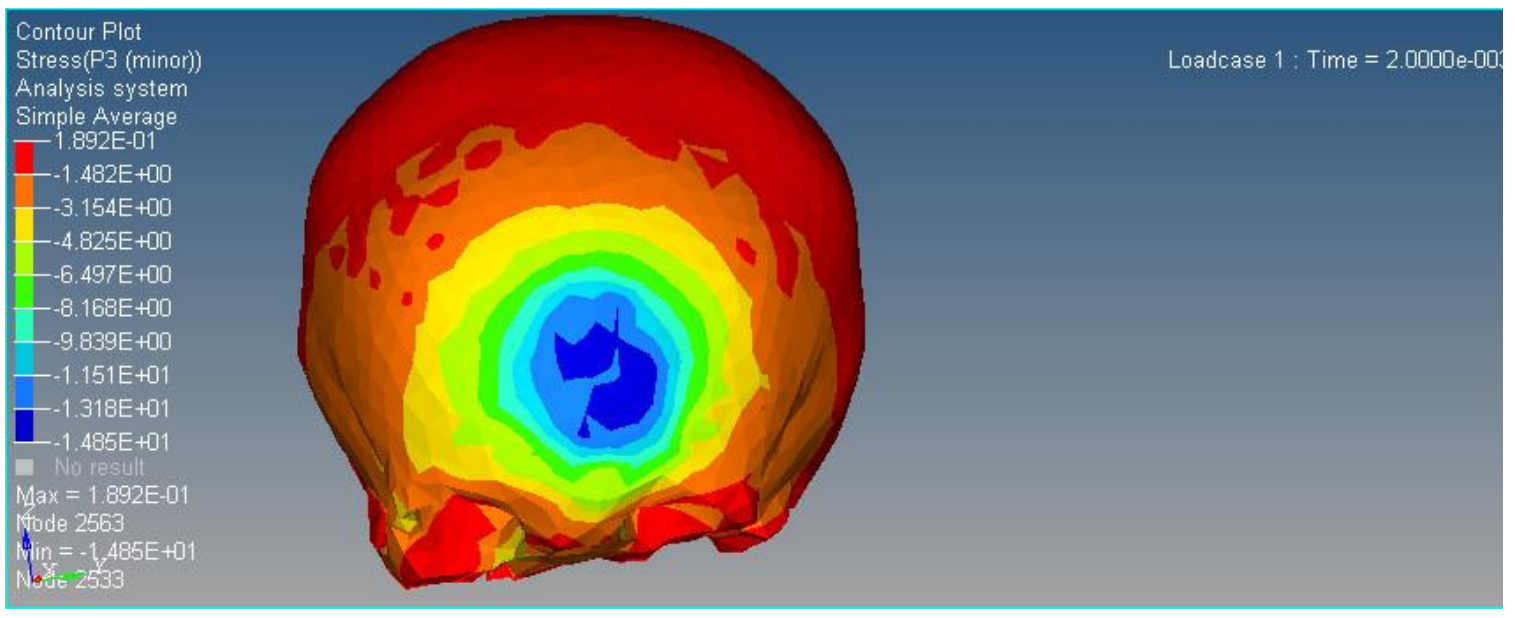

Figure 23: 45-cm Drop Minor Principle Stress Distribution (Frontal Impact)

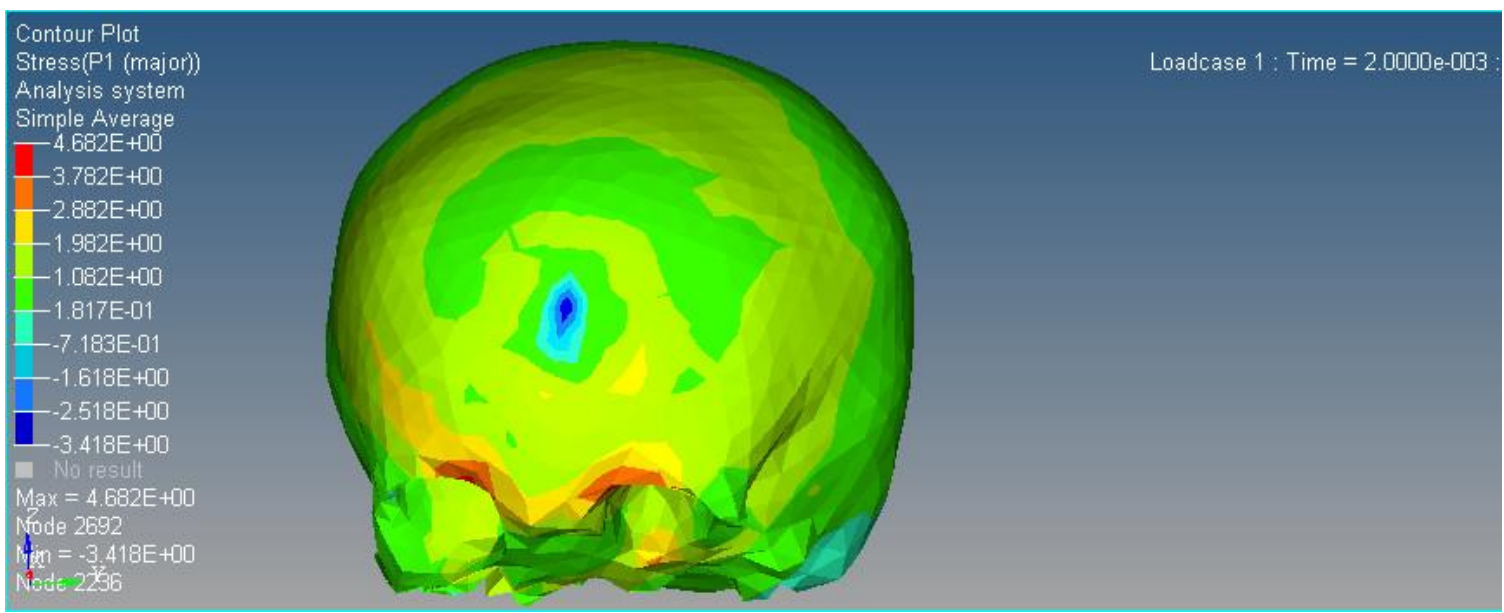

Figure 24: 35-cm Drop Major Principle Stress Distribution (Frontal Impact)

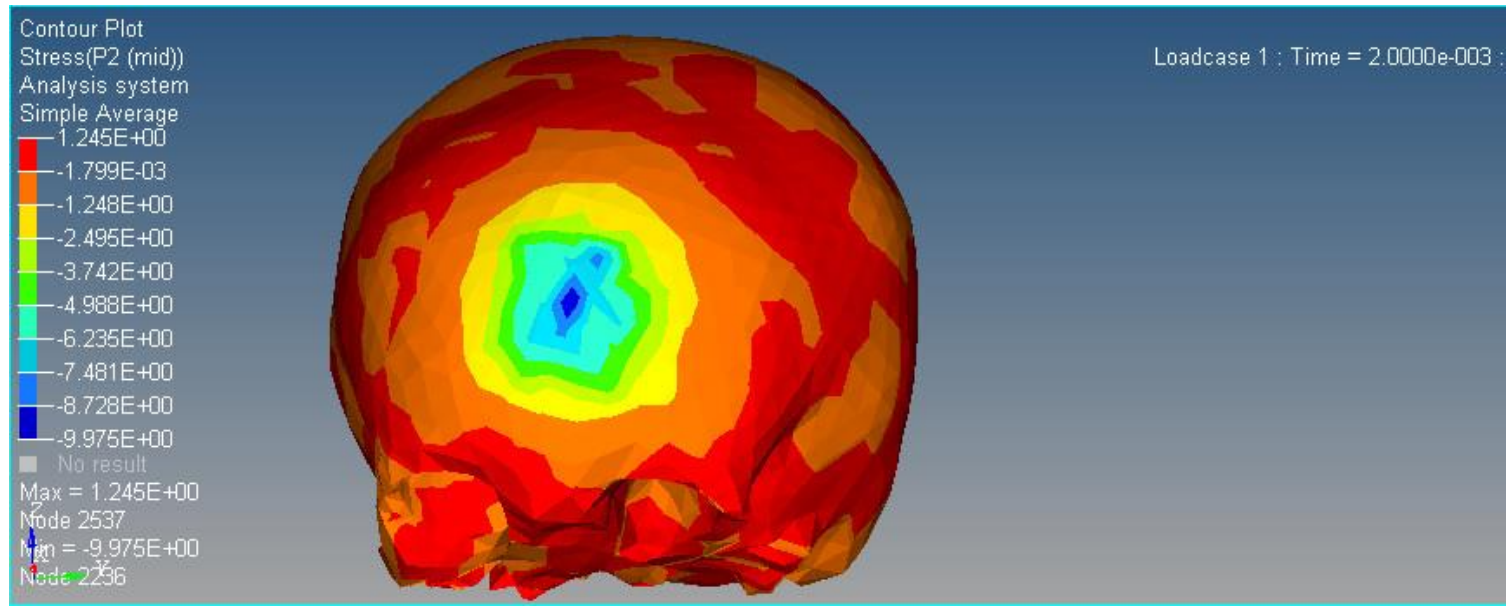

Figure 25: 35-cm Drop Mid Principle Stress Distribution (Frontal Impact) 


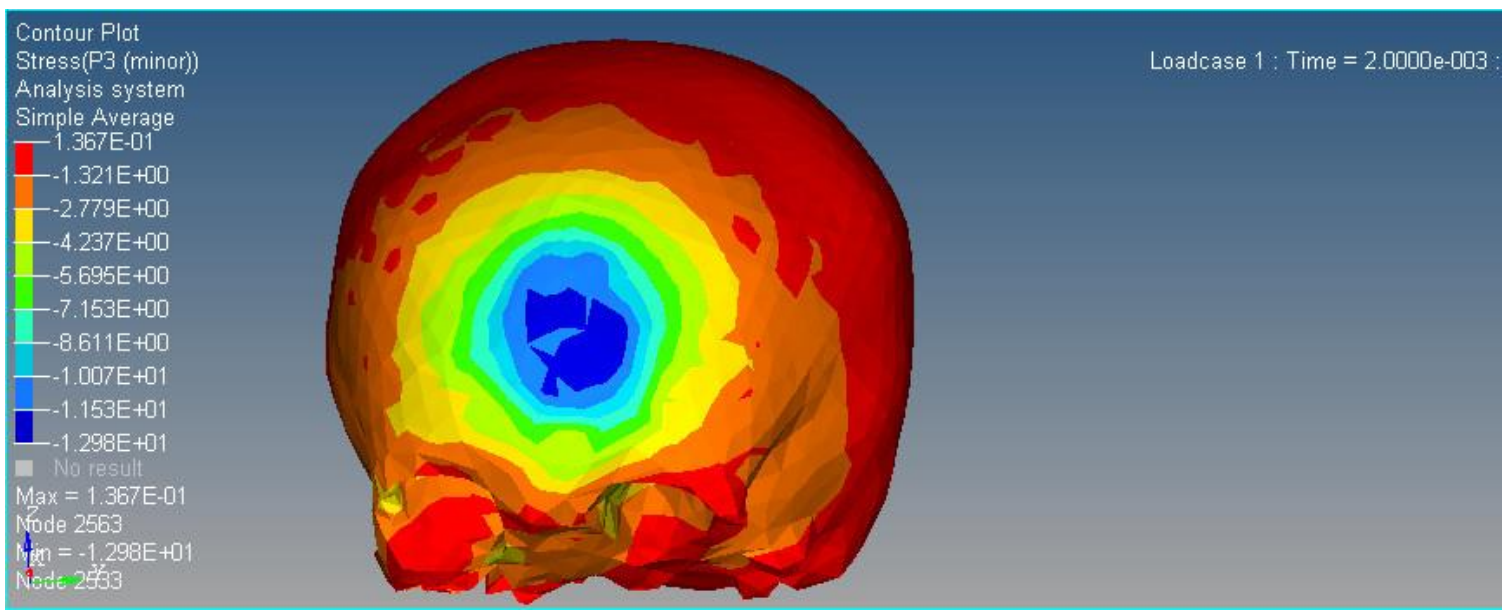

Figure 26: 35-cm Drop Minor Principle Stress Distribution (Frontal Impact)

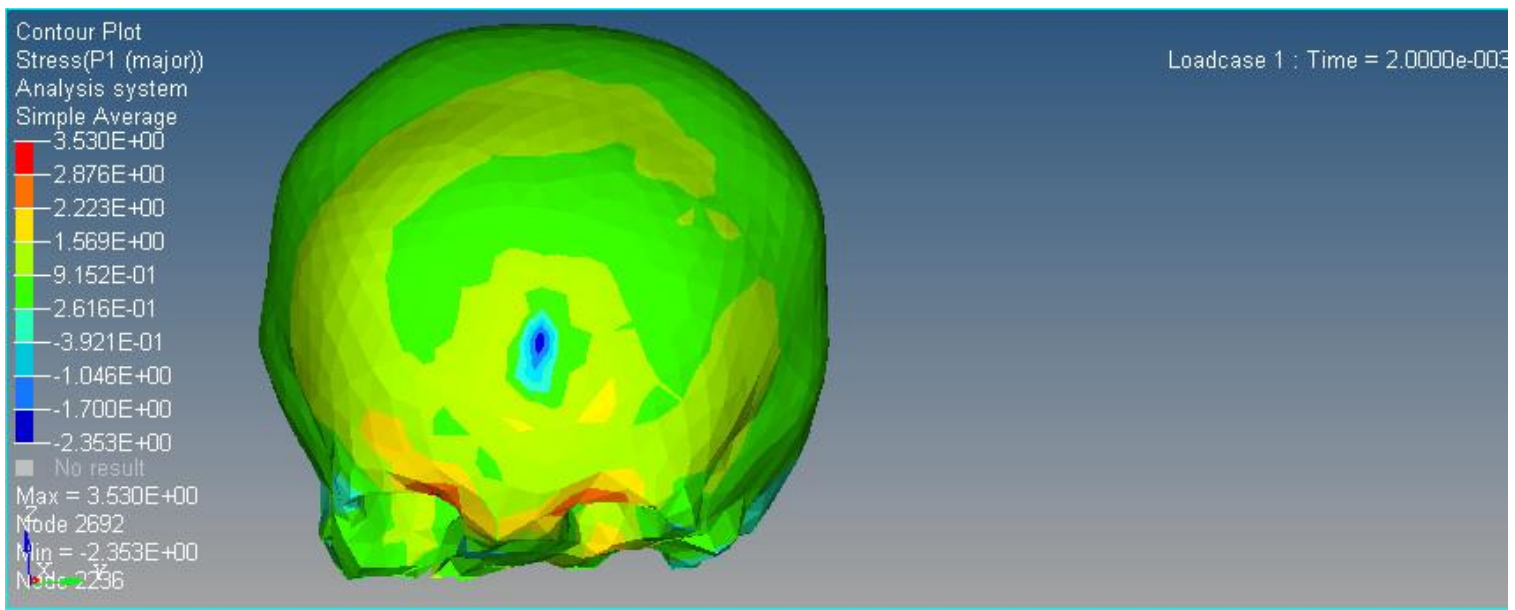

Figure 27: 25-cm Drop Major Principle Stress Distribution (Frontal Impact)

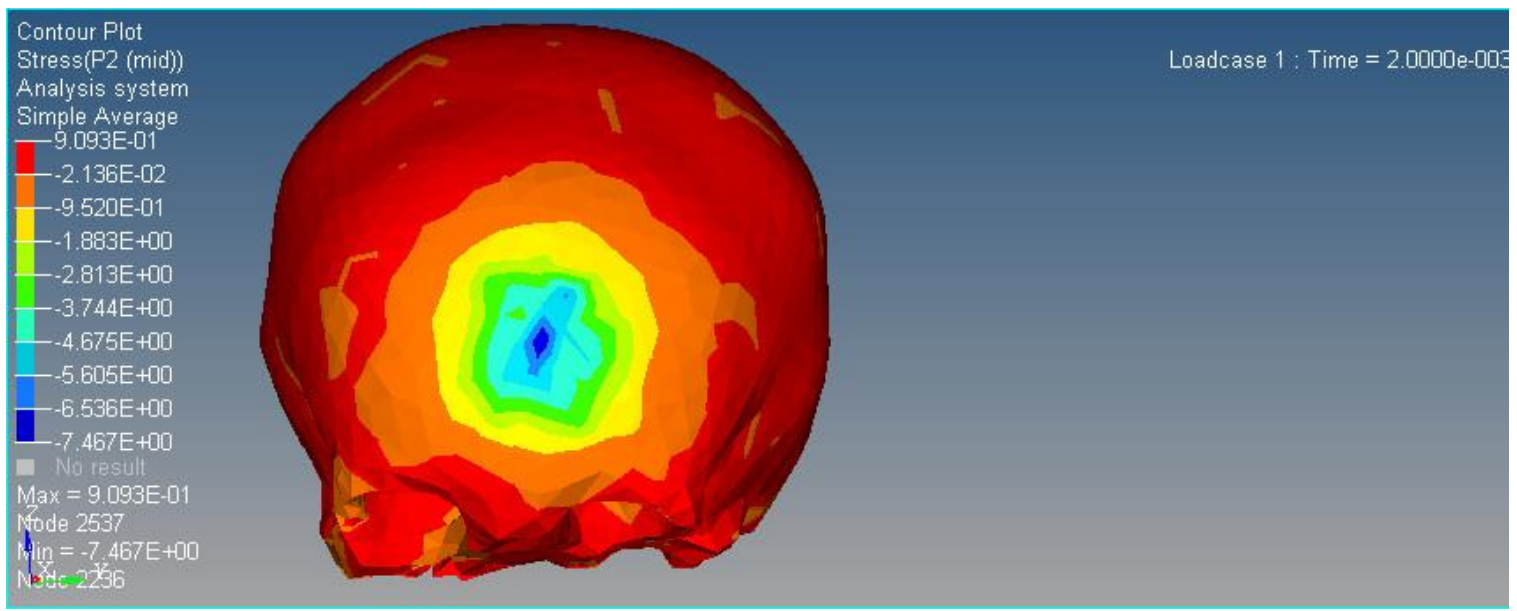

Figure 28: 25-cm Drop Mid Principle Stress Distribution (Frontal Impact) 


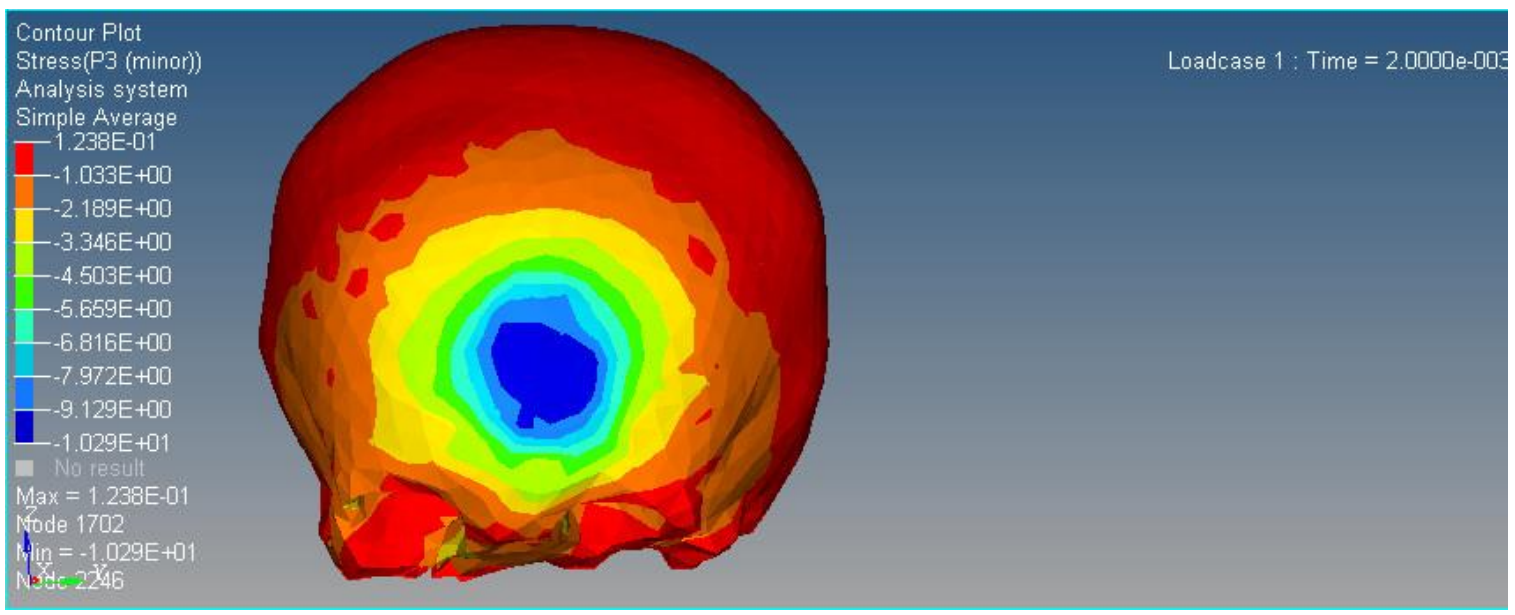

Figure 29: 25-cm Drop Minor Principle Stress Distribution (Frontal Impact)

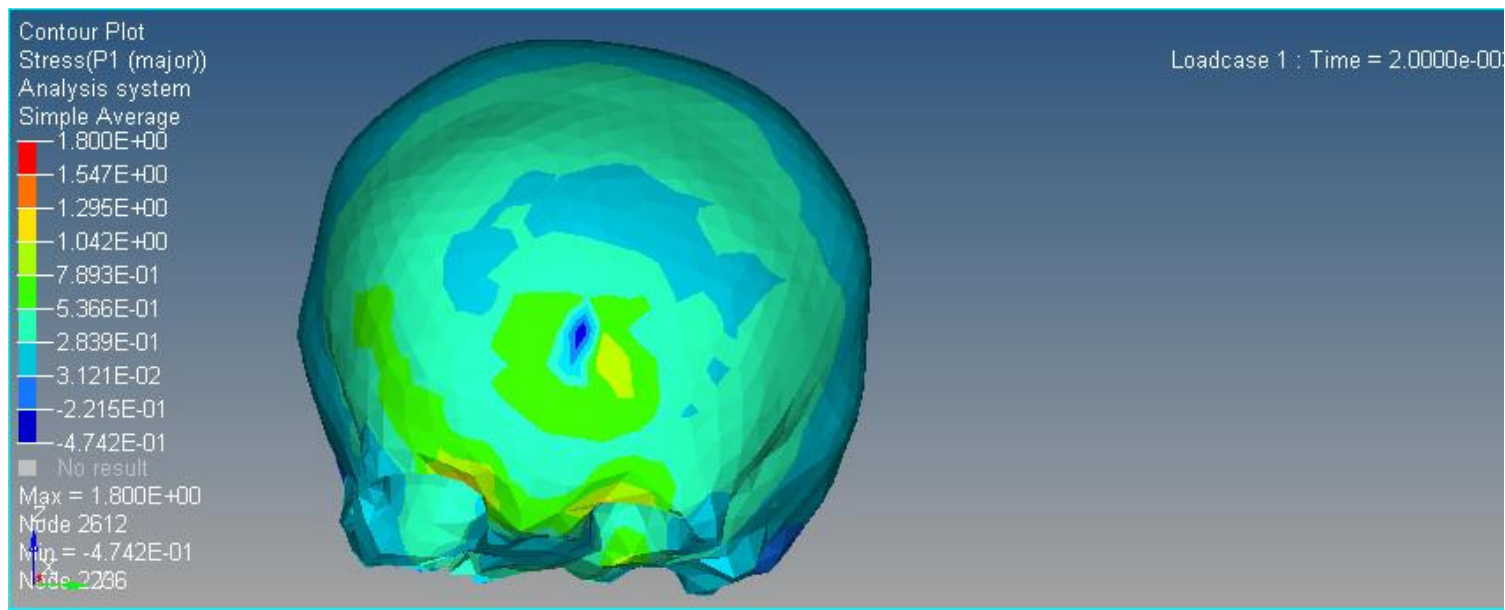

Figure 30: 15-cm Drop Major Principle Stress Distribution (Frontal Impact)

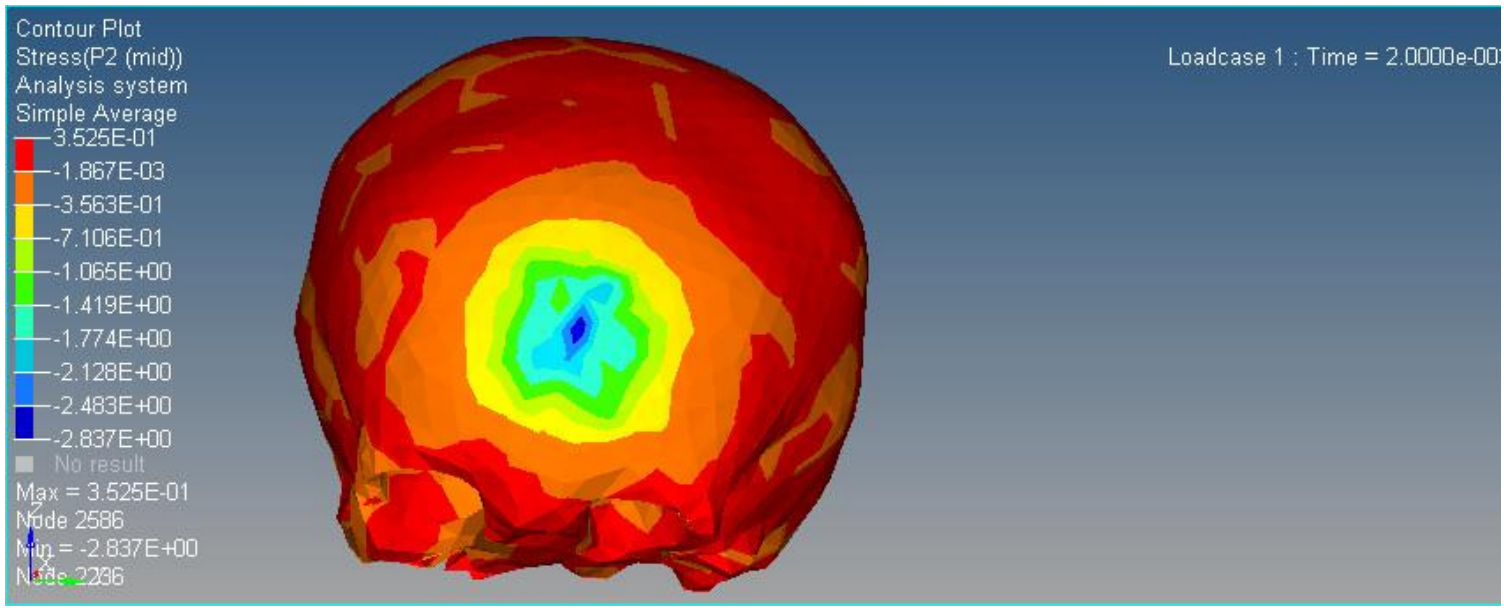

Figure 31: 15-cm Drop Mid Principle Stress Distribution (Frontal Impact) 


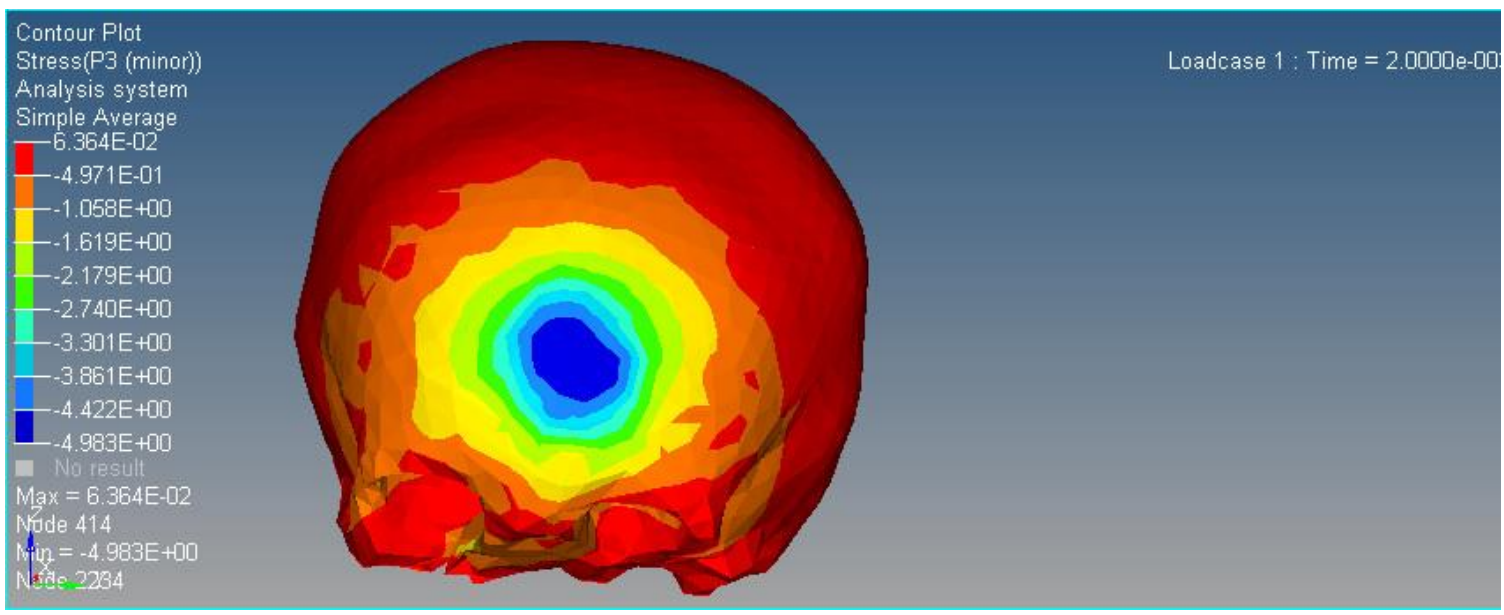

Figure 32: 15-cm Drop Minor Principle Stress Distribution (Frontal Impact)

\subsubsection{Superior Impact}

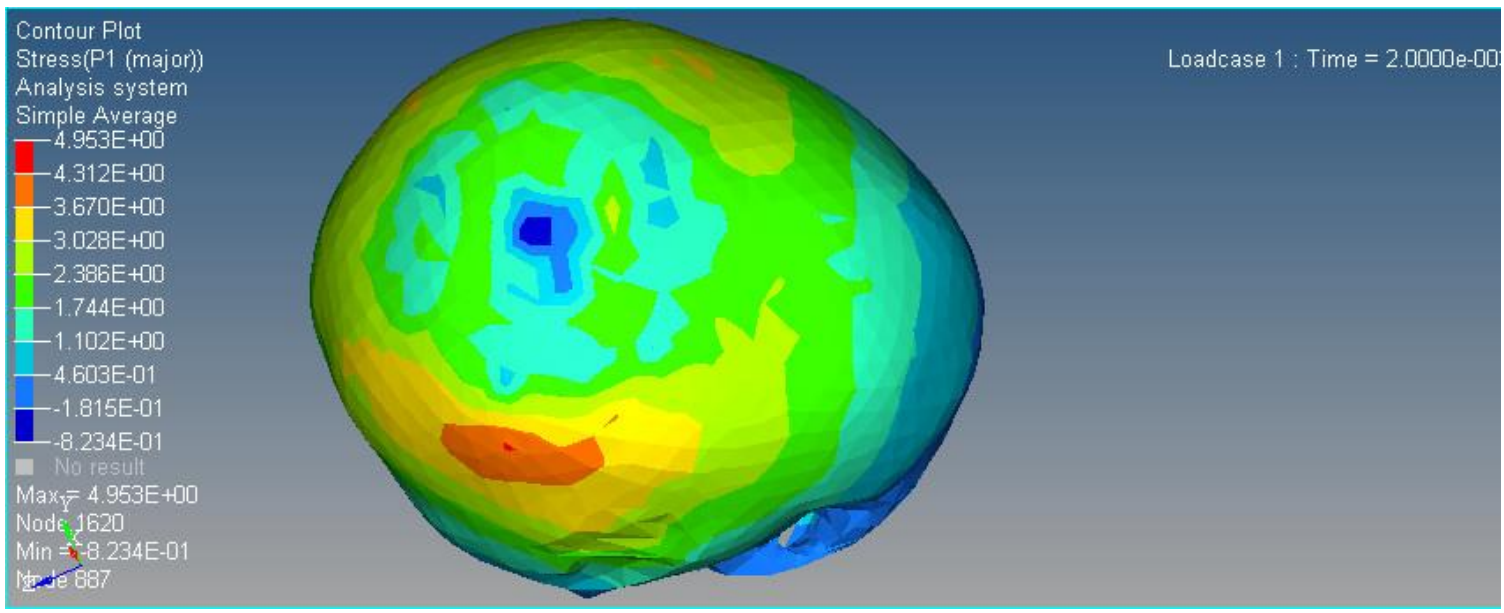

Figure 33: 55-cm Drop Major Principle Stress Distribution (Superior Impact)

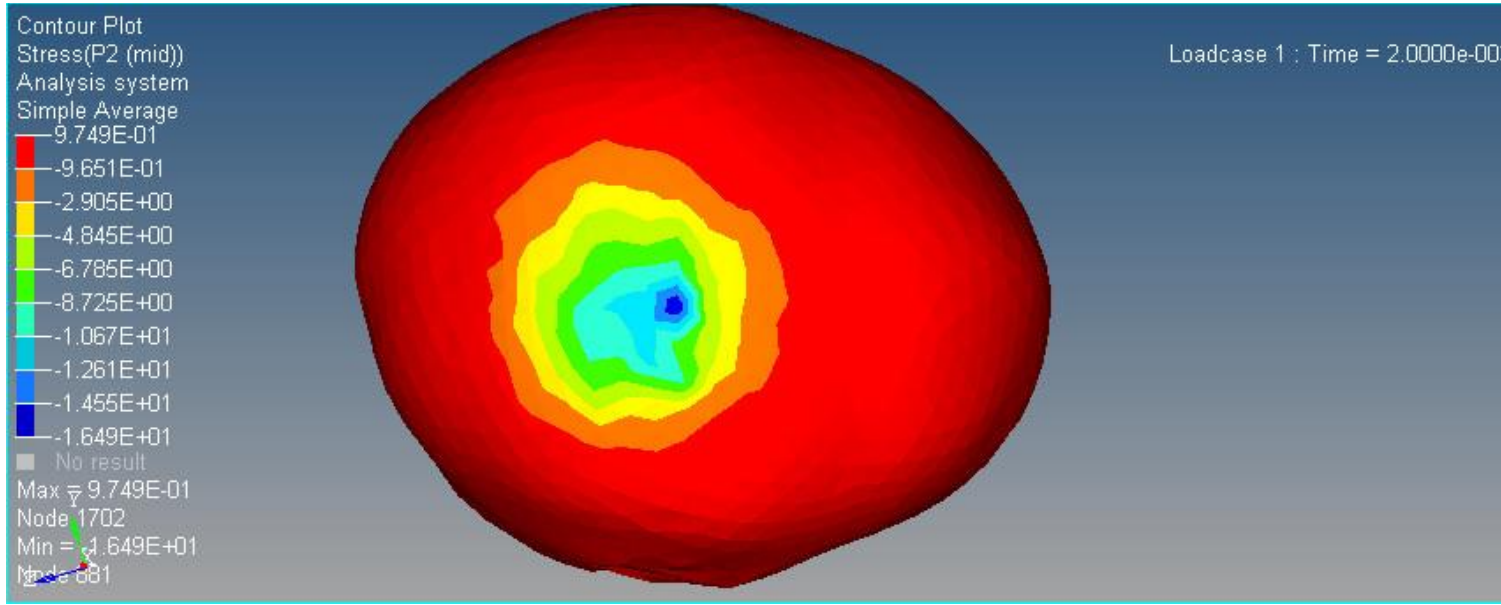

Figure 34: 55-cm Drop Mid Principle Stress Distribution (Superior Impact) 


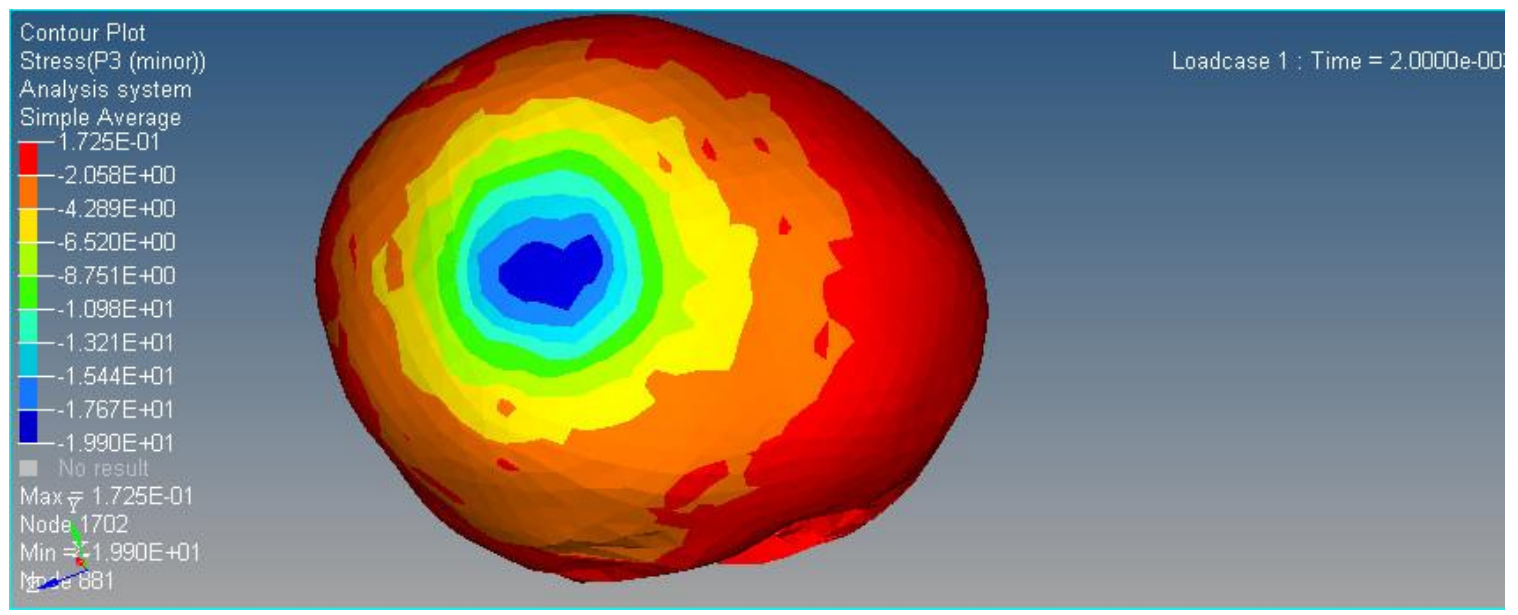

Figure 35: 55-cm Drop Minor Principle Stress Distribution (Superior Impact)

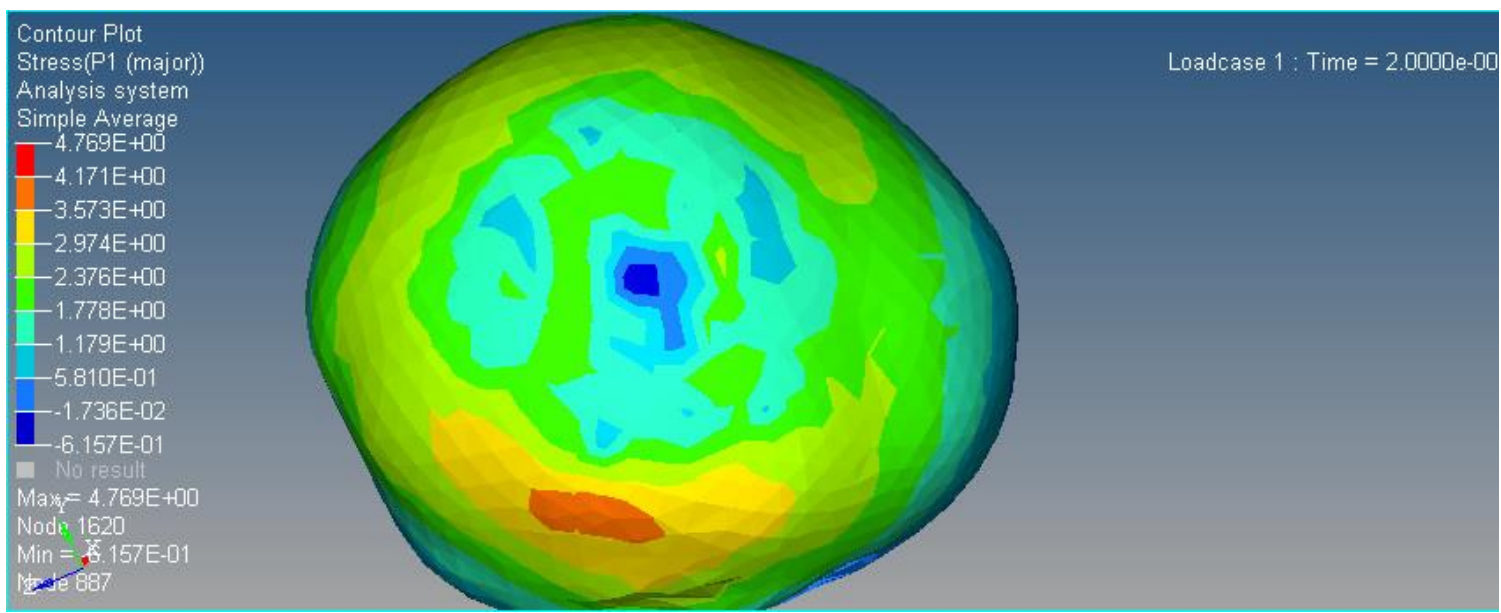

Figure 36: 45-cm Drop Major Principle Stress Distribution (Superior Impact)

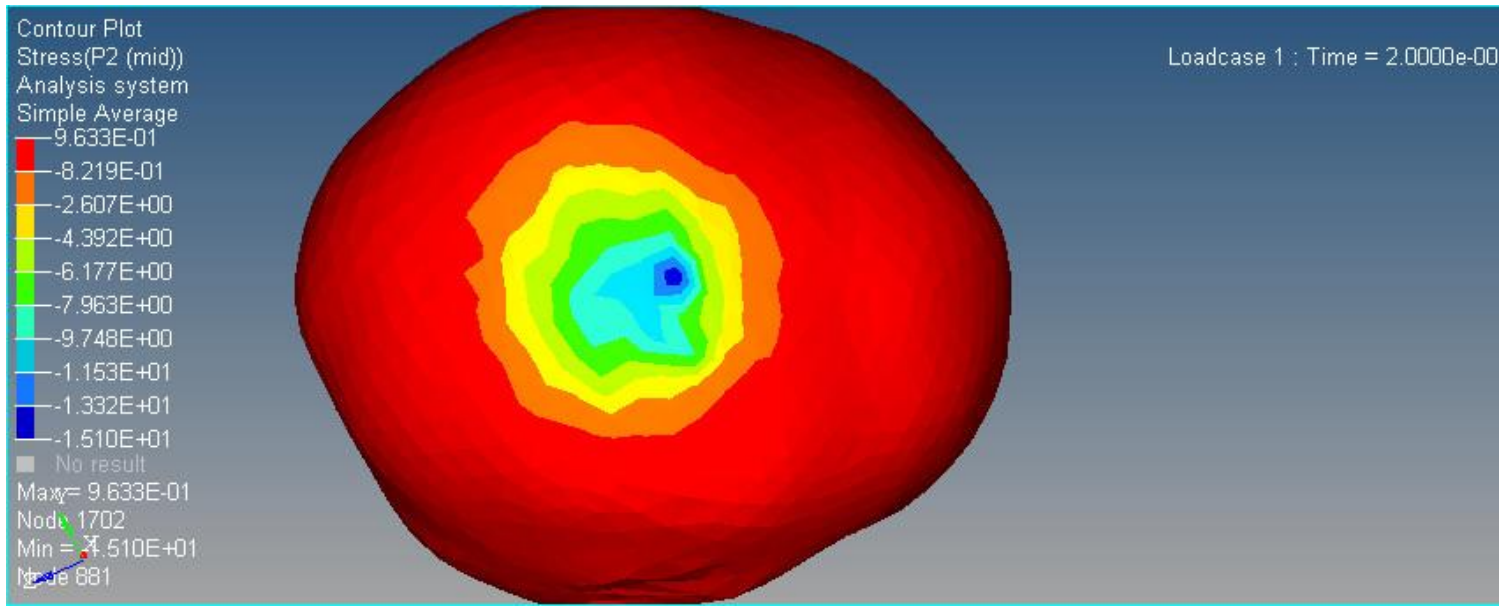

Figure 37: 45-cm Drop Mid Principle Stress Distribution (Superior Impact) 


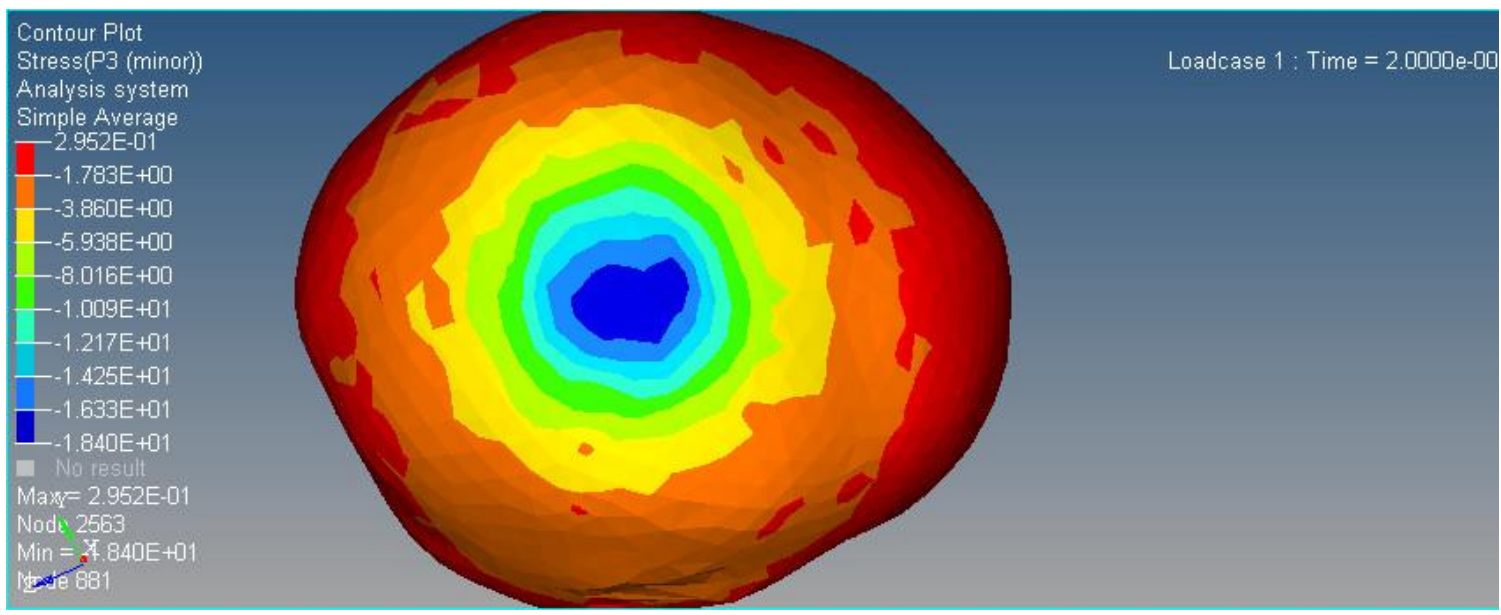

Figure 38: 45-cm Drop Minor Principle Stress Distribution (Superior Impact)

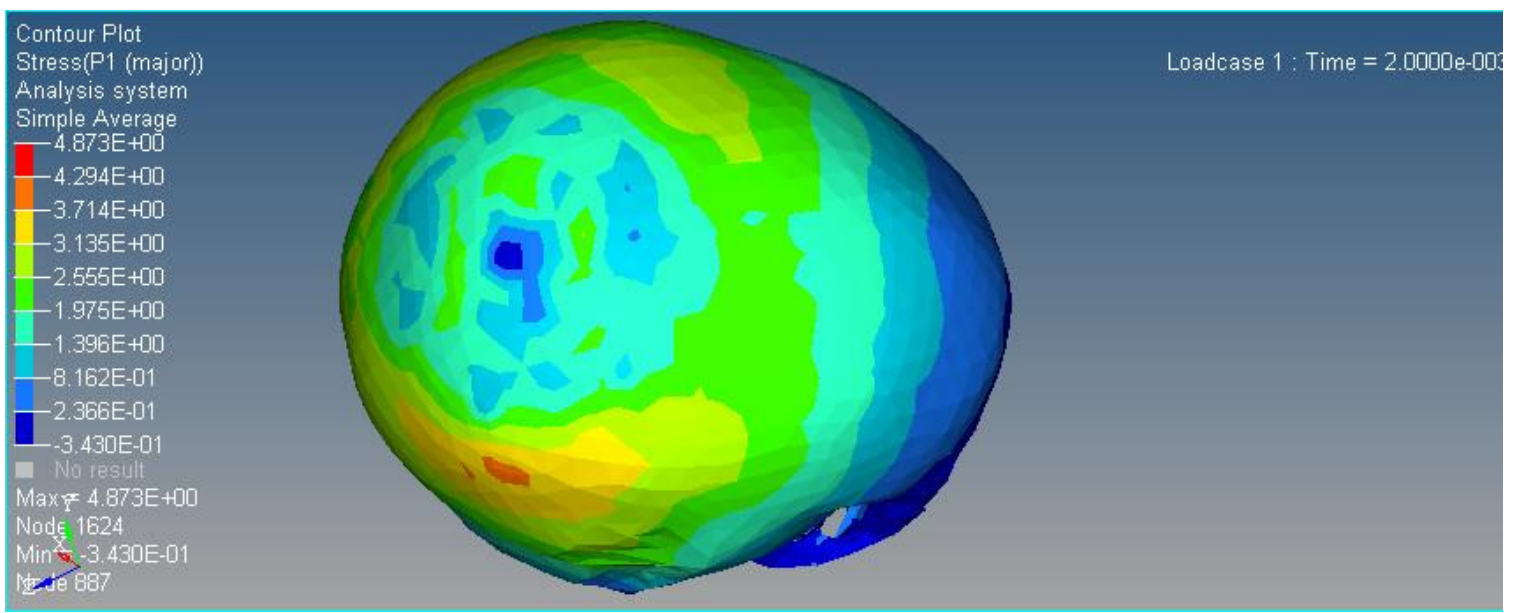

Figure 39: 35-cm Drop Major Principle Stress Distribution (Superior Impact)

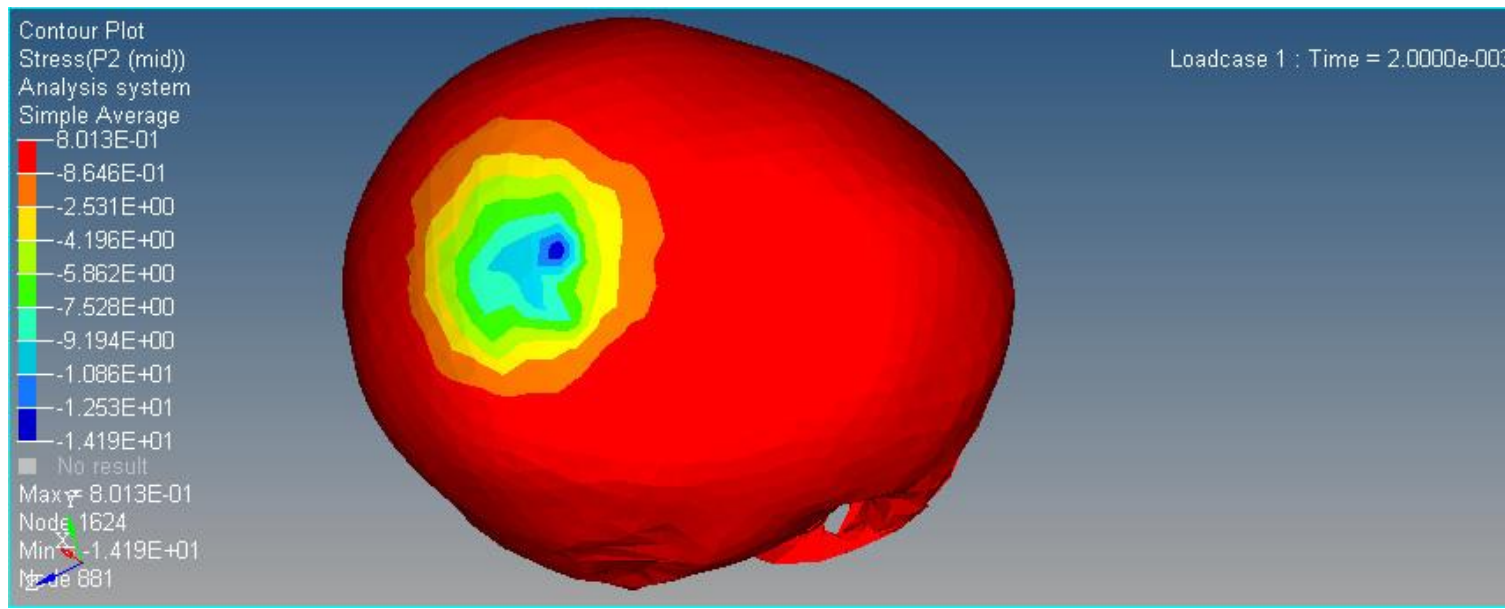

Figure 40: 35-cm Drop Mid Principle Stress Distribution (Superior Impact) 


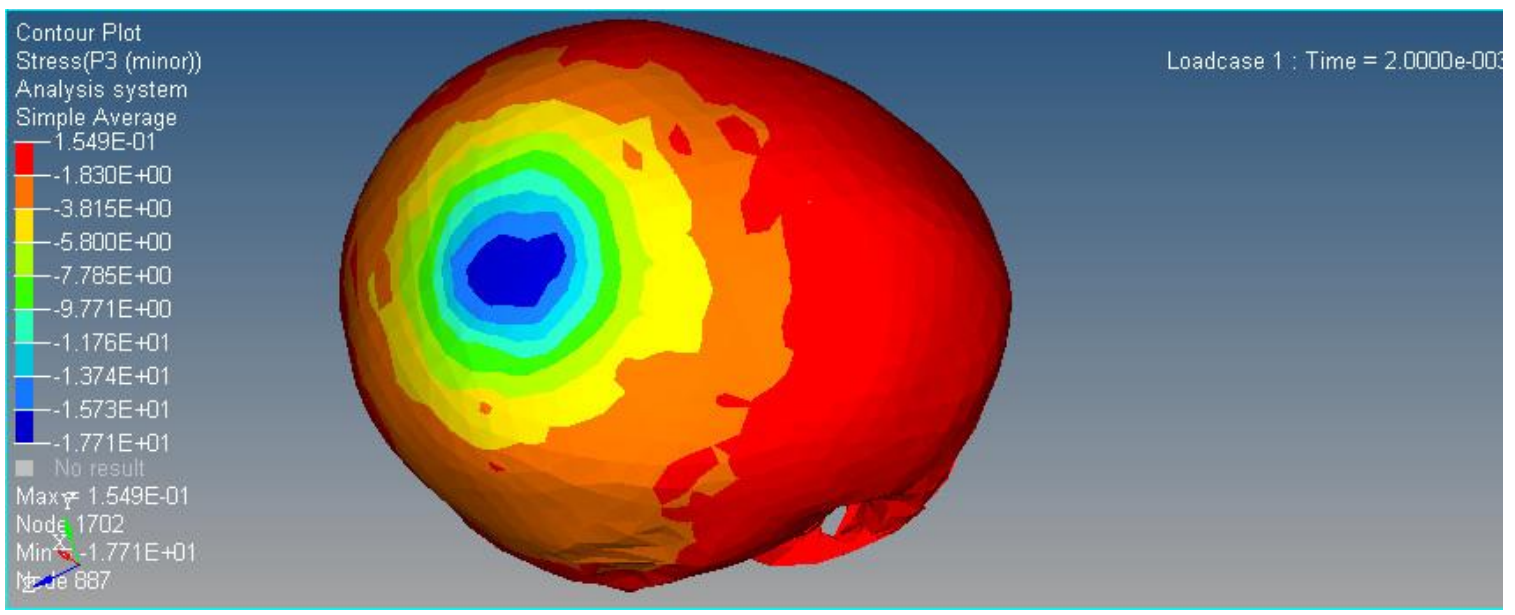

Figure 41: 35-cm Drop Minor Principle Stress Distribution (Superior Impact)

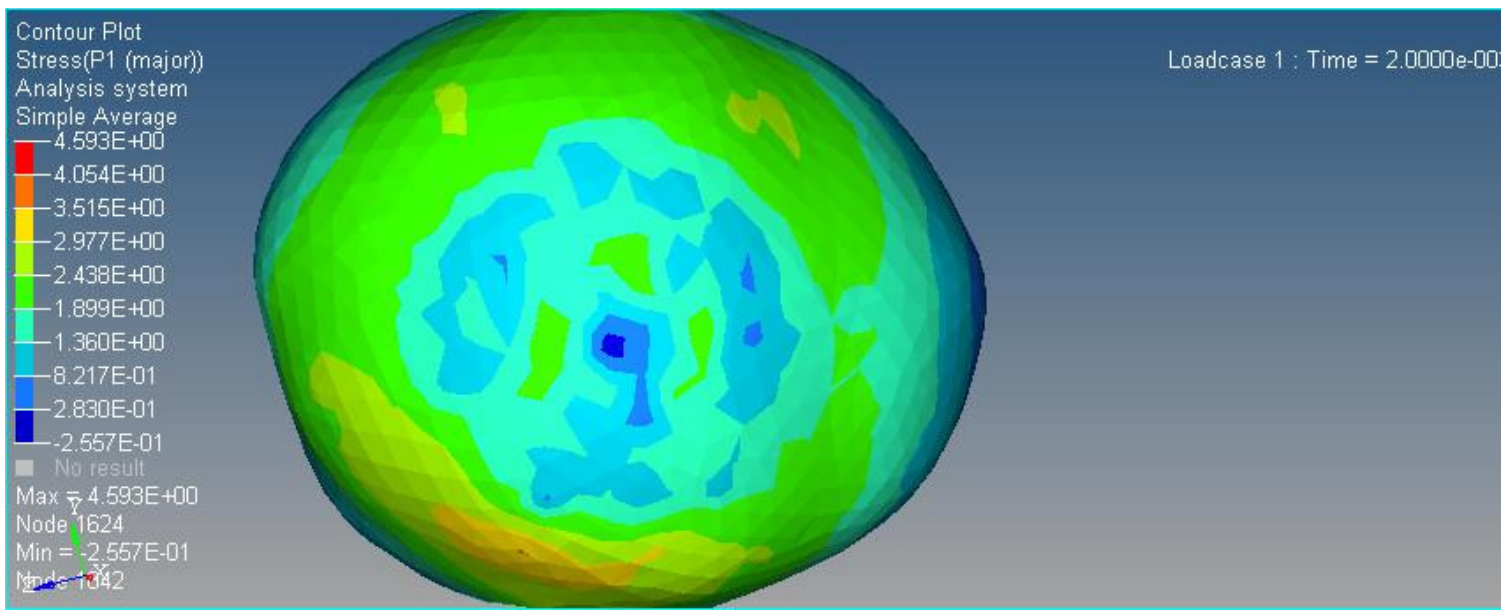

Figure 42: 25-cm Drop Major Principle Stress Distribution (Superior Impact)

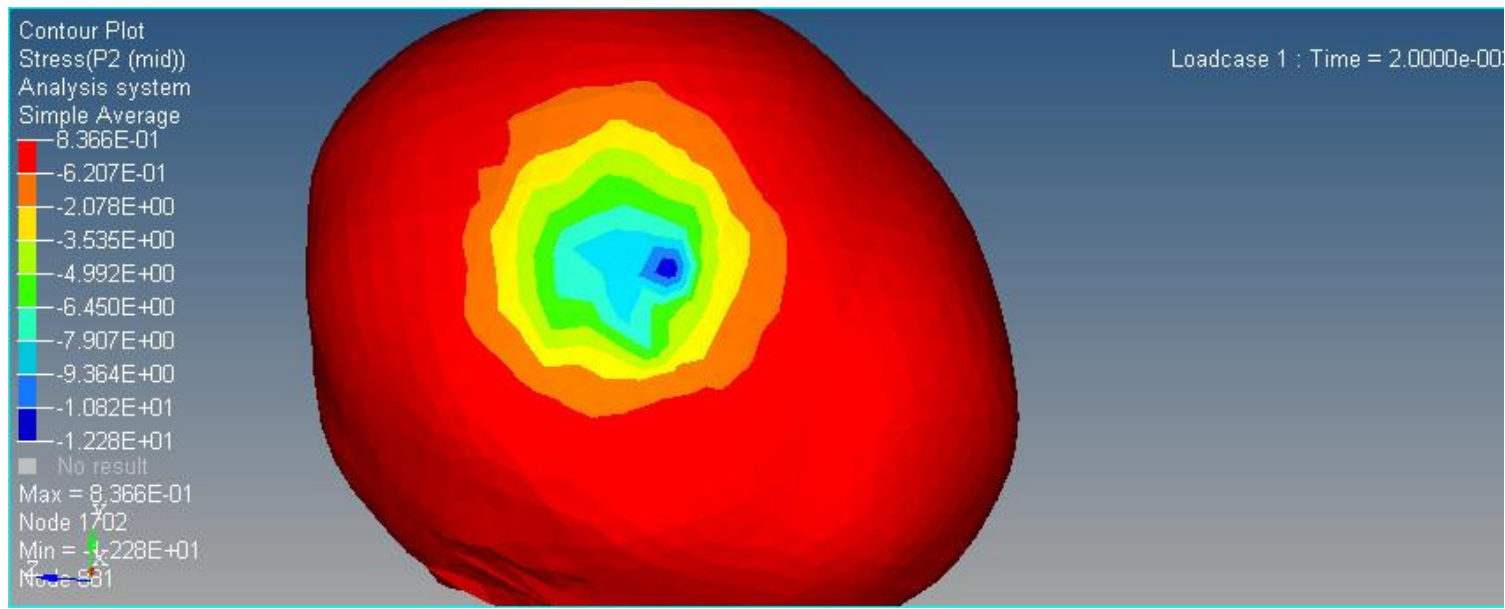

Figure 43: 25-cm Drop Mid Principle Stress Distribution (Superior Impact) 


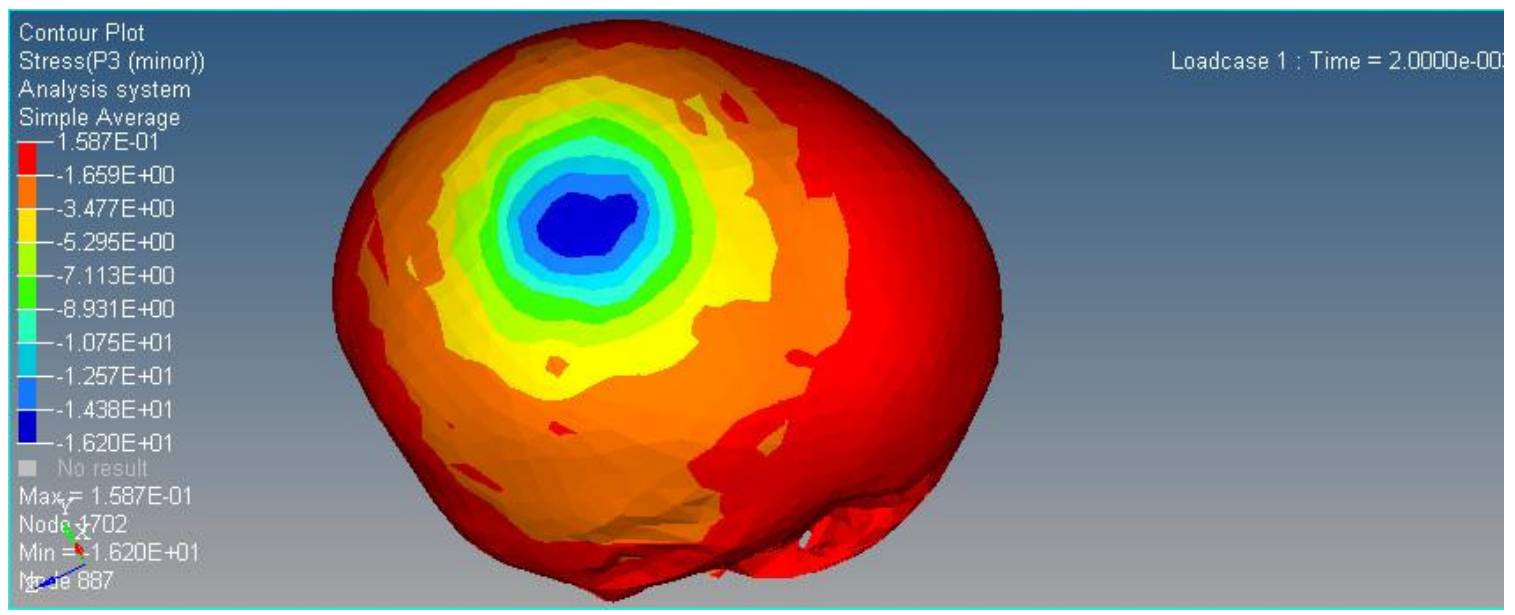

Figure 44: 25-cm Drop Minor Principle Stress Distribution (Superior Impact)

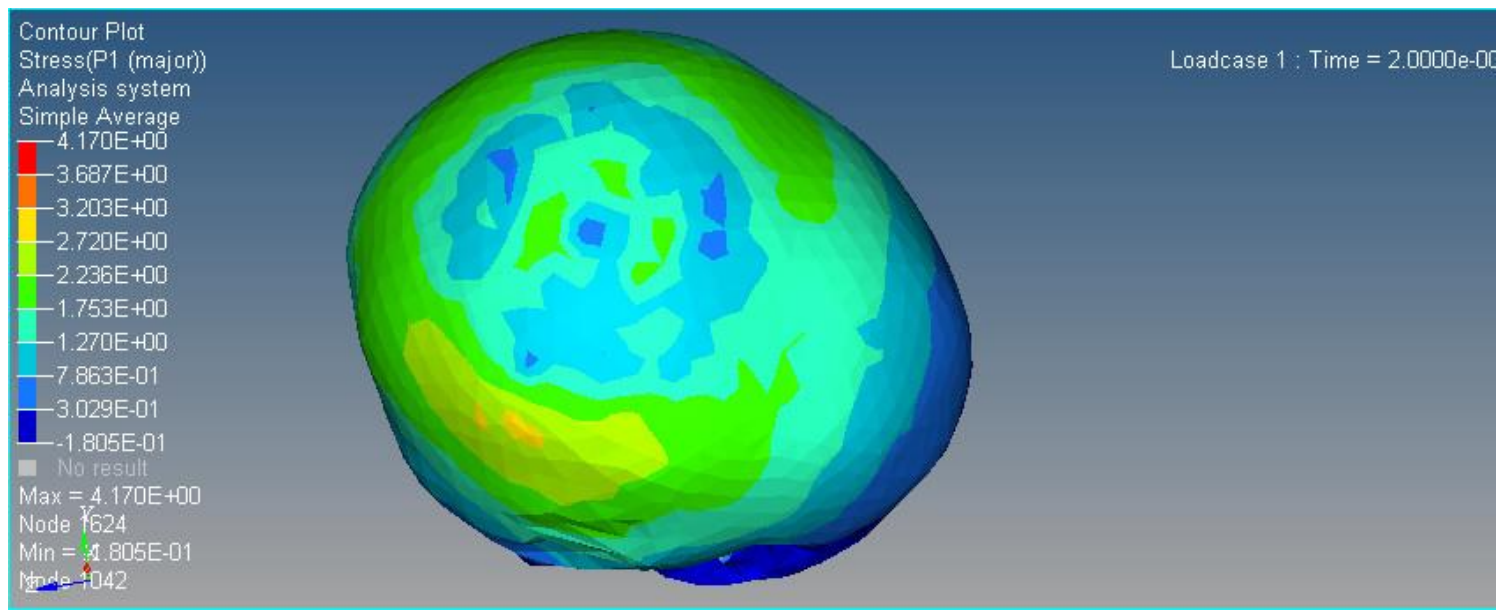

Figure 45: 15-cm Drop Major Principle Stress Distribution (Superior Impact)

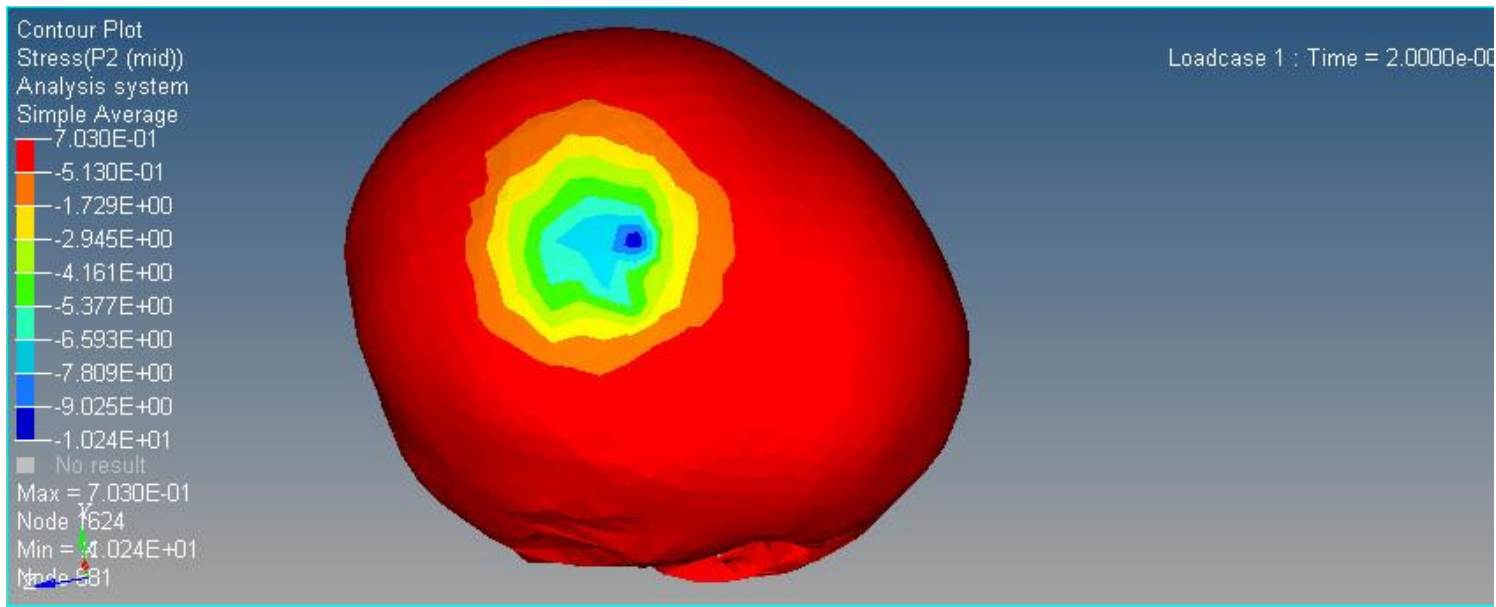

Figure 46: 15-cm Drop Mid Principle Stress Distribution (Superior Impact) 


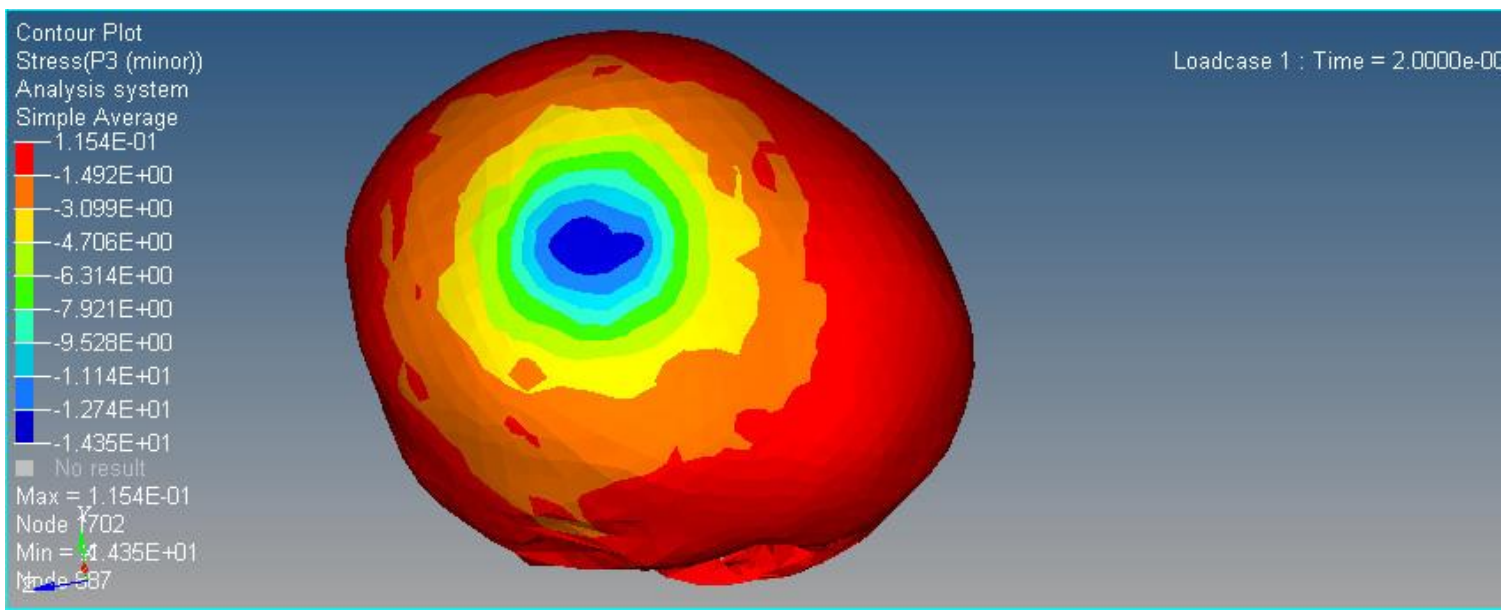

Figure 47: 15-cm Drop Minor Principle Stress Distribution (Superior Impact)

\subsubsection{Lateral Impact}

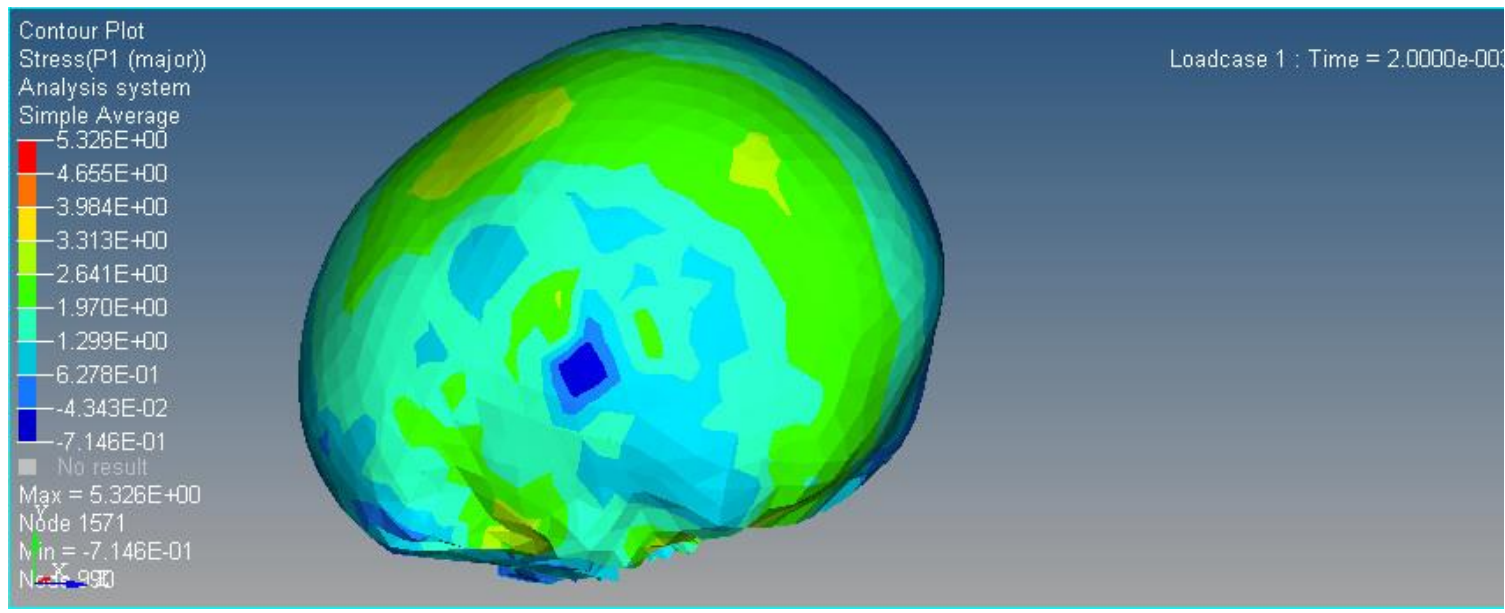

Figure 48: 55-cm Drop Major Principle Stress Distribution (Lateral Impact)

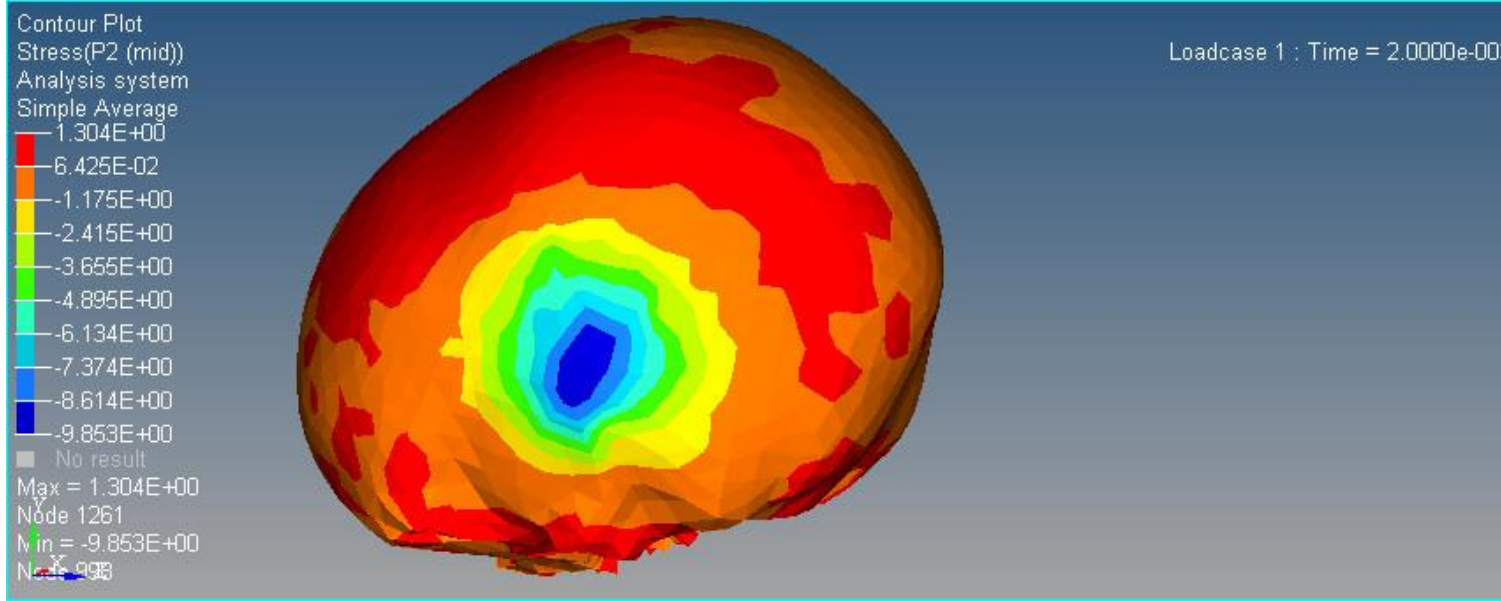

Figure 49: 55-cm Drop Mid Principle Stress Distribution (Lateral Impact) 


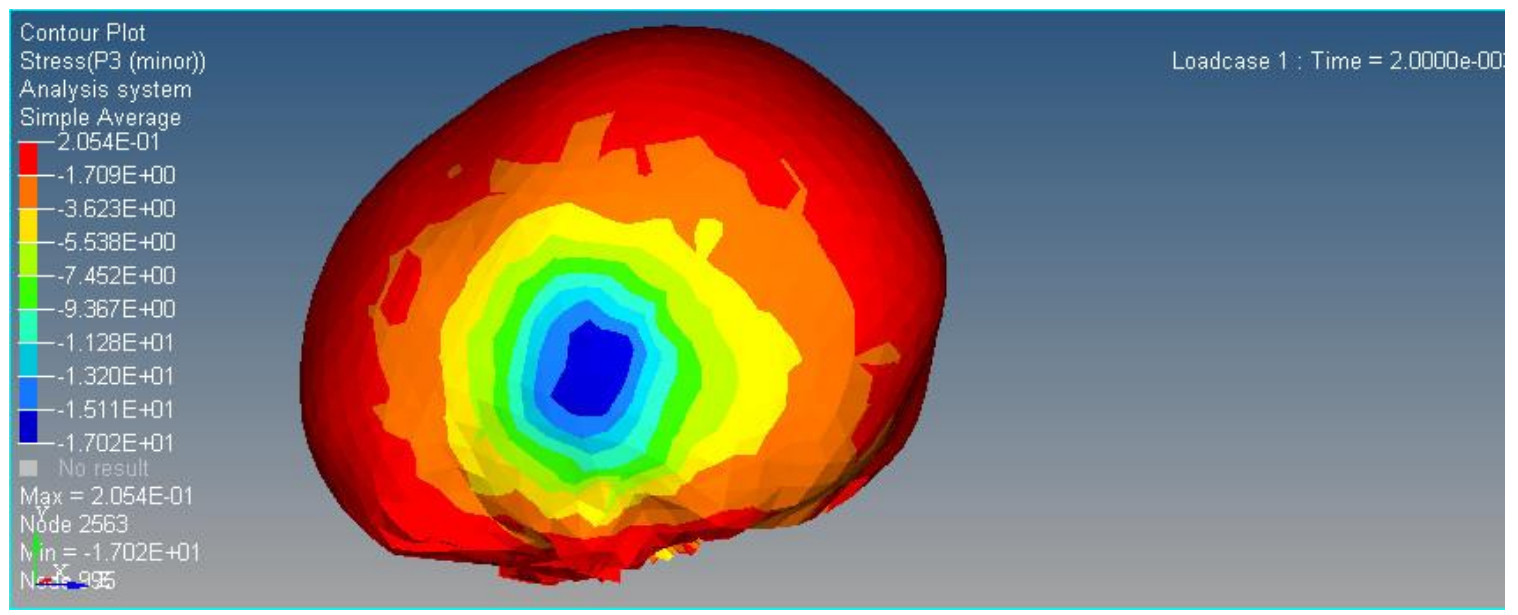

Figure 50: 55-cm Drop Minor Principle Stress Distribution (Lateral Impact)

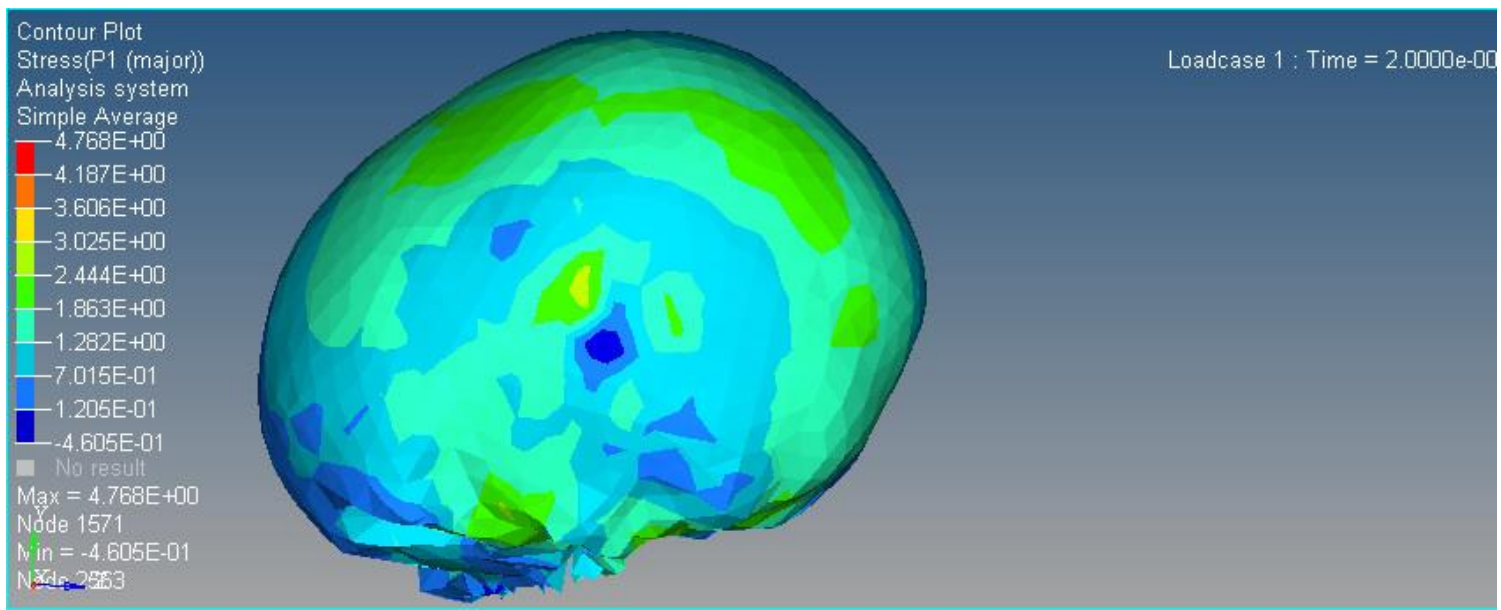

Figure 51: 45-cm Drop Major Principle Stress Distribution (Lateral Impact)

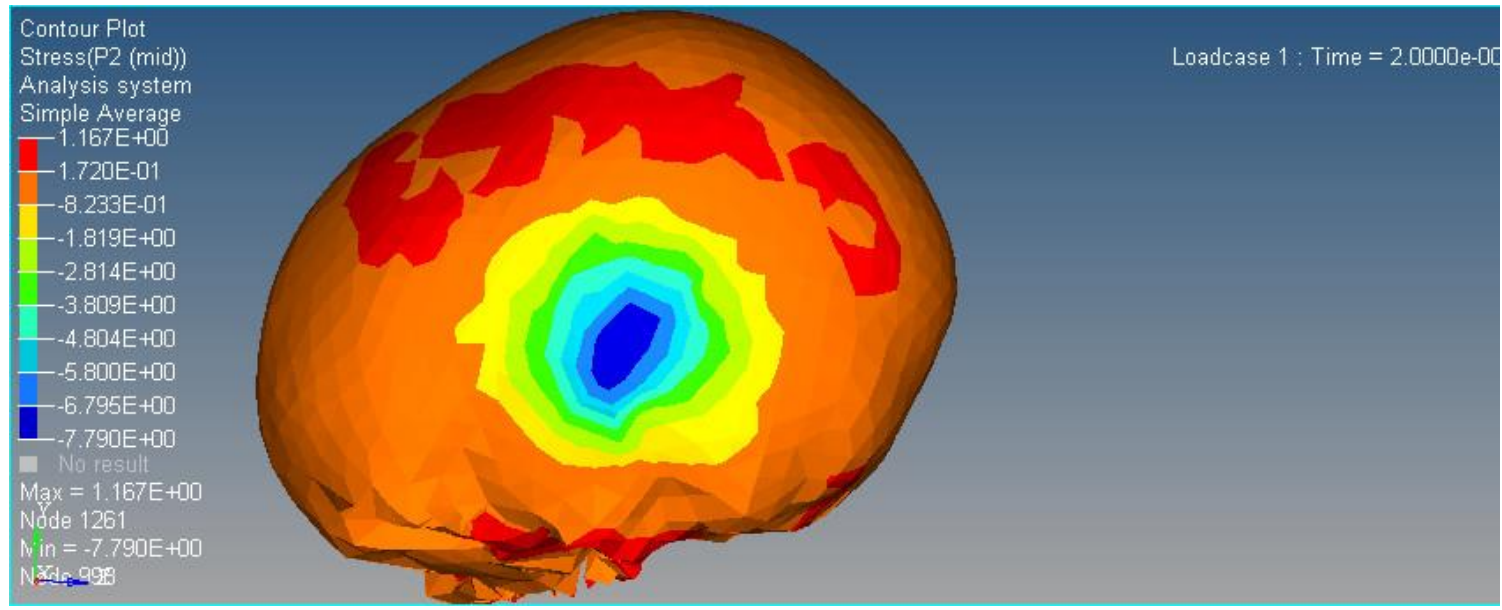

Figure 52: 45-cm Drop Mid Principle Stress Distribution (Lateral Impact) 


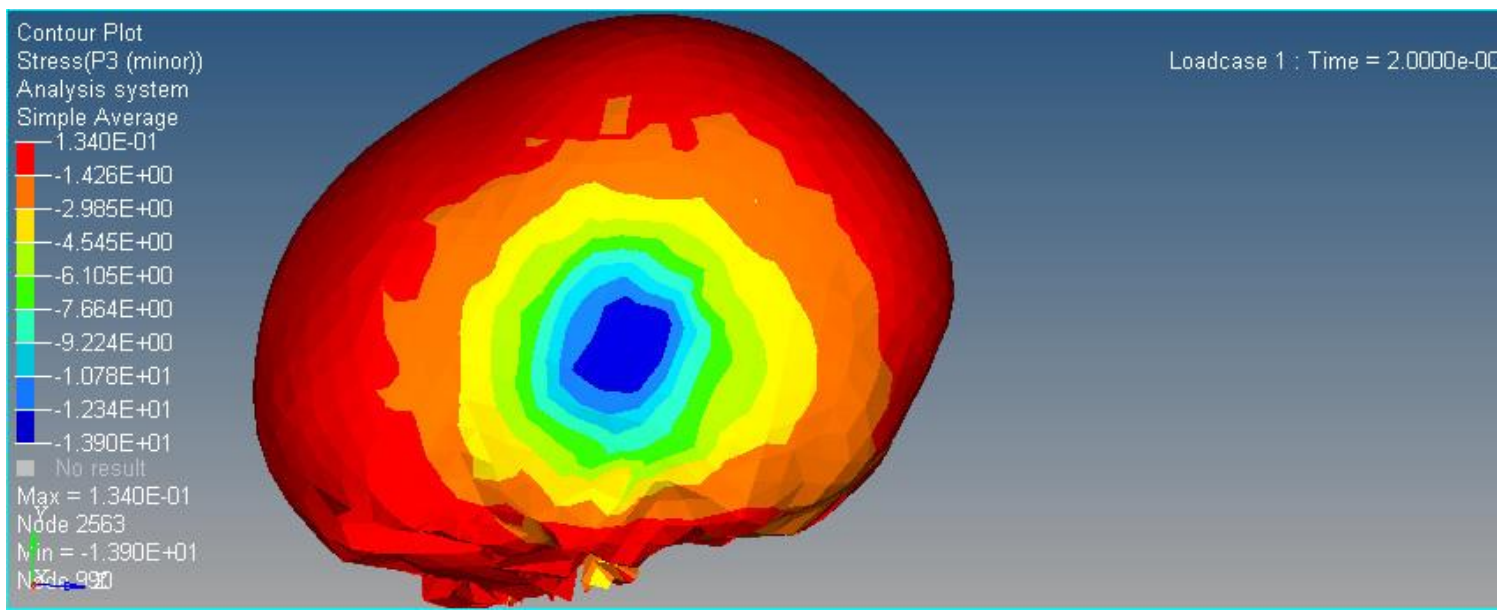

Figure 53: 45-cm Drop Minor Principle Stress Distribution (Lateral Impact)

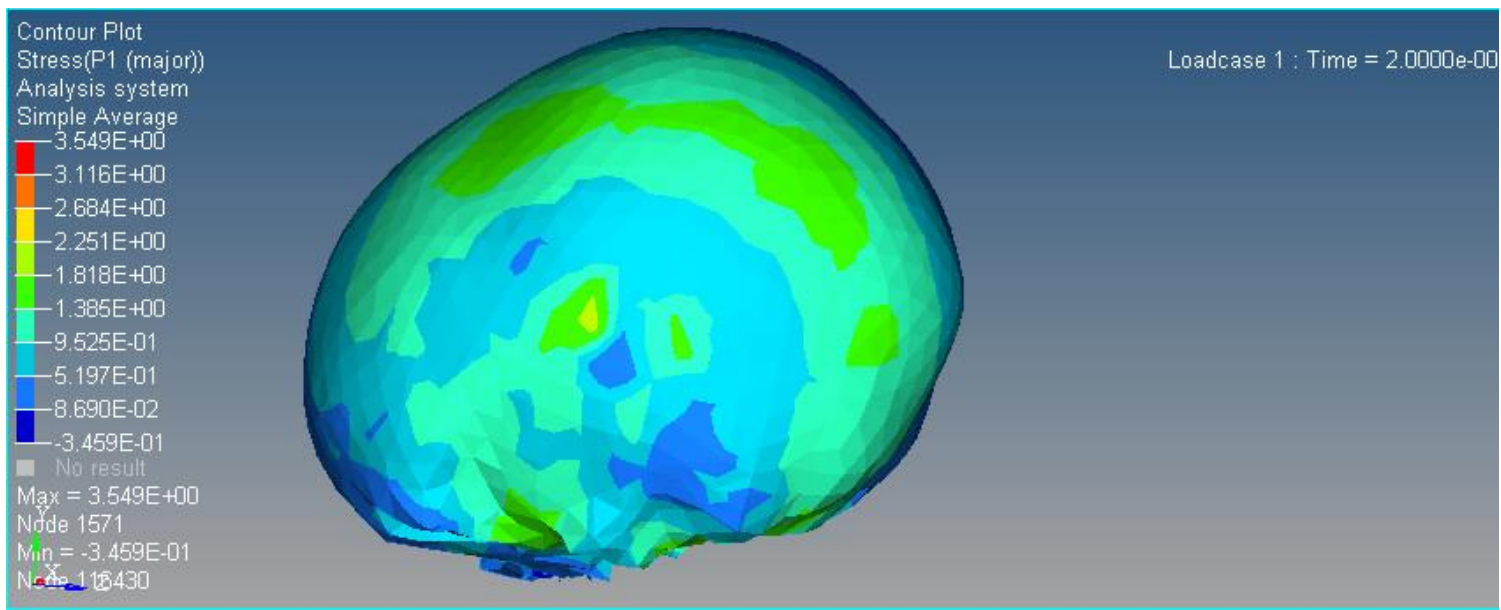

Figure 54: 35-cm Drop Major Principle Stress Distribution (Lateral Impact)

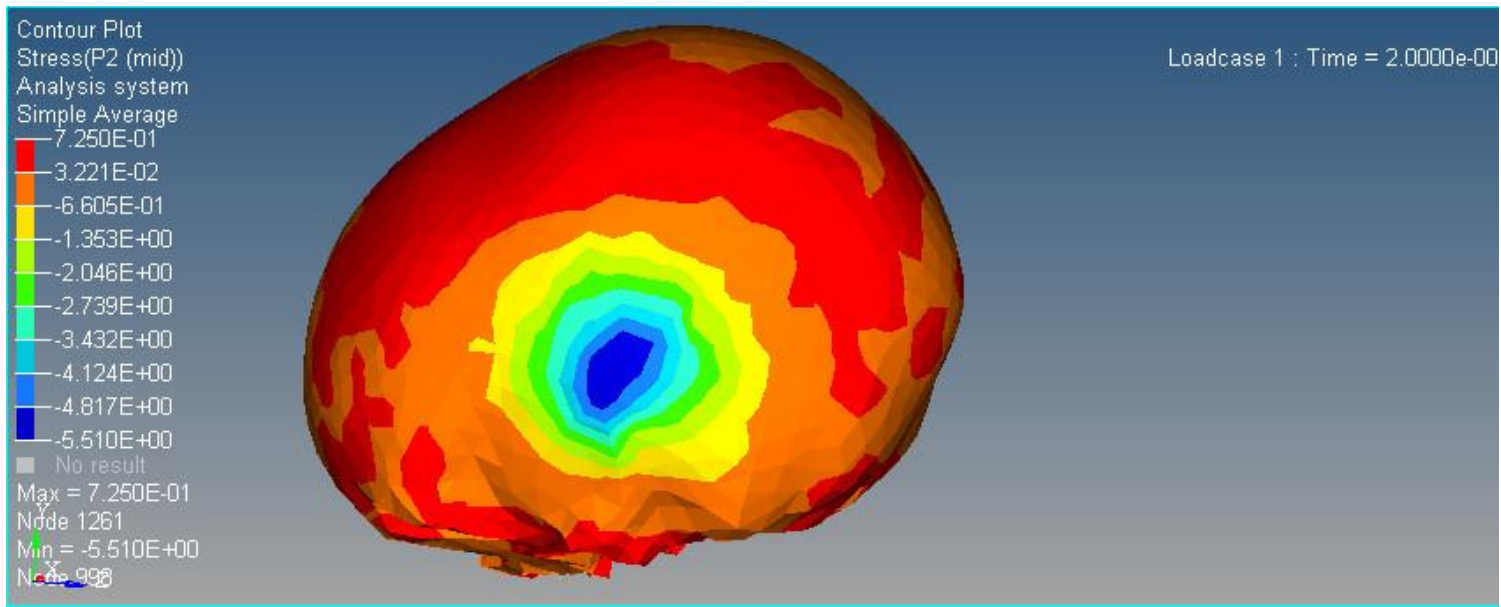

Figure 55: 35-cm Drop Mid Principle Stress Distribution (Lateral Impact) 


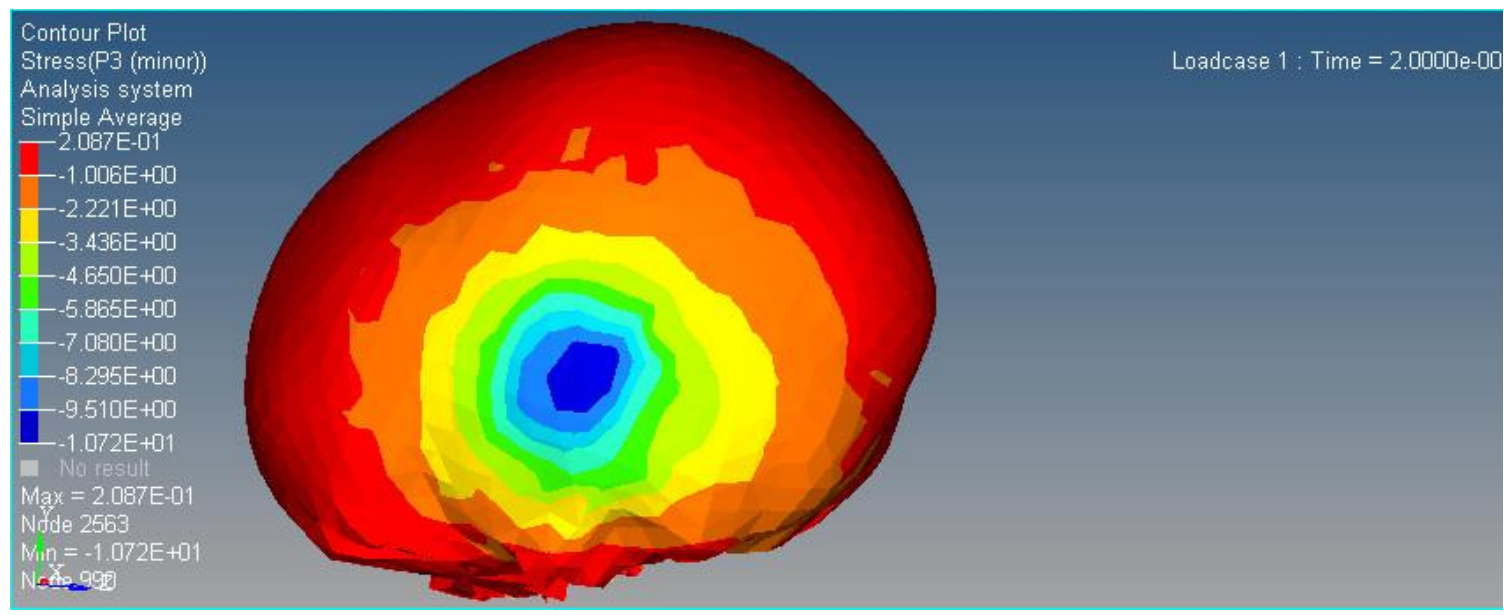

Figure 56: 35-cm Drop Minor Principle Stress Distribution (Lateral Impact)

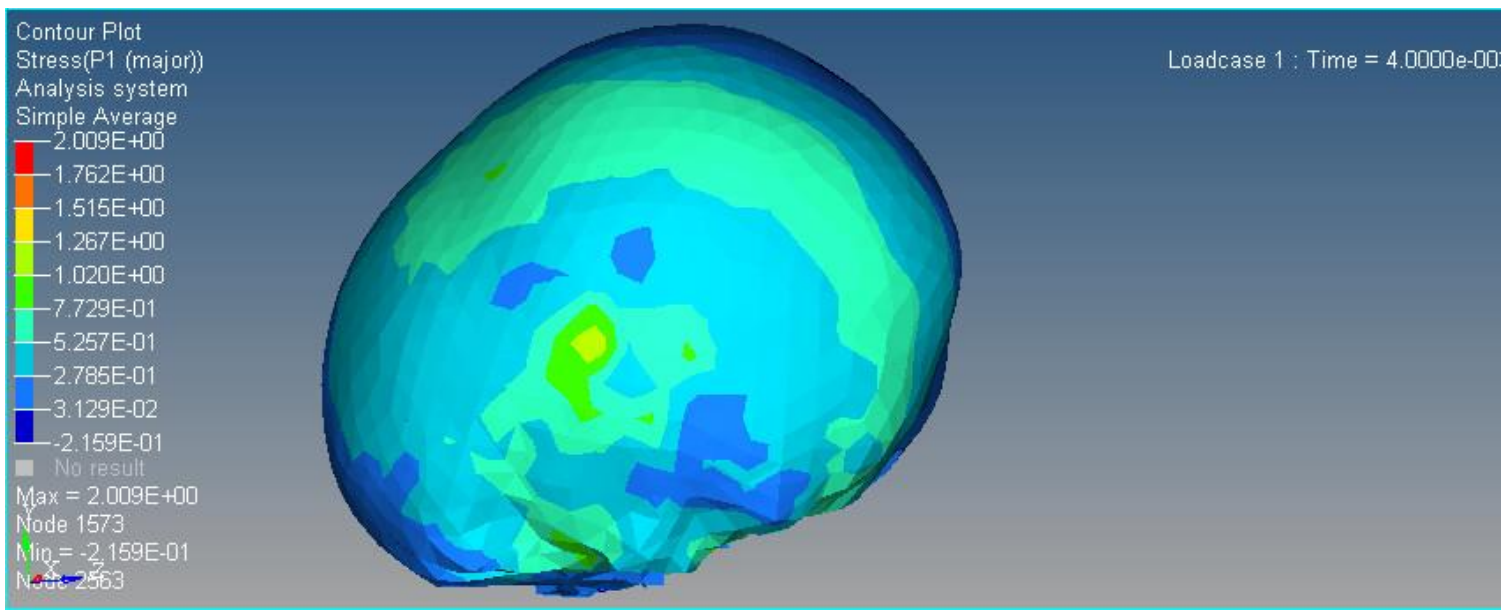

Figure 57: 25-cm Drop Major Principle Stress Distribution (Lateral Impact)

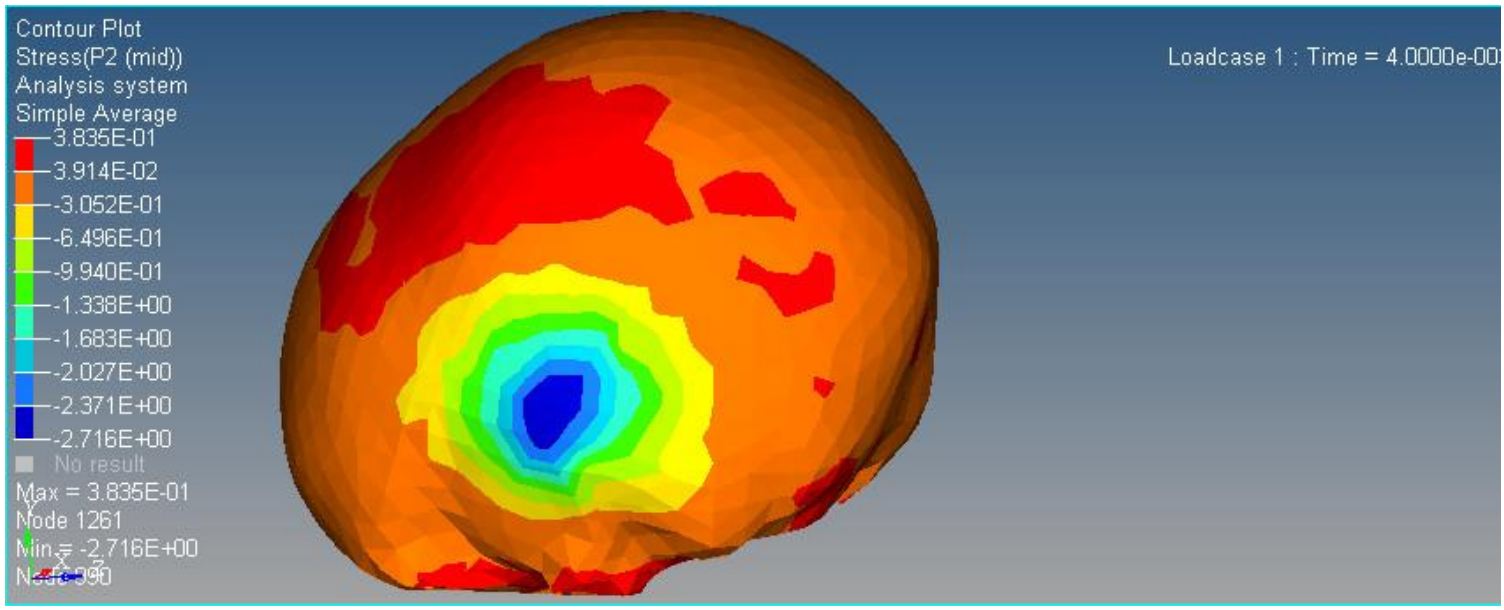

Figure 58: 25-cm Drop Mid Principle Stress Distribution (Lateral Impact) 


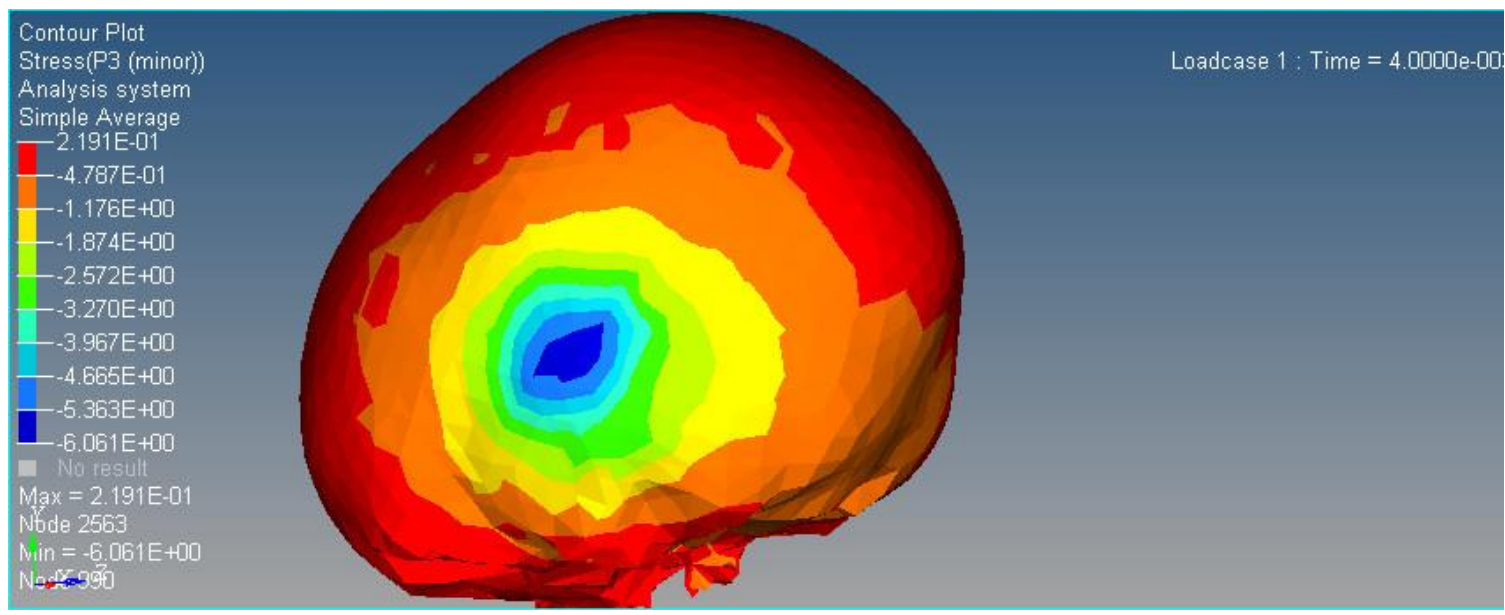

Figure 59: 25-cm Drop Minor Principle Stress Distribution (Lateral Impact)

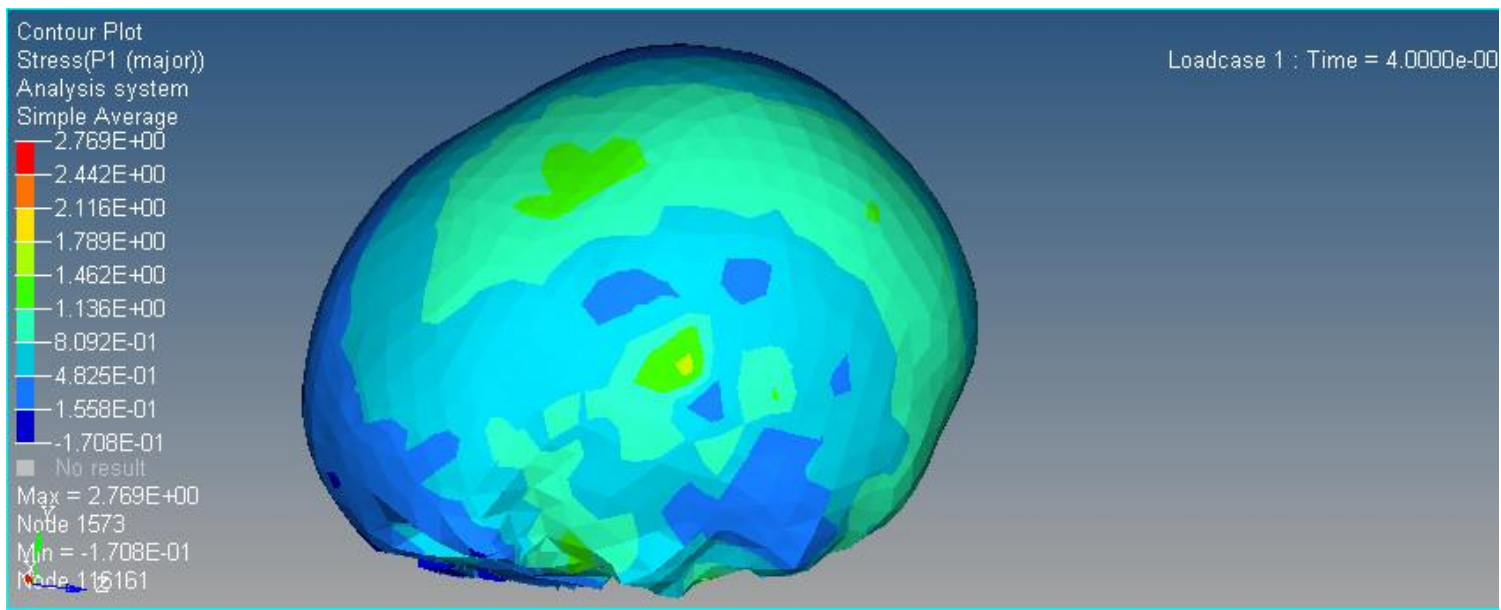

Figure 60: 15-cm Drop Major Principle Stress Distribution (Lateral Impact)

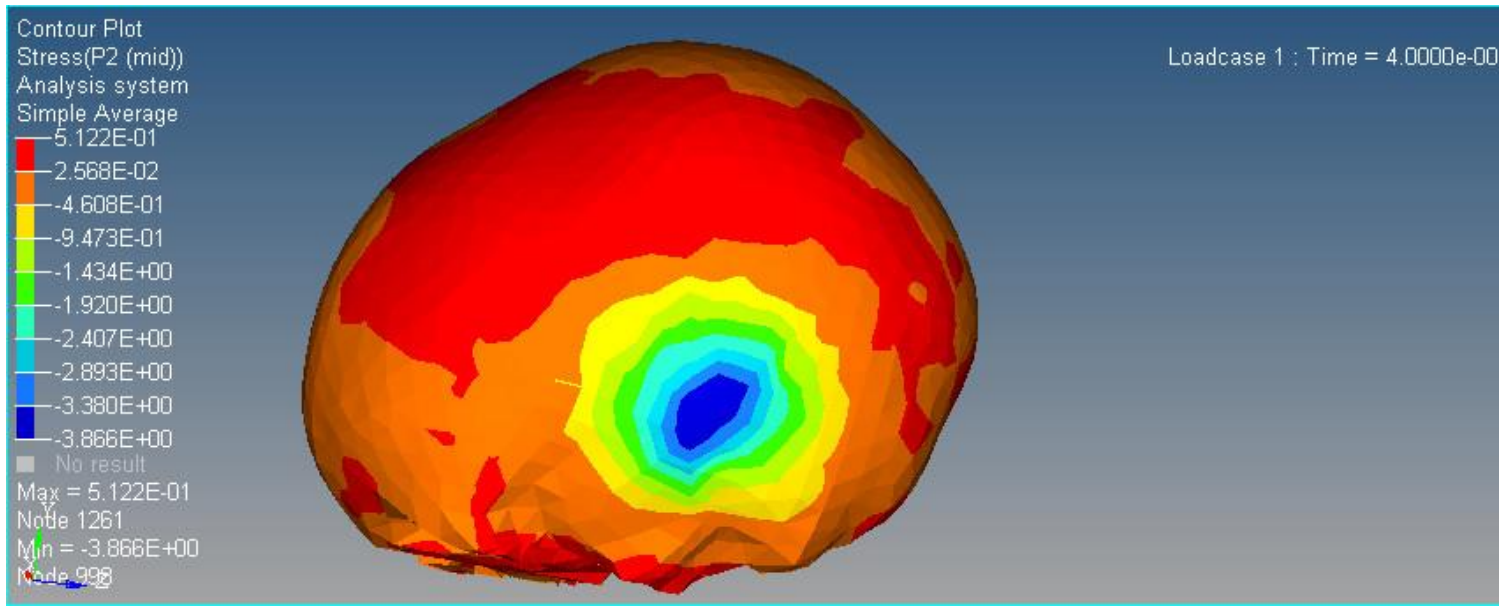

Figure 61: 15-cm Drop Mid Principle Stress Distribution (Lateral Impact) 


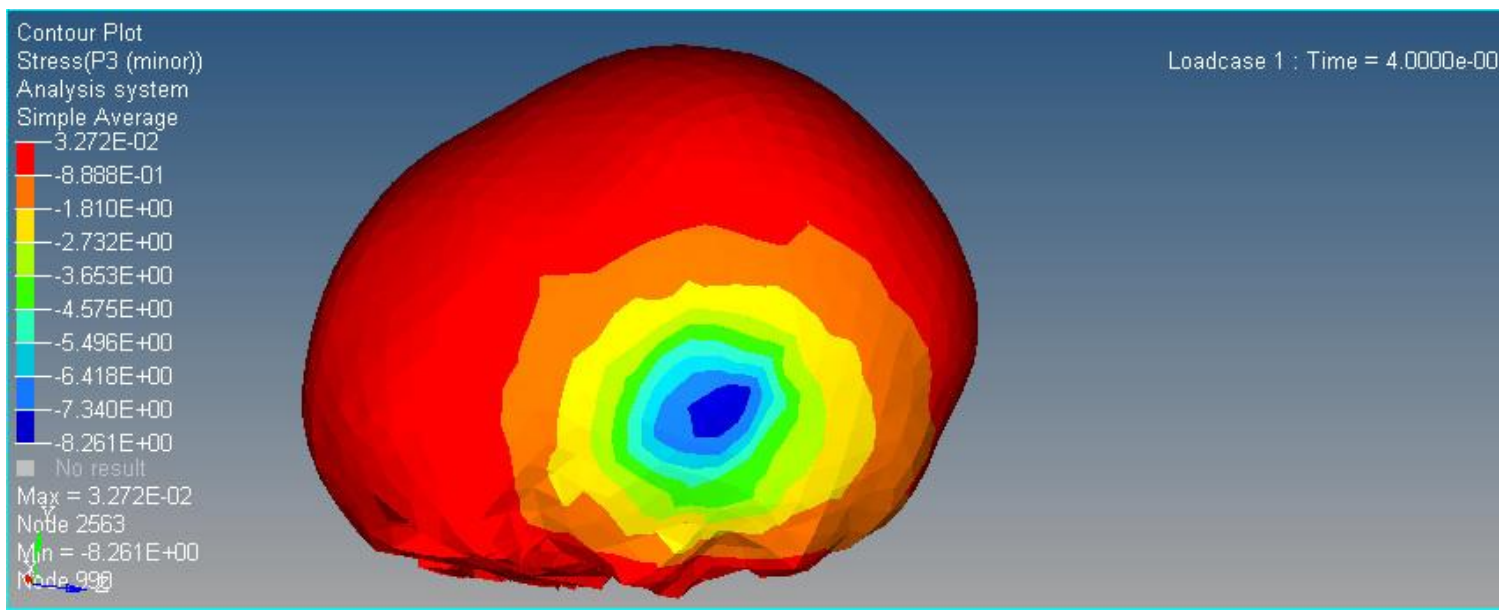

Figure 62: 15-cm Drop Minor Principle Stress Distribution (Lateral Impact)

\subsubsection{Posterior Impact}

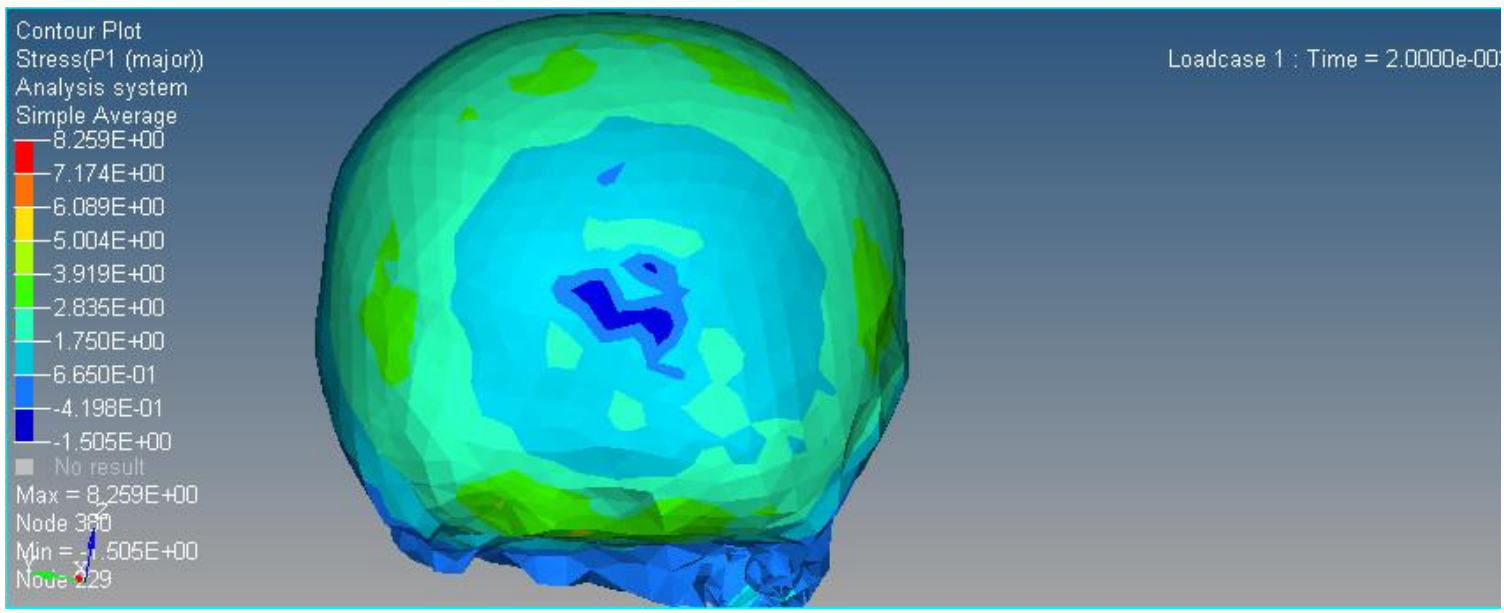

Figure 63: 55-cm Drop Major Principle Stress Distribution (Posterior Impact)

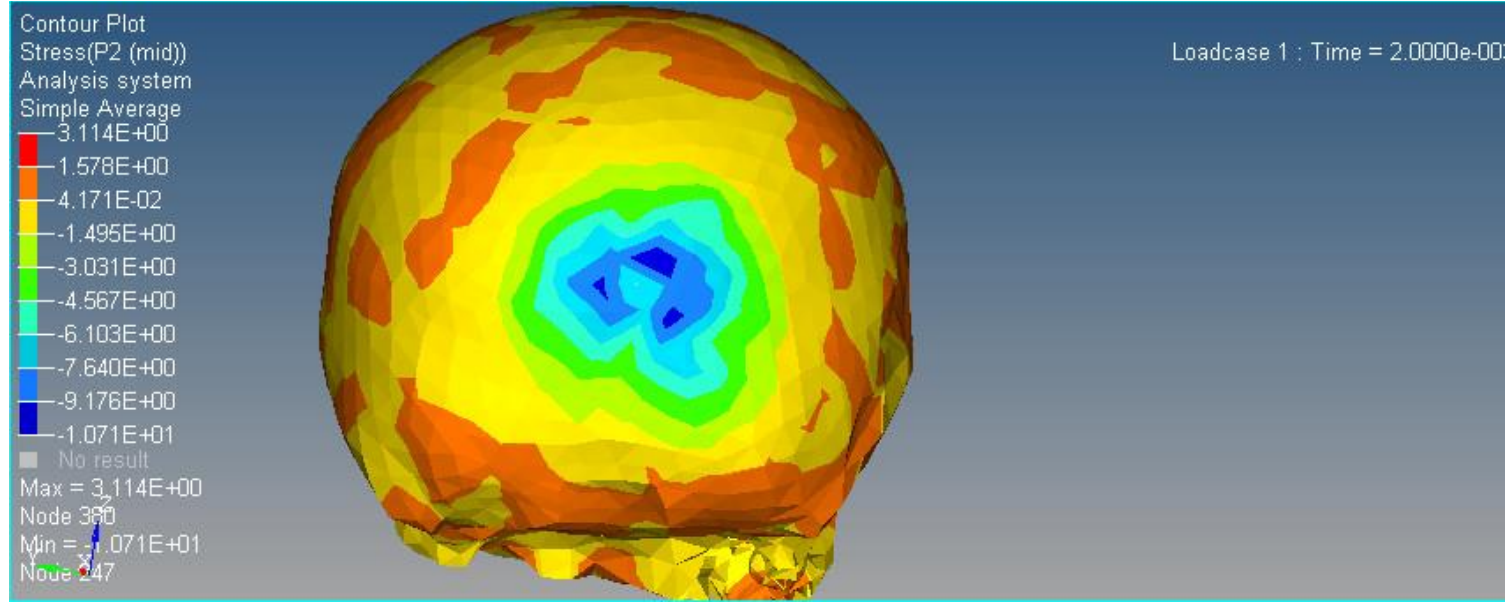

Figure 64: 55-cm Drop Mid Principle Stress Distribution (Posterior Impact) 


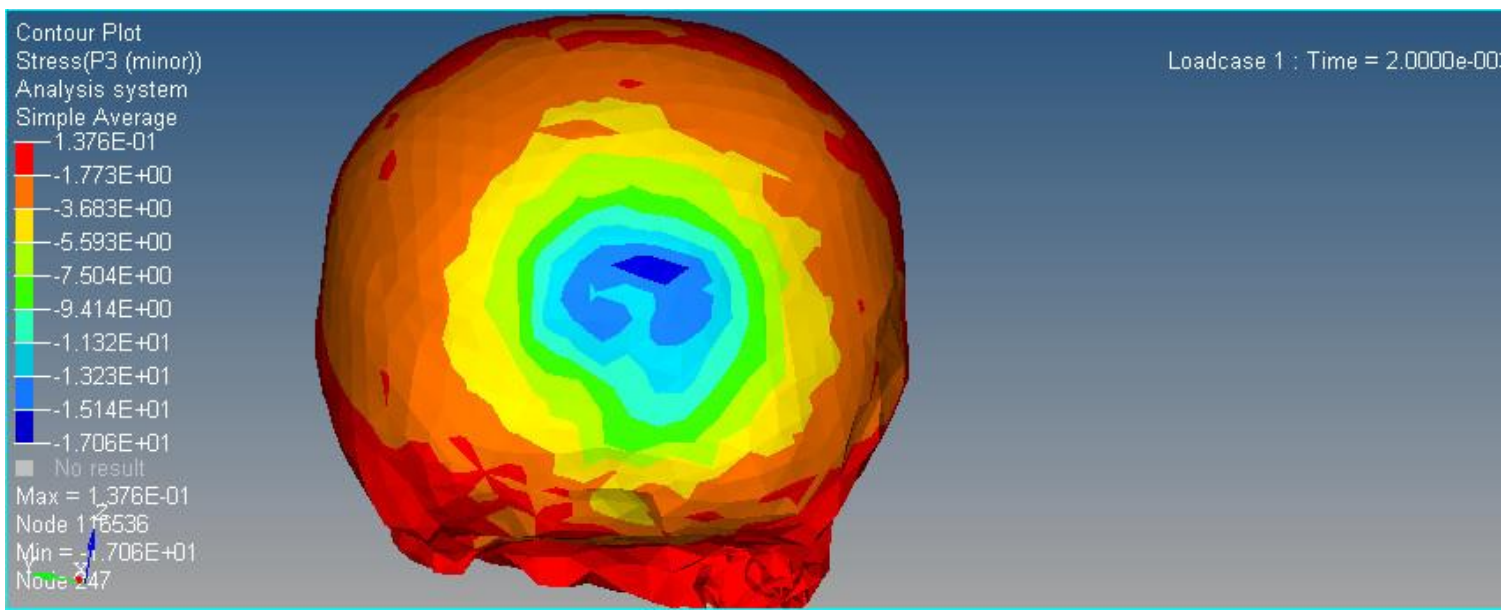

Figure 65: 55-cm Drop Minor Principle Stress Distribution (Posterior Impact)

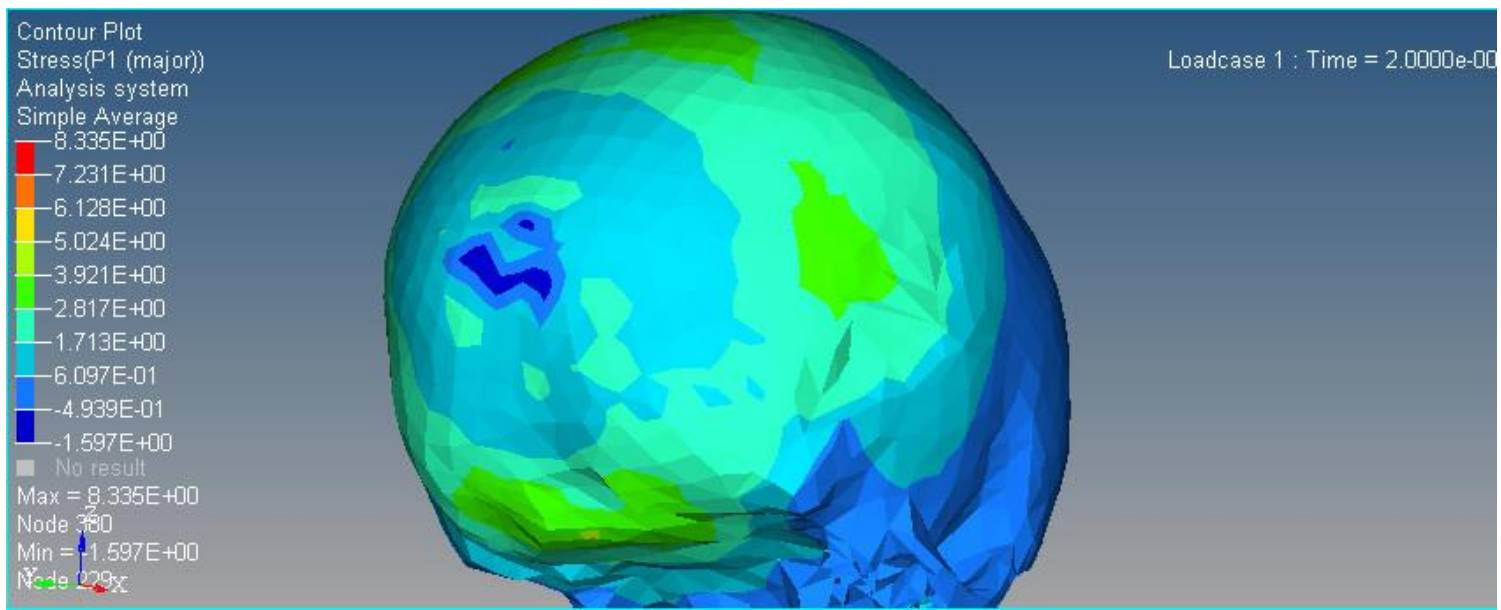

Figure 66: 45-cm Drop Major Principle Stress Distribution (Posterior Impact)

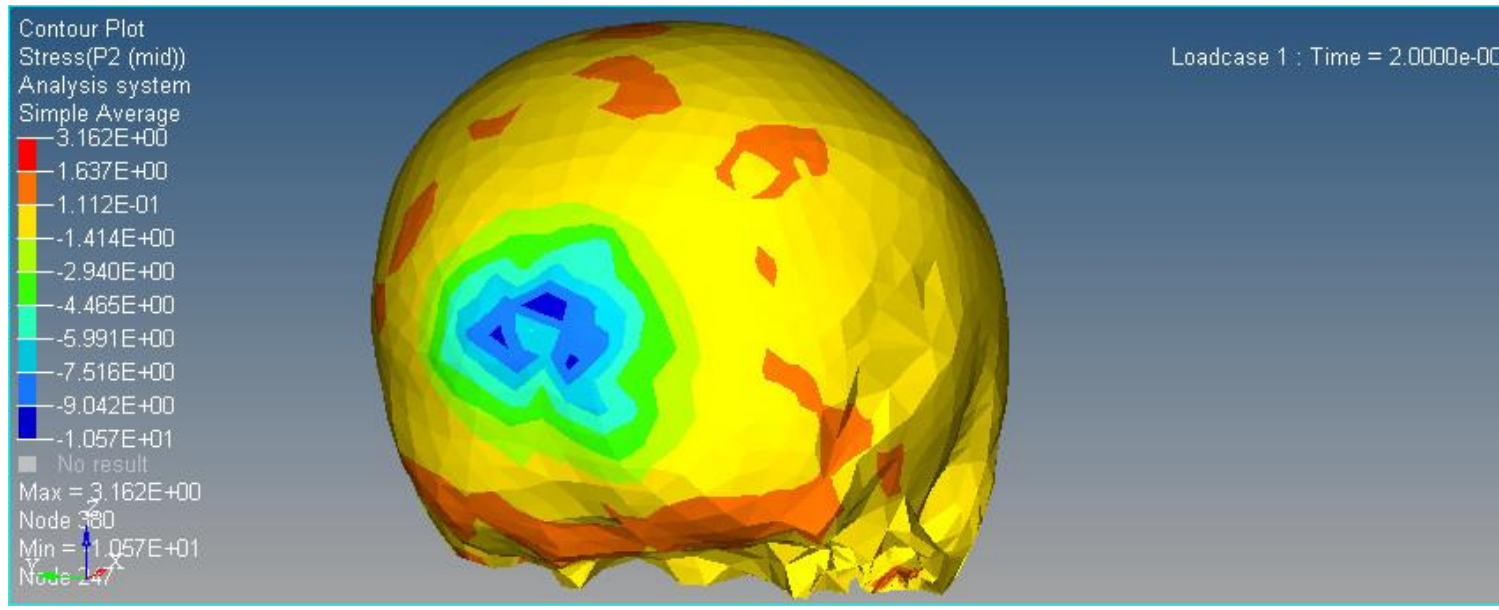

Figure 67: 45-cm Drop Mid Principle Stress Distribution (Posterior Impact) 


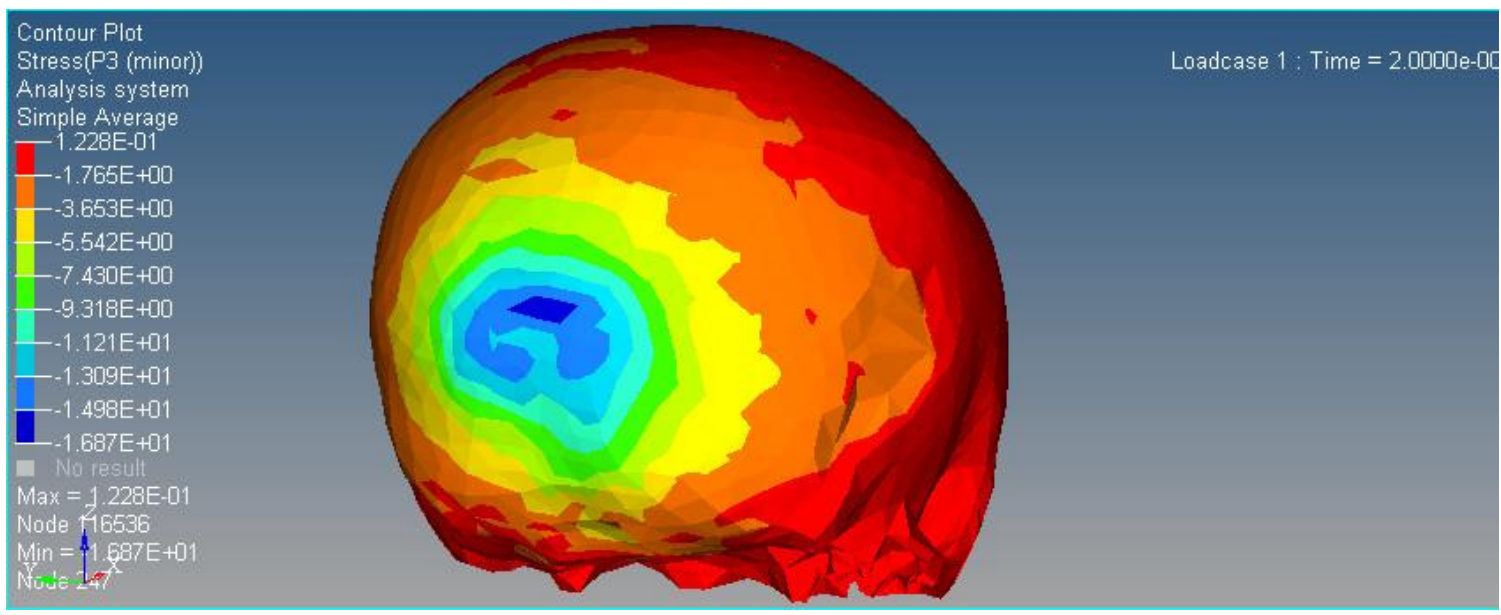

Figure 68: 45-cm Drop Minor Principle Stress Distribution (Posterior Impact)

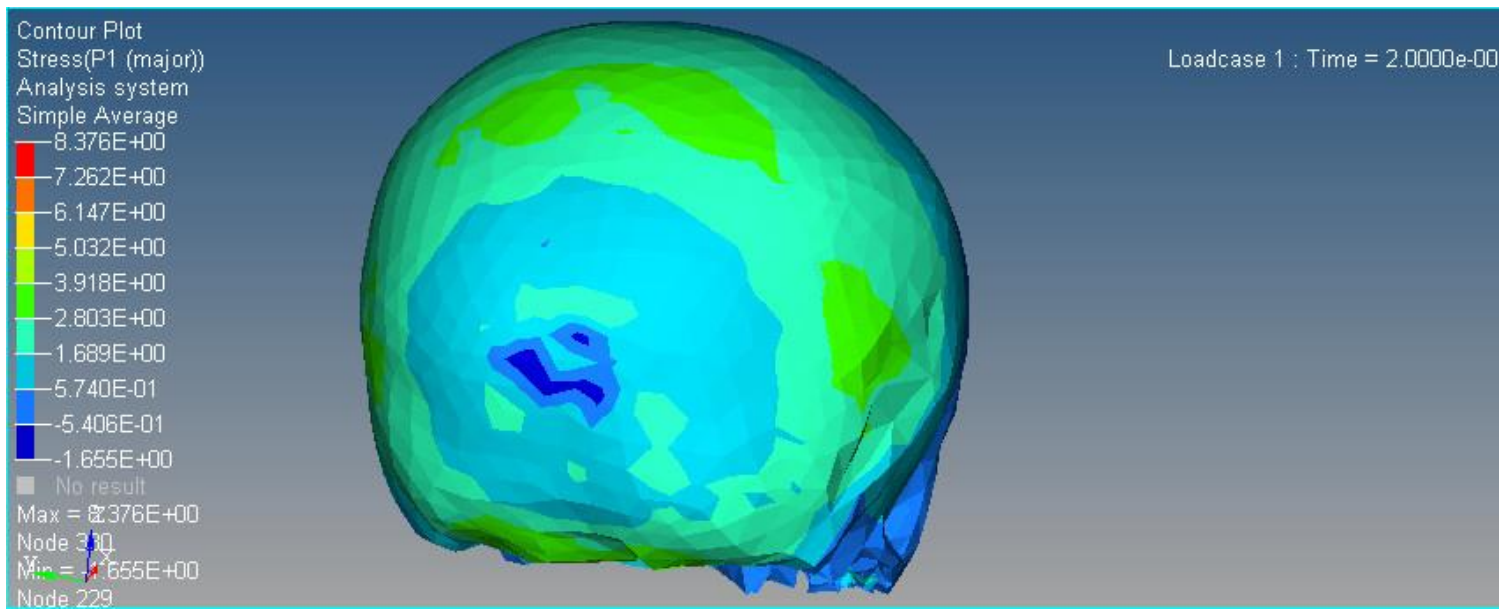

Figure 69: 35-cm Drop Major Principle Stress Distribution (Posterior Impact)

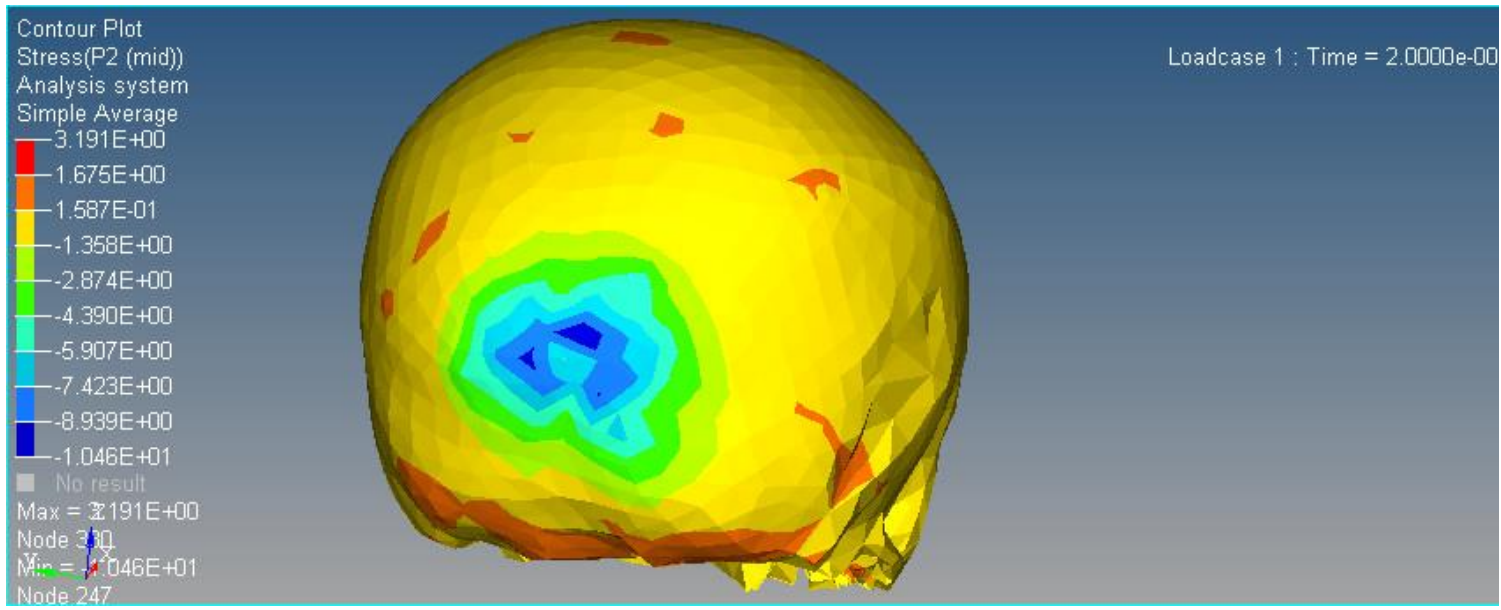

Figure 70: 35-cm Drop Mid Principle Stress Distribution (Posterior Impact) 


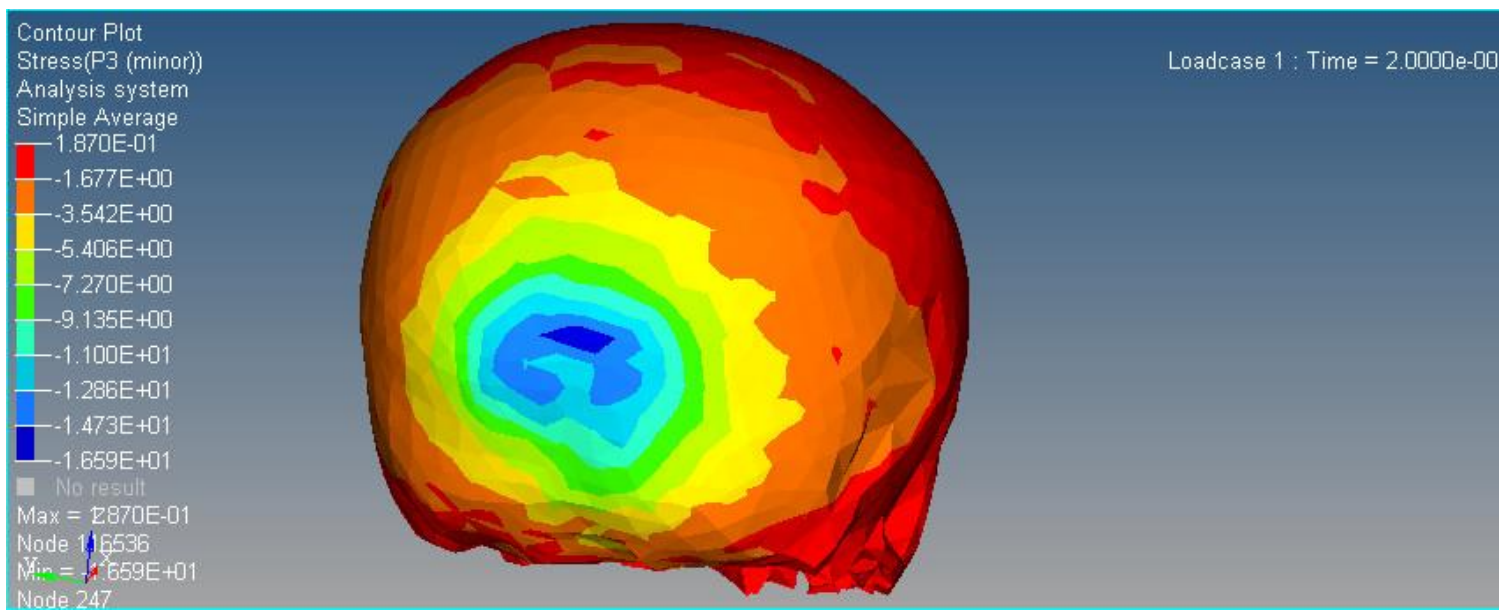

Figure 71: 35-cm Drop Minor Principle Stress Distribution (Posterior Impact)

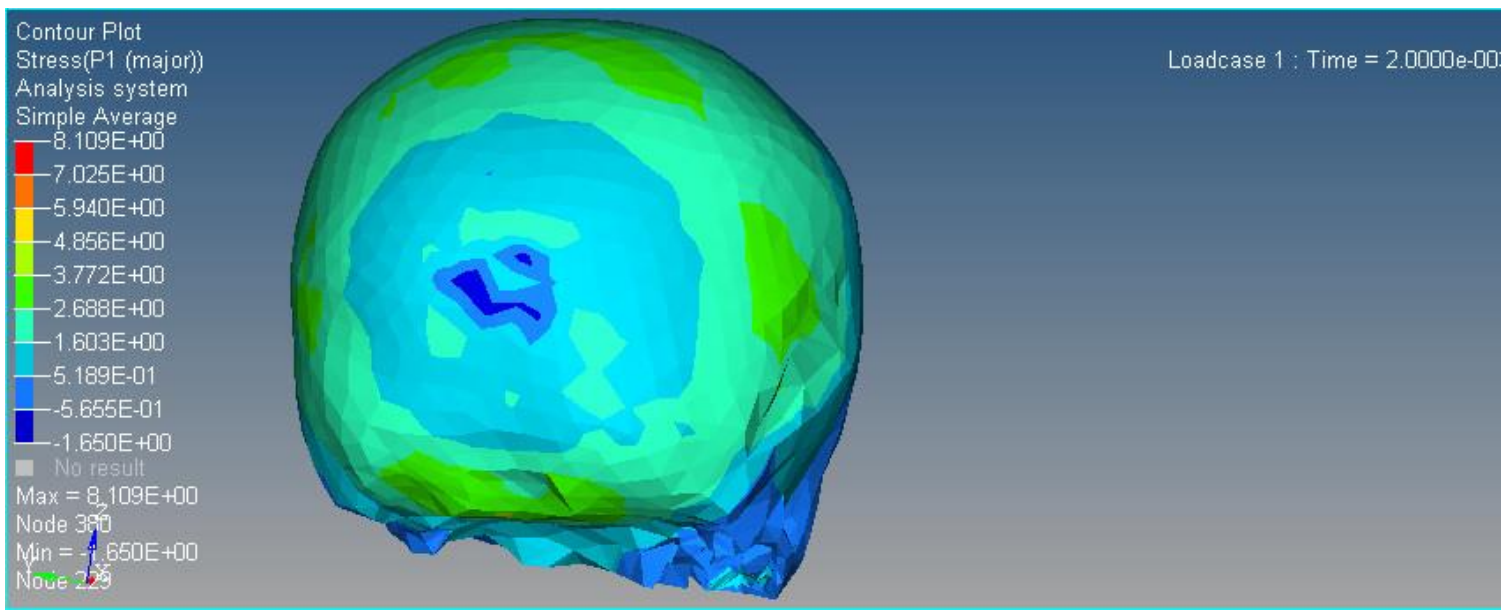

Figure 72: 25-cm Drop Major Principle Stress Distribution (Posterior Impact)

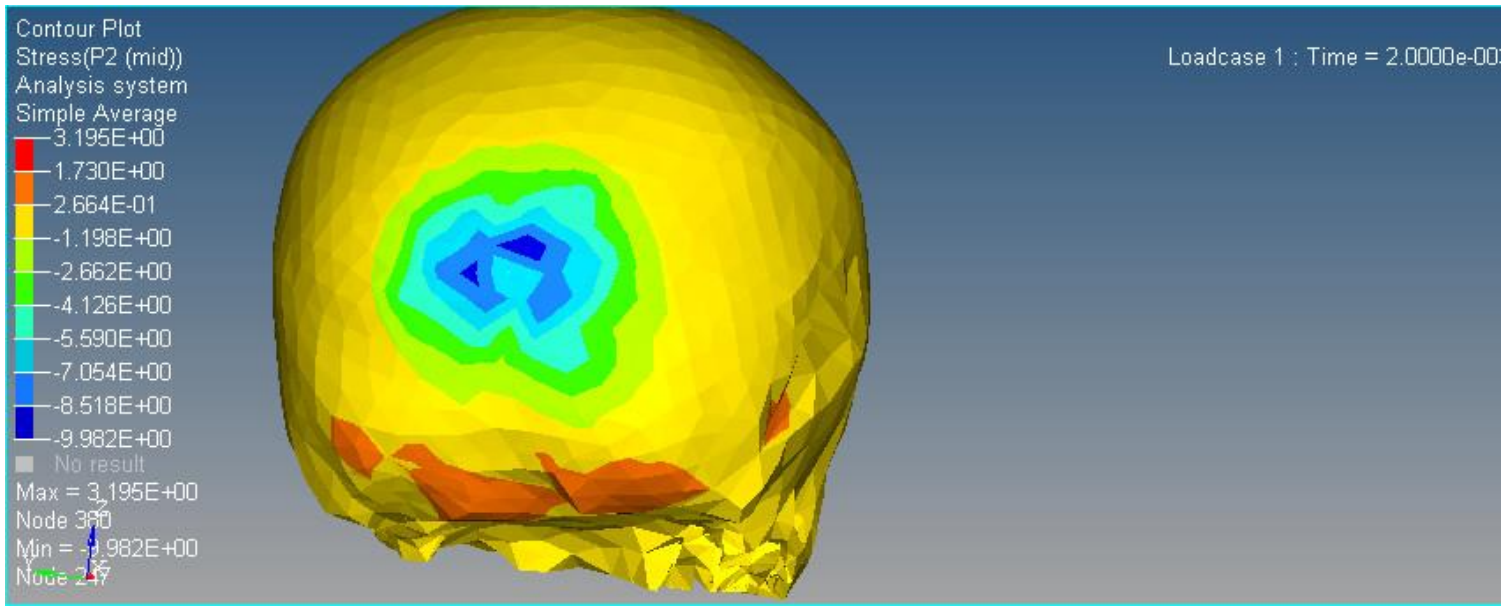

Figure 73: 25-cm Drop Mid Principle Stress Distribution (Posterior Impact) 


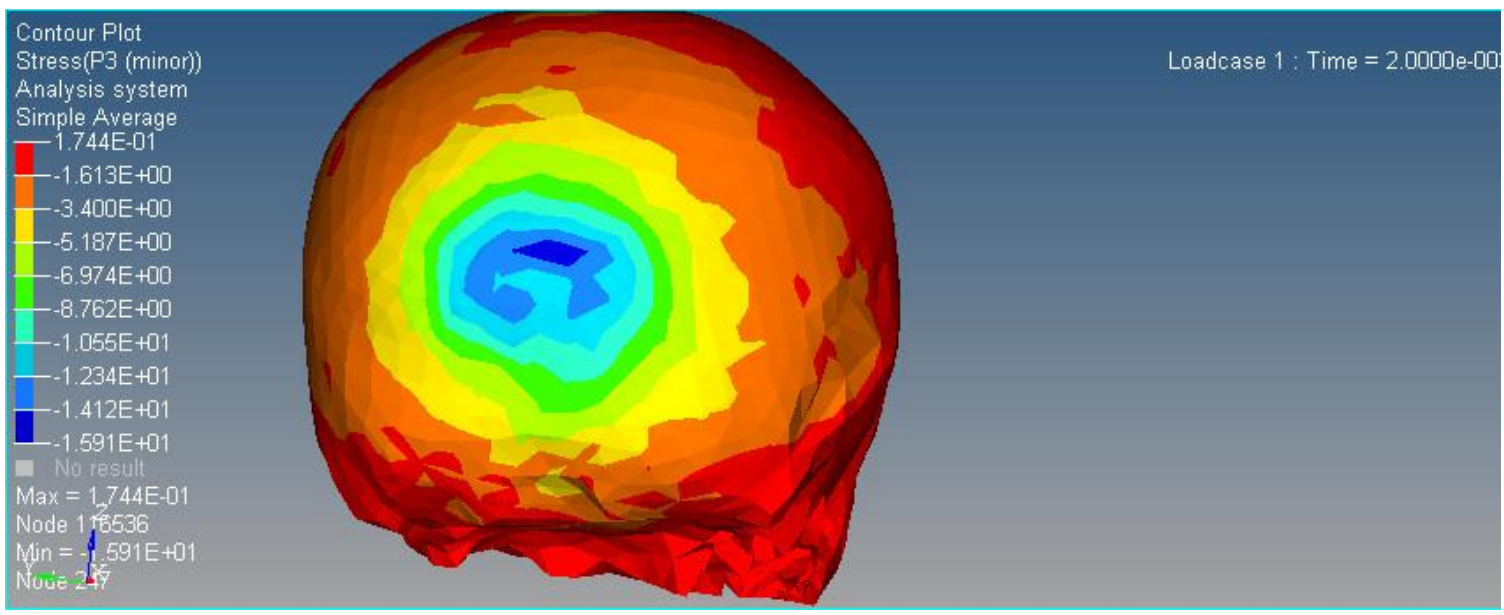

Figure 74: 25-cm Drop Minor Principle Stress Distribution (Posterior Impact)

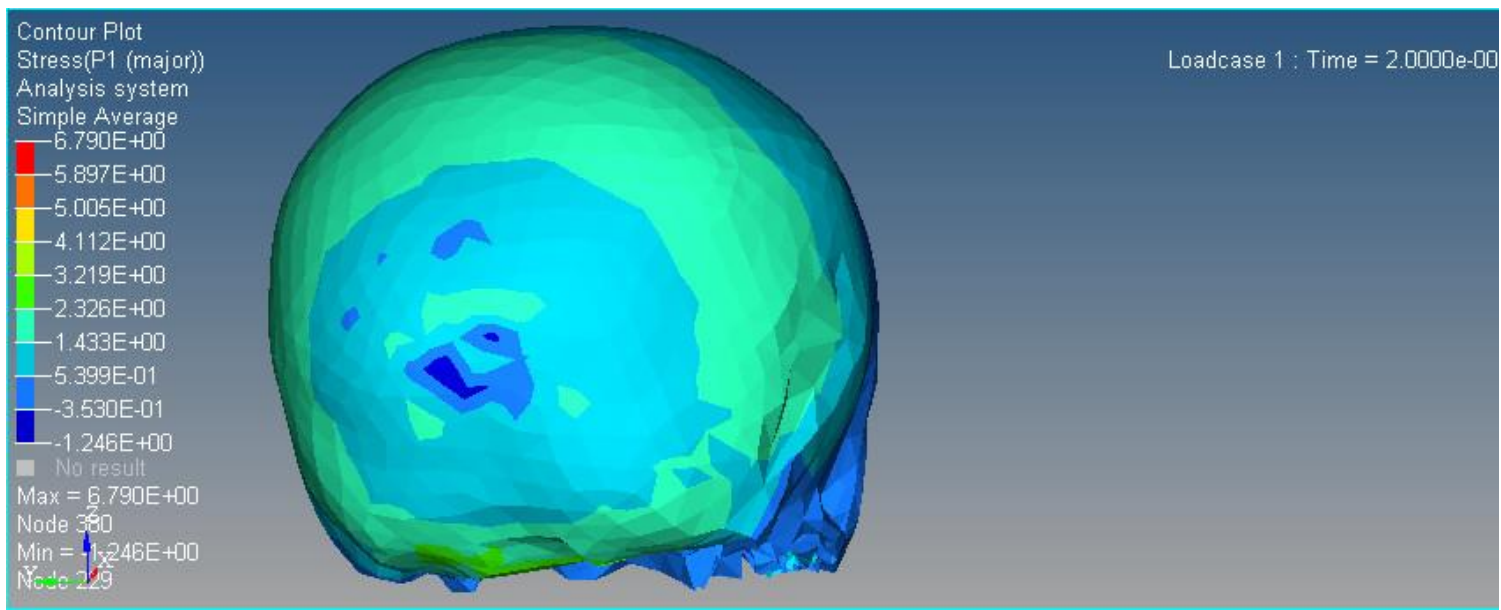

Figure 75: 15-cm Drop Major Principle Stress Distribution (Posterior Impact)

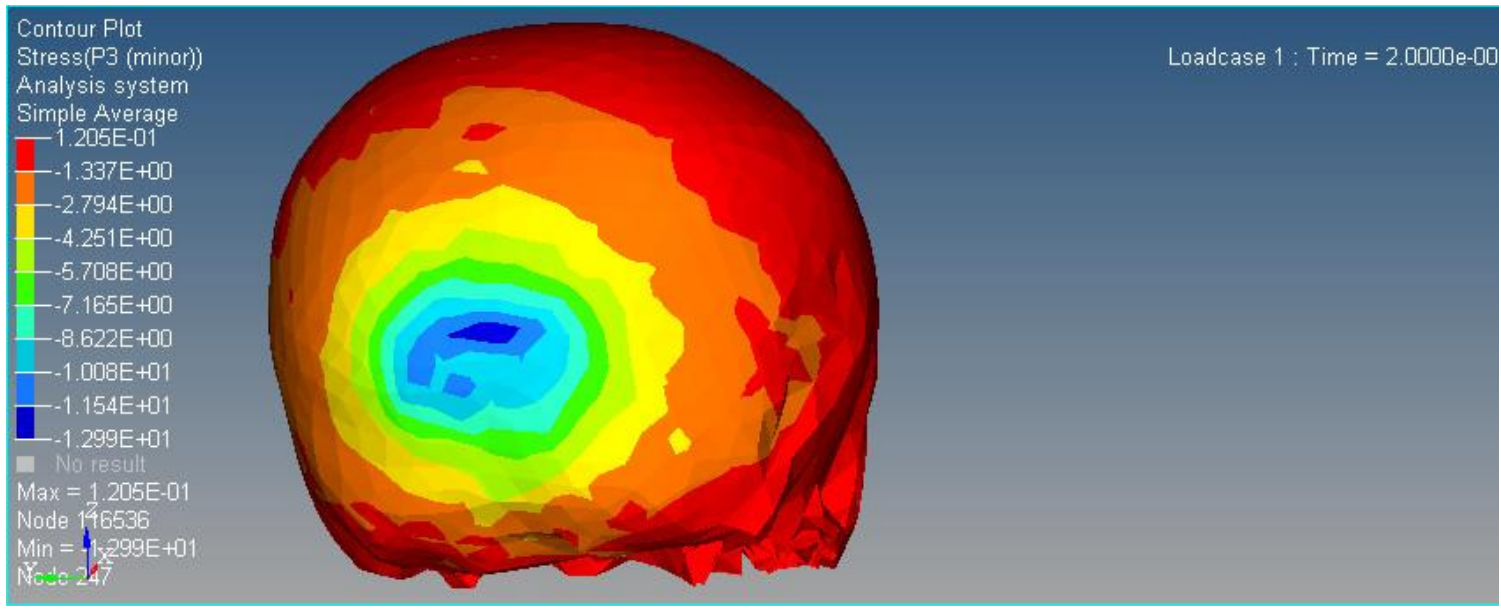

Figure 76: 15-cm Drop Mid Principle Stress Distribution (Posterior Impact) 


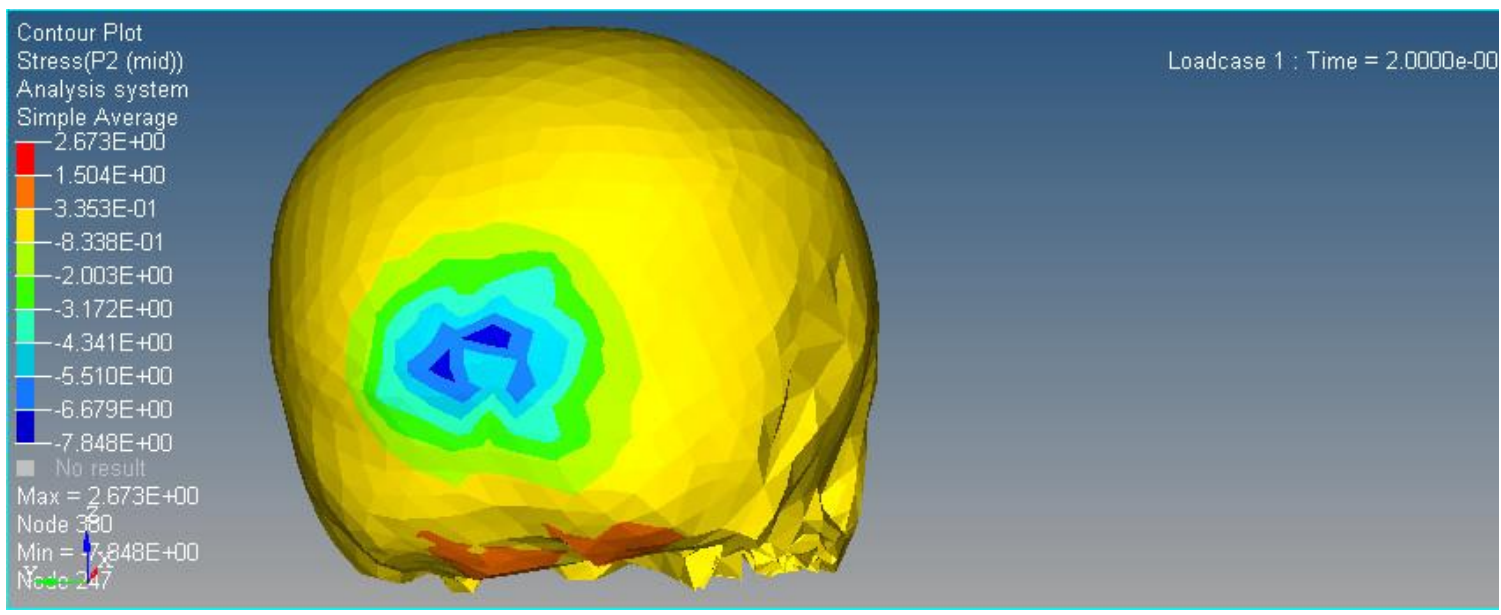

Figure 77: 15-cm Drop Minor Principle Stress Distribution (Posterior Impact) 


\subsection{Von Mises Stress and Strain Distributions}

\subsubsection{Frontal Impact}
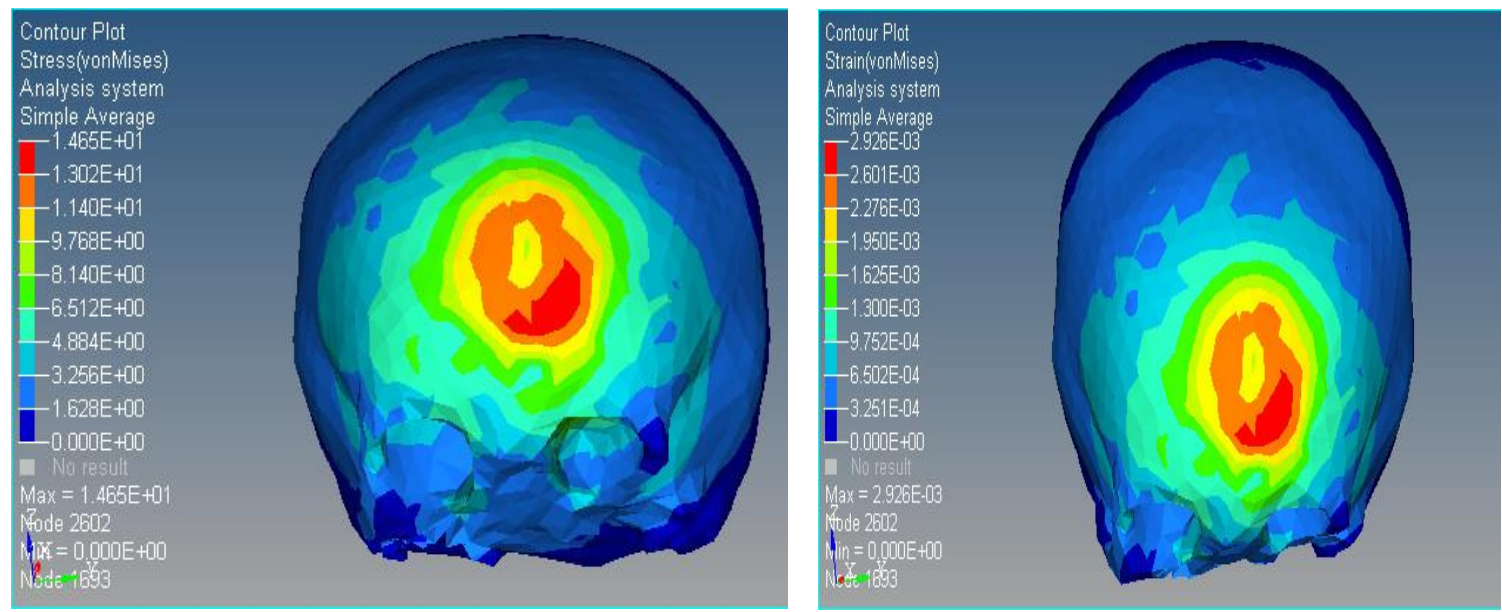

Figure 78: 45-cm Drop Frontal Impact von Mises Stress and Strain Distribution
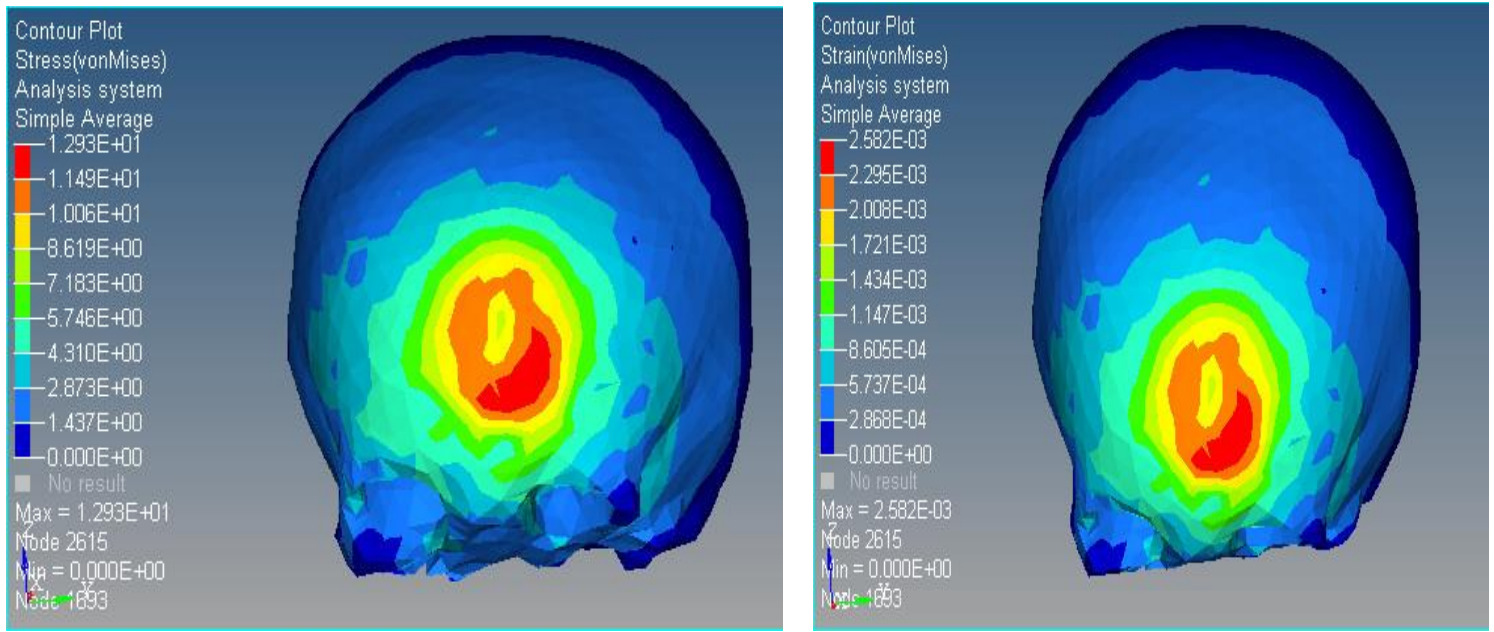

Figure 79: 35-cm Drop Frontal Impact von Mises Stress and Strain Distribution 

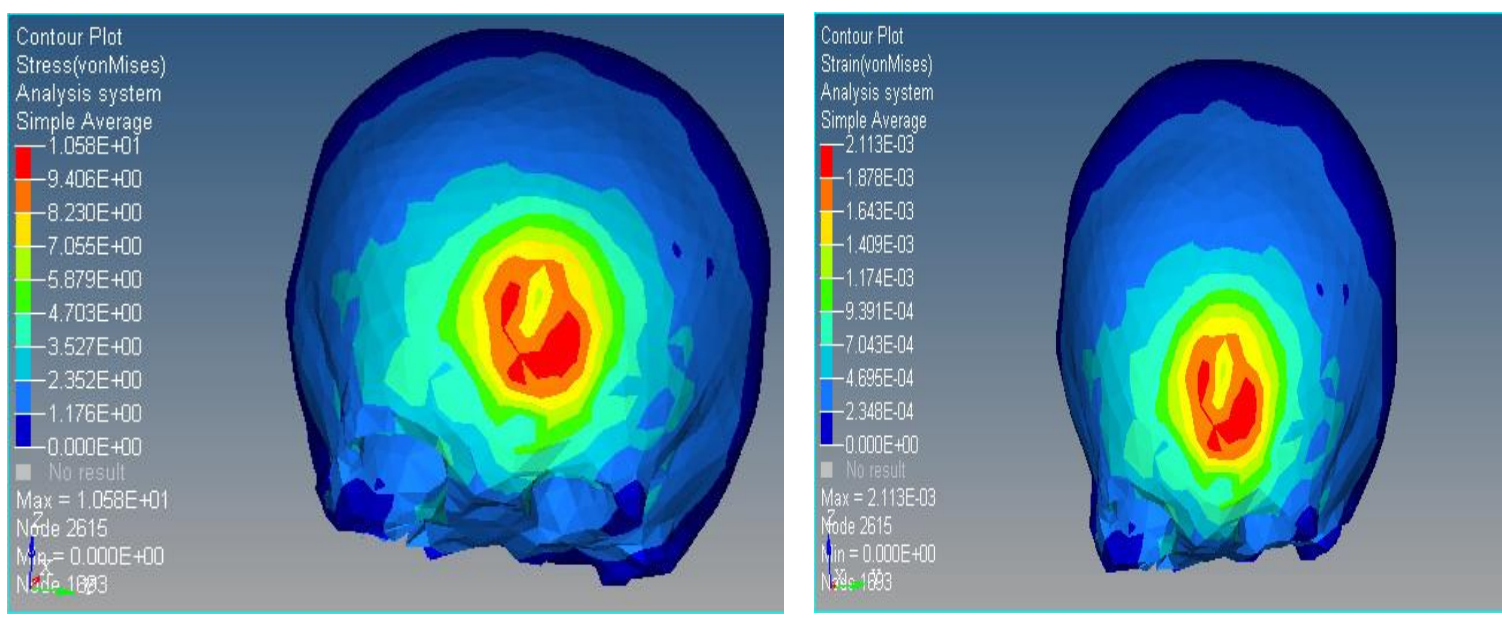

Figure 80: 25-cm Drop Frontal Impact von Mises Stress and Strain Distribution
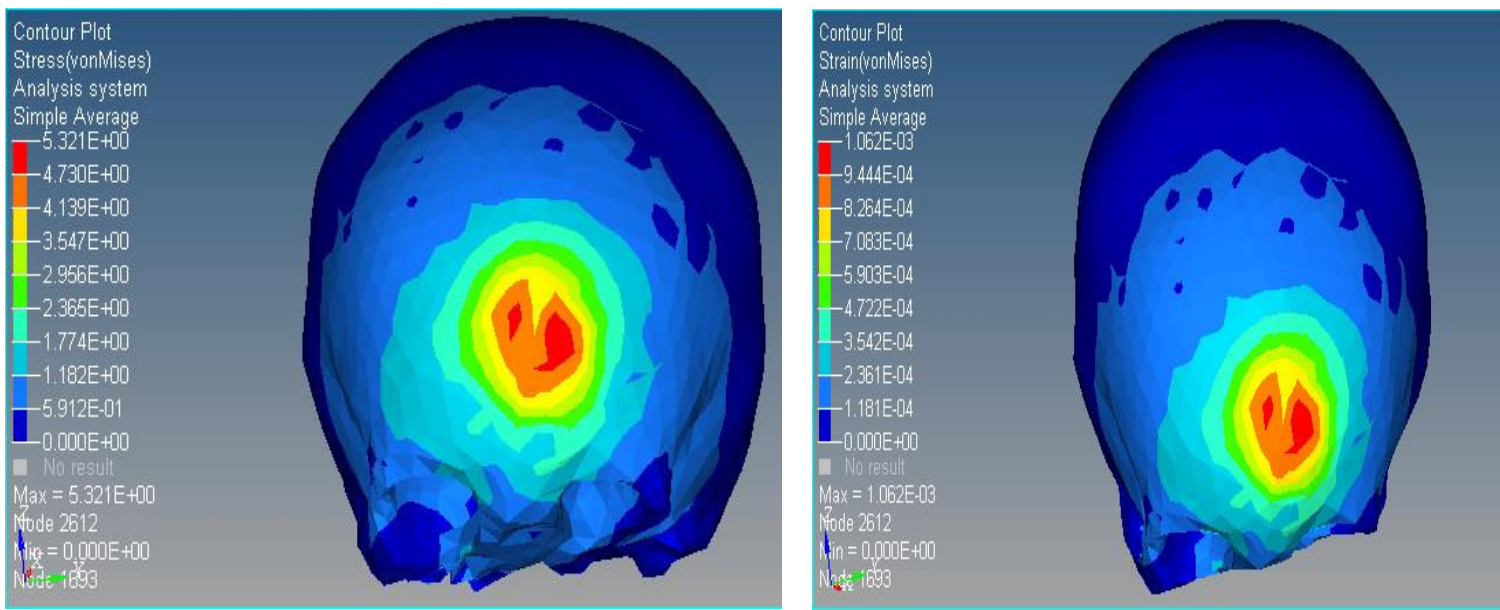

Figure 81: 15-cm Drop Frontal Impact von Mises Stress and Strain Distribution 


\subsubsection{Superior Impact}
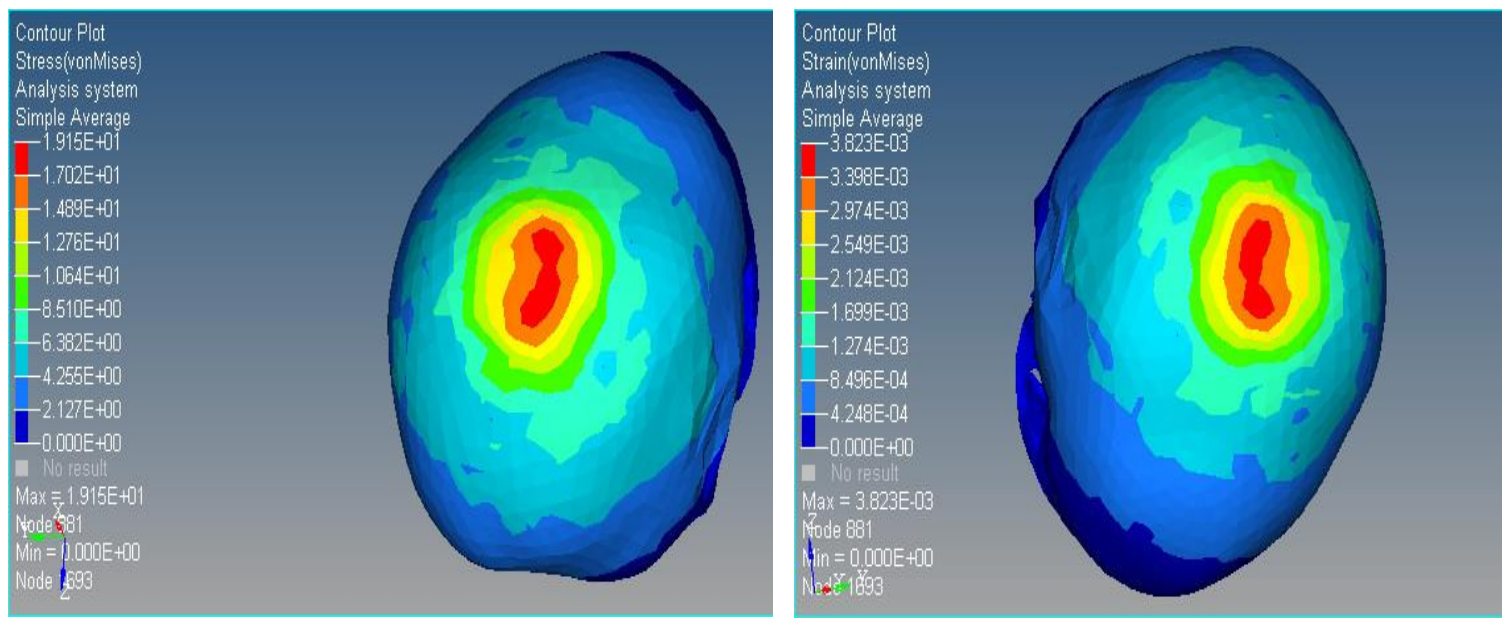

Figure 82: 55-cm Drop Superior Impact von Mises Stress and Strain Distribution
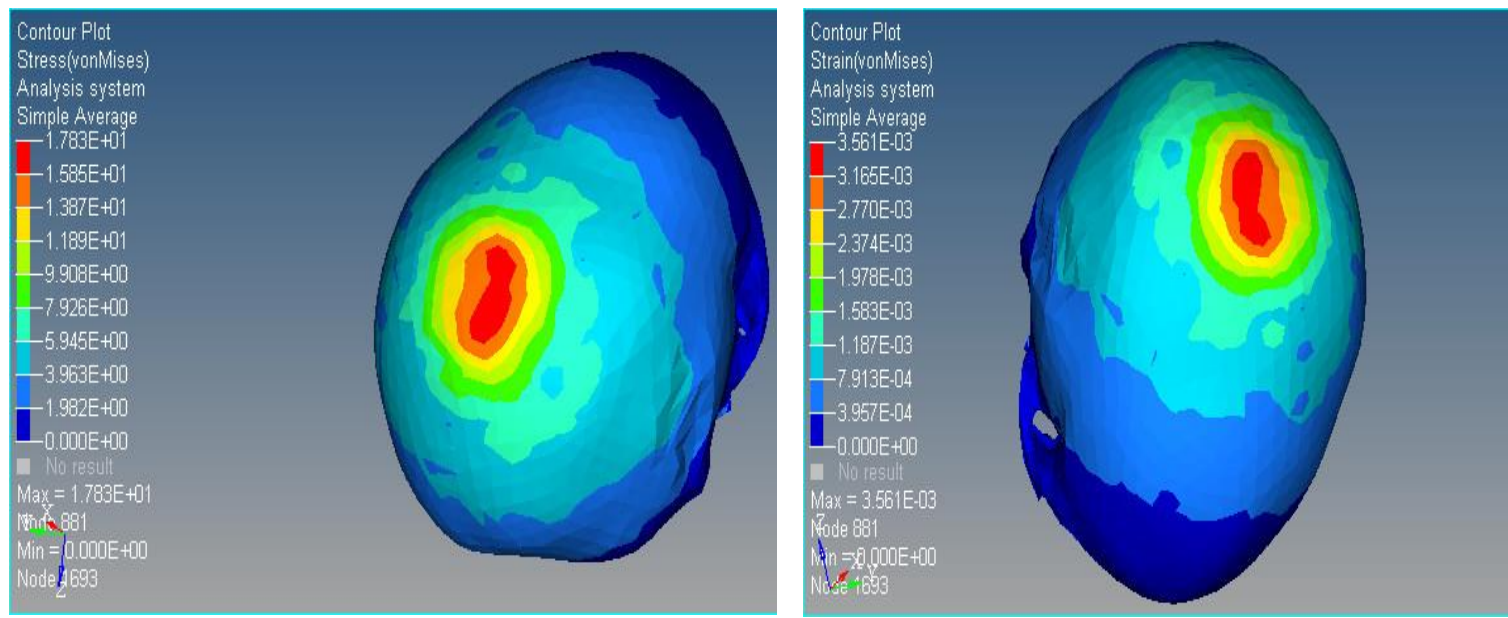

Figure 83: 45-cm Drop Superior Impact von Mises Stress and Strain Distribution
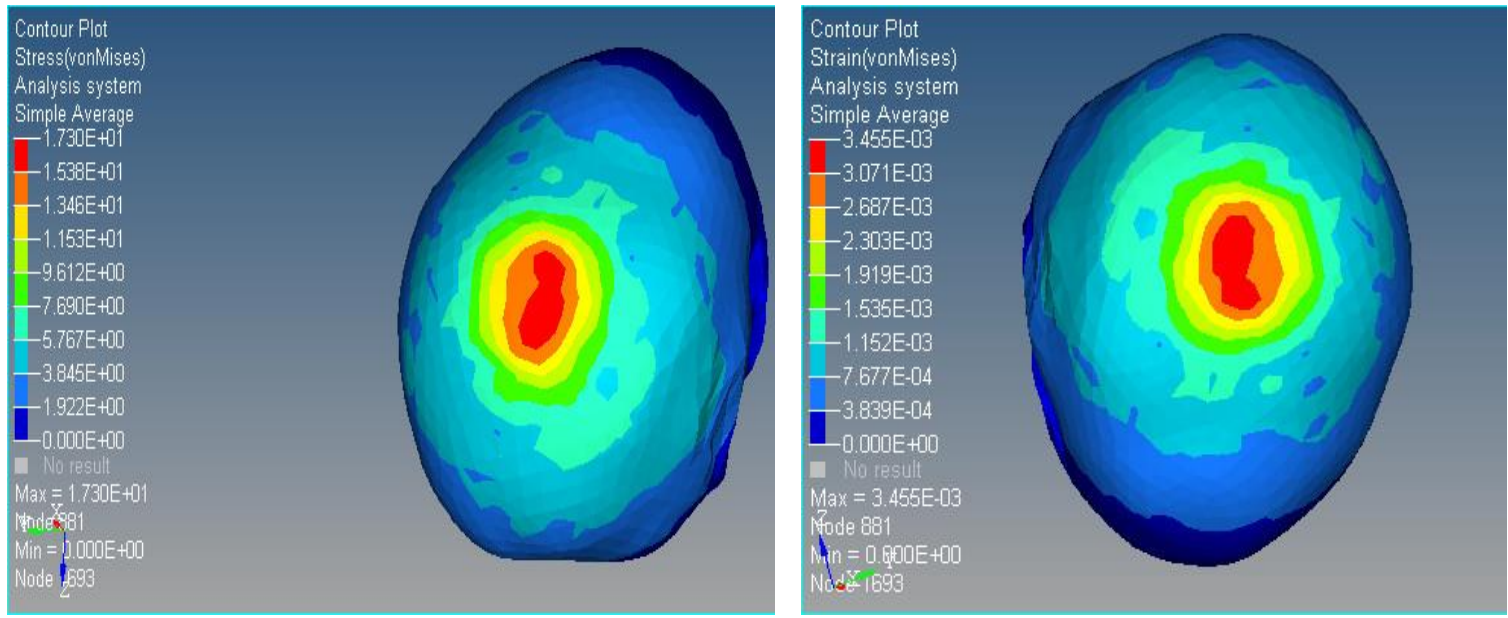

Figure 84: 35-cm Drop Superior Impact von Mises Stress and Strain Distribution 

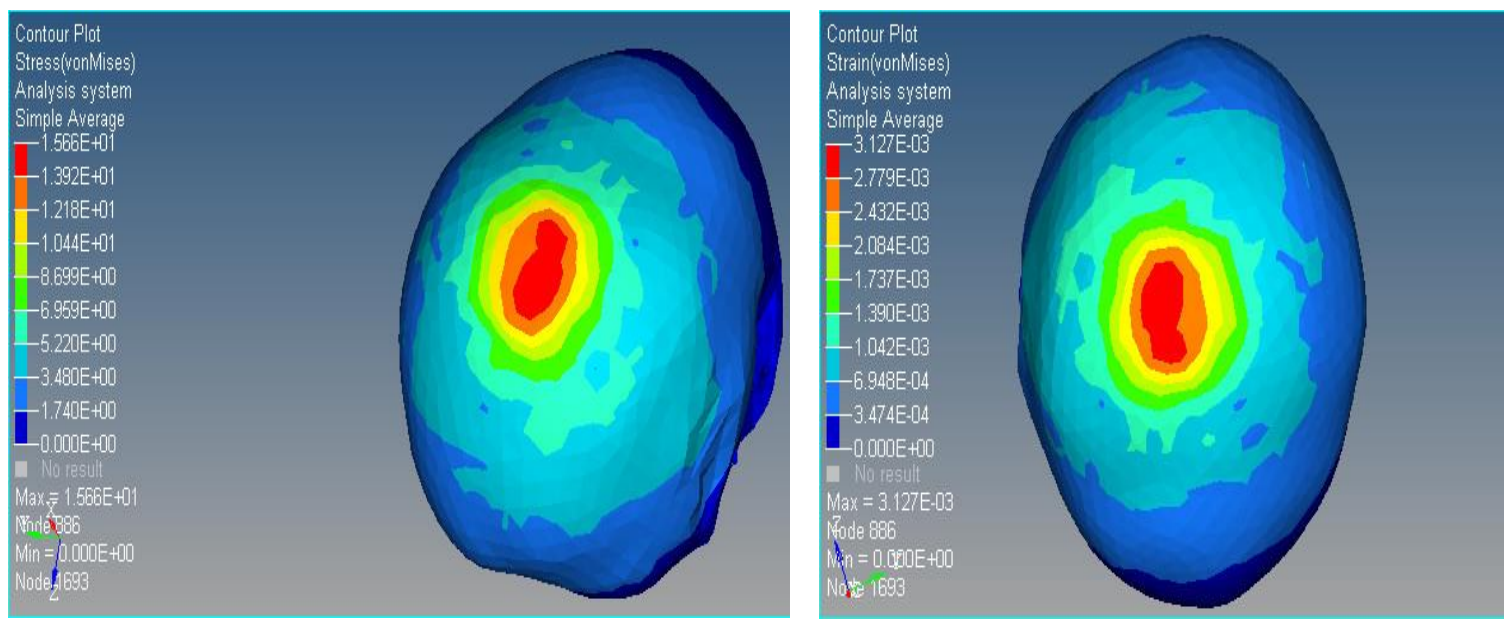

Figure 85: 25-cm Drop Superior Impact von Mises Stress and Strain Distribution
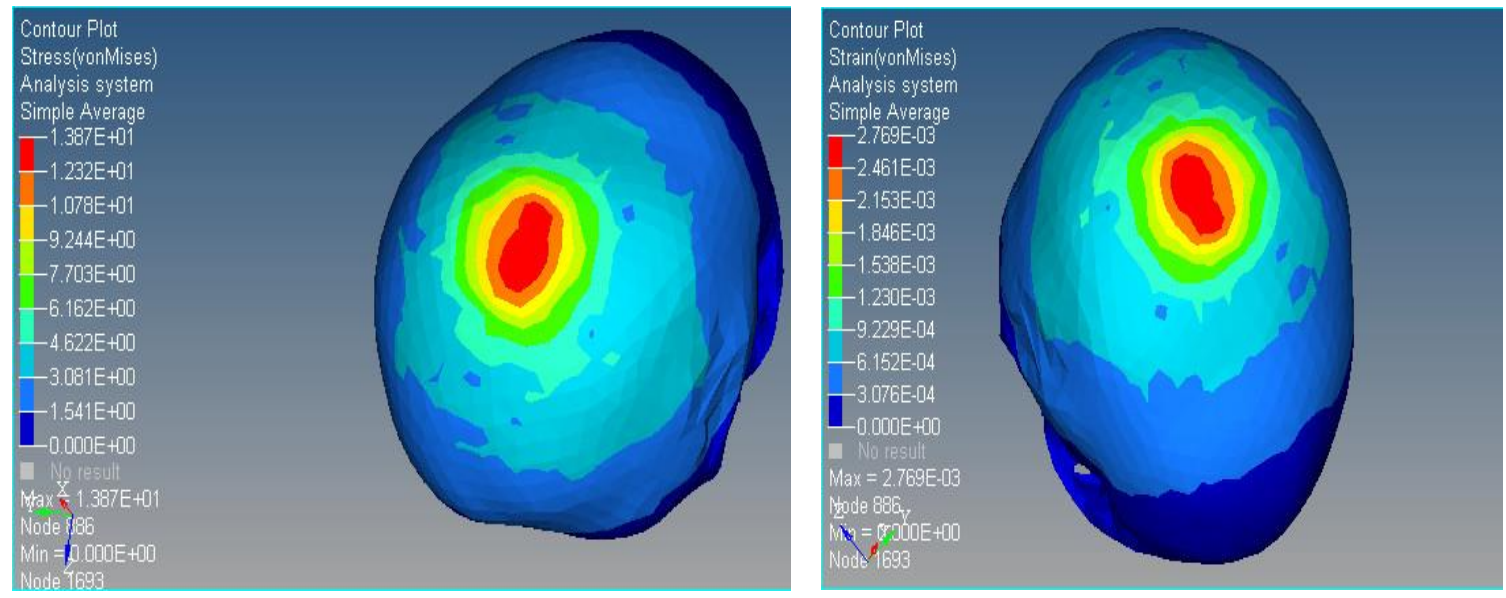

Figure 86: 15-cm Drop Superior Impact von Mises Stress and Strain Distribution

\subsubsection{Lateral Impact}
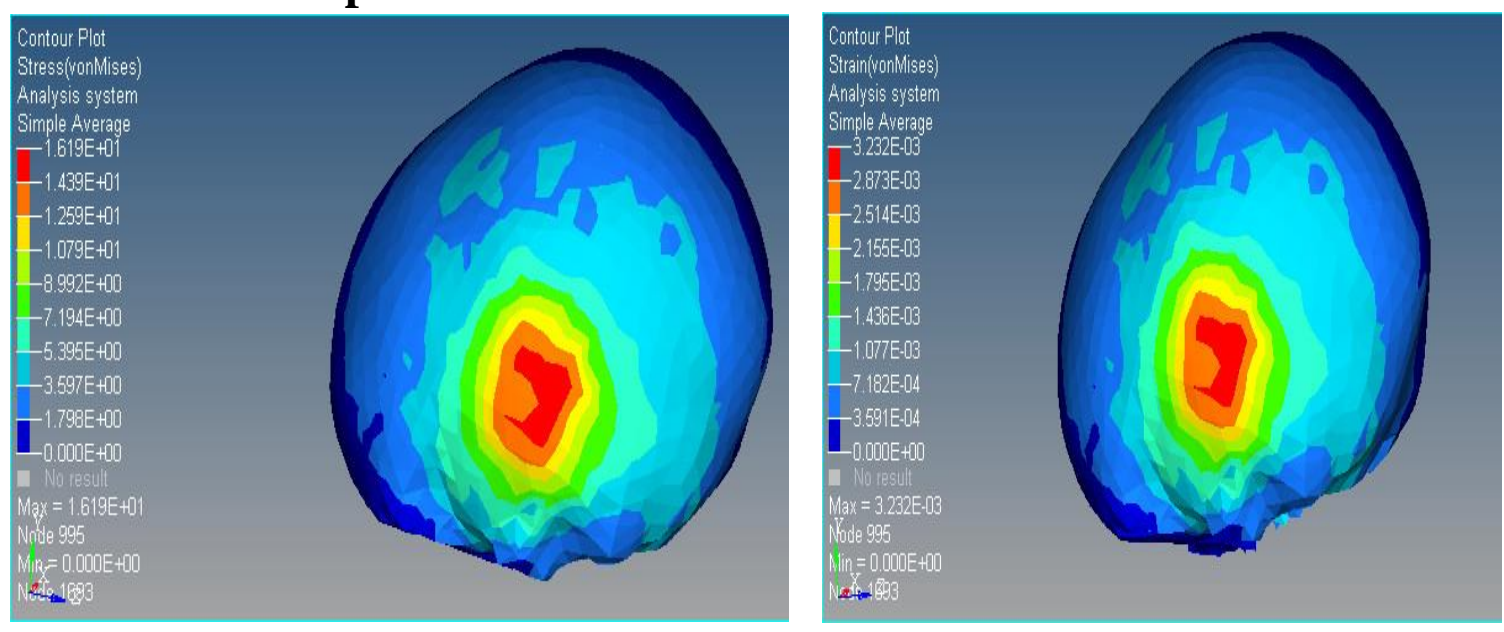

Figure 87: 55-cm Drop Lateral Impact von Mises Stress and Strain Distribution 

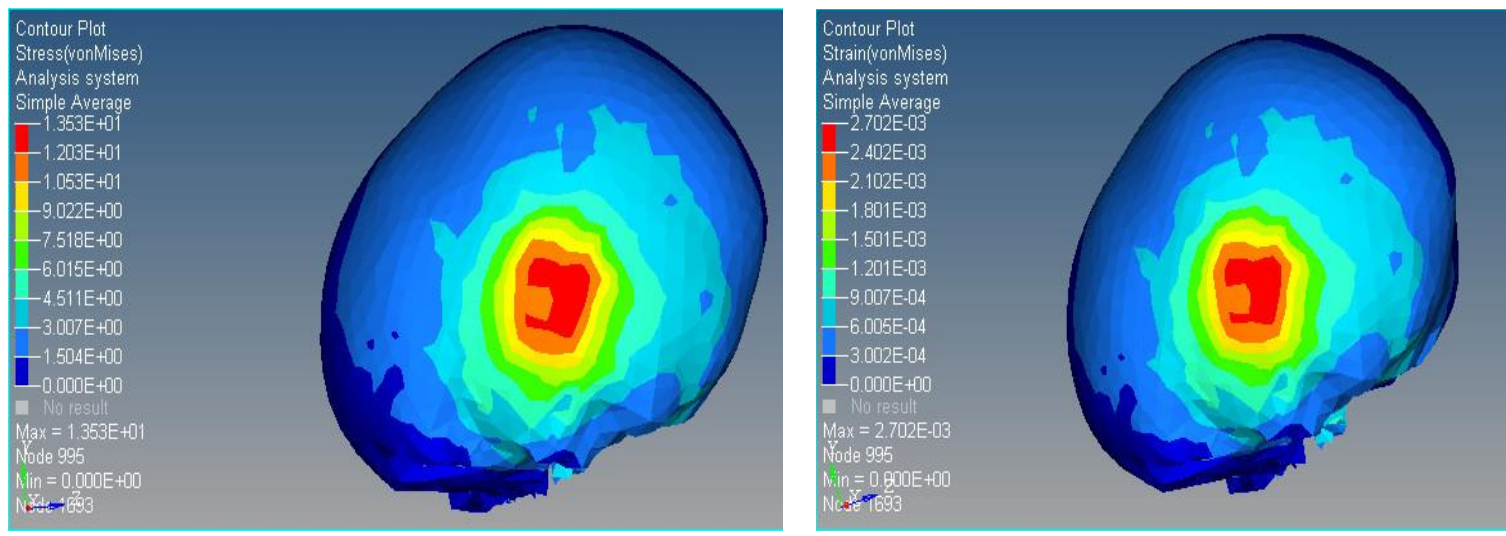

Figure 88: 45-cm Drop Lateral Impact von Mises Stress and Strain Distribution
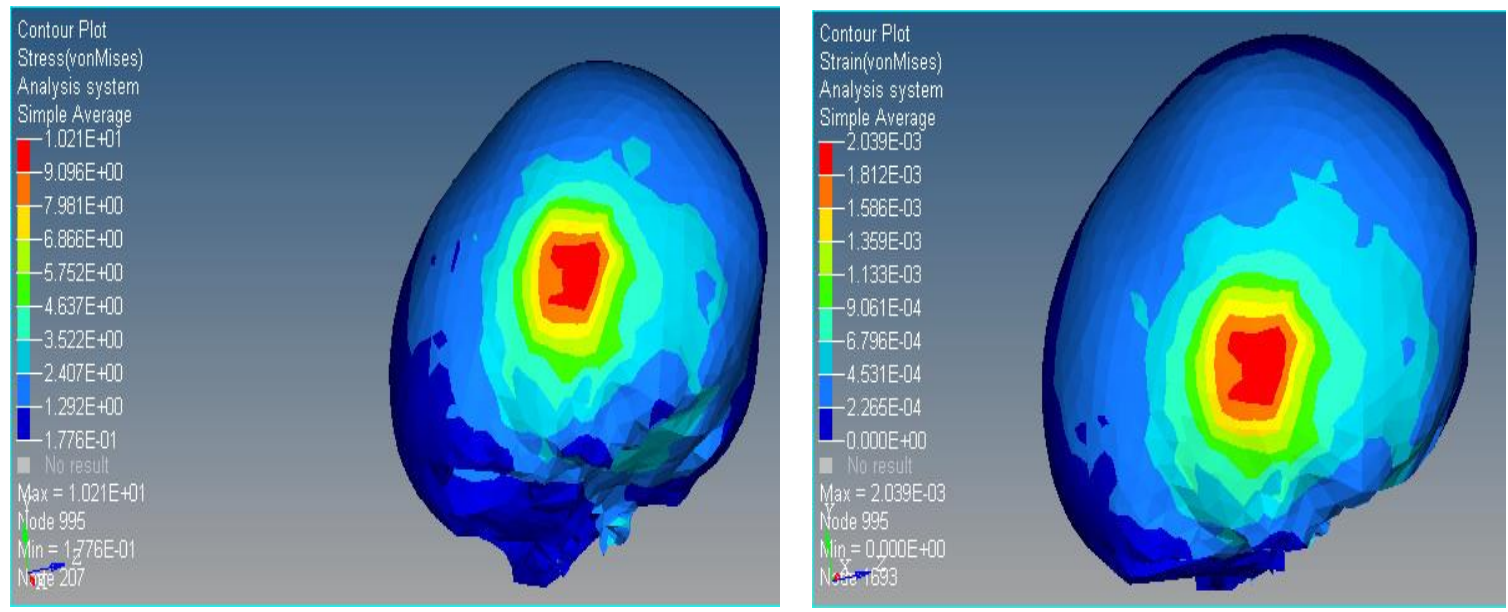

Figure 89: 35-cm Drop Lateral Impact von Mises Stress and Strain Distribution
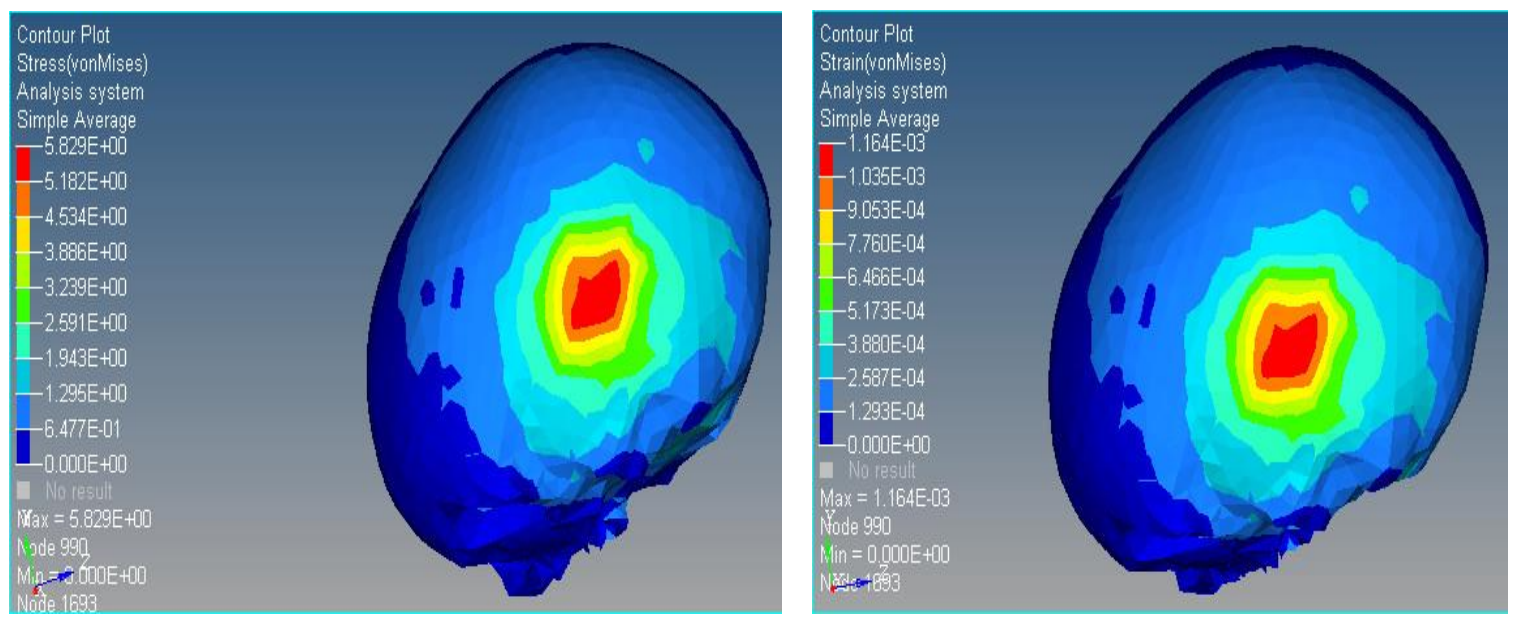

Figure 90: 25-cm Drop Lateral Impact von Mises Stress and Strain Distribution 

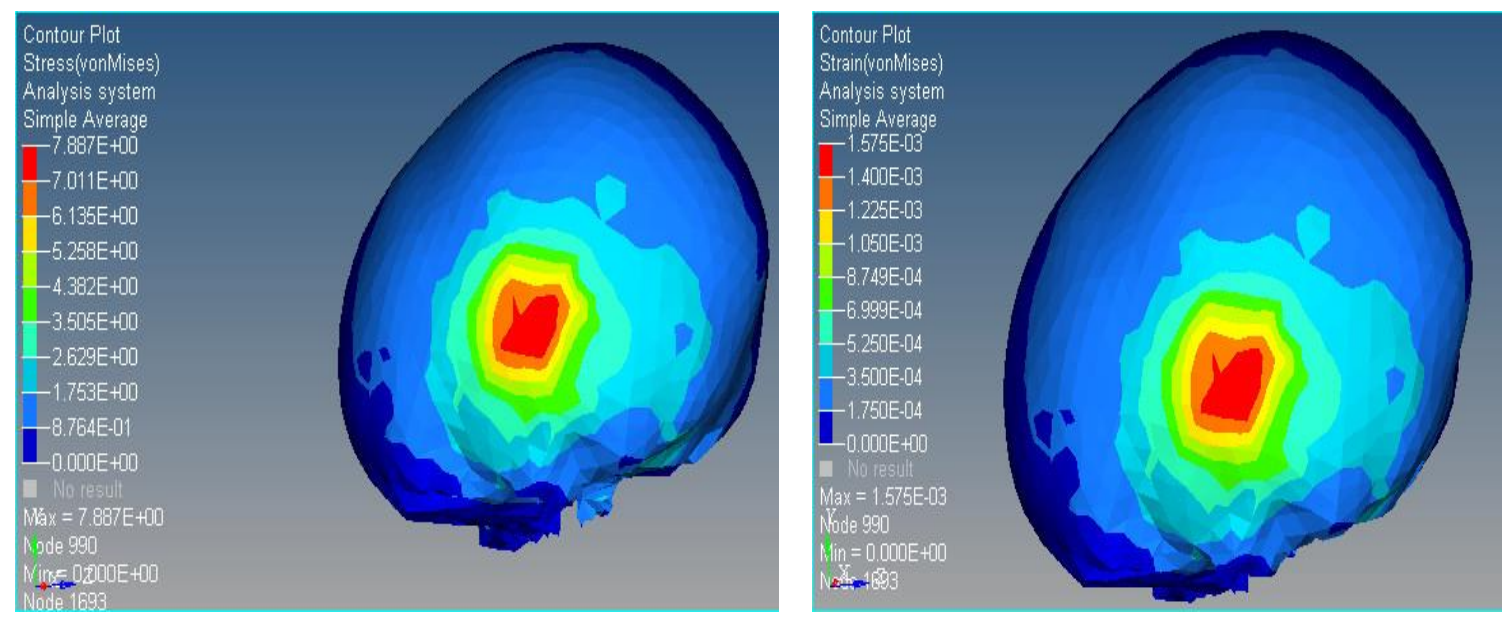

Figure 91: 15-cm Drop Lateral Impact von Mises Stress and Strain Distribution

\subsubsection{Posterior Impact}
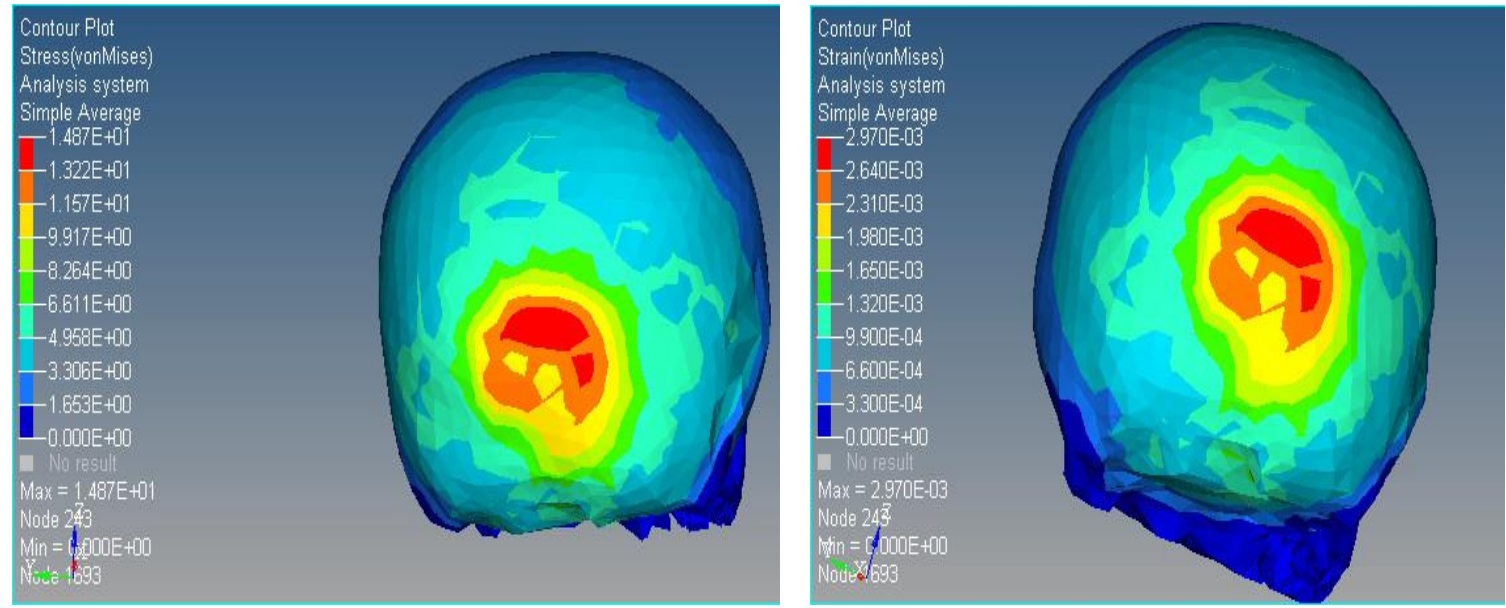

Figure 92: 55-cm Drop Posterior Impact von Mises Stress and Strain Distribution
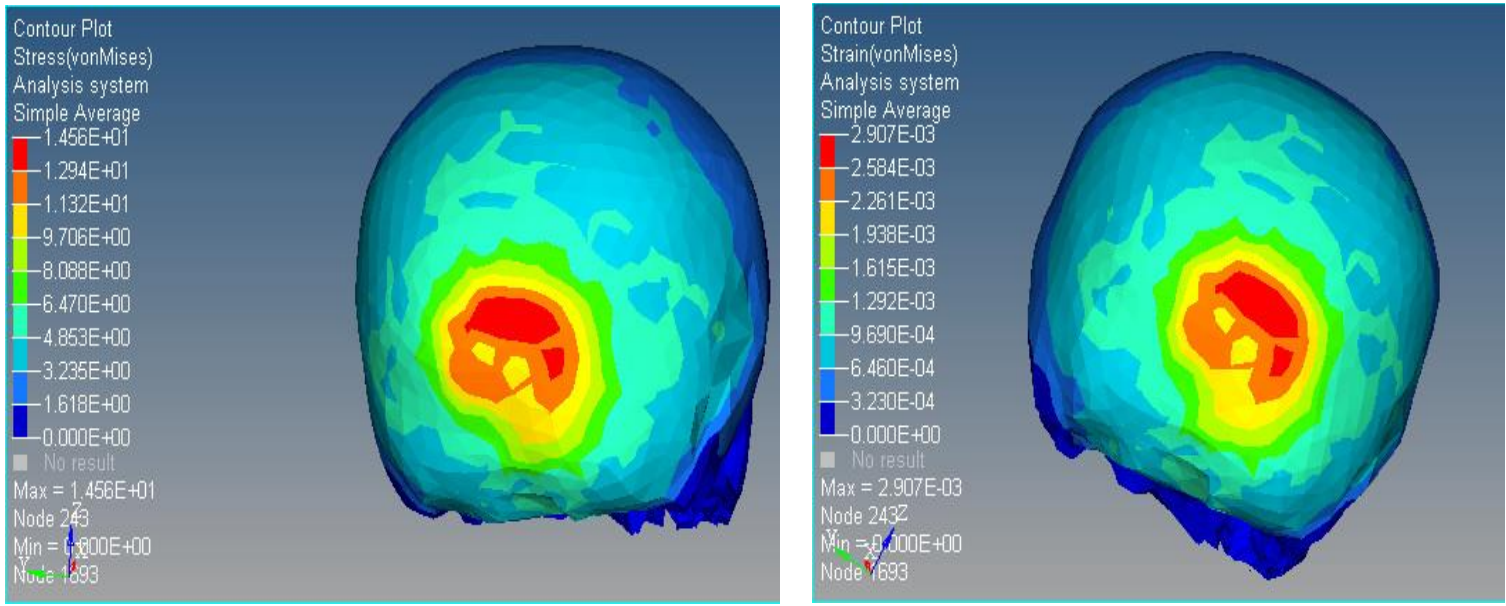

Figure 93: 45-cm Drop Posterior Impact von Mises Stress and Strain Distribution 

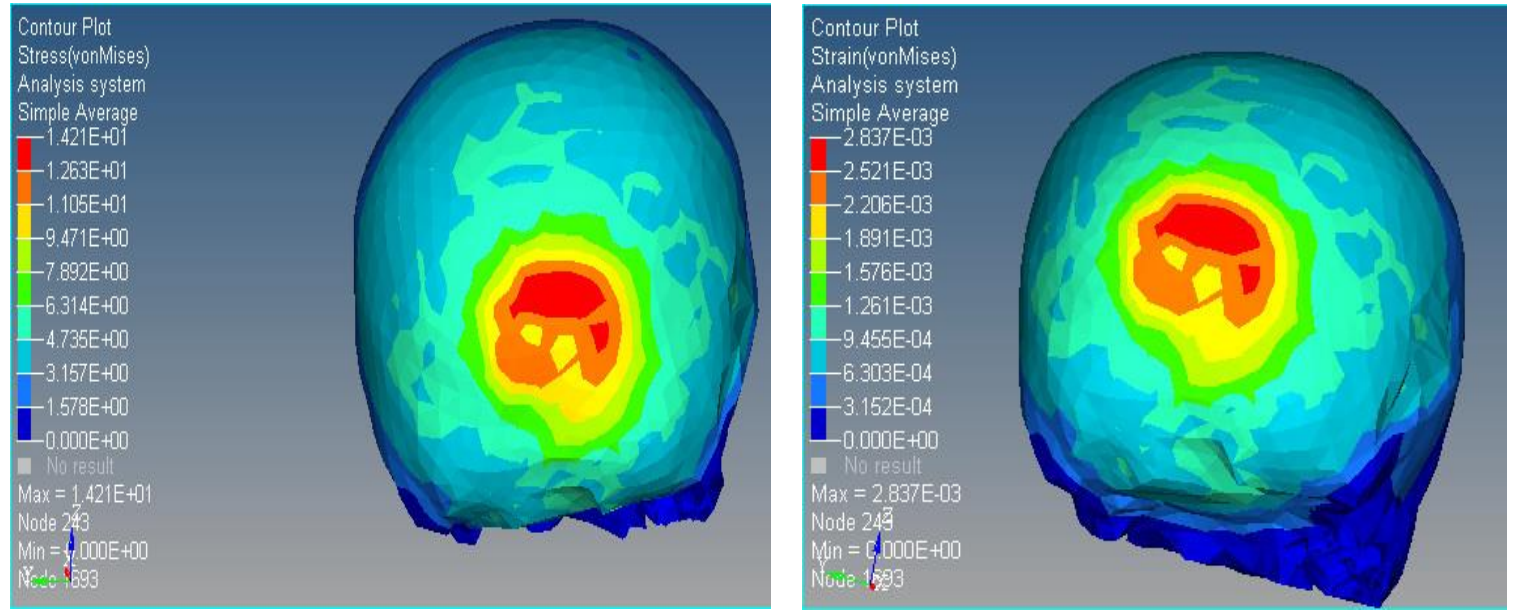

Figure 94: 35-cm Drop Posterior Impact von Mises Stress and Strain Distribution
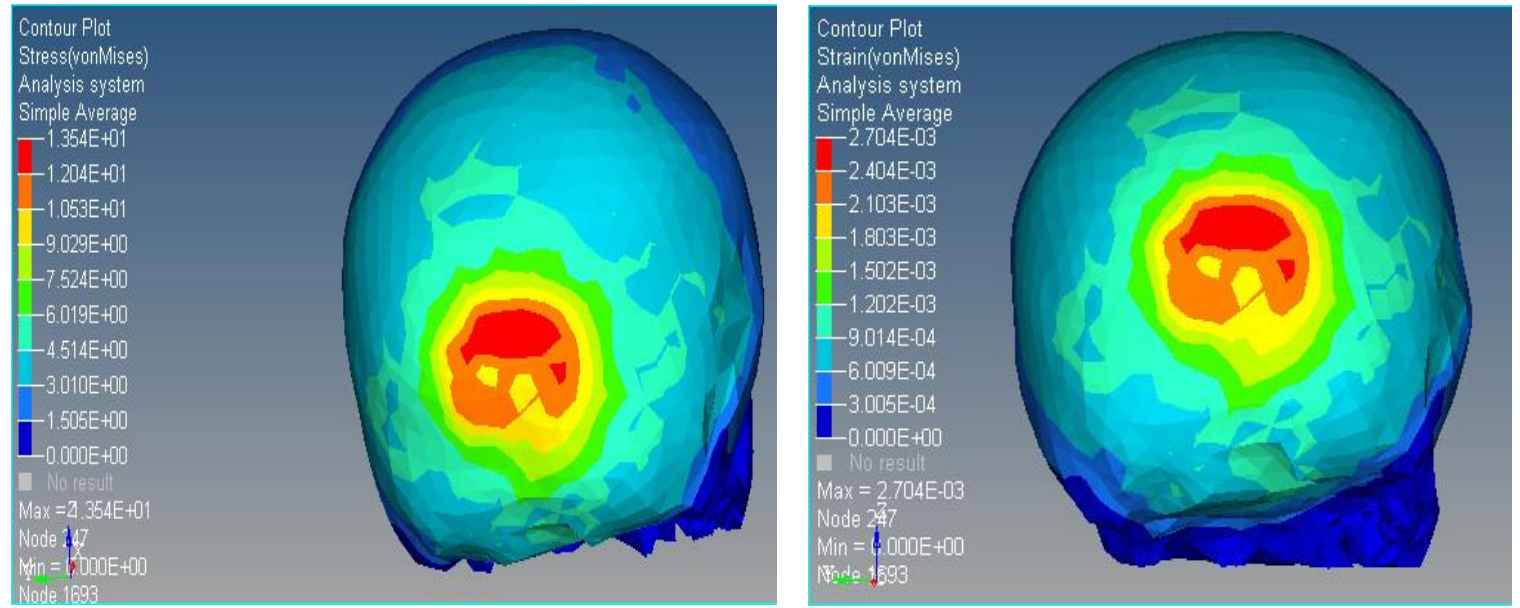

Figure 95: 25-cm Drop Posterior Impact von Mises Stress and Strain Distribution
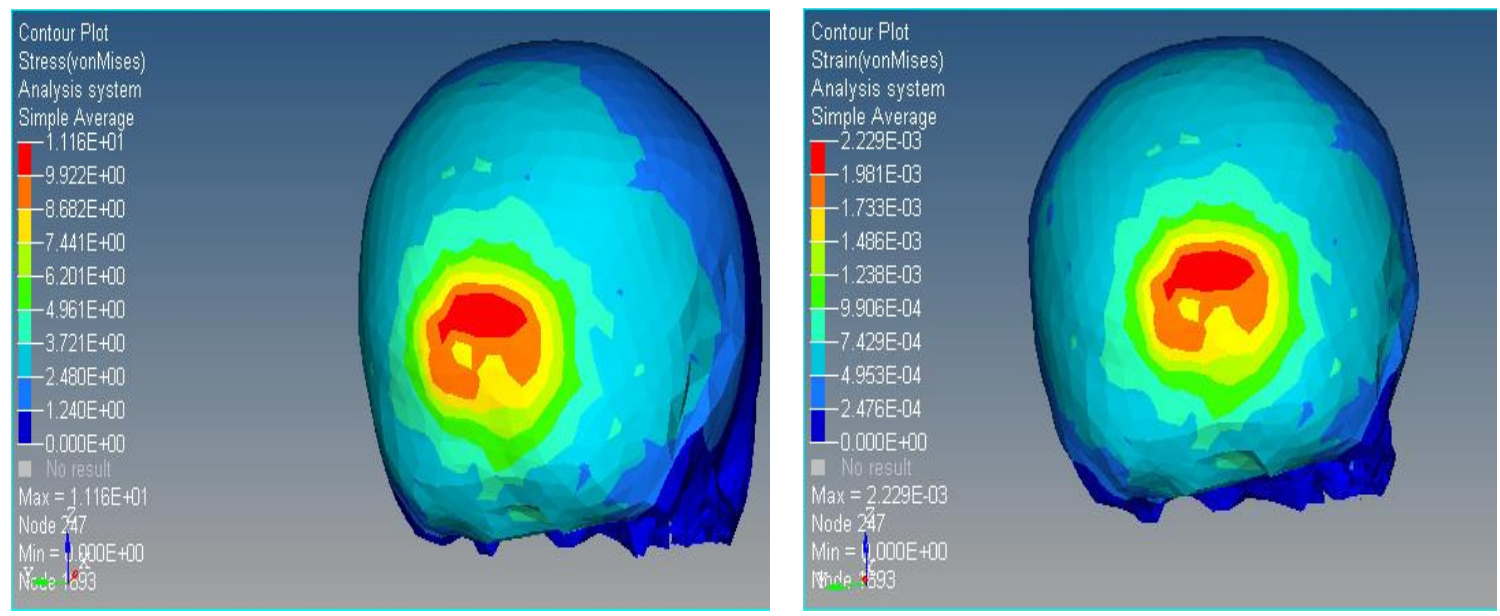

Figure 96: 15-cm Drop Posterior Impact von Mises Stress and Strain Distribution 


\subsection{Tensile and Compressive Stress Distributions}

\subsubsection{Frontal Impact}
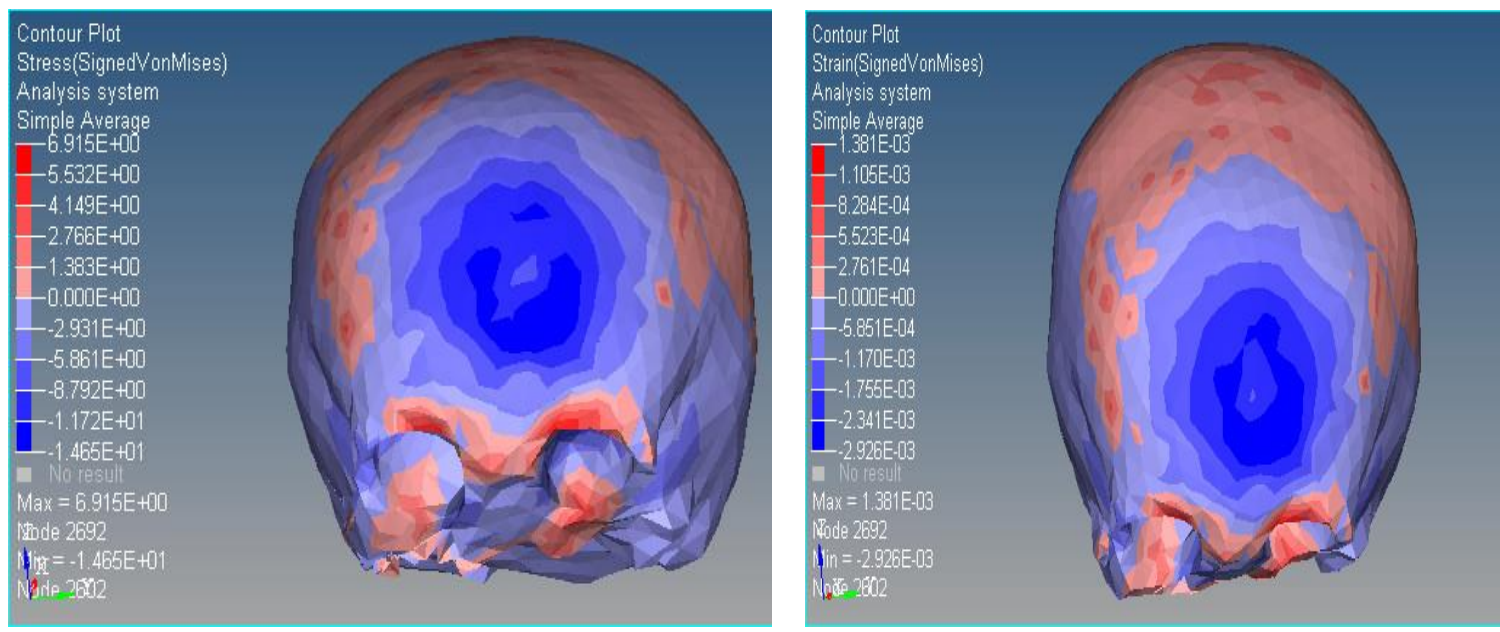

Figure 97: 45-cm Frontal Drop Tensile and Compressive Stresses
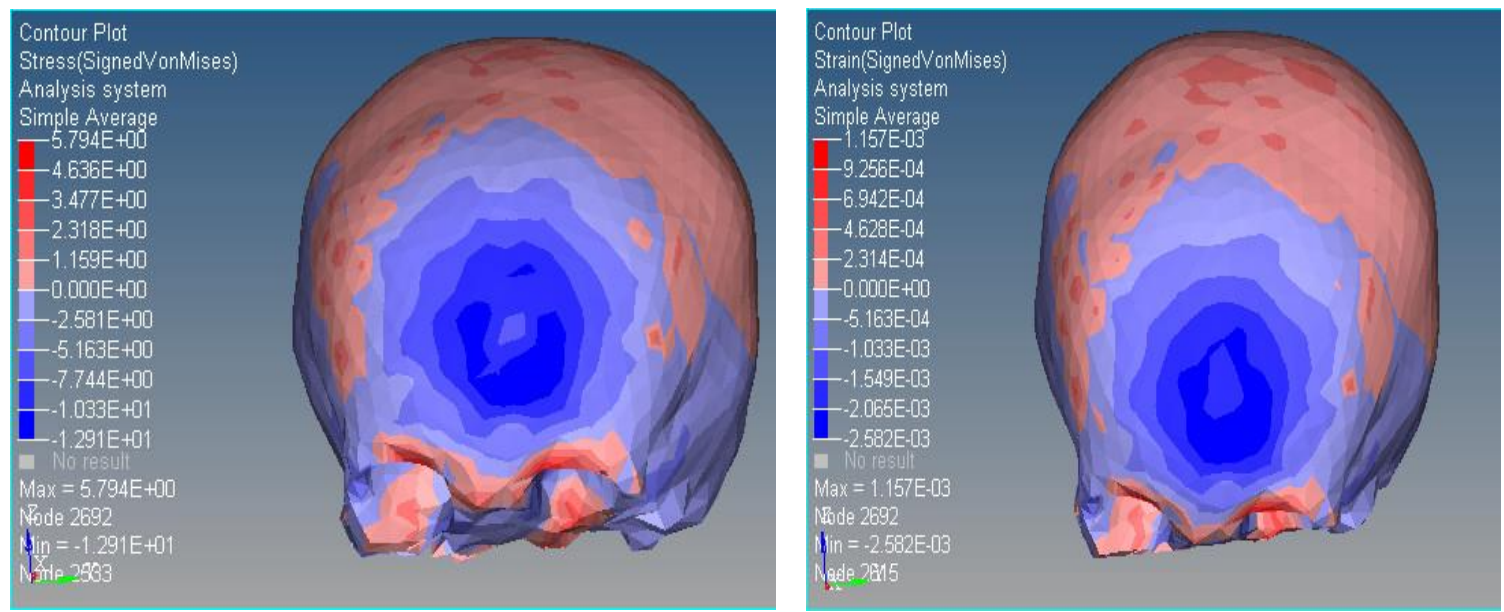

Figure 98: 35-cm Frontal Drop Tensile and Compressive Stresses 

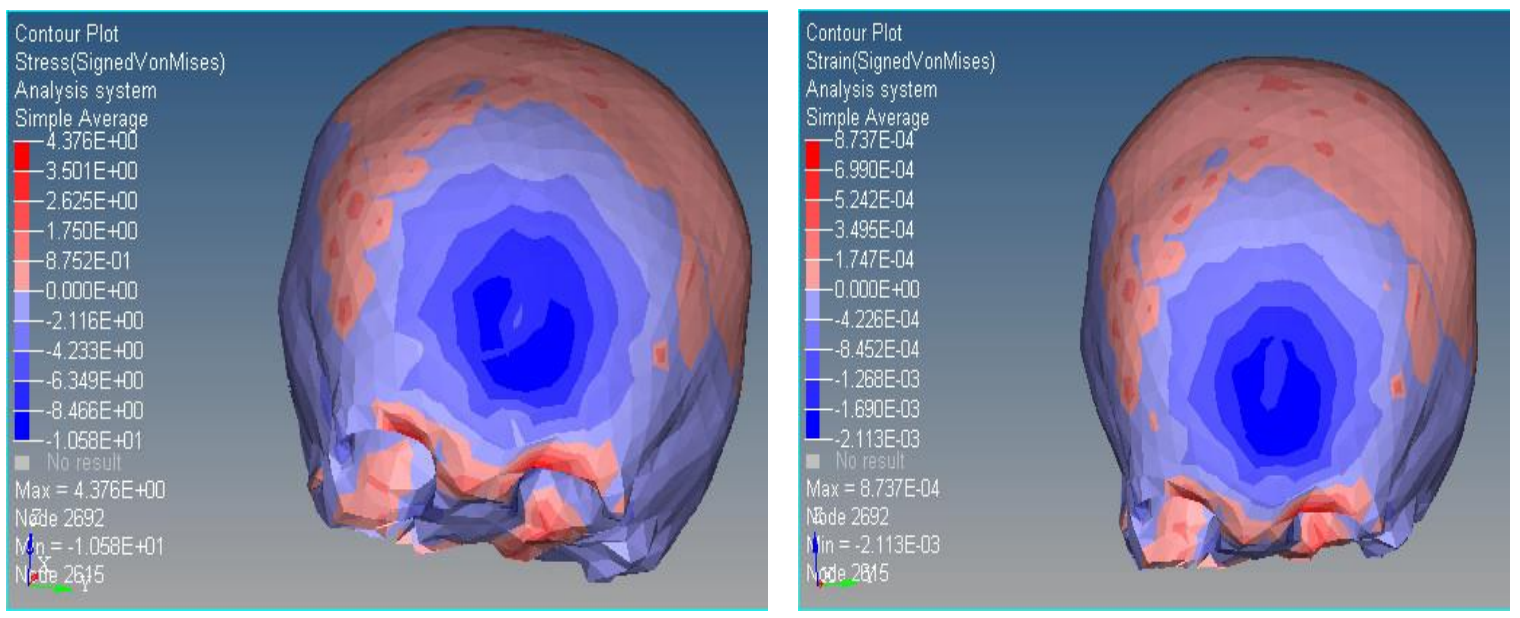

Figure 99: 25-cm Frontal Drop Tensile and Compressive Stresses
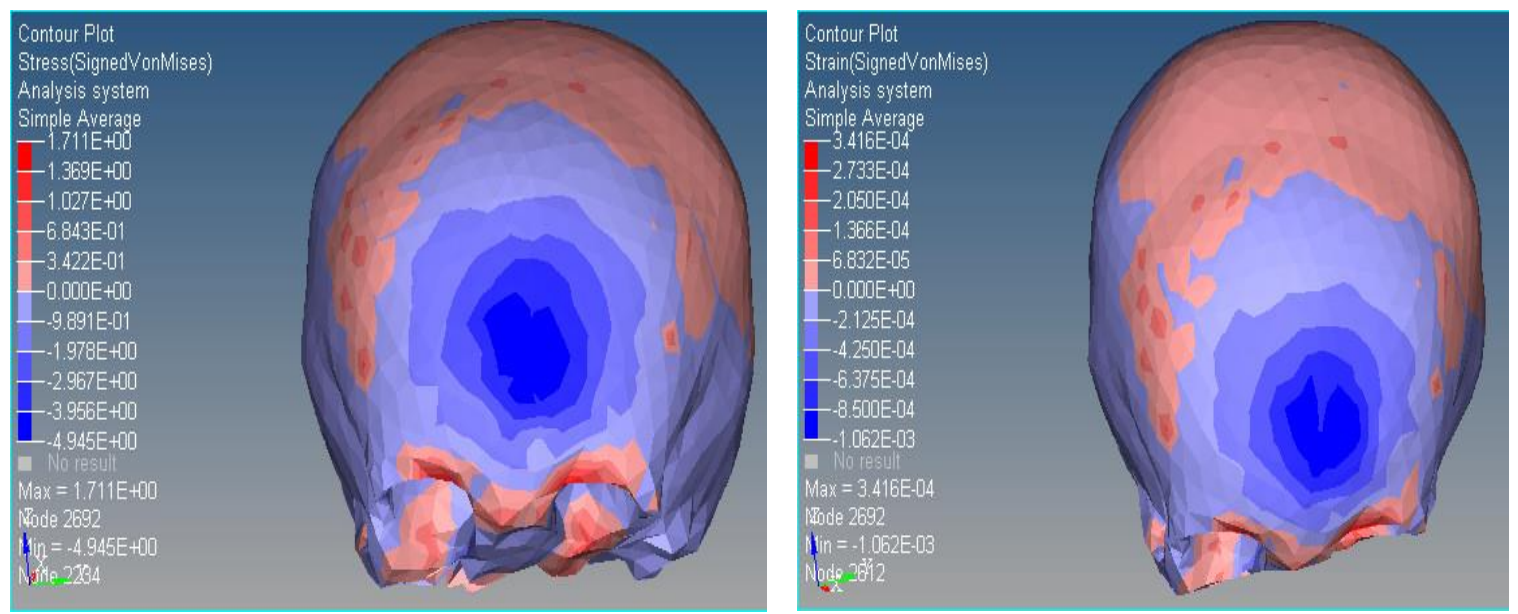

Figure 100: 15-cm Frontal Drop Tensile and Compressive Stresses 


\subsubsection{Superior Impact}
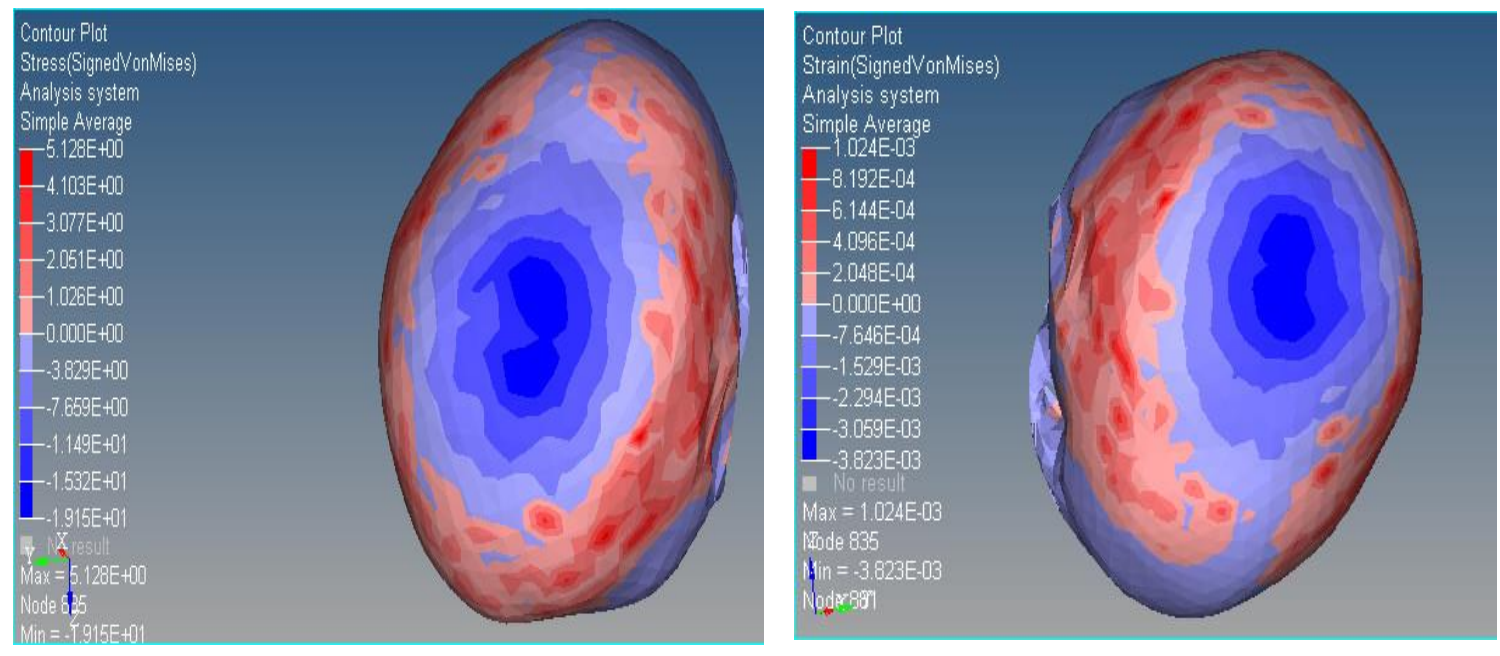

Figure 101: 55-cm Superior Drop Tensile and Compressive Stresses
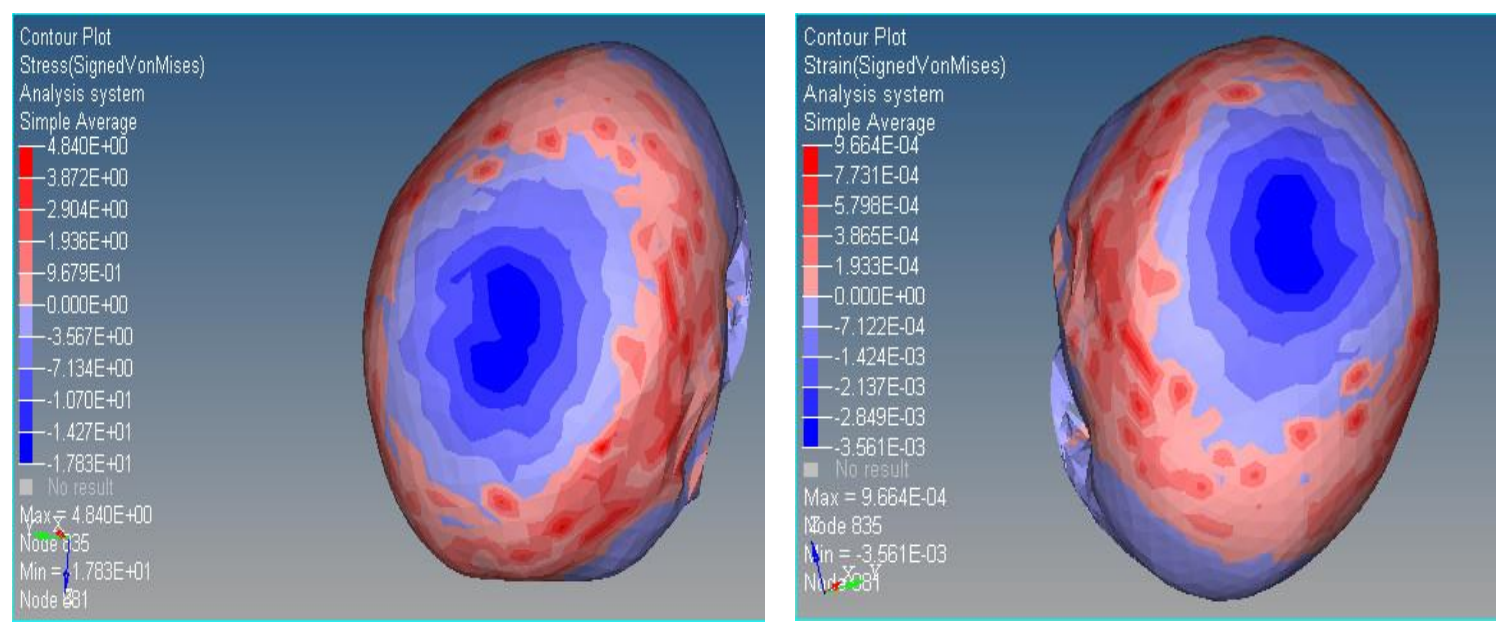

Figure 102: 45-cm Superior Drop Tensile and Compressive Stresses
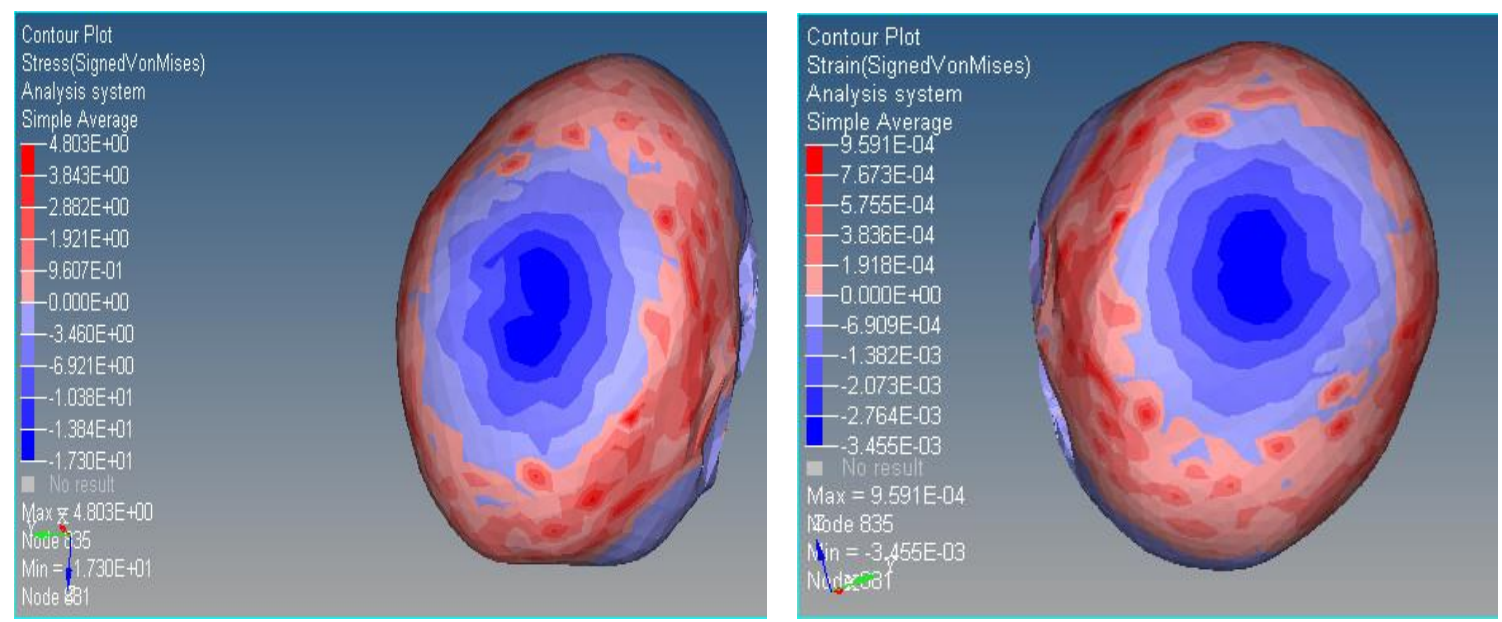

Figure 103: 35-cm Superior Drop Tensile and Compressive Stresses 

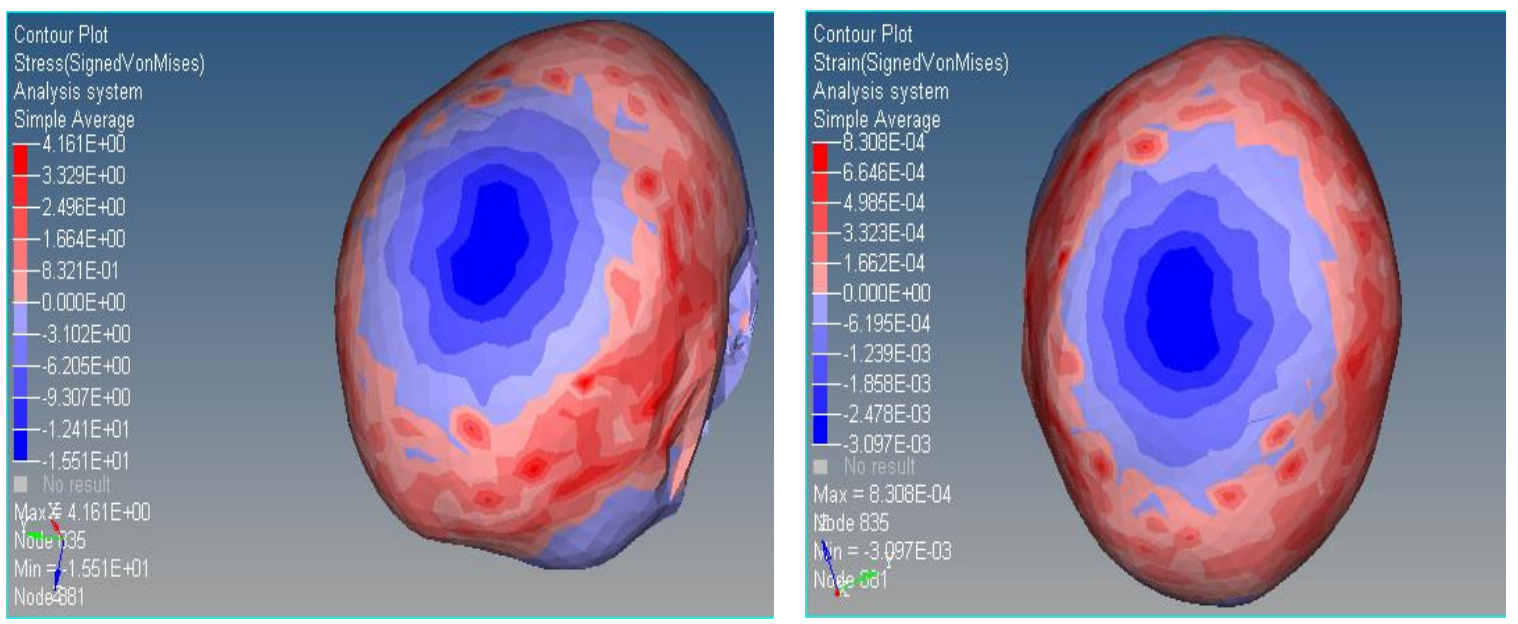

Figure 104: 25-cm Superior Drop Tensile and Compressive Stresses
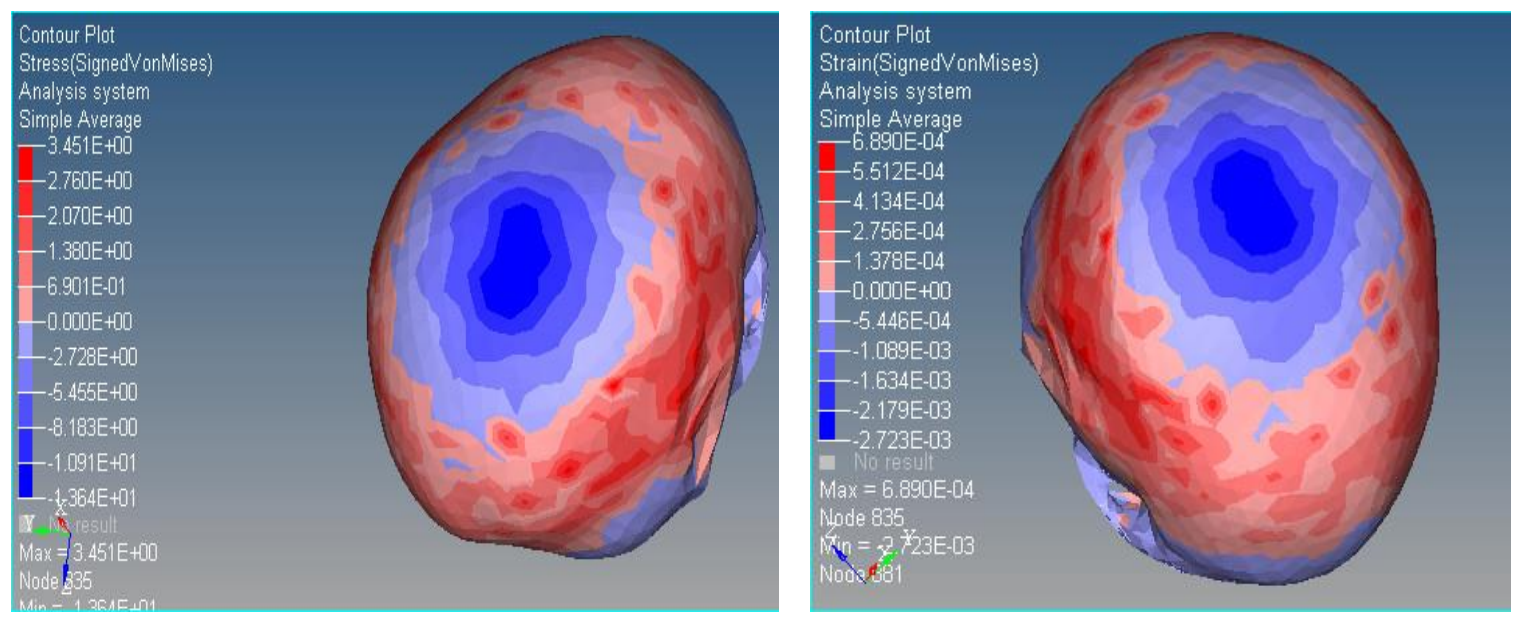

Figure 105: 15-cm Superior Drop Tensile and Compressive Stresses 


\subsubsection{Lateral Impact}
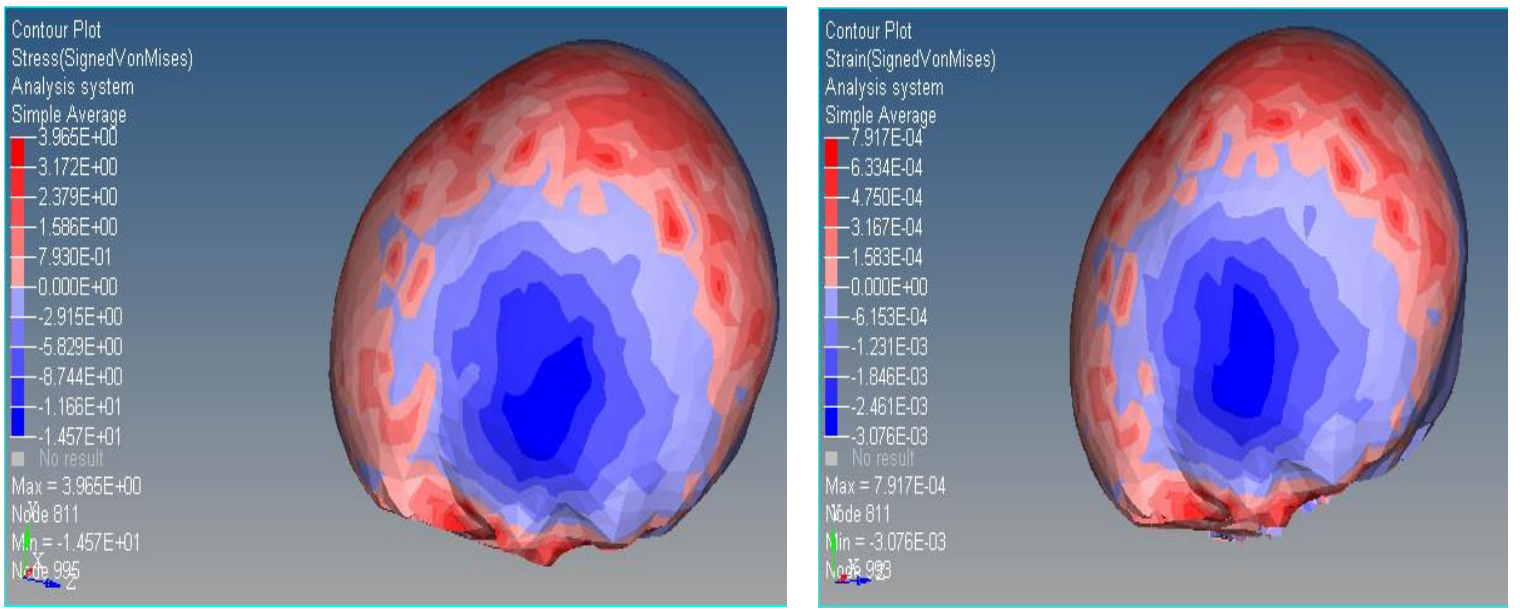

Figure 106: 55-cm Lateral Drop Tensile and Compressive Stresses
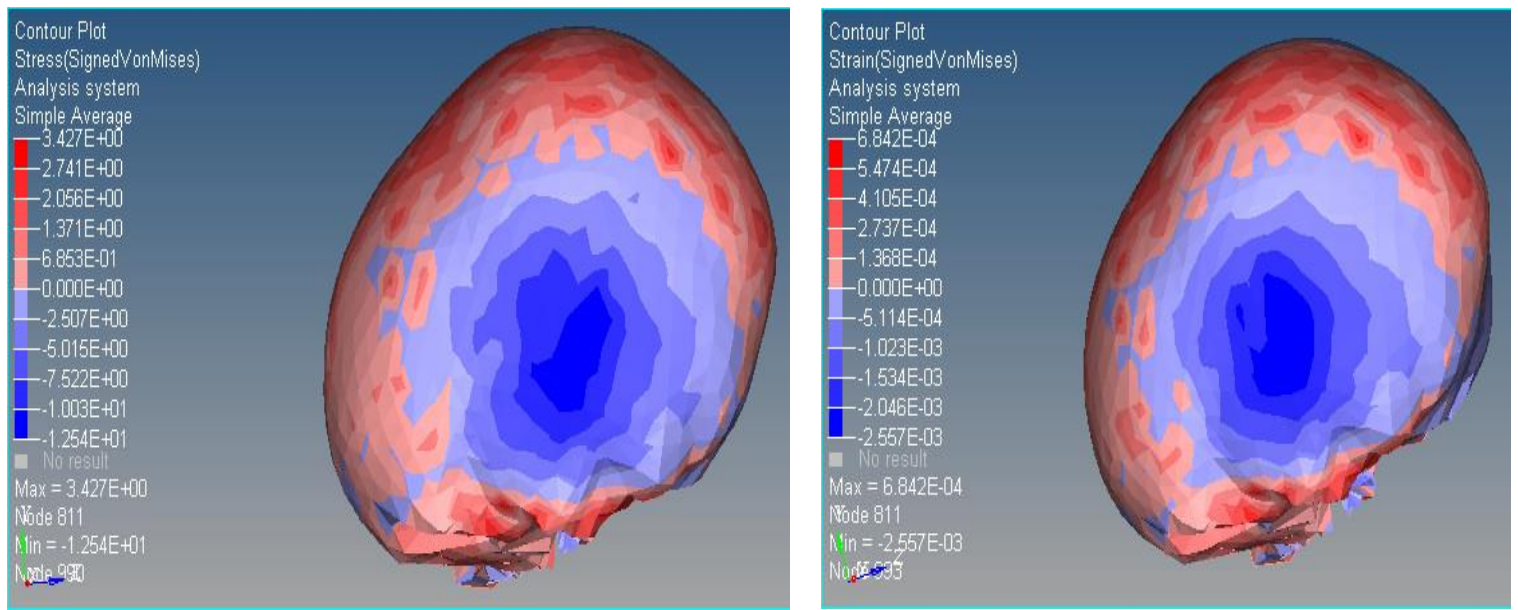

Figure 107: 45-cm Lateral Drop Tensile and Compressive Stresses
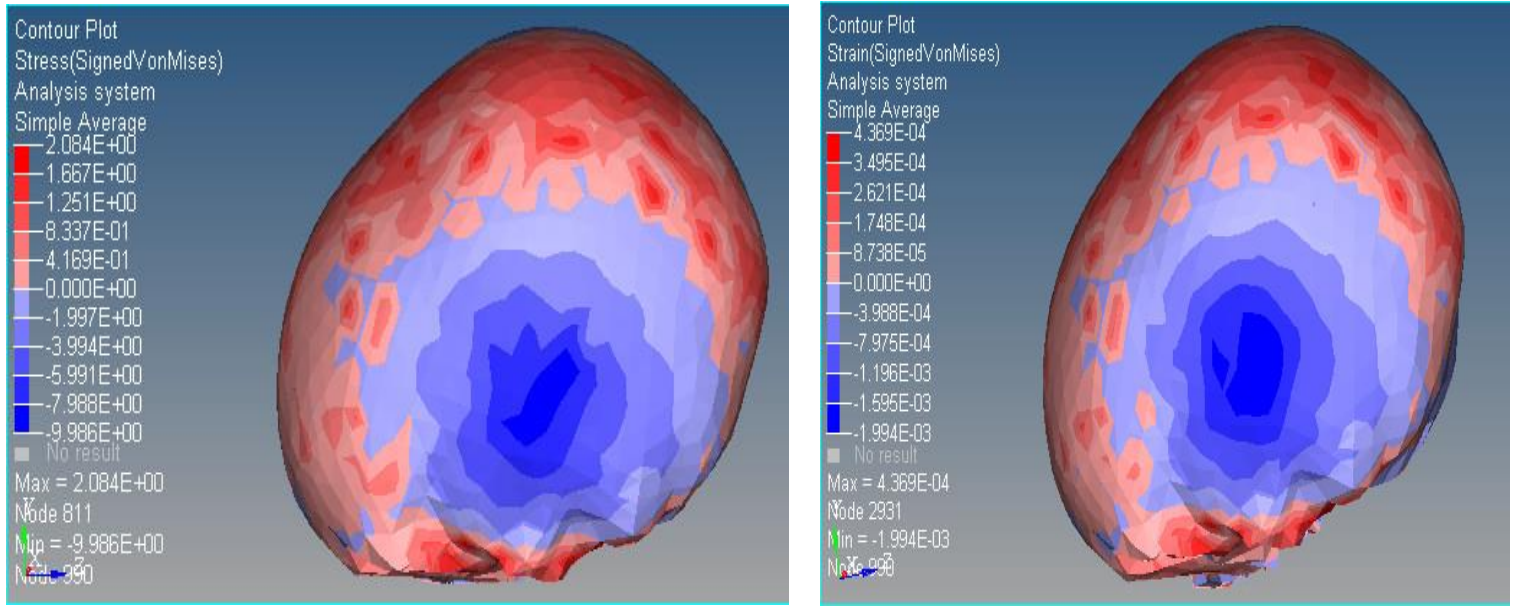

Figure 108: 35-cm Lateral Drop Tensile and Compressive Stresses 

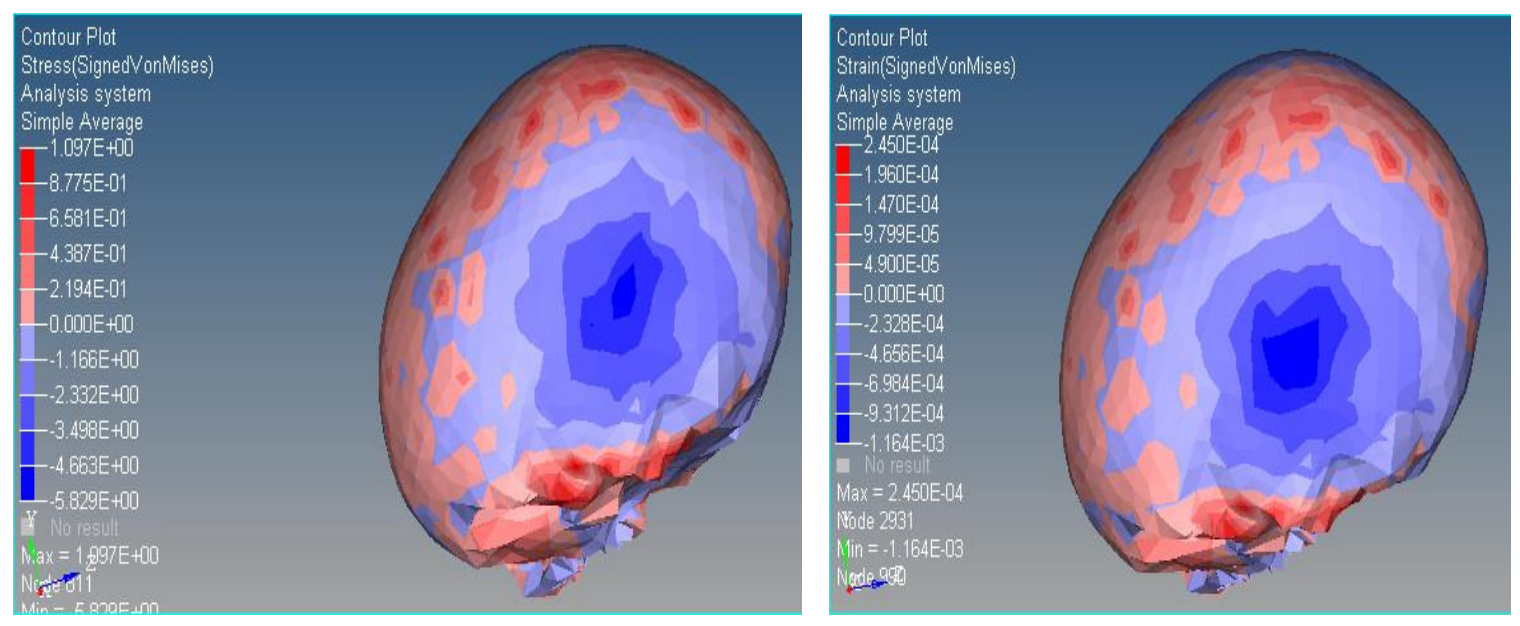

Figure 109: 25-cm Lateral Drop Tensile and Compressive Stresses
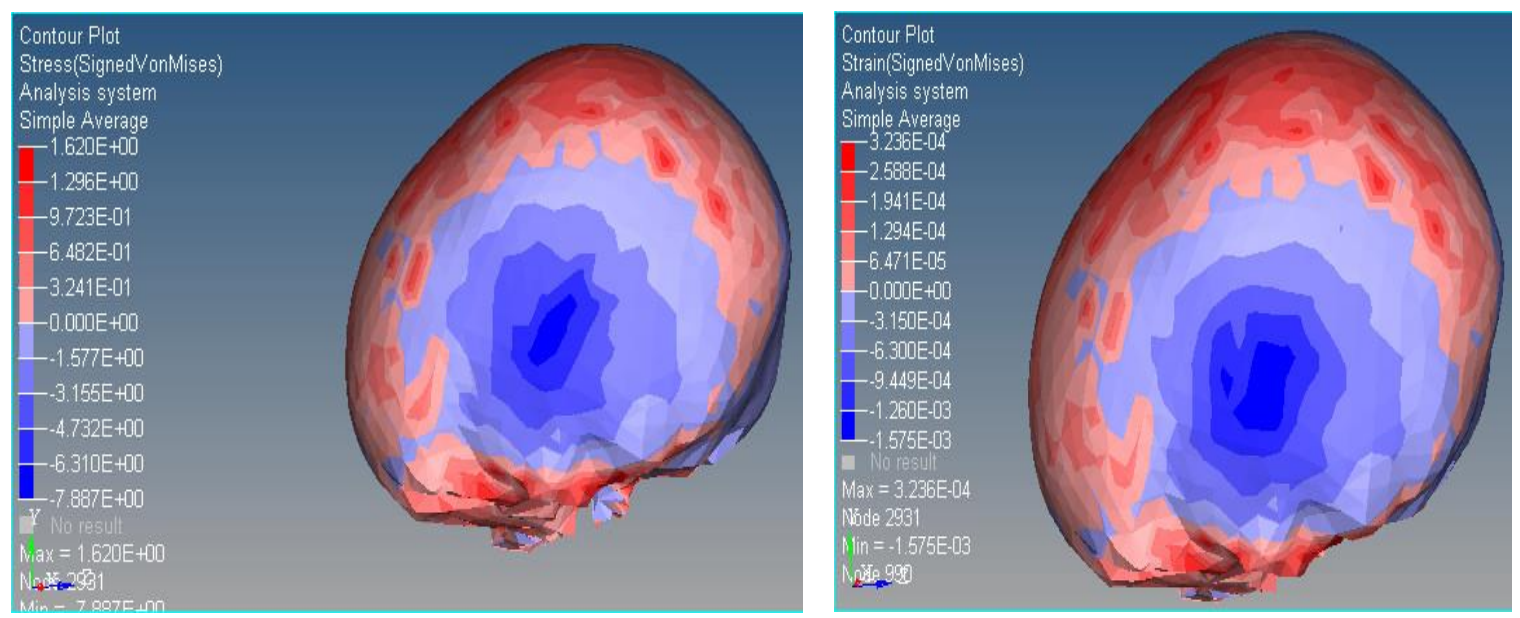

Figure 110: 15-cm Lateral Drop Tensile and Compressive Stresses 


\subsubsection{Posterior Impact}
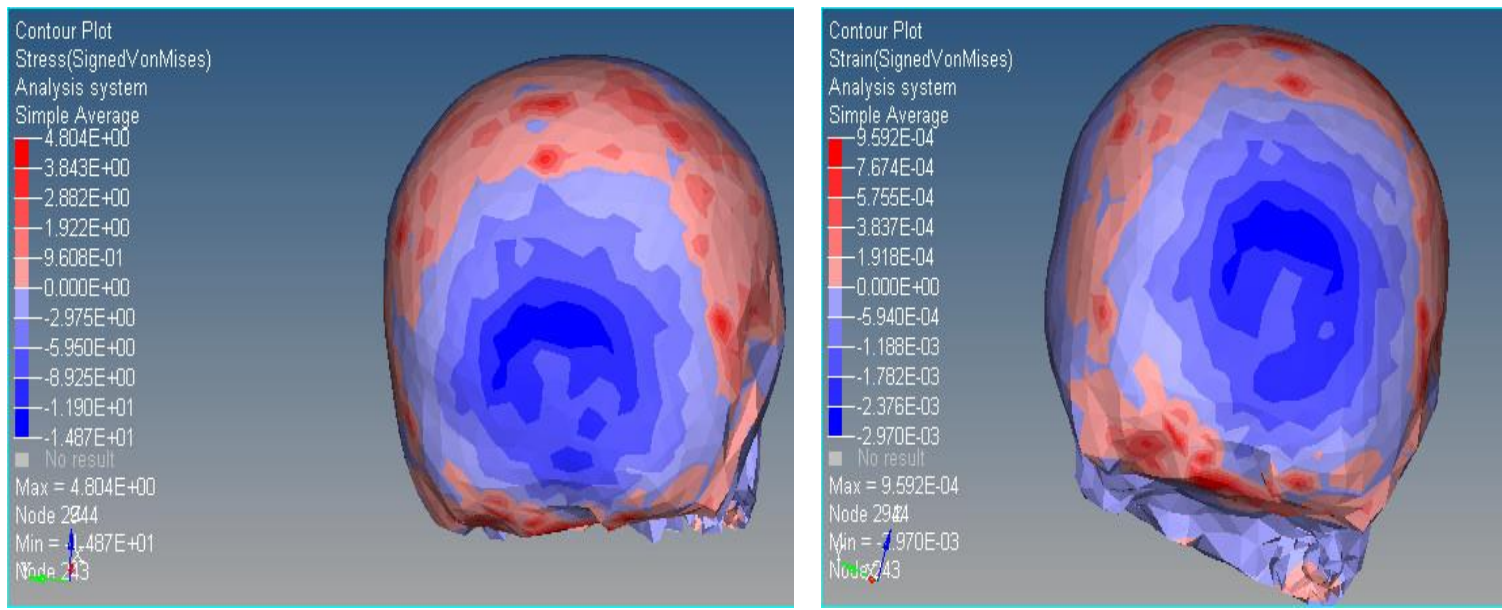

Figure 111: 55-cm Posterior Drop Tensile and Compressive Stresses
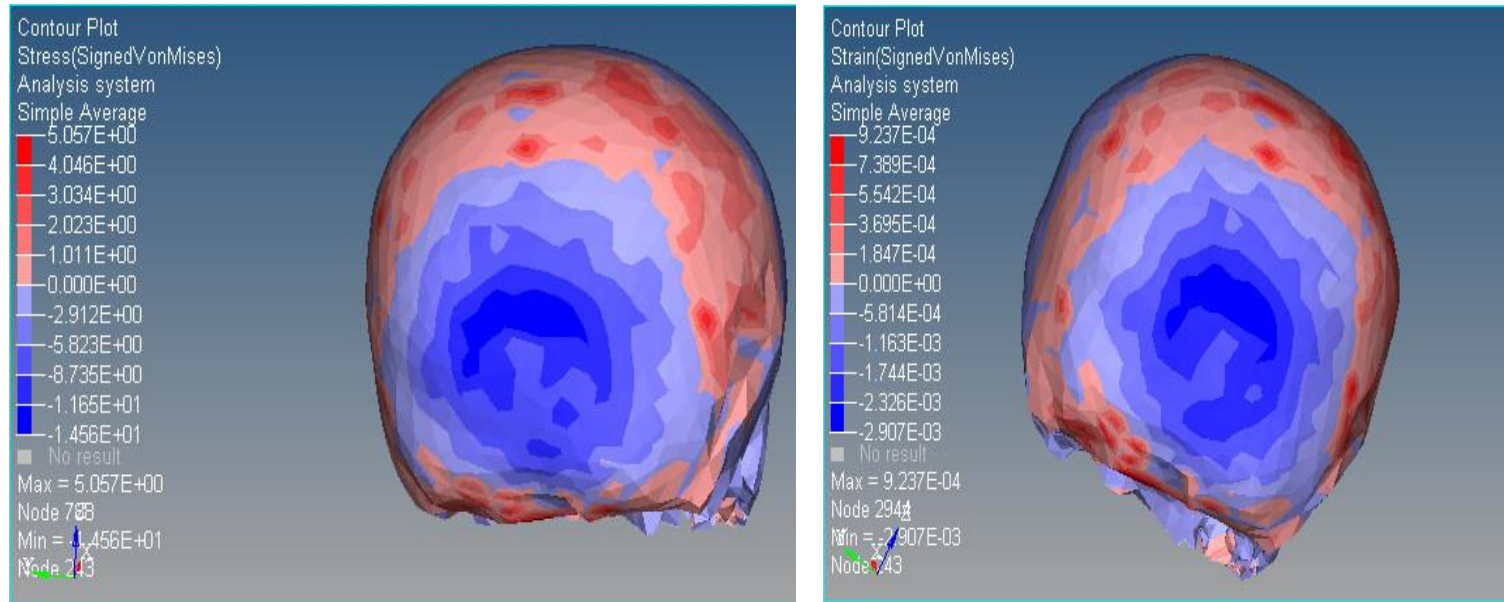

Figure 112: 45-cm Posterior Drop Tensile and Compressive Stresses
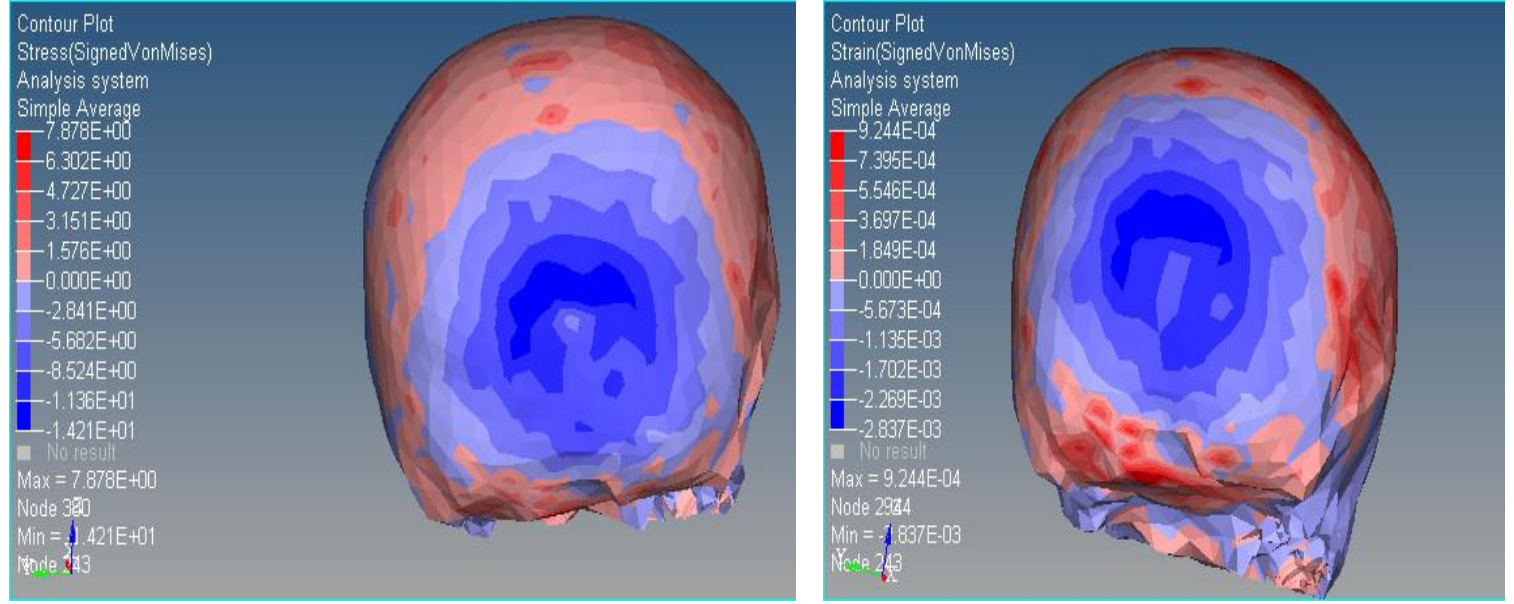

Figure 113: 35-cm Posterior Drop Tensile and Compressive Stresses 

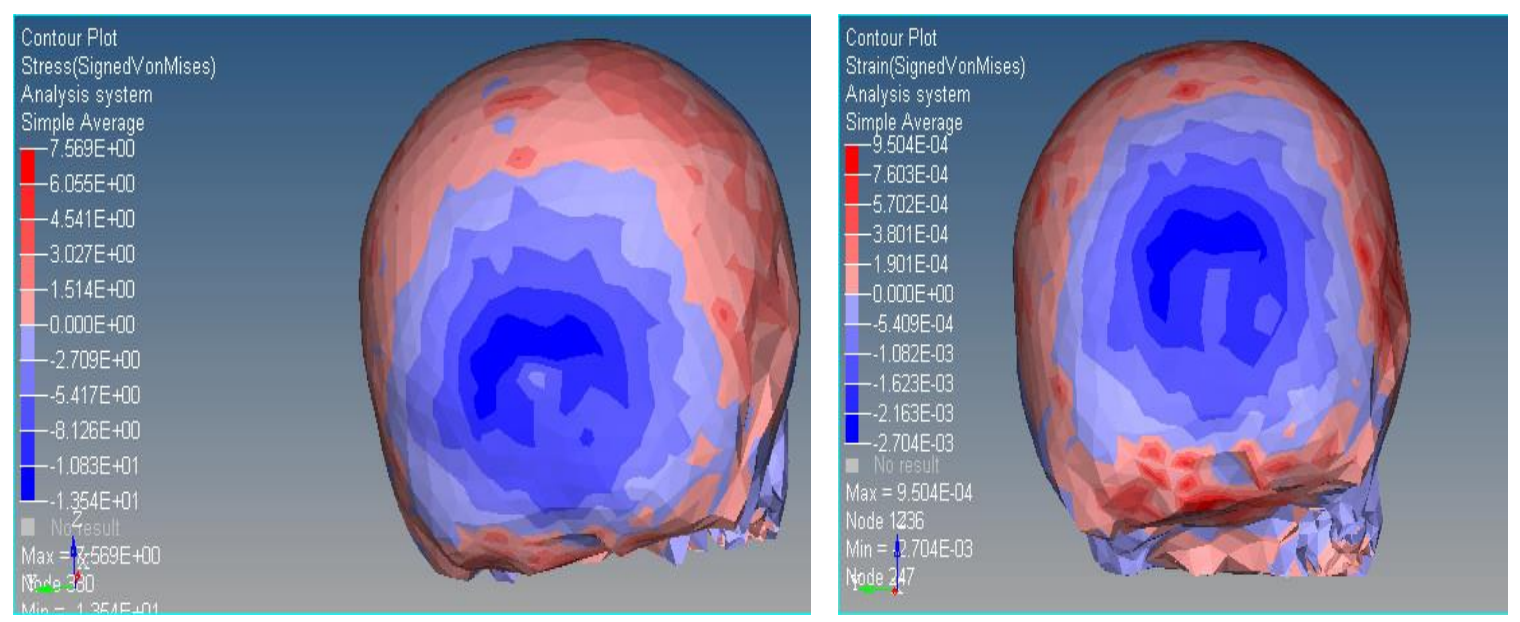

Figure 114: 25-cm Posterior Drop Tensile and Compressive Stresses
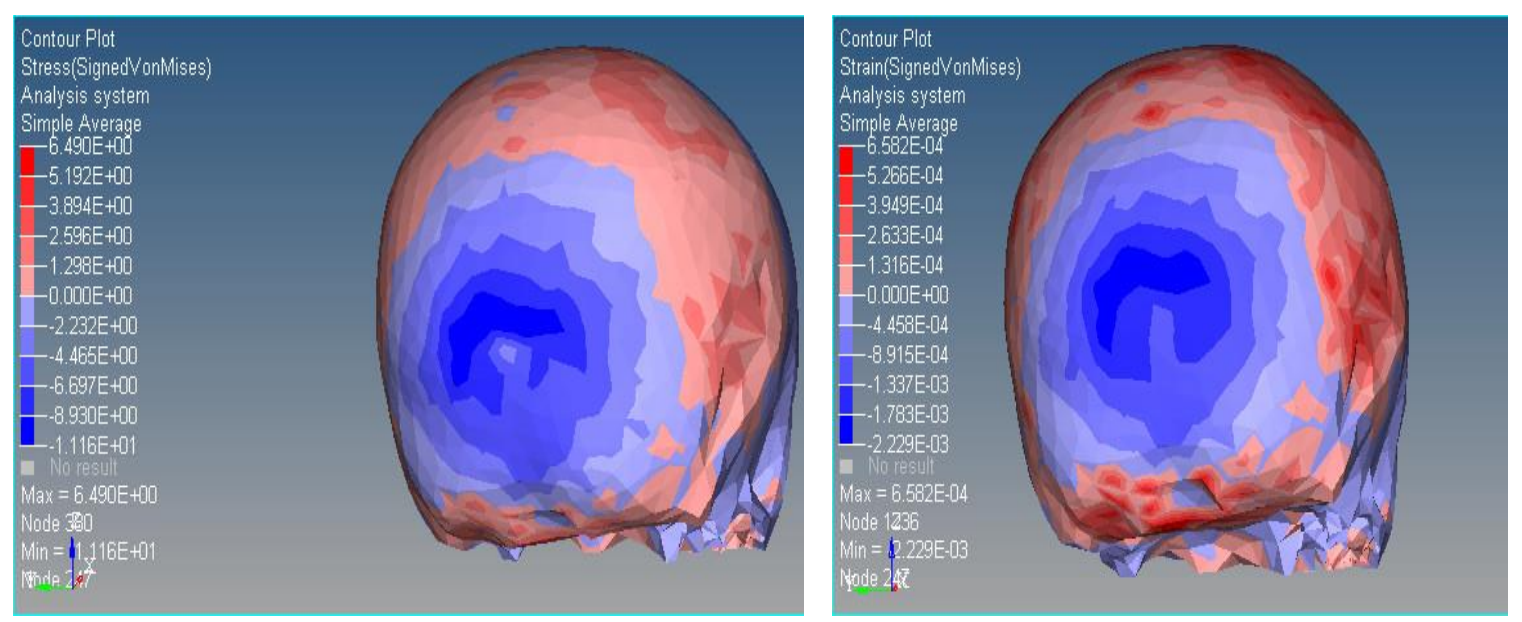

Figure 115: 15-cm Posterior Drop Tensile and Compressive Stresses 


\subsection{Point of Impact from Point of Maximum von Mises Stress}

\subsubsection{Frontal Impact}

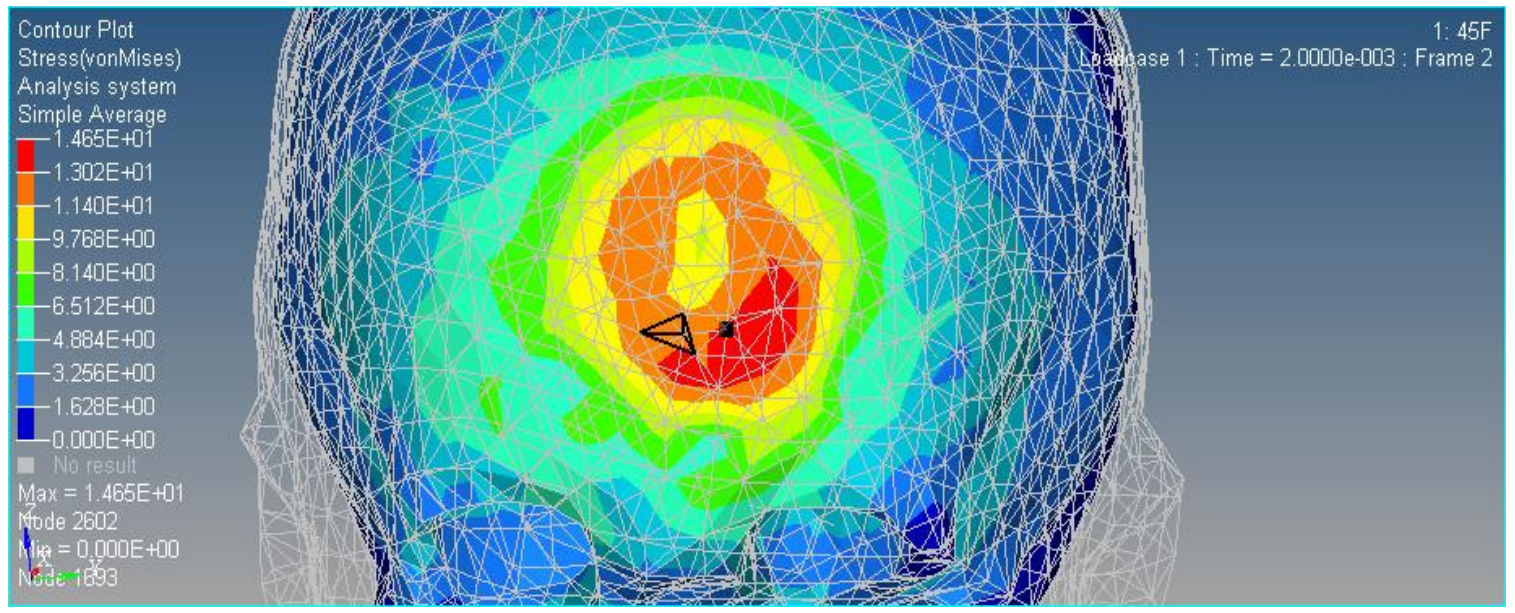

Figure 116: 45-cm Frontal Drop Case

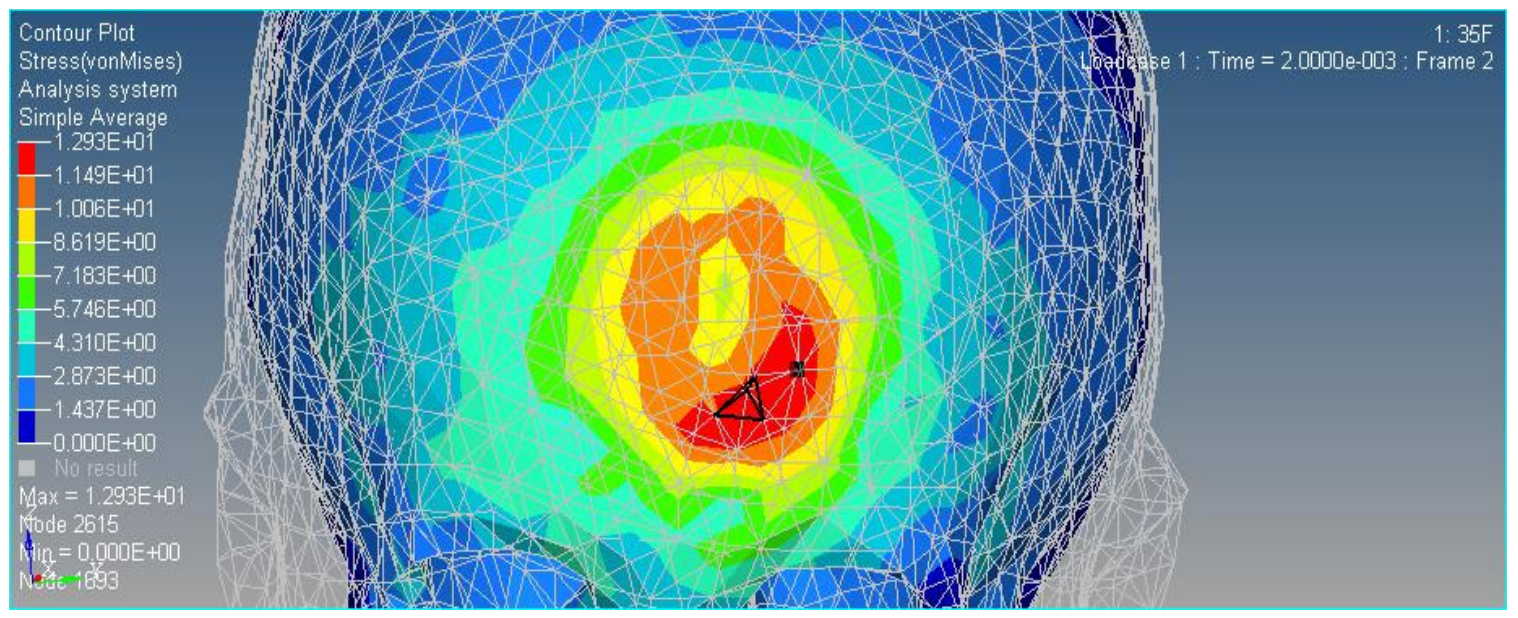

Figure 117: 35-cm Frontal Drop Case 


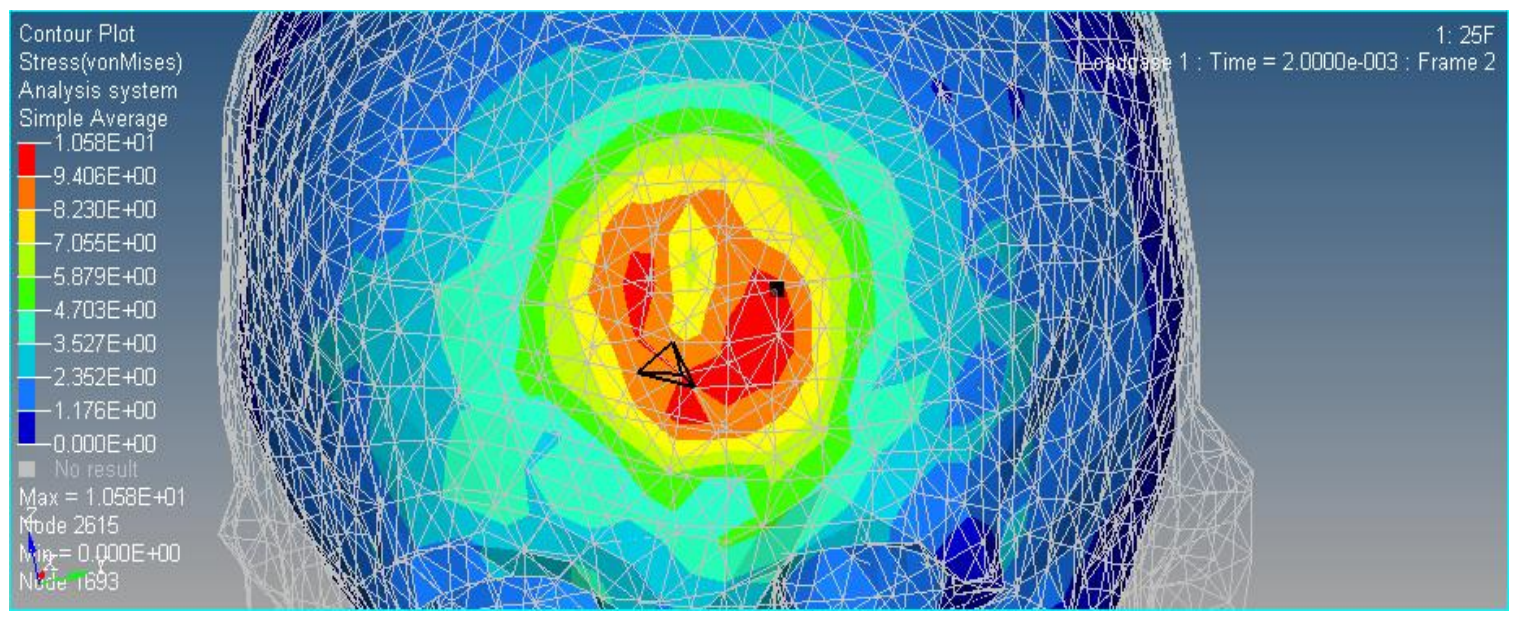

Figure 118: 25-cm Frontal Drop Case

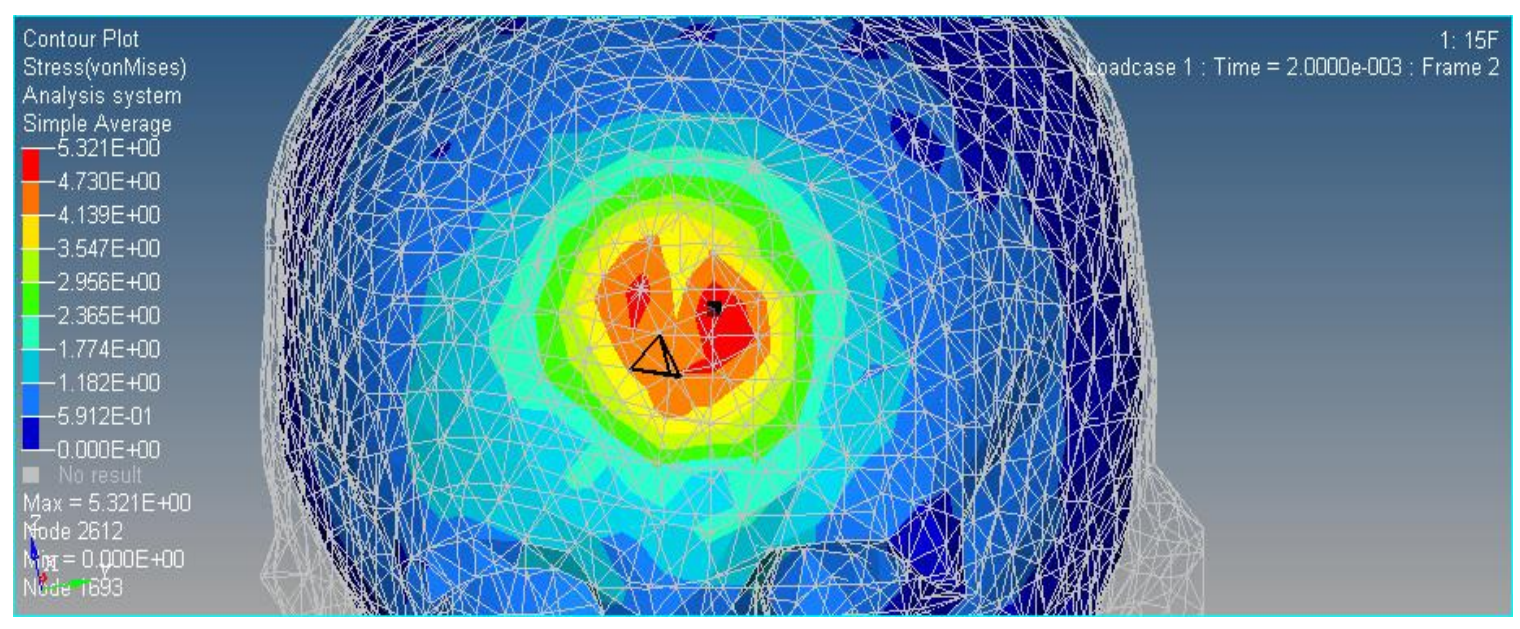

Figure 119: 15-cm Frontal Drop Case 


\subsubsection{Superior Impact}

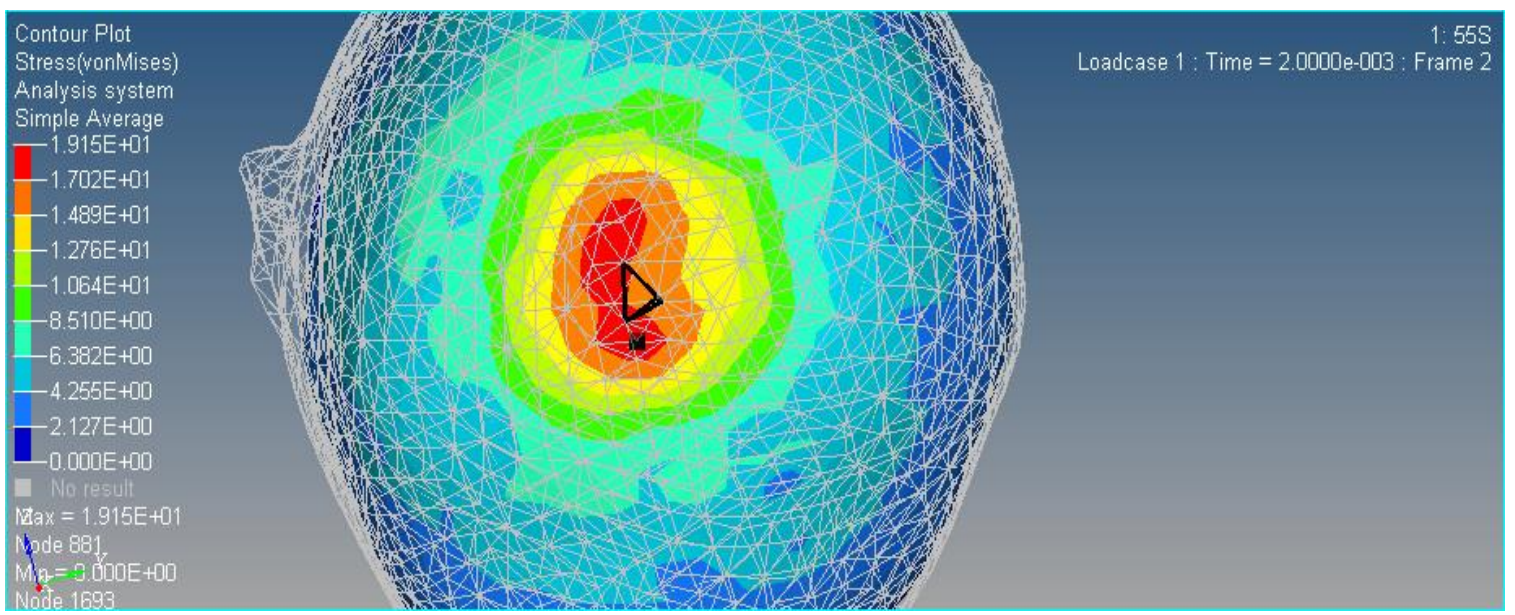

Figure 120: 55-cm Superior Drop Case

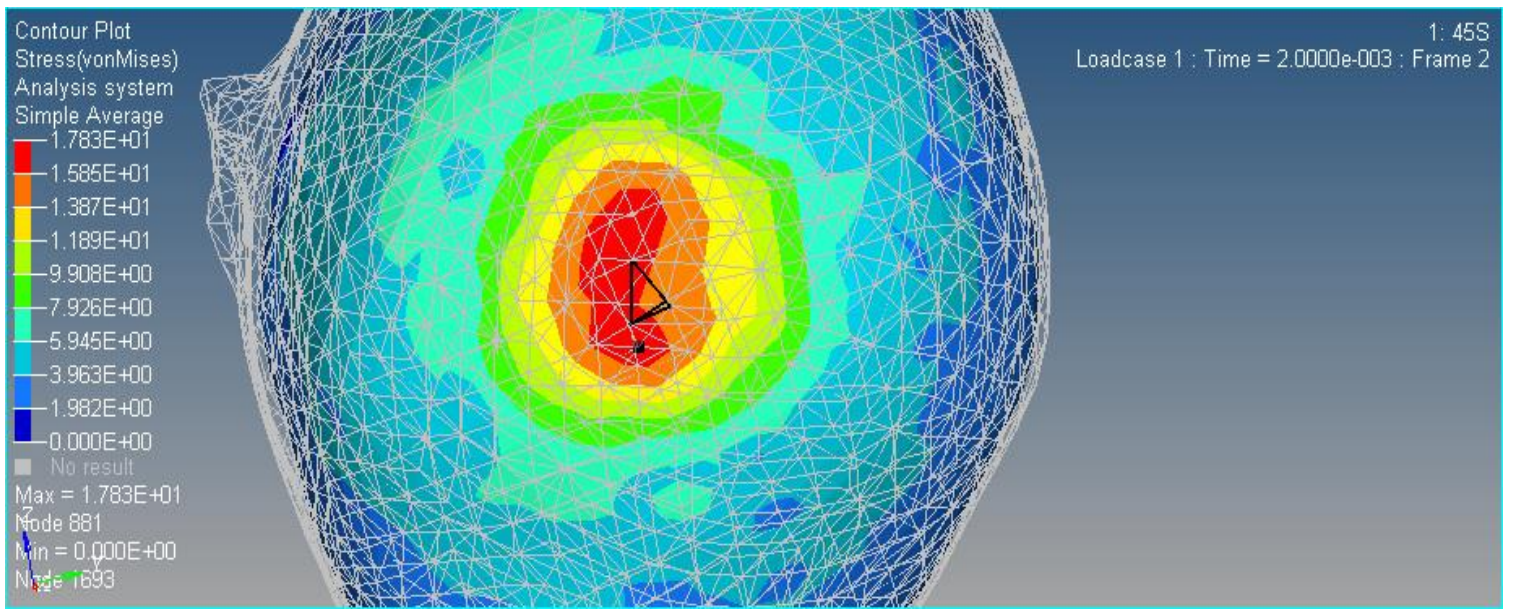

Figure 121: 45-cm Superior Drop Case

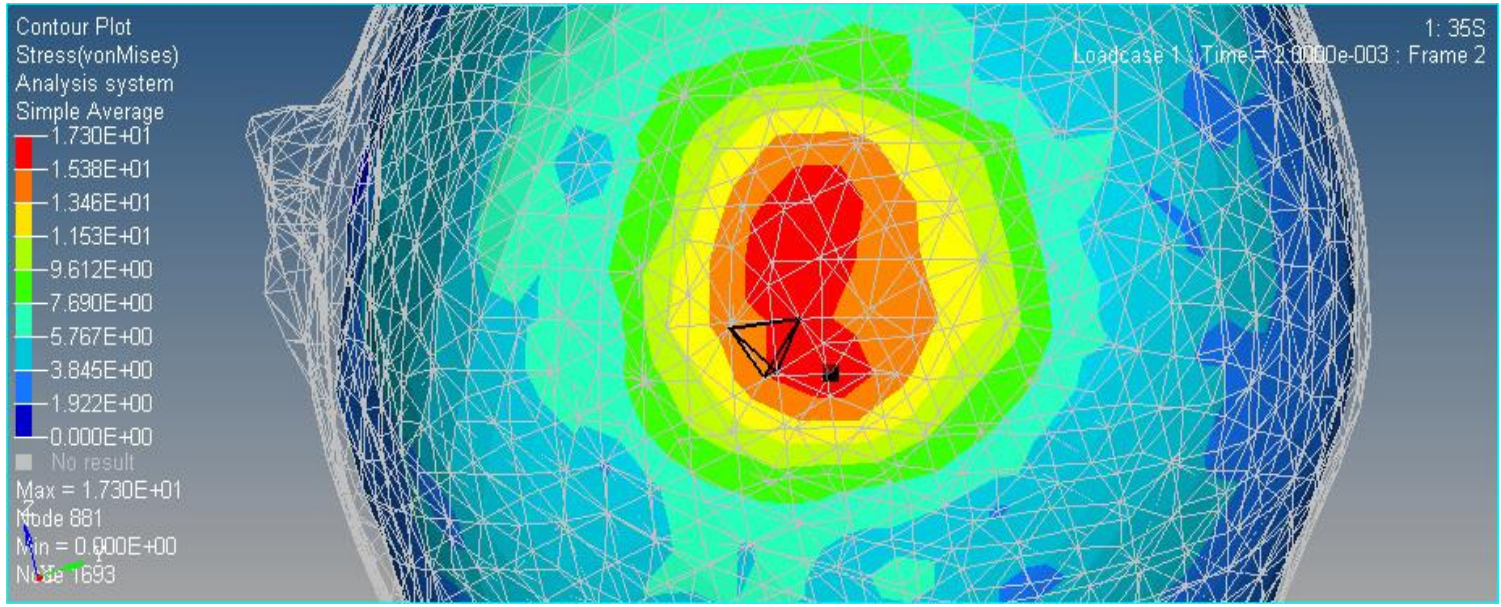

Figure 122: 35-cm Superior Drop Case 


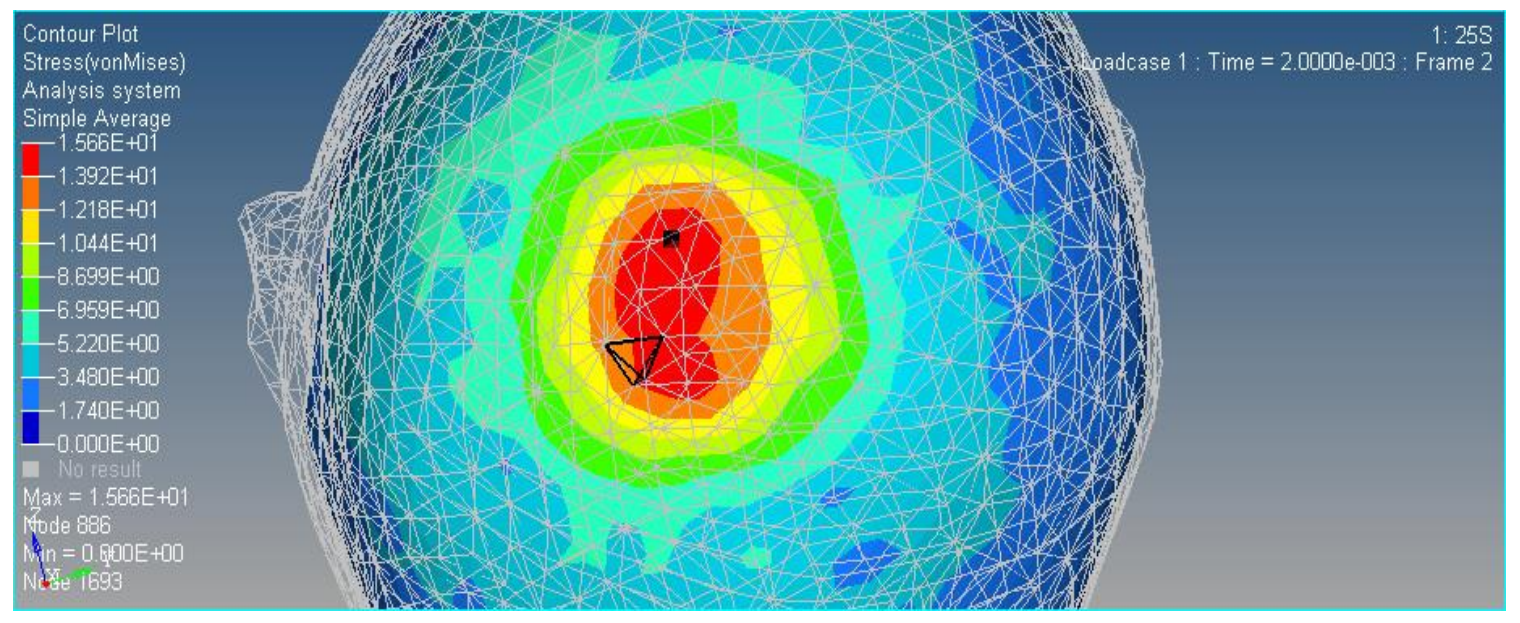

Figure 123: 25-cm Superior Drop Case

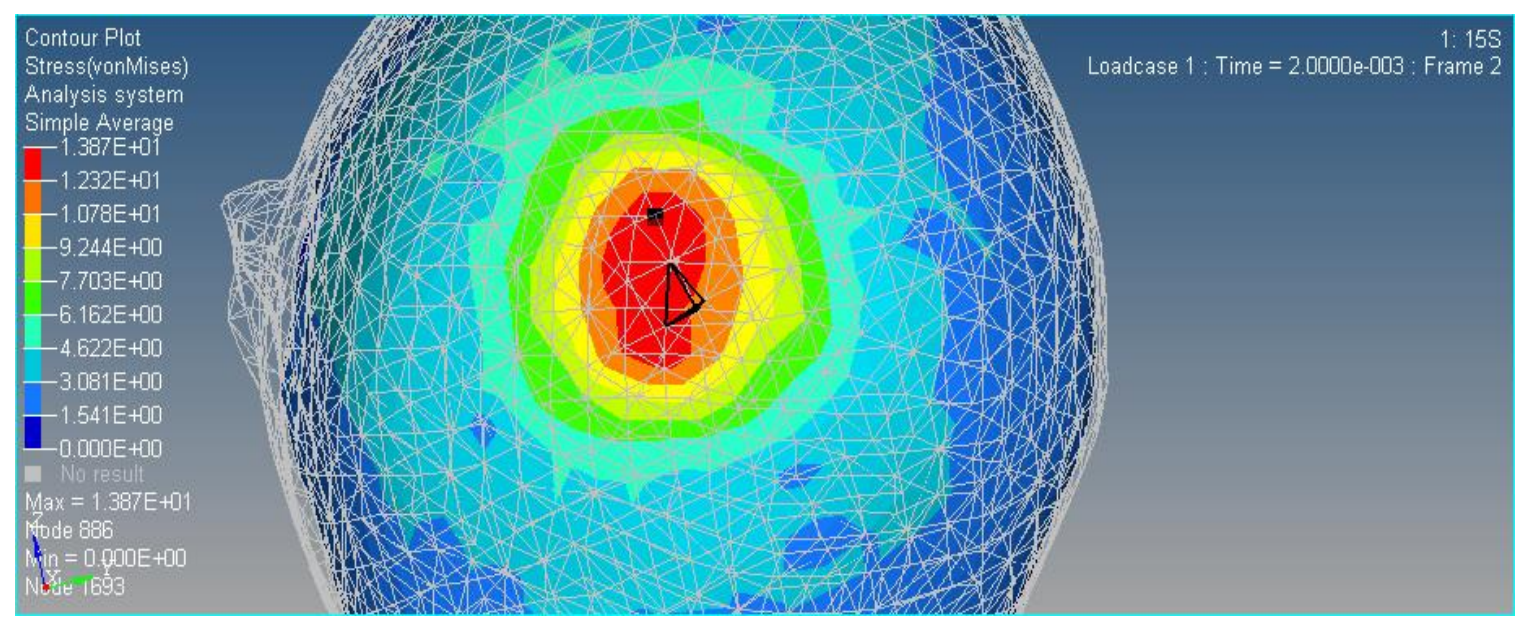

Figure 124: 15-cm Superior Drop Case 


\subsubsection{Lateral Impact}

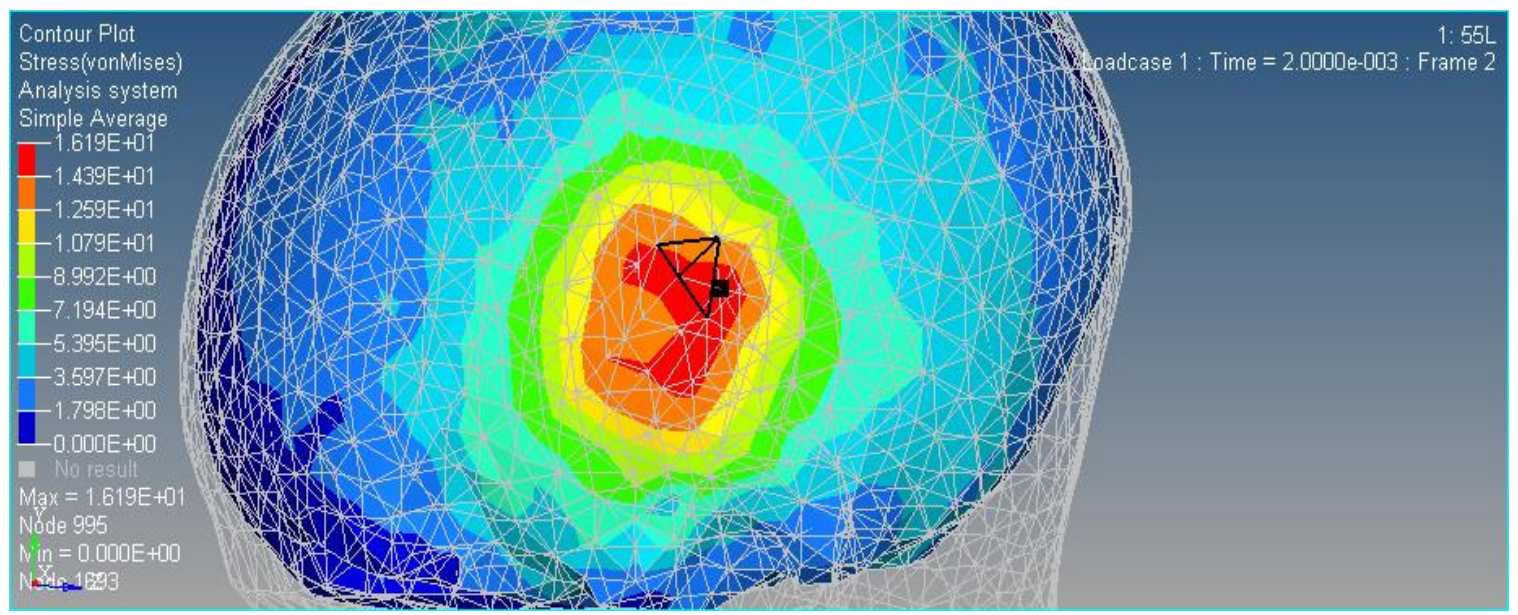

Figure 125: 55-cm Lateral Drop Case

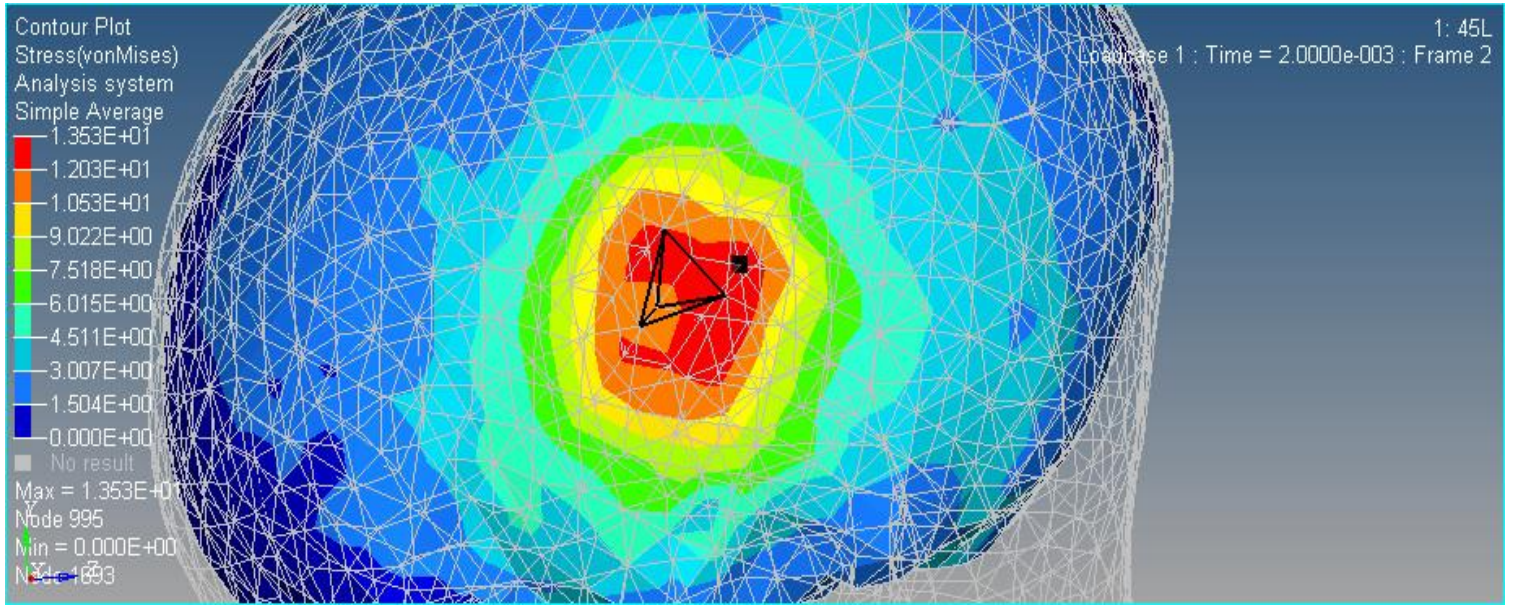

Figure 126: 45-cm Lateral Drop Case

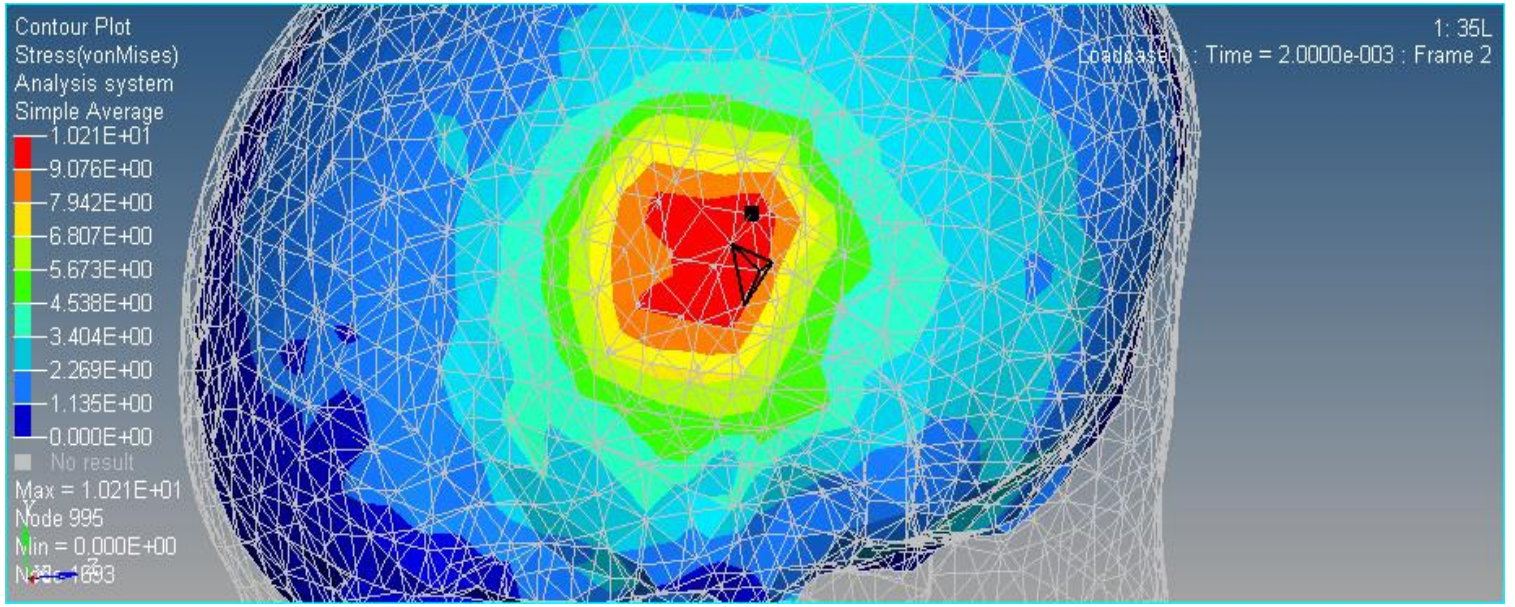

Figure 127: 35-cm Lateral Drop Case 


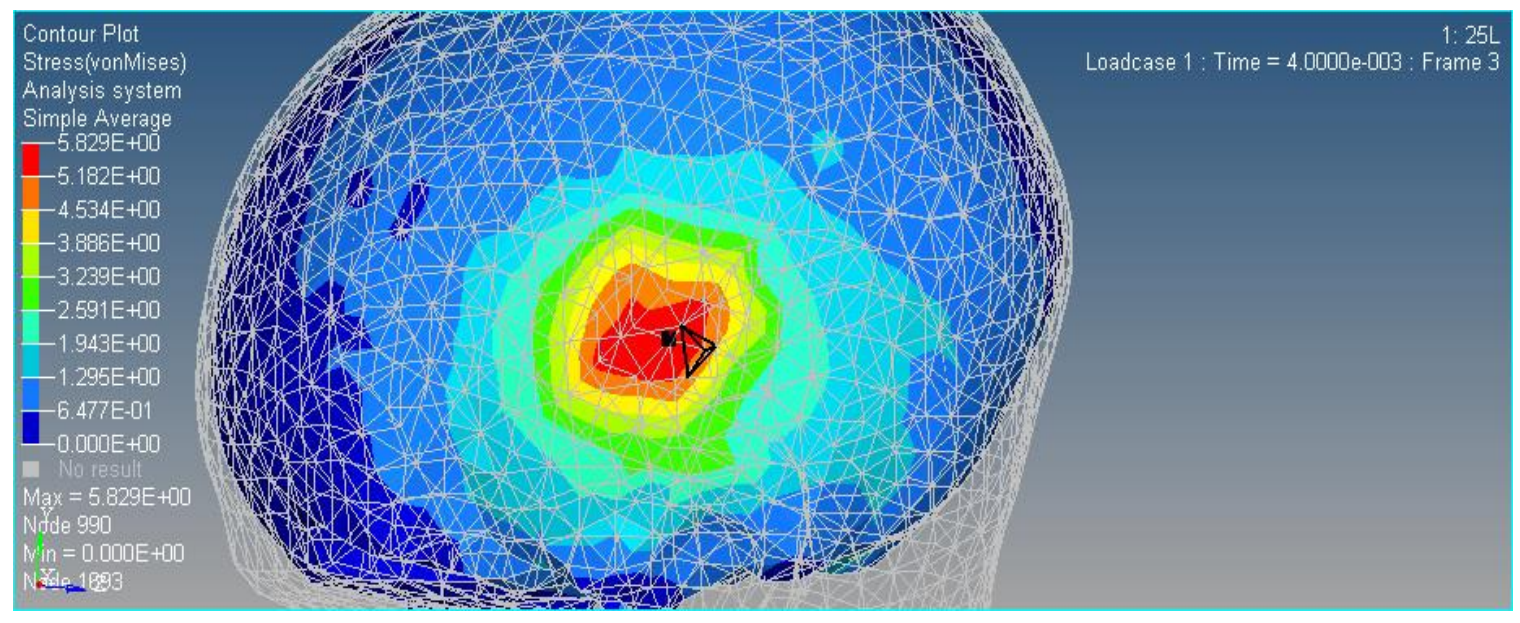

Figure 128: 25-cm Lateral Drop Case

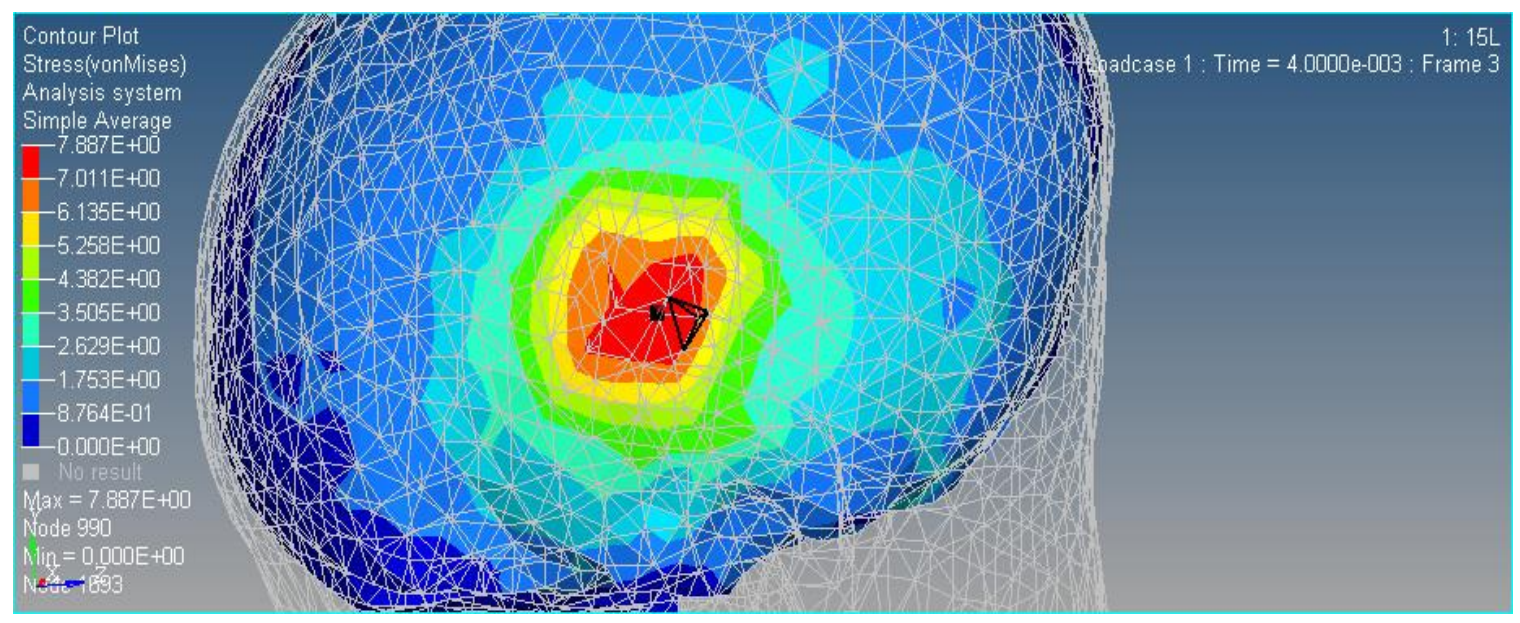

Figure 129: 15-cm Lateral Drop Case 


\subsubsection{Posterior Impact}

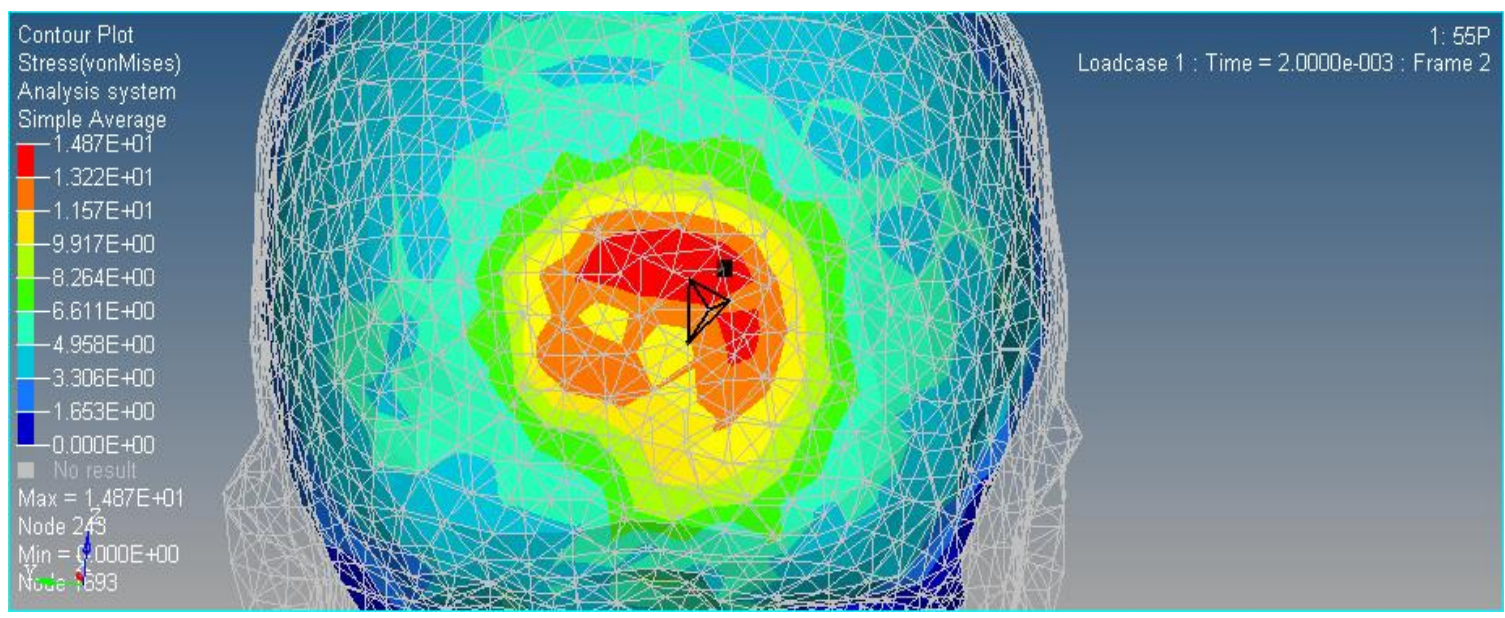

Figure 130: 55-cm Posterior Drop Case

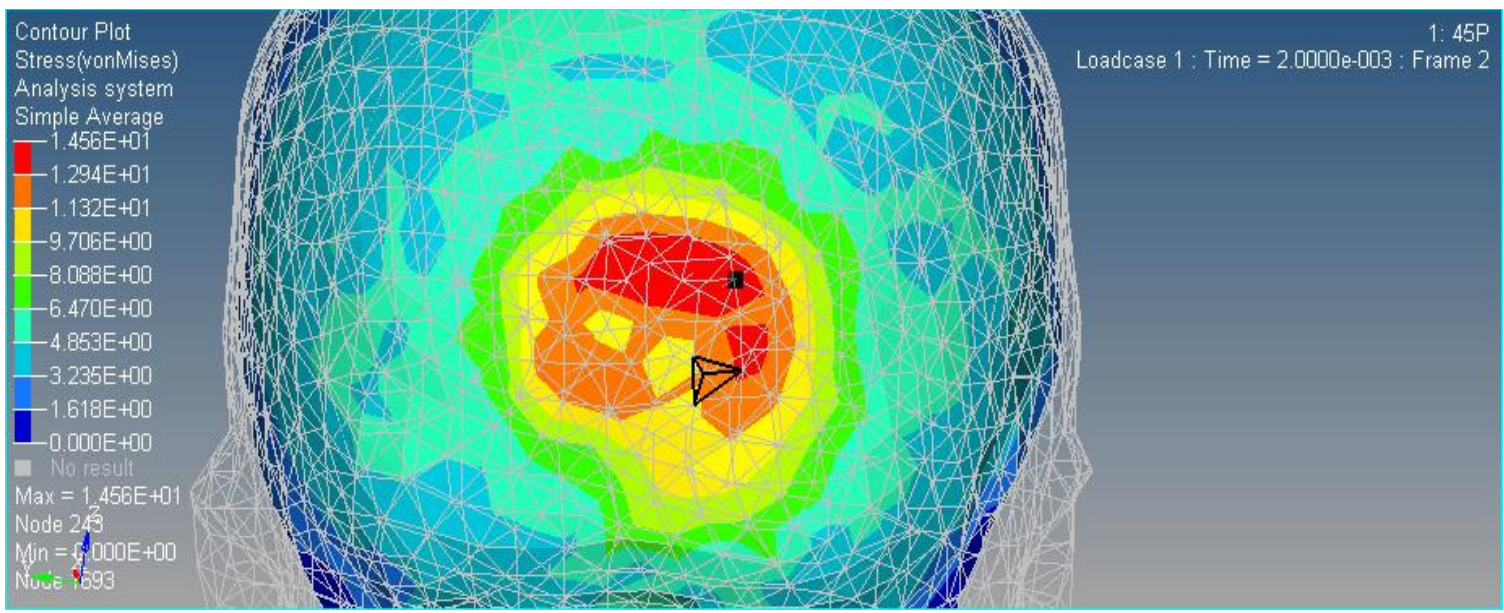

Figure 131: 45-cm Posterior Drop Case

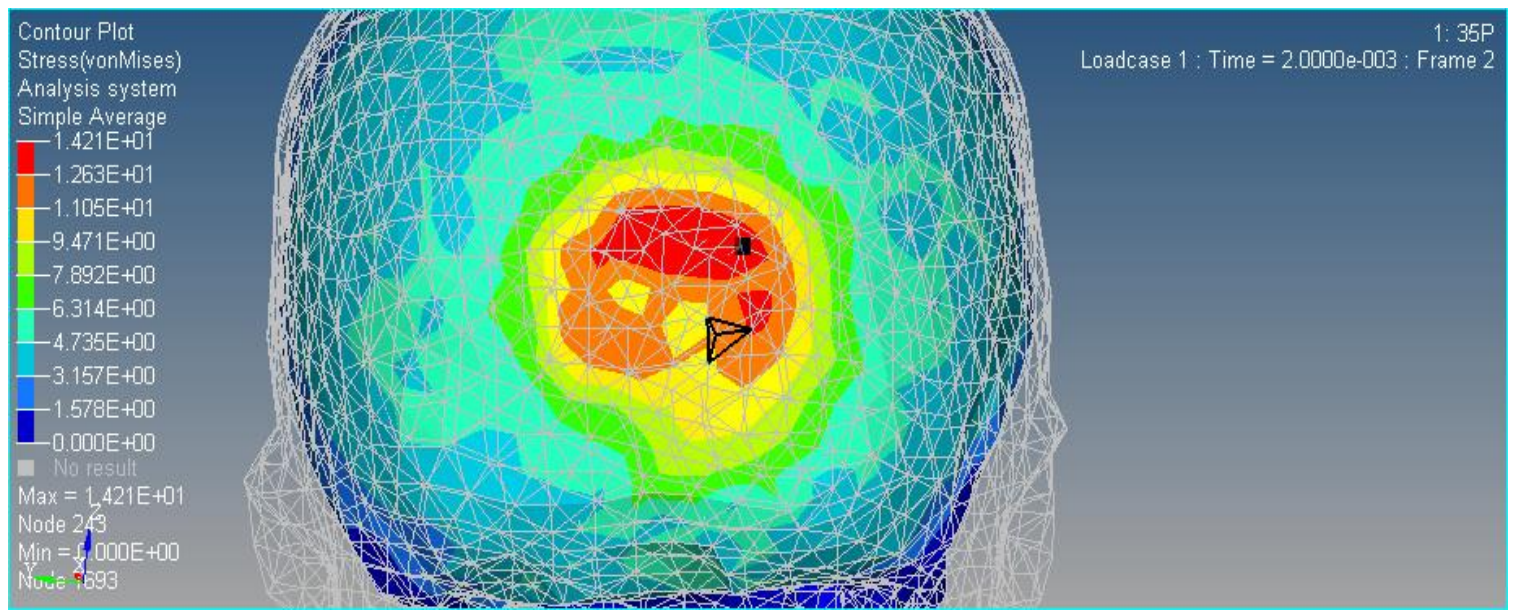

Figure 132: 35-cm Posterior Drop Case 


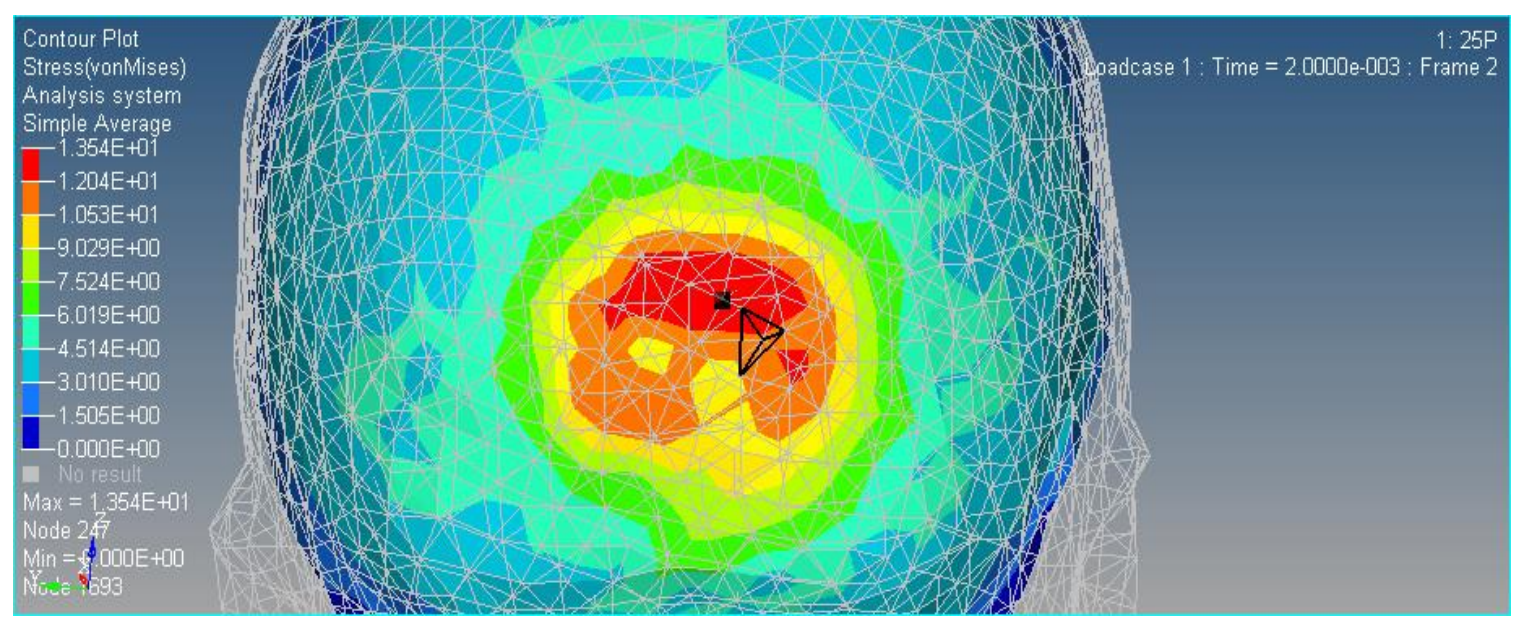

Figure 133: 25-cm Posterior Drop Case

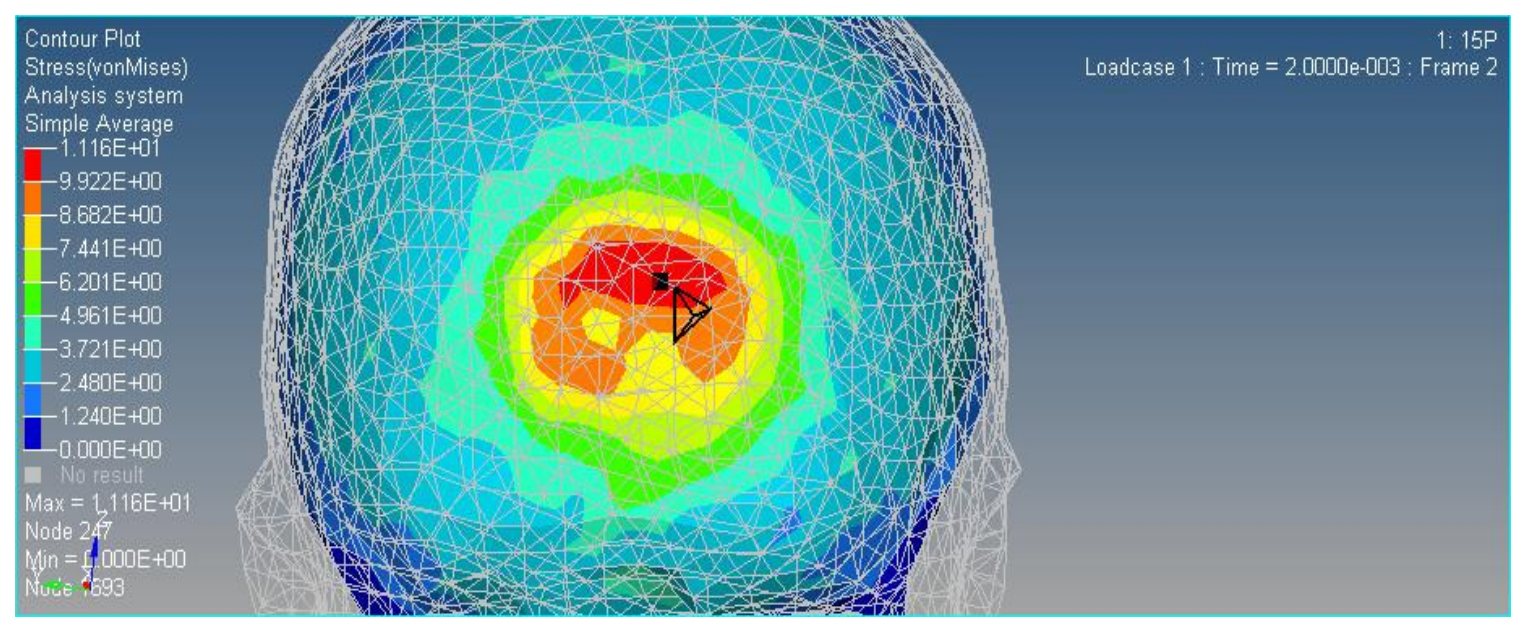

Figure 134: 15-cm Posterior Drop Case 


\section{References}

[1] Slip-Fall Statistics, hspsupplyinc.com/stats.htm.

[2] "Find a Surgeon." American College of Surgeons, www.facs.org/search/find-a-surgeon.

[3] "Important Facts about Falls." Centers for Disease Control and Prevention, Centers for Disease Control and Prevention, 10 Feb. 2017, www.cdc.gov/homeandrecreationalsafety/falls/adultfalls.html.

[4] K.L. Thibault, S.M. Kurtz, Material properties of the infant skull and application to numerical analysis of pediatric head injury, IRCOBI Conference - Sitges (Spain), September 1999.

[5] S. S. Margulies, K. L. Thibault, Infant Skull and Suture Properties: Measurements and Implications for Mechanisms of Pediatric Brain Injury, Journal of Biomechanical Engineering, AUGUST 2000, Vol. 122 (364-371).

[6] C. J. HOBBS, Skull fracture and the diagnosis of abuse, Archives of Disease in Childhood, 1984, 59, (246-252).

[7] S. Ji, B Coats, S. Margulies, Parametric Study of Head Impact in the Infant, Stapp car crash journal, Vol. 51 (October 2007) 1-15.

[8] C. Zhou, T.B. Kahlil, L.J. Dragovic, Head injury assessment of a real-world crash by finite element modelling, in: Proceedings of the AGARD Conference, 1996.

[9] S. Roth, et al, Child head injury criteria investigation through numerical simulation of real world trauma. (2008).

[10] R. Willinger, L. Taleb, Model and temporal analysis of head mathematical models, J. Neurotrauma 12 (4) (1995) 743-754.

[11] L.Z. Shuck, S.H. Advani, Rheological response of human brain tissue in shearing, J. Basic Eng. (1972) 905-911.

[12] Project menu script submitted to Michigan Technological University under special topic named "3D-FEM Study on the Pediatric Head Response to Impact due to Free Fall to Predict TBI Risk" by Prajwal Mahesh (2016).

[13] M.T. Prange, J. F. Luck, A. Dibb, C.A. Van Ee, R.W. Nightingale, B.S. Mayers, Mechanical properties and anthropometry of the human infant head, Stapp Car Crash J.48 (2004) 279-299. 